\title{
Development of Site- Specific Soil Design Basis Earthquake (DBE) Parameters for the Integrated Waste Treatment Unit (IWTU)
}

\author{
S. J. Payne
}

August 2008

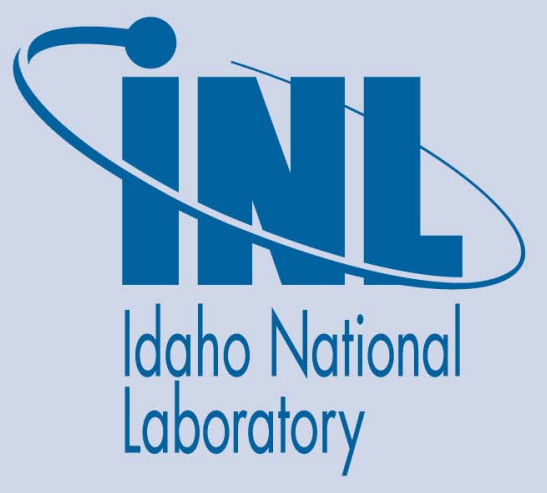

The INL is a U.S. Department of Energy National Laboratory operated by Battelle Energy Alliance 
INL/EXT-07-12716

Rev. 1

\title{
Development of Site-Specific Soil Design Basis Earthquake (DBE) Parameters for the Integrated Waste Treatment Unit (IWTU)
}

\author{
S. J. Payne
}

August 2008

Idaho National Laboratory

Applied Mechanics Department

Idaho Falls, Idaho 83415

http://www.inl.gov

Prepared for the

U.S. Department of Energy

Office of Nuclear Energy

Under DOE Idaho Operations Office

Contract DE-AC07-05ID14517 
Revision 1 


\section{SUMMARY}

Horizontal and vertical PC 3 (2,500 yr) Soil Design Basis Earthquake (DBE) 5\% damped spectra, corresponding time histories, and strain-compatible soil properties were developed for the Integrated Waste Treatment Unit (IWTU). The IWTU is located at the Idaho Nuclear Technology and Engineering Center (INTEC) at the Idaho National Laboratory (INL). Mean and $84^{\text {th }}$ percentile horizontal DBE spectra derived from site-specific site response analyses were evaluated for the IWTU. The horizontal and vertical PC 3 (2,500 yr) Soil DBE $5 \%$ damped spectra at the $84^{\text {th }}$ percentile were selected for Soil Structure Interaction (SSI) analyses at IWTU. The site response analyses were performed consistent with applicable Department of Energy (DOE) Standards, recommended guidance of the Nuclear Regulatory Commission (NRC), American Society of Civil Engineers (ASCE) Standards, and recommendations of the Blue Ribbon Panel (BRP) and Defense Nuclear Facilities Safety Board (DNFSB).

Site-specific site response analyses were conducted for three soil layers (Layer A - disturbed alluvial soils; Layer B - alluvial soils; and Layer C - clay) above basalt bedrock (Layer D). The analyses used measured shear wave velocities (Vs) and densities at the IWTU site to determine shear modulus and its variability for each soil and rock layer. Two sets of random soil profiles were generated with normal and log normal distributions of shear modulus. Two horizontal INTEC/RTC/RWMC/PBF Rock DBE acceleration time histories were propagated through the soil profiles. Strain-dependent soil properties were computed using shear modulus reduction and damping curves appropriate for alluvial and clay soils at IWTU.

The mean spectral peaks of the soil response spectra exceed the preliminary horizontal spectrum used in initial SSI analyses of IWTU by $30 \%$. The "IWTU SSI Spectrum" was determined by increasing the horizontal RTC/INTEC PC 3 Soil DBE 5\% damped spectrum by 10\%. Sensitivity analyses indicated the greater spectral peaks of the site-specific soil response analyses can be attributed to less variability of the shear modulus in the random soil profiles, use of different degradation models, and the low Vs for Layer A.

Results of the site response analyses were used to develop horizontal and vertical IWTU PC 3 Soil DBE 5\% damped spectra for the mean and $84^{\text {th }}$ 
percentile. The mean DBE peak spectral acceleration was set to $1.1 \mathrm{~g}$ to envelop the mean spectral peak of the site-specific soil response spectra. The spectral acceleration region was broadened by a factor of 1.5 from the mean spectral peak frequency of $7.18 \mathrm{~Hz}$. Spectral accelerations at higher and lower frequencies were set equivalent to the RTC/INTEC PC 3 Soil DBE spectrum. An $84^{\text {th }}$ percentile horizontal spectrum was calculated for the 30 site-specific soil response spectra with the log-normal distribution of shear modulus. To envelop the $84^{\text {th }}$ percentile soil spectrum, the spectral peak was set to $1.25 \mathrm{~g}$ and spectral accelerations at the higher and lower frequencies were set equivalent to the RTC/INTEC PC 3 Soil DBE spectrum. Vertical IWTU PC 3 soil DBE 5\% damped spectra for the mean and $84^{\text {th }}$ percentile were calculated by multiplying the spectral accelerations of the respective horizontal IWTU PC 3 soil DBE 5\% damped spectrum by vertical to horizontal $(\mathrm{V} / \mathrm{H})$ spectral ratios appropriate for INL.

Corresponding horizontal and vertical soil DBE acceleration time histories were developed for the mean and $84^{\text {th }}$ percentile IWTU PC 3 Soil DBE 5\% damped spectra. Horizontal time histories from the output of site response analyses were used as seeds to develop the two orthogonal horizontal IWTU PC 3 soil DBE acceleration time histories. The vertical INTEC/RTC/RWMC/PBF PC 3 rock DBE time history was used as a seed to develop the vertical IWTU PC 3 soil DBE acceleration time history. Spectra of the horizontal and vertical IWTU PC 3 soil DBE acceleration time histories match their respective DBE target spectra for frequencies from 0.3 to $25 \mathrm{~Hz}$, which is consistent with NUREG/CR-6728 and ASCE/SEI 43-05 recommendations.

Strain-compatible soil properties were calculated as a function of depth for the horizontal and vertical soil DBE spectra and corresponding time histories. Iterated Vs and damping were calculated based on ratios of the iterated Vs to the low-strain Vs. The ratios were used with Vs of the base case soil profile to calculate the best estimate, lower bound, and upper bound iterated Vs. The squared ratios were then used with the corresponding shear modulus reduction and damping curves to determine the best estimate, lower bound, and upper bound damping values. This approach was used to determine the iterated soil properties as function of depth because iterated Vs that cross the boundary between Layers A and B have bimodal distributions. Low-strain compressional wave velocities as function of depth were calculated using the low-strain Vs and Poisson's ratios measured at the IWTU site. 


\section{FOREWORD}

The purpose of this report is to summarize the development of site-specific PC 3 (2,500 yr) soil DBE 5\% damped spectra, corresponding time histories, and strain-compatible soil properties for the Integrated Waste Treatment Unit (IWTU). The site response analyses incorporate geotechnical data measured at the IWTU site. The Blue Ribbon Panel (BRP), retained as independent reviewers of IWTU seismic analyses, reviewed the approaches, methods, and calculations used in the site response analyses and development of the IWTU DBE parameters. BRP recommendations for Phase I were incorporated into the sitespecific site response analyses. Limited sensitivity analyses were performed in support of developing a mean horizontal and vertical IWTU PC 3 Soil DBE 5\% damped spectra. The BRP proposed that additional sensitivity analyses be conducted as part of Phase 2. Prior to Phase 2, the Defense Nuclear Facilities Safety Board (DNFSB) performed a review of the proposed mean soil DBE spectra. They recommended that the IWTU project use soil DBE spectra at an $84^{\text {th }}$ percentile. The BRP concurred with the DNFSB recommendations and eliminated the need to perform the Phase 2 sensitivity analyses. Revision 1 of this report was issued to include the calculations and development of the site-specific $84^{\text {th }}$ percentile horizontal and vertical IWTU PC 3 soil DBE 5\% damped spectrum and corresponding time histories. 
(Intentionally Blank) 


\section{ACKNOWLEDGMENTS}

I appreciate the reviews and guidance of the Blue Ribbon Panel: Tom Houston, Bob Pyke, Carl Costantino, Richard Lee, Bill Lettis, and Bob Creed. I also thank Don Fox for help checking all of the calculations per the quality requirements. I appreciate the support of Bill Landman, Norm Boyter and William Kerley. The U. S. Department of Energy (DOE), Office of Nuclear Energy, Science, and Technology funded this work under DOE Idaho Field Office Contract DE-AC07-05ID14517. 
(Intentionally Blank) 


\section{CONTENTS}

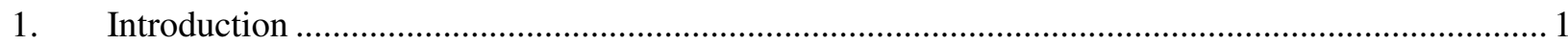

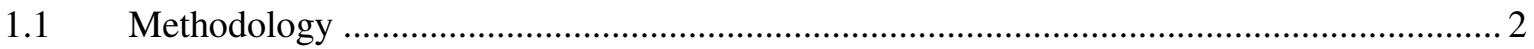

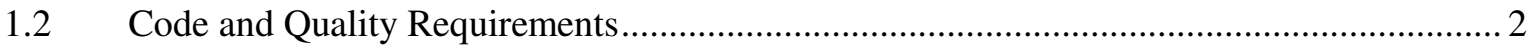

2. Development of the Horizontal Soil Design Spectra................................................................. 5

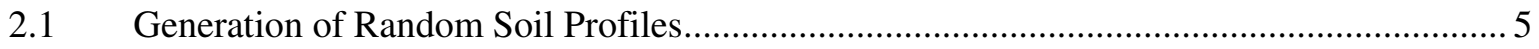

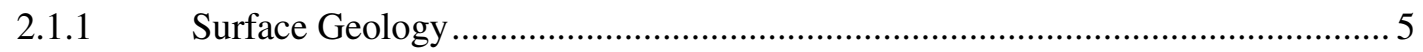

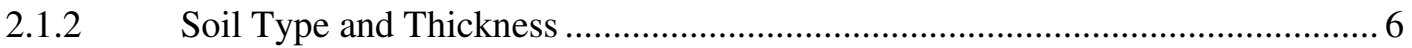

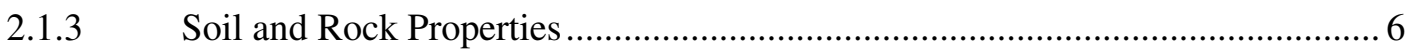

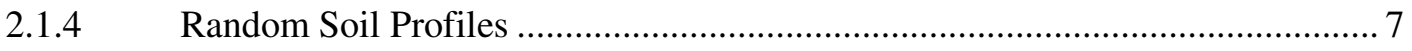

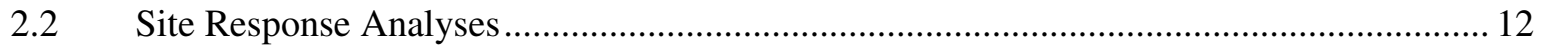

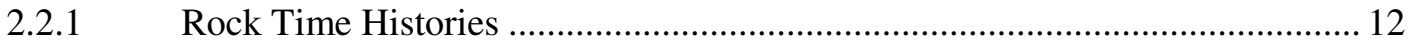

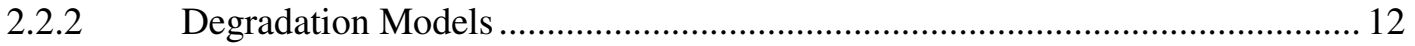

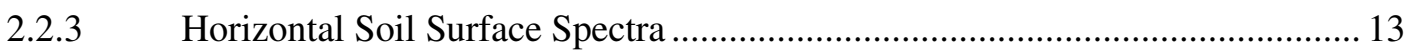

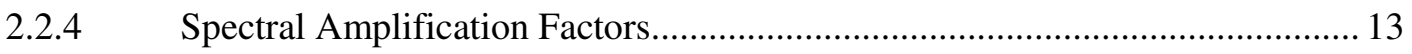

2.3 Horizontal IWTU PC 3 Soil DBE 5\% Damped Spectrum …......................................... 30

2.3.1 Comparison to IWTU SSI Spectrum.......................................................... 30

2.3.2 Development of the IWTU Mean DBE Spectrum …......................................... 30

2.3.3 Development of the IWTU $84^{\text {th }}$ Percentile DBE Spectrum............................... 31

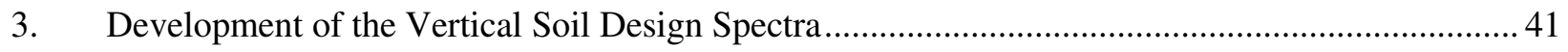

3.1 Development of the Mean Vertical Soil DBE Spectrum............................................... 41

3.2 Development of the $84^{\text {th }}$ Percentile Vertical Soil DBE Spectrum ...................................... 42

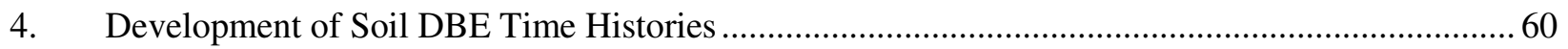

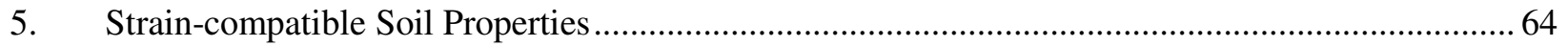

5.1 Iterated Shear Wave Velocity and Damping Calculations ............................................... 64 
5.2 Low-strain Compressional Wave Velocity Calculations................................................ 65

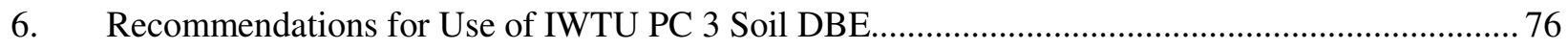

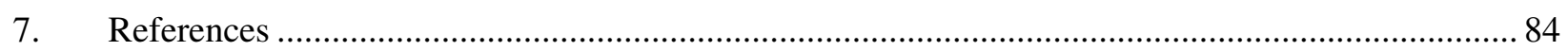




\section{FIGURES}

Figure 1. Map of the facility areas at the Idaho National Laboratory (INL) ........................................ 4

Figure 2. Plot of thirty random and starting soil profile for (a) normal and (b) log normal distributions of shear modulus.

Figure 3. INTEC/RTC/RWMC/PBF PC 3 (2,500 years) Rock DBE time histories for the horizontal 1 component.

Figure 4. INTEC/RTC/RWMC/PBF PC 3 (2,500 years) Rock DBE time histories for the horizontal 2 component.

Figure 5. INTEC/RTC/RWMC/PBF PC 3 (2,500 years) Rock DBE time histories for the vertical component.

Figure 6. "Darendeli/Menq CU 40" shear modulus (G) reduction and damping curves for alluvial soils at $5 \mathrm{ft}$ depth.

Figure 7. "Darendeli/Menq CU 40" shear modulus (G) reduction and damping curves for alluvial soils at $25 \mathrm{ft}$ depth.

Figure 8. Shear modulus $(\mathrm{G})$ reduction and damping curves for fine-grained soils with a Plasticity Index (PI) of 15.

Figure 9. PC 3 (2,500 yr) mean and 30 soil surface $5 \%$ damped spectra for: $\mathrm{H} 1$ and $\mathrm{H} 2$ corresponding to random soil profiles with normal distribution of $\mathrm{G}$.

Figure 10. PC 3 (2,500 yr) mean and 30 soil surface $5 \%$ damped spectra for: $\mathrm{H} 1$ and $\mathrm{H} 2$ corresponding to random soil profiles with log normal distribution of $\mathrm{G}$.

Figure 11. Strain as a function of depth corresponding to 30 random soil profiles with the normal distribution of $\mathrm{G}$ from the output of SHAKE2000.

Figure 12. Damping as a function of depth corresponding to 30 random soil profiles with the normal distribution of $\mathrm{G}$ from the output of SHAKE2000. 26

Figure 13. Strain as a function of depth corresponding to 30 random soil profiles with the $\log$ normal distribution of $\mathrm{G}$ from the output of SHAKE2000.

Figure 14. Damping as a function of depth corresponding to 30 random soil profiles with the $\log$ normal distribution of $\mathrm{G}$ from the output of SHAKE2000..... 28

Figure 15. Spectral amplification factors as function of frequency of the mean soil surface spectra for normal and log normal distributions of shear modulus.

Figure 16. Horizontal PC 3 (2,500 yr) mean soil surface 5\% damped spectra for the two sets of random soil profiles (log normal and normal distribution of $\mathrm{G}$ ). 
Figure 17. The mean horizontal IWTU PC 3 (2,500 yr) Soil DBE 5\% damped spectrum, RTC/INTEC PC 3 DBE spectrum, and mean soil surface spectra for the two sets of random soil profiles (log normal and normal distribution of $\mathrm{G}$ ).

Figure 18. The $84^{\text {th }}$ percentile horizontal IWTU PC 3 (2,500 yr) Soil DBE 5\% damped spectrum, the mean IWTU PC 3 (2,500 yr) Soil DBE 5\% damped spectrum, and the $84^{\text {th }}$ percentile soil surface spectra for the 30 random soil profiles with the log normal distribution of shear modulus

Figure 19. The $84^{\text {th }}$ percentile horizontal IWTU PC 3 (2,500 yr) soil DBE 5\% damped spectrum and individual soil surface spectra for the 30 random soil profiles with the $\log$ normal distribution of shear modulus.

Figure 20. The mean vertical and horizontal IWTU PC 3 Soil DBE 5\% damped spectra and the mean vertical spectral curve....

Figure 21. The $84^{\text {th }}$ percentile vertical and horizontal IWTU PC 3 Soil DBE 5\% damped spectra and the $84^{\text {th }}$ percentile vertical spectral curve.

Figure 22. $84^{\text {th }}$ percentile IWTU PC 3 (2,500 yr) soil DBE time histories for the horizontal 1 component.

Figure 23. $84^{\text {th }}$ percentile IWTU PC 3 (2,500 yr soil DBE time histories for the horizontal 2 component.

Figure 24. $84^{\text {th }}$ percentile IWTU PC 3 (2,500 yr) soil DBE time histories for the vertical component.

Figure 25. The mean horizontal and vertical IWTU PC 3 (2,500 yr) Soil DBE $5 \%$ damped spectra.

Figure 26. The $84^{\text {th }}$ percentile horizontal and vertical IWTU PC 2 (2,500 yr) Soil DBE $5 \%$ damped spectra.

Figure 27. Best estimate, lower bound, and upper bound soil iterated shear wave velocities and corresponding damping ratios for the horizontal IWTU PC 3 Soil DBE spectra and time histories.

Figure 28. Low-strain compressional wave velocities of the soils for the vertical IWTU PC 3 Soil DBE spectra and corresponding time history. 


\section{TABLES}

Table 1. Soil layer thicknesses and soil column heights of IWTU boreholes......................................... 9

Table 2. Properties of the IWTU three-layer starting soil profile for the normal distribution of shear modulus.

Table 3. Properties of the IWTU three-layer starting soil profile for the log normal distribution of shear modulus.

Table 4. "Darendeli/Menq CU 40" shear modulus reduction and damping curves for alluvial soils at $5 \mathrm{ft}$ depth.

Table 5. "Darendeli/Menq CU 40" shear modulus reduction and damping curves for alluvial soils at $25 \mathrm{ft}$ depth

Table 6. Shear modulus reduction and damping curves for fine-grained soils with a Plasticity Index (PI) of 15.

Table 7. Spectral accelerations, velocities, and displacements of the mean horizontal IWTU PC 3 (2,500 yr) Soil DBE 5\% damped spectrum.

Table 8. Spectral accelerations, velocities, and displacements of the $84^{\text {th }}$ percentile horizontal IWTU PC 3 (2,500 yr) Soil DBE 5\% damped spectrum.

Table 9. Calculation of the mean vertical IWTU PC 3 spectral curve.

Table 10. Spectral accelerations, velocities, displacements of the mean vertical IWTU PC 3 spectral curve.

Table 11. Spectral accelerations, velocities, and displacements of the mean vertical IWTU PC 3 (2,500 yr) Soil DBE 5\% damped spectrum.

Table 12. Calculation of the $84^{\text {th }}$ percentile vertical IWTU PC 3 spectral curve. 52

Table 13. Spectral accelerations, velocities, and displacements of the $84^{\text {th }}$ percentile vertical IWTU PC 3 (2,500 yr) Soil DBE 5\% damped spectrum.

Table 14. Calculations of iterated best estimate, lower bound, and upper bound shear wave velocities as function of depth.

Table 15. Calculations of the best estimate, lower bound, and upper bound damping.

Table 16. Calculations of the best estimate, lower bound, and upper bound low-strain compressional wave velocities.

Table 17. Iterated shear wave velocities and corresponding damping values for IWTU PC 3 Soil DBE. .78

Table 18. Low-strain compressional wave velocities for IWTU PC 3 Soil DBE. .79 
(Intentionally Blank) 


\section{ACRONYMS}

ASCE

BRP

COV

$\mathrm{CU}$

CWI

DBE

DNFSB

DOE

EDF

ESRP

G

$\mathrm{G}_{\mathrm{M}}$

$\mathrm{H}$

H1

H2

ICP

INTEC

INL

IWTU

NRC

PC

PGA

RTC

SA

SD
American Society of Civil Engineers

Blue Ribbon Panel

Coefficient of Variation

Coefficient of Uniformity

CH2M Hill Washington Group, Idaho

Design Basis Earthquake

Defense Nuclear Facilities Safety Board

U.S. Department of Energy

Engineering Design File

Eastern Snake River Plain

Shear Modulus

Median Shear Modulus

Soil Column Height

Horizontal One Component

Horizontal Two Component

Idaho Cleanup Project

Idaho Nuclear Technology and Engineering Center

Idaho National Laboratory

Integrated Waste Management Unit

Nuclear Regulatory Commission

Performance Category

Peak Ground Acceleration

Reactor Technology Complex

Spectral Acceleration

Spectral Displacement 
Soil Structure Interaction

STD

Standard

SV

Spectral Velocity

$\mathrm{V} / \mathrm{H}$

Vertical to Horizontal Ratio

Vs

Shear Wave Velocity

$\mathrm{Vp}$

Compressional or Primary Wave Velocity 


\section{Development of Site-specific Soil Design Basis Earthquake (DBE) Parameters for the Integrated Waste Treatment Unit (IWTU)}

\section{Introduction}

The purpose of this report is to summarize the development of the site-specific Performance Category (PC) 3 (2,500 yr) Design Basis Earthquake (DBE) parameters for the Integrated Waste Treatment Unit (IWTU). The IWTU is located at the Idaho Nuclear Technology and Engineering Center (INTEC), which is at the Idaho National Laboratory (INL). The PC 3 DBE soil parameters for IWTU are in the form of horizontal and vertical soil DBE response 5\% damped spectra, corresponding time histories, and strain-compatible soil properties. They were developed for use in IWTU soil structure interaction (SSI) analyses.

Several independent reviews were conducted of the IWTU seismic analyses. The Blue Ribbon Panel (BRP), retained as independent reviewers, reviewed the approaches, methods, and calculations used in the site response analyses and development of the IWTU DBE parameters that are documented in this report. Phase I recommendations of the BRP were incorporated into the site-specific site response analyses, which included limited sensitivity analyses. The BRP proposed that additional sensitivity analyses be conducted as part of a "Phase 2" to evaluate the peak spectral levels and broadness of the peak spectral acceleration region of the mean DBE spectrum (Houston 2007a). Before the start of Phase 2, the Defense Nuclear Facilities Safety Board (DNFSB) conducted a review of the proposed horizontal and vertical soil DBE response 5\% damped spectra developed using the mean results of the site-specific site response analyses. They recommended that the IWTU project adopt an $84^{\text {th }}$ percentile horizontal and vertical PC 3 DBE 5\% damped spectra for SSI analyses (Eggenberger 2008). Further, the DNFSB suggested that this approach adequately accounts for uncertainty in the soil profile randomizations. The BRP concurred with the recommendations of the DNFSB, thus eliminating the need to conduct Phase 2 sensitivity analyses (Houston 2007b).

Initially in response to BRP recommendations, site-specific site response analyses were conducted to determine whether site-specific response spectra for site conditions at IWTU are bounded by or exceed the design spectrum used in the preliminary IWTU SSI analyses (Houston et al. 2006). The preliminary design spectrum for the IWTU SSI analyses was determined by increasing the horizontal RTC/INTEC PC 3 Soil DBE spectrum by 10\%. The horizontal RTC/INTEC PC 3 soil DBE spectrum is contained in the ICP Architectural Engineering Standards (2007) and is based on the report INEEL/EXT-03-00942 (Payne 2006). A factor of 1.1 was applied to the RTC/INTEC PC 3 soil DBE spectrum to account for mean spectral peaks of the three-layer soil profiles with the "Clay" layer that slightly exceed the RTC/INTEC PC 3 soil DBE spectrum (Appendix A; Payne 2006). Preliminary investigations by MSE Technology Applications, Inc. (2006) at the proposed IWTU site indicated boreholes with the "clay" layer.

This document summarizes the approaches and site response analyses performed to determine the horizontal and vertical PC 3 soil DBE spectra, corresponding time histories, and strain-compatible soil properties for IWTU. The site response analyses incorporate geotechnical data measured at the IWTU site. The IWTU is located in the region of the INTEC facility area (Figure 1) that, prior to IWTU geotechnical investigations, had limited borehole and soil property information. As part of the IWTU project, MSE Technology Applications, Inc. (2006) and Kleinfelder, Inc (2007a) collected geotechnical data for design of the IWTU. Site-specific geotechnical data were incorporated into the site-specific site response analyses based on recommendations of the BRP (Houston et al. 2006; Houston 2007a). Recommended degradation models were used in the site-specific site response analyses. The properties 
and degradation models are different from those used in the Payne (2006), which determined the RTC/INTEC PC 3 (2,500 yr) Soil DBE spectrum. The soil surface response spectra from the IWTU sitespecific site response analyses were compared to the "IWTU SSI Spectrum". Results indicate the horizontal IWTU soil DBE spectrum should be based on the soil surface spectra generated by site-specific site response analyses.

\subsection{Methodology}

Site response analyses were conducted using random soil profiles to determine the mean and $84^{\text {th }}$ percentile spectral peak amplitude and frequency for soil conditions at IWTU. Two sets of 30 random soil profiles with normal and lognormal distributions of shear modulus were developed using geotechnical data measured at IWTU. The soil profiles were then used as input to the site response analyses. Horizontal INTEC/RTC/RWMC/PBF PC 3 rock DBE time histories were propagated through each soil profile using degradation models for alluvial (Pyke 2007) and fine-grained (Vucetic and Dobry 1991) soils and SHAKE2000 (Deng and Ostadan 2000) to produce horizontal soil response spectra. The means of the two sets of site-specific soil response spectra exceeded the "IWTU SSI Spectrum".

Horizontal and vertical IWTU PC 3 Soil DBE 5\% damped spectra were developed based on the results of the site response analyses. The mean horizontal DBE peak spectral acceleration was set to 1.100 $\mathrm{g}$ to envelop the largest mean spectral peak of the site-specific soil response spectrum. The spectral acceleration region was broadened by a factor of 1.5 around the frequency $(7.2 \mathrm{~Hz})$ of the spectral peak to produce the mean soil DBE 5\% damped spectrum. For the $84^{\text {th }}$ percentile soil DBE spectrum, the spectral peak acceleration was set to $1.250 \mathrm{~g}$. The mean and $84^{\text {th }}$ percentile horizontal spectra were constructed using an approach similar to Newmark and Hall (1978), having regions of constant acceleration, velocity, and displacement. The mean and $84^{\text {th }}$ percentile vertical IWTU PC 3 soil DBE 5\% damped spectra were determined using their respective horizontal IWTU PC 3 soil DBE 5\% damped spectrum and the vertical to horizontal $(\mathrm{V} / \mathrm{H})$ spectral ratios appropriate for INL.

Horizontal time histories from the output of SHAKE2000 were used as seeds to develop the two orthogonal horizontal IWTU PC 3 soil DBE time histories. The vertical INTEC/RTC/RWMC/PBF PC 3 rock DBE time history was used as a seed to develop the vertical IWTU PC 3 soil DBE time history. The spectra of the horizontal and vertical IWTU PC 3 Soil DBE acceleration time histories were matched to their respective DBE target spectra following the guidance of NUREG/CR-6728 (NRC 2001), which consistent with ASCE/SEI 43-05 (ASCE 2005).

Strain-compatible soil properties were calculated for the horizontal and vertical components. Iterated shear wave velocity (Vs) and damping were based on ratios of the iterated Vs (output from SHAKE2000) to the low-strain Vs (input to SHAKE2000). The ratios were used with Vs of the base case soil profile to calculate the best estimate, lower bound, and upper bound iterated Vs. The squared ratios were then used with the corresponding shear modulus reduction and damping curves to determine the best estimate, lower bound, and upper bound damping values. Low-strain compressional wave velocities were statistically calculated using the input soil profiles to SHAKE2000. The horizontal and vertical IWTU PC 3 (2,500 yr) soil DBE 5\% damped spectra, corresponding time histories, and strain-compatible soil properties developed in this report will be used for SSI analyses of the IWTU.

\subsection{Code and Quality Requirements}

The work and results are consistent with current and applicable U.S. Department of Energy (DOE) Orders and Standards, Nuclear Regulatory Commission (NRC) guidance, American Society of Civil Engineers (ASCE) Standards, and quality requirements. Engineering Design Files (EDF) document the implementation of the quality requirements and their citations are listed in the reference list. EDF-7903 
contains the establishment of the quality requirements for IWTU PC 3 DBE analyses. EDF-5255 and EDF-7905 contain documentation that supports the approaches, technical basis, computer codes, and calculations used in the DBE analyses.

Two separate external peer reviews were conducted for the site response analyses. The first is part of the quality requirements. Dr. Carl Costantino was retained to review spectral matches of the time histories and calculations of the strain-compatible soil properties (EDF-7905). The second is the BRP, an external peer review panel that was retained by Idaho Cleanup Project (ICP) under CH2M Hill Washington Group, Idaho (CWI), which has the lead for the IWTU project. The BRP reviewed methodologies, geotechnical data, horizontal and vertical PC 3 DBE soil spectra, and strain-compatible soil properties. The BRP made recommendations that have been incorporated into the site response analyses. The documentation for these recommendations is held by CWI under the IWTU project number 25051. Where appropriate, copies of the recommendations are contained in the appropriate EDFs. 


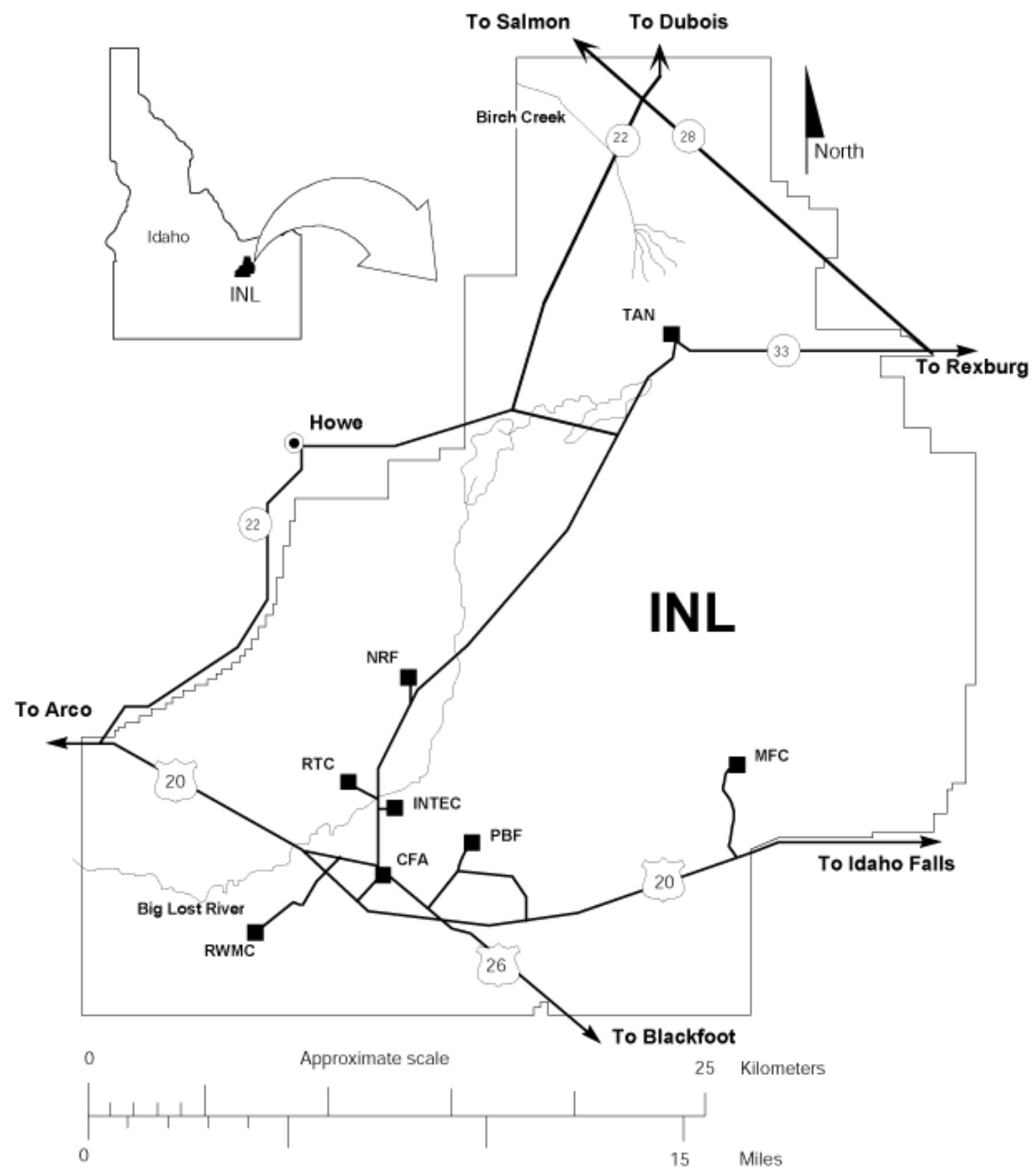

Figure 1. Map of the facility areas at the Idaho National Laboratory (INL). Facility areas include: The IWTU is located at INTEC. Abbreviations: Idaho Nuclear Technology and Engineering Center (INTEC), Materials and Fuels Complex (MFC), Power Burst Facility (PBF), Reactor Technology Complex (RTC), Central Facilities Area (CFA), Radioactive Waster Management Complex (RWMC), Naval Reactor Facility (NRF), and Test Area North (TAN). 


\section{Development of the Horizontal Soil Design Spectra}

Site-specific site response analyses were conducted to develop the horizontal PC 3 (2,500 yr) soil DBE 5\% damped spectrum for IWTU. The site response analyses were performed for two sets of 30 random soil profiles that include variability in layer thickness, soil column heights, and soil properties. Two base case soil profiles were developed using the measured soil and rock properties at the IWTU site. The first base case soil profile was used to generate 30 random soil profiles with the log normal distribution of shear modulus, and the second base case soil profile was used to generate soil profiles with the normal distribution of shear modulus. Random soil profiles were generated for normal and log normal distributions of shear modulus as recommended by the BRP (CWI 2007).

Each soil profile within a set of 30 was used as input to the site response analysis program SHAKE2000 (Deng and Ostadan 2000). The two horizontal components for the PC 3 (2,500 yr) rock time histories were input as outcrop motions at the top of a rock uniform half-space and propagated through each soil profile. Strain-dependent soil properties (shear modulus reduction and hysteretic damping ratio) recommended by the BRP for the alluvial and fine-grained soils at IWTU were used in each of the site response analyses. The mean soil surface spectra were calculated for each set of 30 soil surface spectra generated from the base case profiles and compared with the IWTU SSI spectrum. The soil surface spectra were then enveloped to develop smoothed and broadened horizontal IWTU PC 3 (2,500 yr) soil DBE 5\% damped spectra for the mean and $84^{\text {th }}$ percentile.

\subsection{Generation of Random Soil Profiles}

Base case soil profiles were developed to represent the variability in soil column heights, layer thickness, and soil properties observed in boreholes at IWTU. The base case soil profiles were described by the shear modulus for each soil layer, individual layer thickness, soil column height, and shear modulus for the basement rock. The measured soil and rock properties were obtained from geotechnical investigations at IWTU.

\subsubsection{Surface Geology}

The INL covers 890 square miles of the eastern Snake River Plain (ESRP). The ESRP is commonly recognized as representing the track of a hotspot currently centered beneath Yellowstone National Park, Wyoming. About 4 to $6 \mathrm{Ma}$, the hotspot was centered in the region of the ESRP near INL (Pierce and Morgan 1992). Since the passage of the hotspot, the ESRP has subsided and filled with 1 to $2 \mathrm{~km}$ of basalt lava flows and sediments from the surrounding Basin and Range (Reilinger et al. 1977; Brott et al. 1981; Kuntz et al. 1992; McQuarrie and Rodgers 1998).

IWTU is located at INTEC, which is within the floodplain of the Big Lost River (Figure 1). The Big Lost River flows south out of the Lost River valley onto the ESRP. On the ESRP the Big Lost River flows to the north into the Big Lost Sinks River area. The Big Lost River has been flowing to the north for about 0.5 to $1 \mathrm{Ma}$ depositing alluvial sediments such as sands, silts, gravel and clay (which is mainly fine-grained sediments) over basalt lava flows (Scott, 1982). As a consequence, Big Lost River deposits form alluvial soil layers that overlie basalt bedrock beneath INTEC. At some locations immediately above bedrock and below the Big Lost River alluvial deposits is an older alluvium composed of fine-grained sediments of sandy clays, clayey sands, and fine silty sands primarily derived from wind blown loess (Dames and Moore 1976; 1977; EG\&G Idaho Inc. 1984a; 1984b; Northern Engineering and Testing 1987; Hull 1989; Golder Associates 1992; Kleinfelder, Inc. 2007a). 


\subsubsection{Soil Type and Thickness}

Soil profiles were developed using geotechnical data collected at the IWTU site that included: layer descriptions, layer thicknesses, ranges of layer thicknesses, and soil column heights. Based on the geomechanical model of Kleinfelder, Inc. (2007a), soil layers A, B, and C were used to describe the soil deposits above the basalt rock layers $D_{1}$ and $D_{2}$ for the site response analyses. The soil deposits and rock layer are:

- $\quad$ Layer A: Surface soils (man-made debris, fill material, and/or disturbed soils);

- $\quad$ Layer B: Alluvial soils (alternating layers of cohesionless gravels and sands that are poorly to well graded and contain silt that ranges from trace amounts up to $30-40 \%$ by weight with occasional cobbles);

- $\quad$ Layer C: Clay (cohesive silty clay and clayey silt);

- $\quad$ Layer D: Basalt layers $\mathrm{D}_{1}$ and $\mathrm{D}_{2}$ above the first sedimentary interbed.

Kleinfelder, Inc. (2007a) determined elevations of the soil and rock layers for boreholes drilled at the proposed IWTU site. The elevations were used to compute layer thicknesses. Soil layer thicknesses, variability of soil layer thicknesses, and range of soil column heights were calculated to develop base case soil profiles. The thickness of Layer A ranges from 9.0 to $15.0 \mathrm{ft}$, Layer B from 25.0 to $29.0 \mathrm{ft}$, and Layer $\mathrm{C}$ from 1.2 to $8.0 \mathrm{ft}$. The total thickness of soil deposits over bedrock or soil column height ranges from 40.0 to $47.0 \mathrm{ft}$ (Table 1$)$.

\subsubsection{Soil and Rock Properties}

Base case soil profiles that were used to generate random soil profiles have layer properties described by the shear modulus and variability of the shear modulus. The variability of shear modulus was calculated using normal and log normal distributions. Shear modulus (G) of the soil and rock layers were determined from down-hole Vs measurements obtained in eight boreholes at IWTU and using the calculated mean densities of the soil and rock layers, respectively, based on measurements at IWTU.

\subsubsection{Density}

Kleinfelder, Inc. (2007a; 2007b) measured densities in the soil and rock layers and computed their respective average densities (Table 2). The densities measured in basalt rock layers $D_{1}$ and $D_{2}$ were combined to compute one average density for rock (Kleinfelder, Inc. 2007b). The average densities were used to calculate $\mathrm{G}$ for the soil and rock layers.

\subsubsection{Shear Wave Velocities}

Kleinfelder, Inc. (2007a) computed Vs for the soil and rock layers from down- and cross-hole measurements in boreholes at the proposed IWTU site. Down-hole Vs measurements in boreholes B-31, B-33, B-34, B-35, B-37, B-38, B-39, B-41 were used to compute $\mathrm{G}$ for soil and rock layers of the soil profiles (Kleinfelder, Inc. 2007a). Vs measurements in basalt layers $D_{1}$ and $D_{2}$ above the first sedimentary interbed were used to calculate $G$ for the rock layer of the starting soil profiles used to generate sets of random soil profiles. No cross-hole Vs measurements were used in the site response analyses since measurements were influenced by frozen ground (Kleinfelder, Inc. 2007a). 


\subsubsection{Shear Modulus and Variability}

$\mathrm{G}$ and its variability were used in the base case soil profiles for input to the soil randomization programs. These values were calculated using standard statistical methods for normal and log normal distributions. For the soil and rock layers, $G$ was calculated using the measured borehole Vs, average densities, and Equation [1]:

$$
\mathrm{G}=\left(\mathrm{Vs}^{2} \rho\right) / \mathrm{g}
$$

Where: $\mathrm{G}$ is in units of ksf; $\mathrm{Vs}$ is in $\mathrm{ft} / \mathrm{s}$; $\rho$ is density in $\mathrm{kcf}$; and $\mathrm{g}$ is the acceleration of gravity or 32.17 $\mathrm{ft} / \mathrm{s}^{2}$ ( $\mathrm{kcf}$ is kips/ $\mathrm{ft}^{3}$ and $\mathrm{ksf}$ is kips/ $/ \mathrm{ft}^{2}$ where kips is $\left.1000 \mathrm{lbs}\right)$.

The first base case soil profile was developed for the normal distribution of $\mathrm{G}$ (Table 2). Vs of individual soil layers (Layers A, B, and C) were used in the statistical calculations of $\mathrm{G}$ for each soil layer, and the measured Vs in Layers $D_{1}$ and $D_{2}$ were used in the statistical calculations of $G$ for rock (Layer D). The mean and standard deviation of $\mathrm{G}$ of each soil layer and rock layer were used as input to the computer program (SPNORM; EDF-7905) to generate random soil profiles with the normal distribution of $\mathrm{G}$.

The second base case soil profile was developed for the log normal distribution (Table 3 ). The median $\mathrm{G}$ and coefficient of variation (COV) were calculated for each soil layer and rock layer. The calculations were performed with $\log _{10} \mathrm{G}$ data and standard statistical methods using the program SPRAND (Structural Dynamics Engineering 2000a). The uncertainty in the soil properties represented by the COV was calculated using equations:

$$
\begin{aligned}
& \operatorname{COV}=\left(\log _{10} G_{U B}-\log _{10} G_{M}\right) / \log _{10} G_{M} \\
& \log _{10} G_{U B}=\log _{10} G_{M}+\log _{10} S D E V
\end{aligned}
$$

Where: $\mathrm{G}_{\mathrm{UB}}$ is the upper bound; and SDEV is the standard deviation determined using $\log _{10} \mathrm{G}$.

Normal and log normal distributions of $\mathrm{G}$ were used in the site response analyses based on the recommendations of the BRP. Past site response analyses for INTEC with a greater number of Vs showed a reasonable match of $\mathrm{G}$ data to a log normal distribution for each soil layer (Structural Dynamics Engineering 2000b; also see Houston 2007a). Due to limited Vs data at IWTU for each soil layer and the rock layer, the normal distribution was also considered.

\subsubsection{Random Soil Profiles}

For the site response analyses, 30 random soil profiles were generated from base case soil profiles to incorporate uncertainty in subsurface data and variability at IWTU based on eleven borehole measurements. 30 was chosen for the number of random soil profiles consistent with the numbers of random soil profiles used to compute mean surface spectra for other site response analyses at INTEC (URS Greiner Woodward Clyde Federal Services et al. 1999; Structural Dynamics Engineering, 2000a).

Two sets of 30 random soil profiles were generated using the normal and log normal distributions of $\mathrm{G}$. The starting three-layer soil profile listed in Table 2 was used as input to the computer program SPNORM (EDF-7905) to generate 30 random soil profiles with a normal distribution of G. The starting three-layer soil profile in Table 3 lists the soil and rock properties that were used as input to the computer program SPRAND (Structural Dynamics Engineering, 2000a) to generate 30 random soil profiles with a $\log$ normal distribution of $\mathrm{G}$. The SPNORM and SPRAND programs use a uniform distribution about a 
mean to calculate layer thickness and soil column heights. The soil layer thicknesses, thickness variations, and soil column height variation were derived from Table 1 for the boreholes at IWTU. For the two sets of random soil profiles generated, some thicknesses for Layer $\mathrm{C}$ exceed the maximum observed thickness by $2 \mathrm{ft}$ (observed $8 \mathrm{ft}$ and modeled $10 \mathrm{ft}$ ) so that the soil column heights generated by the program are consistent with the range observed in the boreholes. Figure 2 shows the starting soil profiles with their respective sets of 30 random soil profiles generated for each distribution of shear modulus.

The rock properties were also randomized based on the recommendations by Payne et al., (2002; Appendix F). They recommend randomizing the rock properties when using PC 3 and PC 4 rock motions as outcrop motions at the top of a rock uniform half-space for site response modeling that uses a program such as SHAKE2000 (Deng and Ostadan 2000). This approach is used to be consistent with the rock profile that is not uniform but is interspersed with a series of sedimentary interbeds. The PC 3 DBE rock motions can be treated as normal outcrop motions at the top of a uniform half-space, provided that randomization techniques are used for both soil and rock properties to determine mean soil surface spectra (Payne 2006; Payne et al. 2002).

For comparison, eight individual soil profiles were developed for IWTU boreholes with Vs measurements. They include both two and three-layer soil profiles. The three-layer soil profiles were compared to the resulting 30 soil profiles for the normal and log normal distribution of $\mathrm{G}$. The comparisons show a reasonable match of the generated soil profiles to the borehole soil profiles. Eight or less out of thirty generated profiles have Vs values greater or less than the measured Vs values of the soil and rock layers (Figure A-2; Appendix A). Also, the plots show the generated soil profiles have Vs for Layer A greater than Layer B as observed in the measured Vs. Some Vs for Layer C are greater or less than those in Layer B, which is also consistent with the measured Vs.

Additionally, each borehole soil profile was used as input to SHAKE2000 and the resulting soil surface spectra were compared to the soil spectra generated by the normal and log normal distribution of shear modulus. The individual borehole soil surface spectra are within the 30 soil surface spectra for both distributions (Figure A-5; Appendix A). 
Table 1. Soil layer thicknesses and soil column heights of IWTU boreholes.

\begin{tabular}{|c|c|c|c|c|c|c|c|c|c|c|c|}
\hline \multirow{2}{*}{ Layer } & \multicolumn{11}{|c|}{ IWTU Borehole $^{\mathrm{a}}$} \\
\hline & B-31 & $\mathrm{B}-32$ & B-33 & B-34 & B-35 & $\mathrm{B}-36$ & B-37 & B-38 & B-39 & B-40 & B-41 \\
\hline A (Thickness ft) & 10.0 & 15.0 & 11.0 & 10.0 & 10.0 & 10.0 & 12.0 & 9.0 & 10.0 & 10.0 & 13.0 \\
\hline B (Thickness ft) & 27.7 & 25.0 & 25.5 & 29.0 & 28.8 & 28.8 & 27.0 & 27.6 & 27.0 & 29.0 & 26.3 \\
\hline $\mathrm{C}$ (Thickness ft) & 2.3 & 6.0 & 7.0 & 2.0 & 1.2 & 1.2 & 8.0 & 7.4 & 8.0 & 4.5 & 2.2 \\
\hline $\begin{array}{c}\text { D (Depth to Top } \\
\text { of Basalt }\end{array}$ & 40.0 & 46.0 & 43.5 & 41.0 & 40.0 & 40.0 & 47.0 & 44.0 & 45.0 & 43.5 & 41.5 \\
\hline
\end{tabular}


Table 2. Properties of the IWTU three-layer starting soil profile for the normal distribution of shear modulus $(\mathrm{G})$.

\begin{tabular}{|c|c|c|c|c|c|}
\hline \multirow[b]{2}{*}{ Layer } & \multirow[b]{2}{*}{$\begin{array}{l}\text { Thickness Range } \\
(\mathrm{ft})\end{array}$} & \multirow[b]{2}{*}{$\begin{array}{l}\text { Average Density } \\
\quad(\mathrm{kcf})^{\mathrm{a}}\end{array}$} & \multicolumn{2}{|c|}{$\mathrm{G}^{\mathrm{b}}(\mathrm{ksf})$} & \multirow{2}{*}{$\begin{array}{c}\mathrm{Vs}^{\mathrm{c}}(\mathrm{ft} / \mathrm{s}) \\
\text { Mean }\end{array}$} \\
\hline & & & Mean & $\begin{array}{l}\text { Standard } \\
\text { Deviation }\end{array}$ & \\
\hline A & 9 to 13 & 0.1184 & 2385 & 576 & 805 \\
\hline B & 25 to 29 & 0.1248 & 9371 & 1702 & 1554 \\
\hline $\mathrm{C}$ & 2 to $10^{d}$ & 0.1257 & 8830 & 1288 & 1503 \\
\hline $\mathrm{D}$ & Half-space & 0.1599 & 84756 & 23484 & 4129 \\
\hline \multicolumn{6}{|c|}{$\begin{array}{l}\text { b. Mean and standard deviation } \mathrm{G} \text { were calculated by converting borehole Vs measurements to G using average } \\
\text { densities. }\end{array}$} \\
\hline $\begin{array}{l}\text { c. Equival } \\
\text { d. Thickne }\end{array}$ & $\begin{array}{l}\text { Vs for the mean } \mathrm{G} \text {. } \\
\text { ange exceeds maxim }\end{array}$ & layer thickness $\mathrm{b}$ & to acco & & \\
\hline
\end{tabular}

Table 3. Properties of the IWTU three-layer starting soil profile for the log normal distribution of shear modulus $(\mathrm{G})$.

\begin{tabular}{ccccccc}
\hline Layer & $\begin{array}{c}\text { Thickness } \\
\text { Range (ft) }\end{array}$ & $\begin{array}{c}\text { Average } \\
\text { Density (kcf) }\end{array}$ & $\begin{array}{c}\text { Median G } \\
(\mathrm{ksf})^{\mathrm{b}}\end{array}$ & $\begin{array}{c}\text { Median Vs } \\
(\mathrm{ft} / \mathrm{s})^{\mathrm{c}}\end{array}$ & $\begin{array}{c}\text { Coefficient of } \\
\text { Variation - COV } \\
\mathrm{d}\left(\text { Log }_{10}\right)\end{array}$ & $\begin{array}{c}\text { Equivalent } \\
\text { Factor }\end{array}$ \\
\hline A & 9 to 13 & 0.1184 & 2070 & 750 & 0.032 & 0.28 \\
B & 25 to 29 & 0.1248 & 9197 & 1540 & 0.020 & 0.20 \\
C & 2 to $10^{\mathrm{e}}$ & 0.1257 & 9387 & 1550 & 0.017 & 0.17 \\
D & Half-space & 0.1599 & 83115 & 4089 & 0.032 & 0.32 \\
\hline
\end{tabular}

a. Average densities from (Kleinfelder, Inc. 2007a; 2007b). Units are kcf - kips/ft $\mathrm{ft}^{3}$ ksf - kips/ft ${ }^{2}$; kips - $1000 \mathrm{lbs}$.

b. $G_{M}$ calculated by: 1) converting borehole Vs measurements to $G$ using average density; and 2) performing statistical calculations using $\log _{10} \mathrm{G}$ data.

c. Median Vs calculated by converting $\mathrm{G}_{\mathrm{M}}$ using average density.

d. COV was calculated using $\log _{10} \mathrm{G}$ data.

e. Thickness range exceeds maximum layer thickness by $2 \mathrm{ft}$ to account for soil column height range. 
(a)

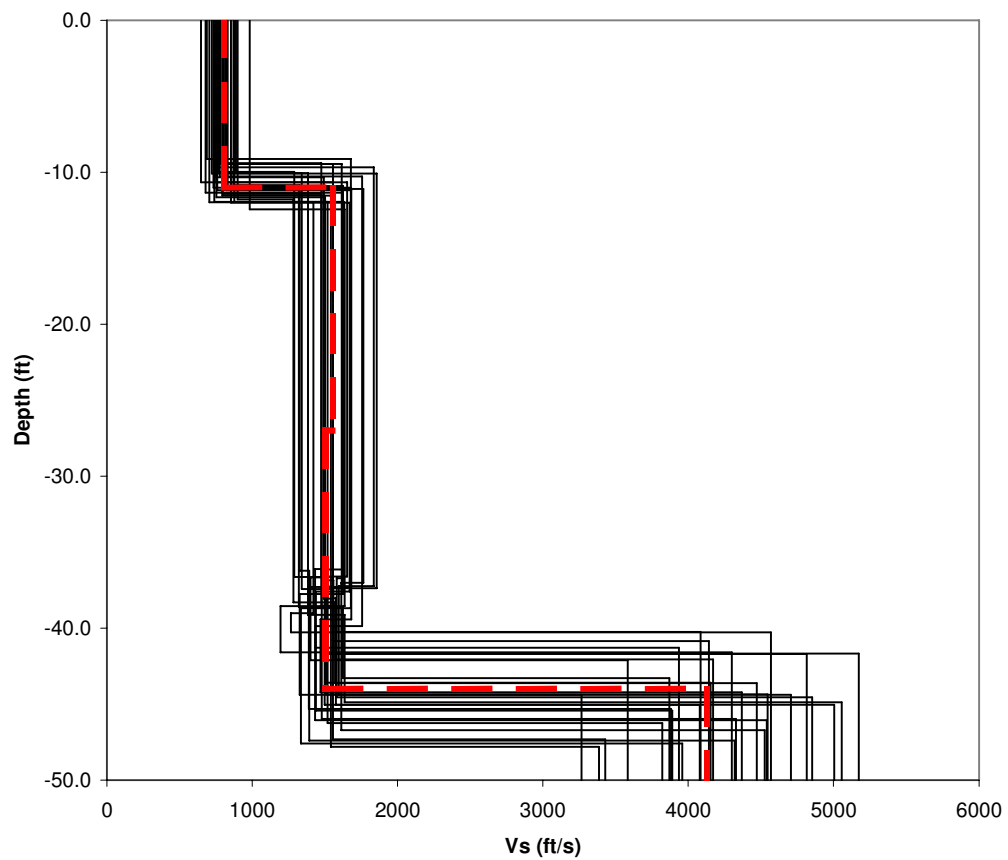

(b)

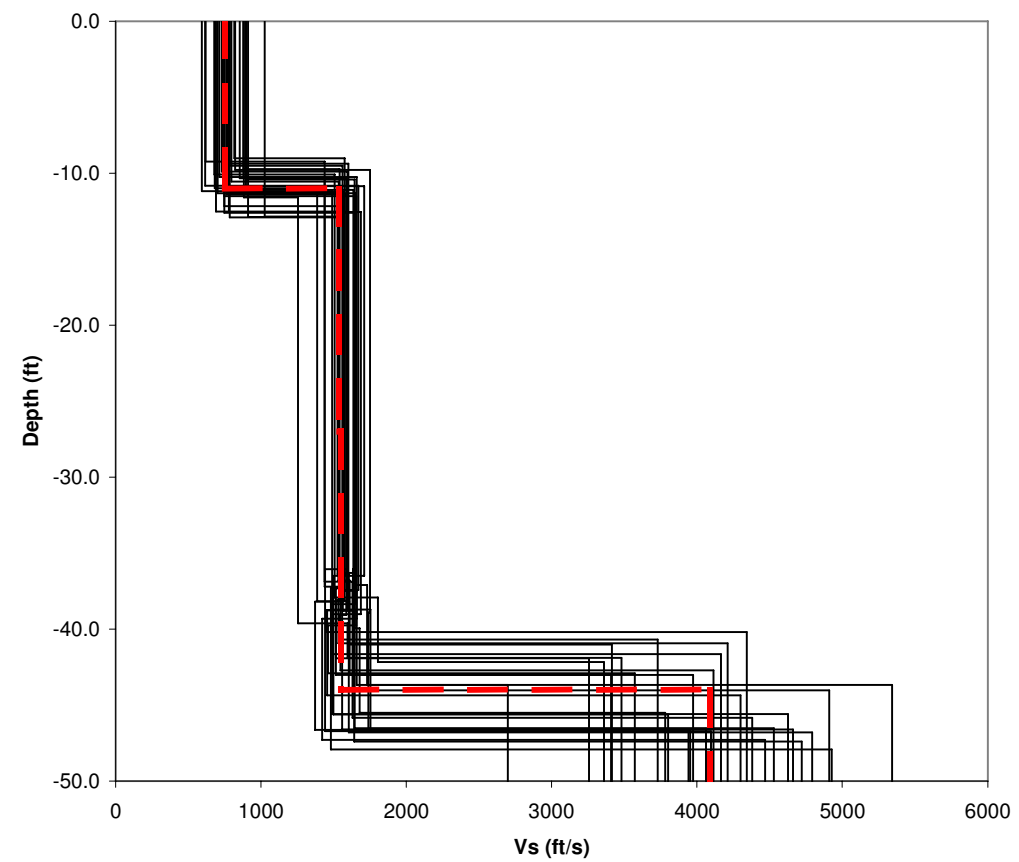

Figure 2. Plot of thirty random (thin black lines) and starting soil profile (red dashed line) for (a) normal and (b) $\log$ normal distributions of shear modulus. 


\subsection{Site Response Analyses}

Soil response spectra were generated using the SHAKE2000 program (Deng and Ostadan 2000). The SHAKE2000 program (Deng and Ostadan 2000) was used to calculate soil surface 5\% damped spectra and time histories. SHAKE is a one-dimensional equivalent linear iterative analysis program. It calculates soil response spectra, time histories and strain-compatible soil properties consistent with the free-field ground surface response of horizontally layered soil deposits. Two horizontal rock acceleration time histories were propagated through each soil profile. Strain-dependent soil properties were determined using soil degradation models for shear modulus and damping as a function of shear strain. The soil profiles were divided into $2 \mathrm{ft}$ sub-layers for input to SHAKE2000. SHAKE2000 computed strain-compatible soil properties for the center of the $2 \mathrm{ft}$ layers. The new strain, shear modulus, and damping values were computed within 15 or less iterations. Thirty soil surface $5 \%$ damped spectra were generated for the 30 random soil profiles of each base case soil profile. Mean and $84^{\text {th }}$ percentile soil surface 5\% damped spectra were then calculated using the 30 soil surface spectra.

\subsubsection{Rock Time Histories}

The two horizontal INTEC/RTC/RWMC/PBF PC 3 (2,500 yr) acceleration rock time histories were used as input to each soil profile. The DBE rock time histories are from the ICP Architectural Engineering Standards (2007), which correspond to the horizontal INTEC/RTC/RWMC/PBF PC 3 Rock DBE 5\% damped spectrum in Payne et al. (2002). Figures 3, 4, and 5 show the INTEC/RTC/RWMC/PBF PC 3 rock acceleration time histories. Arias intensity plots of the rock time histories show smooth increases from 1 to 15 seconds (Appendix B).

The rock time histories were input as outcrop motions at the top of the basalt half-space. This is consistent with current approaches. The response spectrum at the soil ground surface is generated by performing site response analyses using the ground motion defined at the top of rock as input. As currently recommended for site response analyses, soil properties are randomized for the multiple convolution calculations represented in 30 soil profiles. Each soil profile has a Vs for basalt that is represented as a uniform half-space.

\subsubsection{Degradation Models}

The BRP recommended use of three pairs of shear modulus reduction and damping curves (or degradation models) for use in the site response analyses (CWI 2007). The degradation models were selected for alluvial soils in Layers A and B, and for fine-grained soils referred to as clay in Layer C. The degradation models for the alluvial soils are different from those used in Payne (2006). Sensitivity analyses were conducted using three other pairs of shear modulus reduction and damping curves for the alluvial soils, including those used in Payne (2006). In addition to using other degradation models, COV was increased to assess the effects to spectral peak amplitudes and frequencies for all four degradation models. These results are discussed in Appendix C.

The three degradation models used in this site response analyses for the soil layers are:

- $\quad$ Layer A: "Darendeli/Menq CU 40" model for coefficient of uniformity (CU) of 40 at a soil depth of $5 \mathrm{ft}$ (Pyke 2007).

- $\quad$ Layer B: "Darendeli/Menq CU 40" model for CU of 40 at a soil depth of $25 \mathrm{ft}$ (Pyke 2007).

- $\quad$ Layer C: "PI 15" model from Vucetic and Dobry (1991) for Plasticity Index (PI) of 15. 
The degradation models are shown in Figures 6, 7, and 8. The shear modulus reduction and damping values are listed in Tables 4, 5, and 6.

Pyke (2007) developed the "Darendeli/Menq CU 40" shear modulus reduction and damping curves from Darendeli (2001) and Menq (2003) consistent with grain size curves for the alluvial soils at IWTU. The CU for the alluvial soils at IWTU ranges from 30 to 50 (Kleinfelder, Inc. 2007a). Menq (2003) concluded that it is the uniformity of the gradation (or CU) of gravels that affects their nonlinearity, rather than the particle size. For Layer C, Kleinfelder, Inc. (2007a) determined the PI of these fine-grained sediments range from 7 to 28. Based on the PI data, the shear modulus reduction and damping curves of Vucetic and Dobry (1991) for a PI of 15 were used for Layer C.

Two assumptions were made to use the "Darendeli/Menq CU 40" degradation models in the site response analyses. The "Darendeli/Menq CU 40" model at $5 \mathrm{ft}$ was assumed to be applicable to Layer A for depths from 0 to $13 \mathrm{ft}$. The "Darendeli/Menq CU 40" model at $25 \mathrm{ft}$ was assumed to be applicable to Layer B for depths from 13 to $47 \mathrm{ft}$.

\subsubsection{Horizontal Soil Surface Spectra}

The two horizontal PC 3 DBE rock time histories were propagated through the sets of 30 randomized soil profiles to produce horizontal soil surface 5\% damped response spectra. Figures 9 and 10 show the mean soil surface spectra and spectra for 30 random soil profiles for the normal and log normal distributions of G, respectively, are generally similar. Individual spectral peaks exceed the mean spectral peaks for the $\mathrm{H} 1$ and $\mathrm{H} 2$ components. The majority of individual spectral peaks are between 7 and $8 \mathrm{~Hz}$. The individual spectral peak accelerations are up to $1.2 \mathrm{~g}$ for the normal distribution and $1.4 \mathrm{~g}$ for the $\log$ normal distribution.

Strain and damping profiles as a function of depth were computed from the SHAKE2000 output. The individual strain and damping for each soil profile are shown in Figures 11 and 12 for the normal distribution of $\mathrm{G}$ and in Figures 13 and 14 for the log normal distribution. The strain and damping plots show the largest peaks at the boundary between Layers A and B. The strains at this boundary range from 0.01 to $0.06 \%$ with the exception of two soil profiles that are up to $0.11 \%$.

\subsubsection{Spectral Amplification Factors}

One average horizontal spectrum was calculated by averaging spectral amplification factors of each horizontal component ( $\mathrm{H} 1$ and $\mathrm{H} 2$ ). This approach was taken to calculate one soil surface spectrum each for the mean and $84^{\text {th }}$ percentile. Spectral ratios were computed for spectral accelerations as a function frequency for each $\mathrm{H} 1$ and $\mathrm{H} 2$ soil surface spectrum to the corresponding $\mathrm{H} 1$ and $\mathrm{H} 2$ rock outcrop spectrum. The average amplification factors as function of frequency were computed for the two horizontal components. The average horizontal rock outcrop spectrum was computed for the $\mathrm{H} 1$ and $\mathrm{H} 2$ rock spectra. The average horizontal rock outcrop spectrum was multiplied by the average spectral amplification factors to produce the mean and $84^{\text {th }}$ percentile horizontal soil surface spectra that are used to develop design spectra (Appendix A; Table A-2).

The mean spectral amplification factors as a function of frequency are shown in Figure 15 for the normal and log normal distributions of G. The peak amplification factor is 3.5 at the spectral frequency of $7.18 \mathrm{~Hz}$ for both distributions. 
Table 4. "Darendeli/Menq CU 40" shear modulus (G) reduction and damping curves for alluvial soils at $5 \mathrm{ft}$ depth (Pyke 2007).

\begin{tabular}{|c|c|c|c|}
\hline Log (Shear Strain - \%) & G/Gmax & Log (Shear Strain - \%) & Damping Ratio (\%) \\
\hline-4.00 & 0.97 & -4.00 & 0.4 \\
\hline-3.70 & 0.95 & -3.70 & 0.5 \\
\hline-3.52 & 0.94 & -3.52 & 0.7 \\
\hline-3.30 & 0.91 & -3.30 & 1.0 \\
\hline-3.00 & 0.85 & -3.00 & 1.6 \\
\hline-2.70 & 0.76 & -2.70 & 2.8 \\
\hline-2.52 & 0.70 & -2.52 & 3.8 \\
\hline-2.30 & 0.61 & -2.30 & 5.3 \\
\hline-2.00 & 0.47 & -2.00 & 7.8 \\
\hline-1.70 & 0.34 & -1.70 & 10.4 \\
\hline-1.52 & 0.27 & -1.52 & 11.7 \\
\hline-1.30 & 0.20 & -1.30 & 13.1 \\
\hline-1.00 & 0.12 & -1.00 & 14.7 \\
\hline-0.70 & 0.08 & -0.70 & 15.8 \\
\hline-0.52 & 0.06 & -0.52 & 16.2 \\
\hline-0.30 & 0.04 & -0.30 & 16.5 \\
\hline-0.15 & 0.03 & -0.15 & 16.5 \\
\hline 0.00 & 0.02 & 0.00 & 16.5 \\
\hline
\end{tabular}


Table 5. "Darendeli/Menq CU 40" shear modulus (G) reduction and damping curves for alluvial soils at $25 \mathrm{ft}$ depth (Pyke 2007).

\begin{tabular}{|c|c|c|c|}
\hline Log (Shear Strain - \%) & G/Gmax & Log (Shear Strain - \%) & Damping Ratio (\%) \\
\hline-4.00 & 0.99 & -4.00 & 0.2 \\
\hline-3.70 & 0.98 & -3.70 & 0.3 \\
\hline-3.52 & 0.97 & -3.52 & 0.4 \\
\hline-3.30 & 0.95 & -3.30 & 0.6 \\
\hline-3.00 & 0.91 & -3.00 & 1.0 \\
\hline-2.70 & 0.85 & -2.70 & 1.8 \\
\hline-2.52 & 0.80 & -2.52 & 2.5 \\
\hline-2.30 & 0.72 & -2.30 & 3.8 \\
\hline-2.00 & 0.58 & -2.00 & 6.2 \\
\hline-1.70 & 0.43 & -1.70 & 9.2 \\
\hline-1.52 & 0.35 & -1.52 & 11.0 \\
\hline-1.30 & 0.25 & -1.30 & 13.2 \\
\hline-1.00 & 0.16 & -1.00 & 15.7 \\
\hline-0.70 & 0.09 & -0.70 & 17.5 \\
\hline-0.52 & 0.07 & -0.52 & 18.2 \\
\hline-0.30 & 0.04 & -0.30 & 18.7 \\
\hline-0.15 & 0.03 & -0.15 & 18.9 \\
\hline 0.00 & 0.02 & 0.00 & 18.9 \\
\hline
\end{tabular}


Table 6. Shear modulus $(\mathrm{G})$ reduction and damping curves for fine-grained soils with a Plasticity Index (PI) of 15 (Vucetic and Dobry 1991).

\begin{tabular}{|c|c|c|c|}
\hline Log (Shear Strain - \%) & G/Gmax & Log (Shear Strain - \%) & Damping Ratio (\%) \\
\hline-4.0 & 1.000 & -4.0 & 1.6 \\
\hline-3.5 & 1.000 & -3.5 & 1.6 \\
\hline-3.0 & 0.994 & -3.0 & 1.6 \\
\hline-2.5 & 0.935 & -2.5 & 2.6 \\
\hline-2.0 & 0.819 & -2.0 & 4.5 \\
\hline-1.5 & 0.637 & -1.5 & 7.8 \\
\hline-1.0 & 0.410 & -1.0 & 11.5 \\
\hline-0.5 & 0.211 & -0.5 & 16.1 \\
\hline 0.0 & 0.089 & 0.0 & 20.0 \\
\hline
\end{tabular}



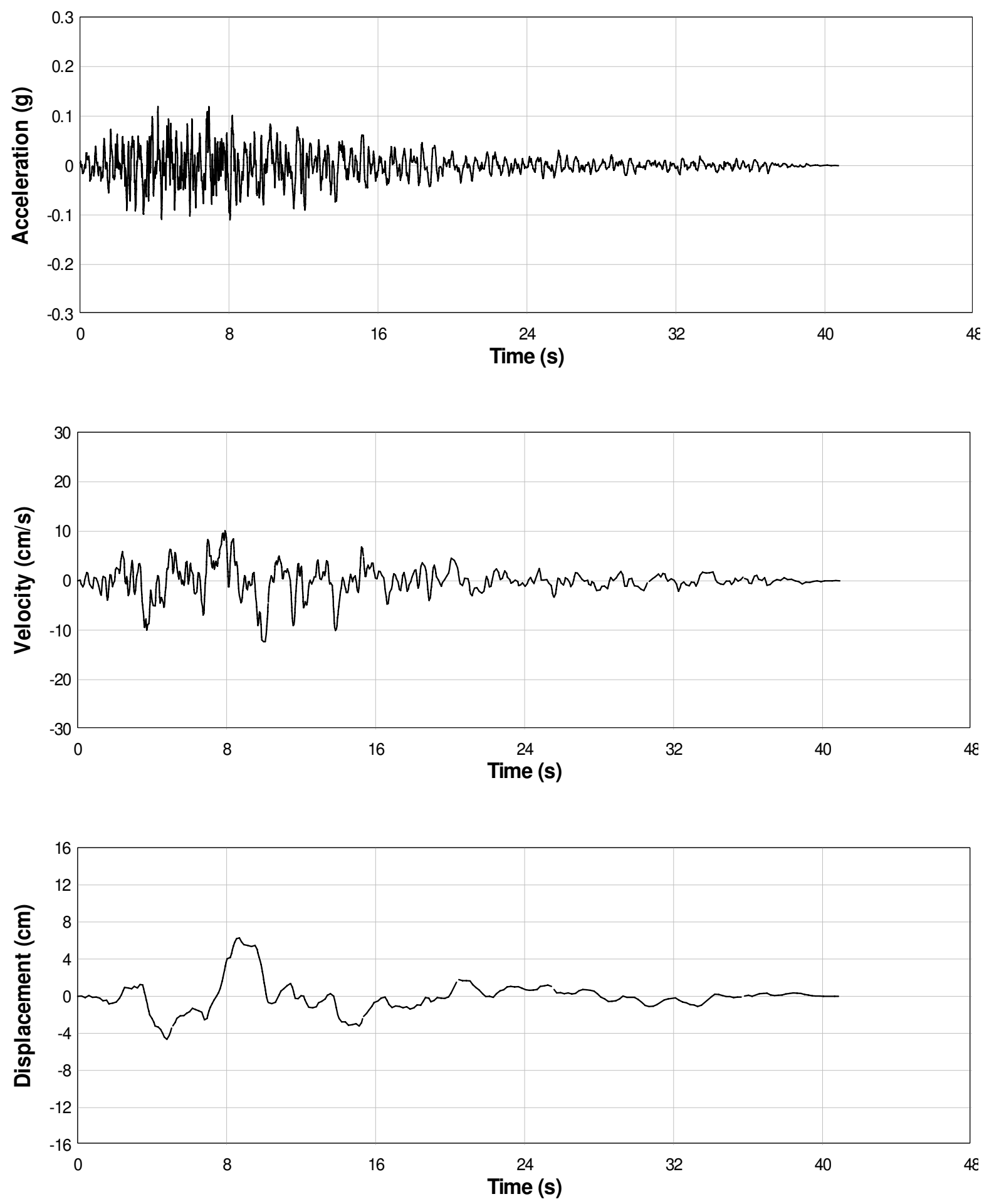

Figure 3. INTEC/RTC/RWMC/PBF PC 3 (2,500 years) Rock DBE time histories for the horizontal 1 component. 

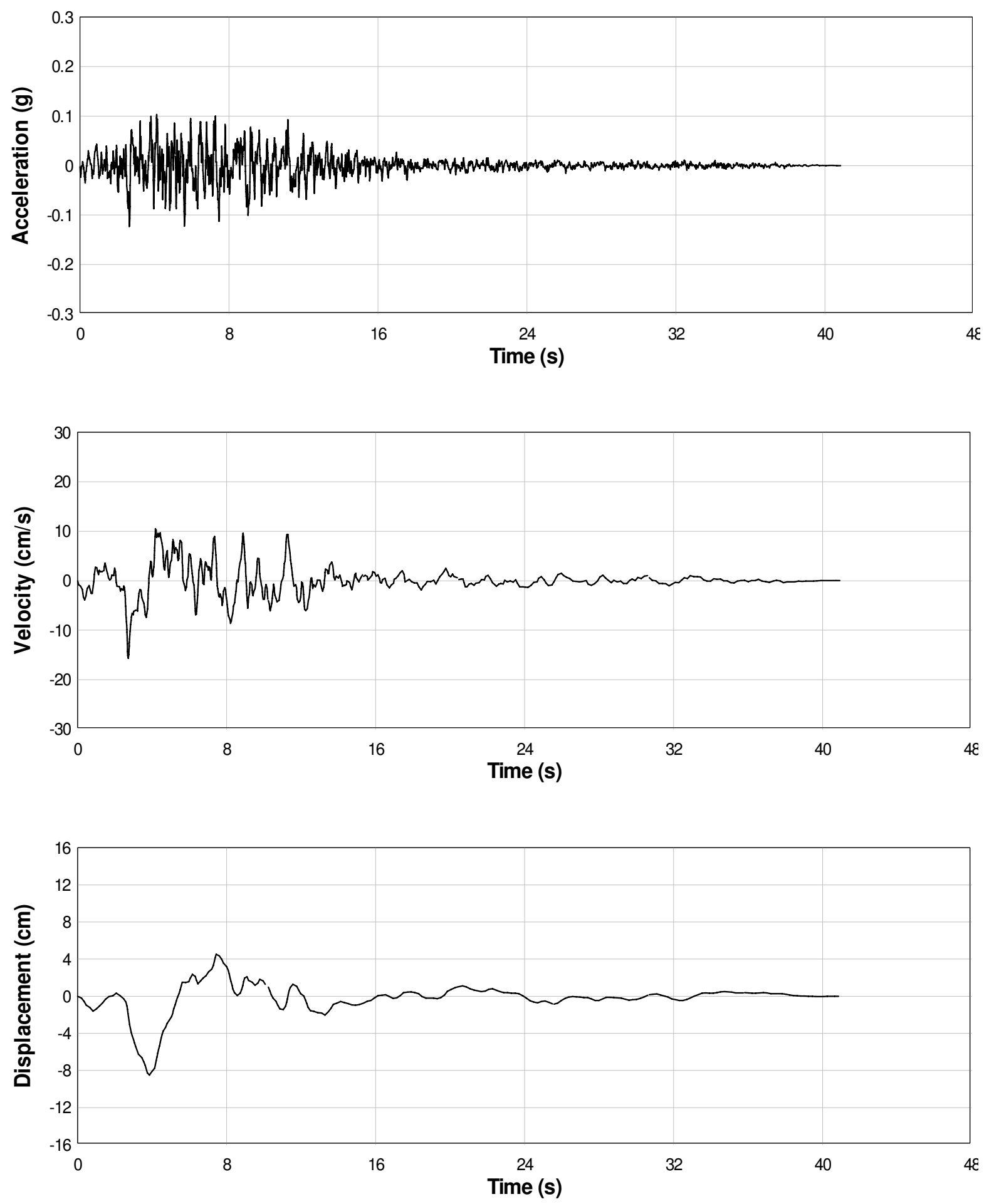

Figure 4. INTEC/RTC/RWMC/PBF PC 3 (2,500 years) Rock DBE time histories for the horizontal 2 component. 

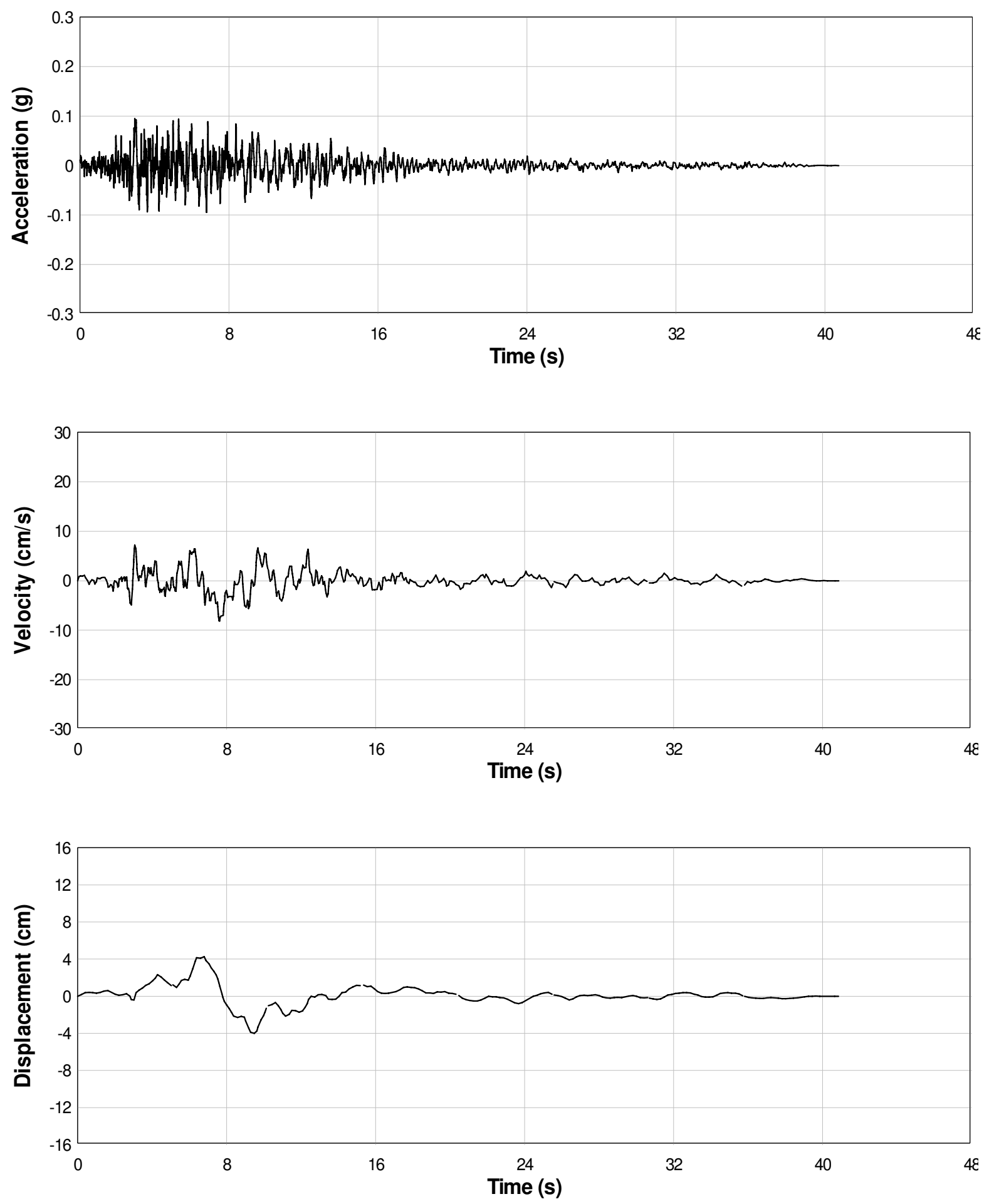

Figure 5. INTEC/RTC/RWMC/PBF PC 3 (2,500 years) Rock DBE time histories for the vertical component. 
(a)
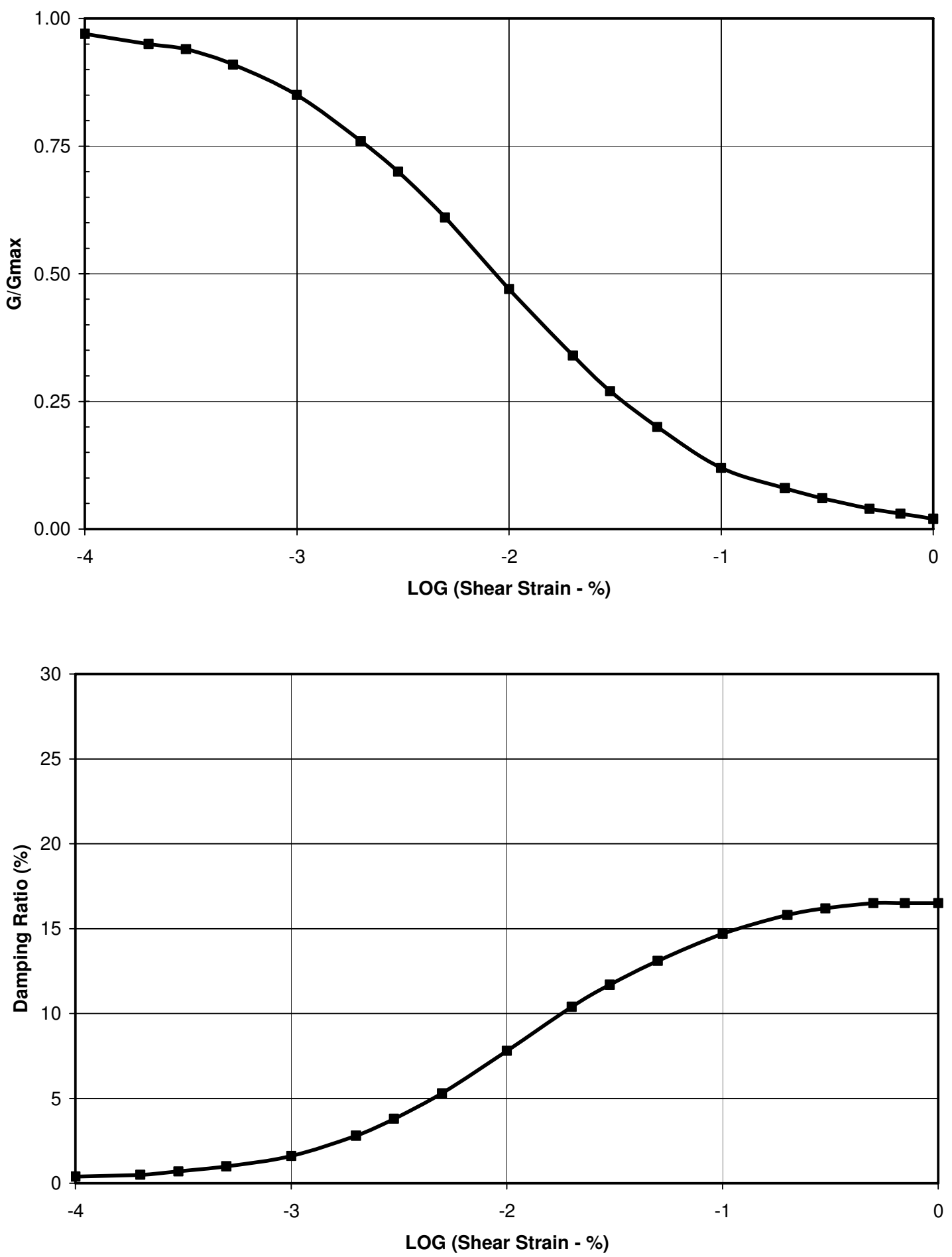

Figure 6. "Darendeli/Menq CU 40" (a) shear modulus (G) reduction and (b) damping curves for alluvial soils at $5 \mathrm{ft}$ depth (Pyke 2007). 
(a)

(b)
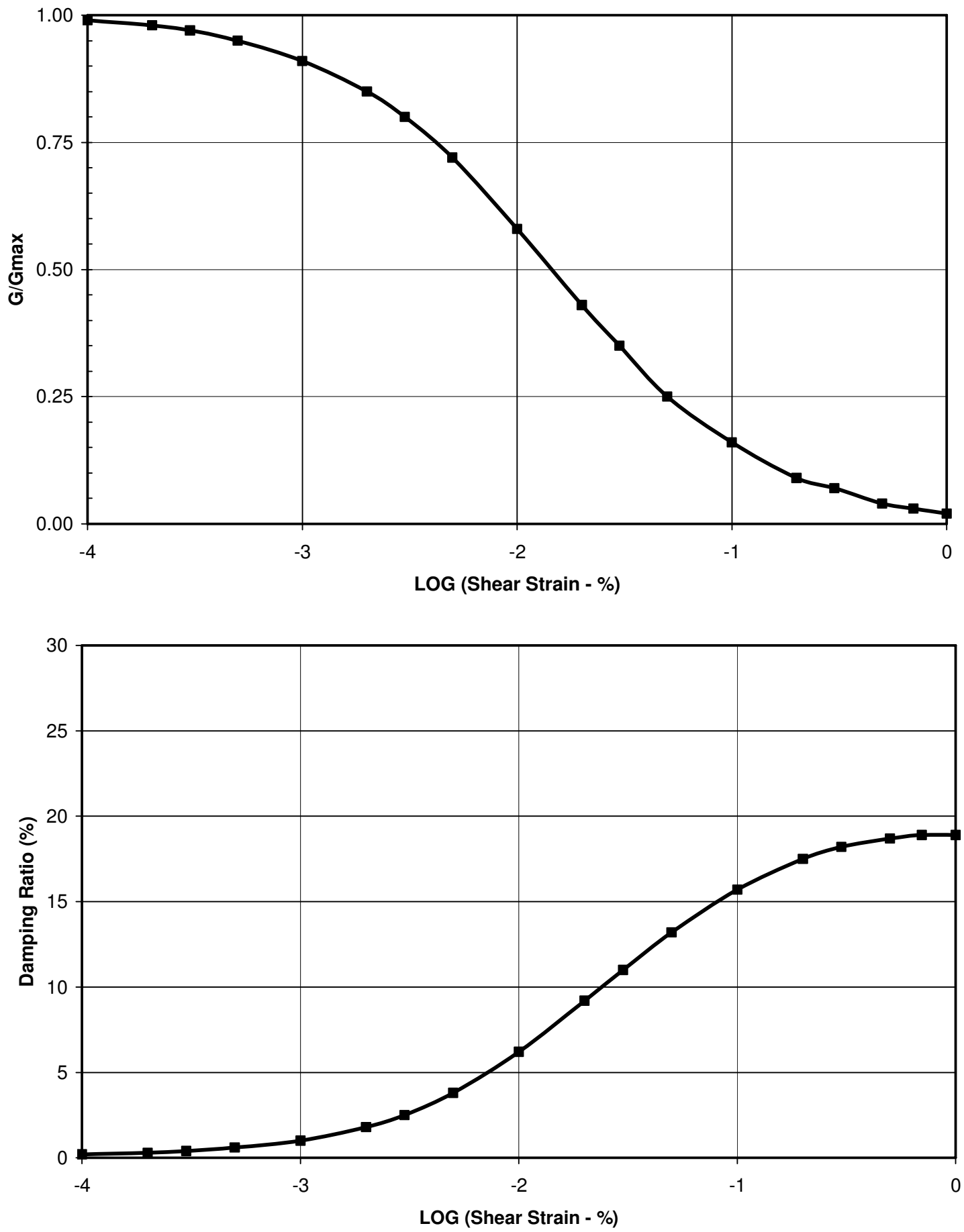

Figure 7. "Darendeli/Menq CU 40" (a) shear modulus (G) reduction and (b) damping curves for alluvial soils at $25 \mathrm{ft}$ depth (Pyke 2007). 
(a)

(b)
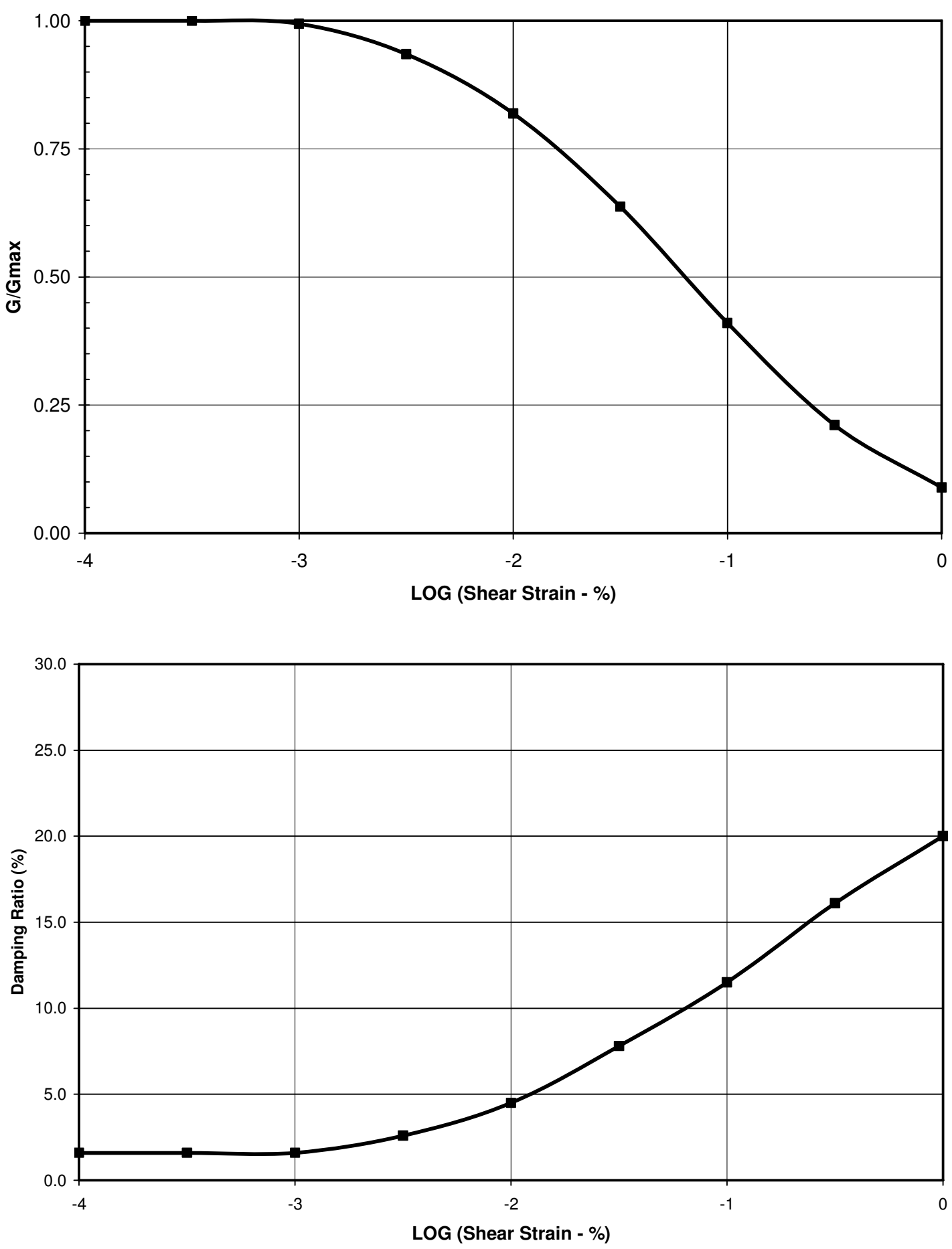

Figure 8. (a) Shear modulus (G) reduction and (b) damping curves for fine-grained soils with a Plasticity Index (PI) of 15 (Vucetic and Dobry 1991). 
(a)

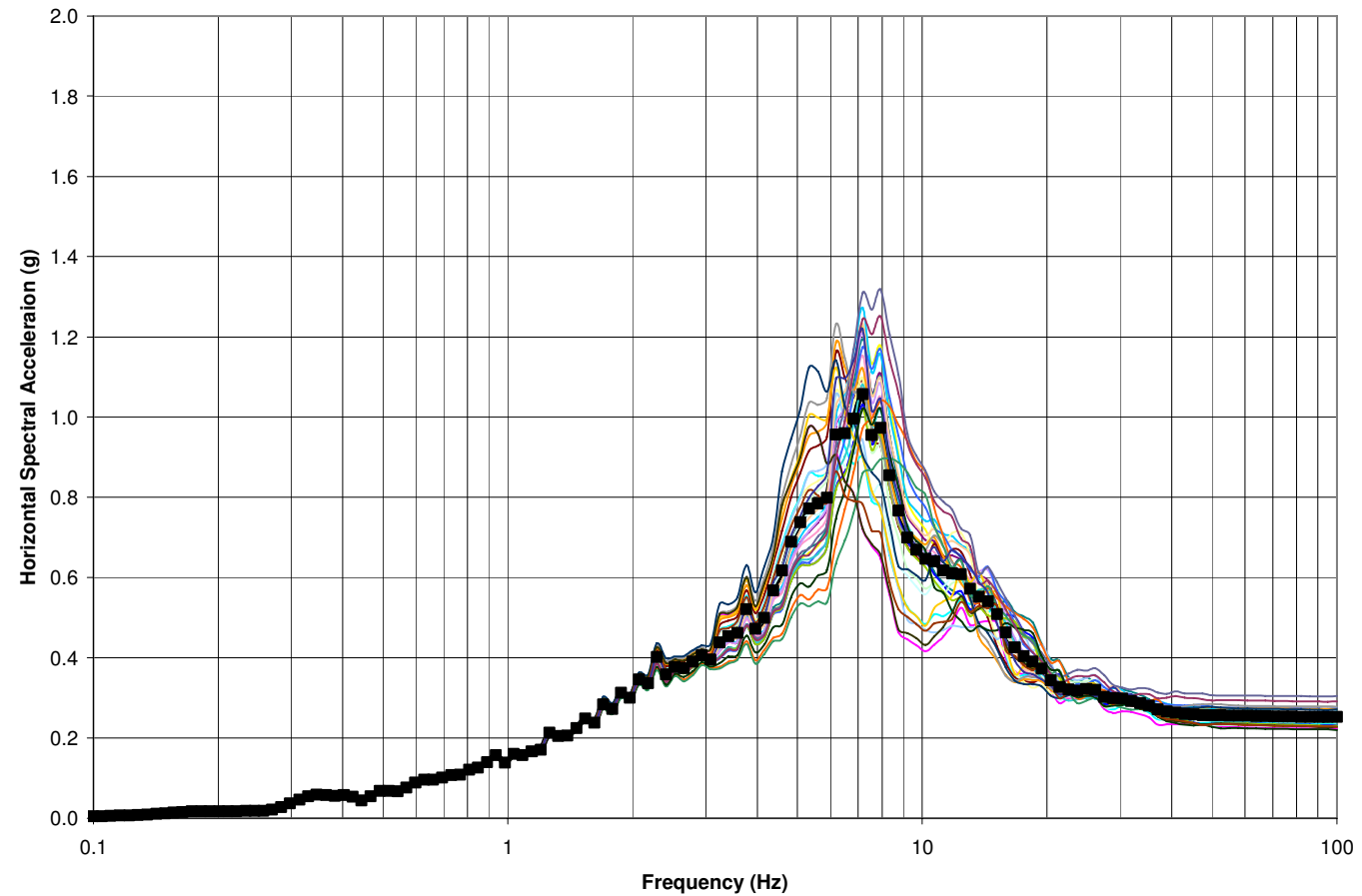

(b)

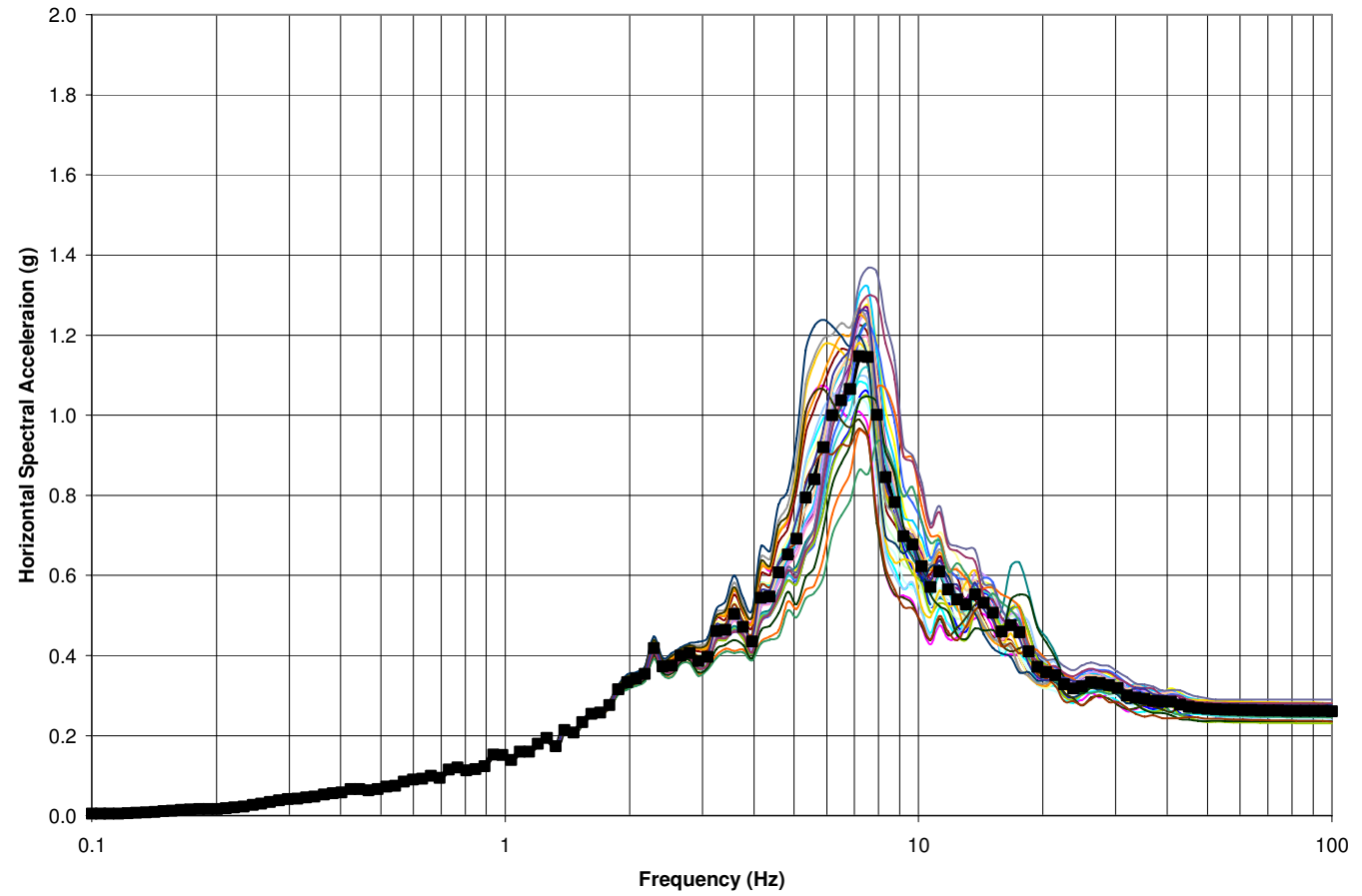

Figure 9. PC 3 (2,500 yr) mean (black jagged line) and 30 soil surface $5 \%$ damped spectra (colored lines) for: (a) $\mathrm{H} 1$ and (b) $\mathrm{H} 2$ corresponding to random soil profiles with normal distribution of $\mathrm{G}$. 
(a)

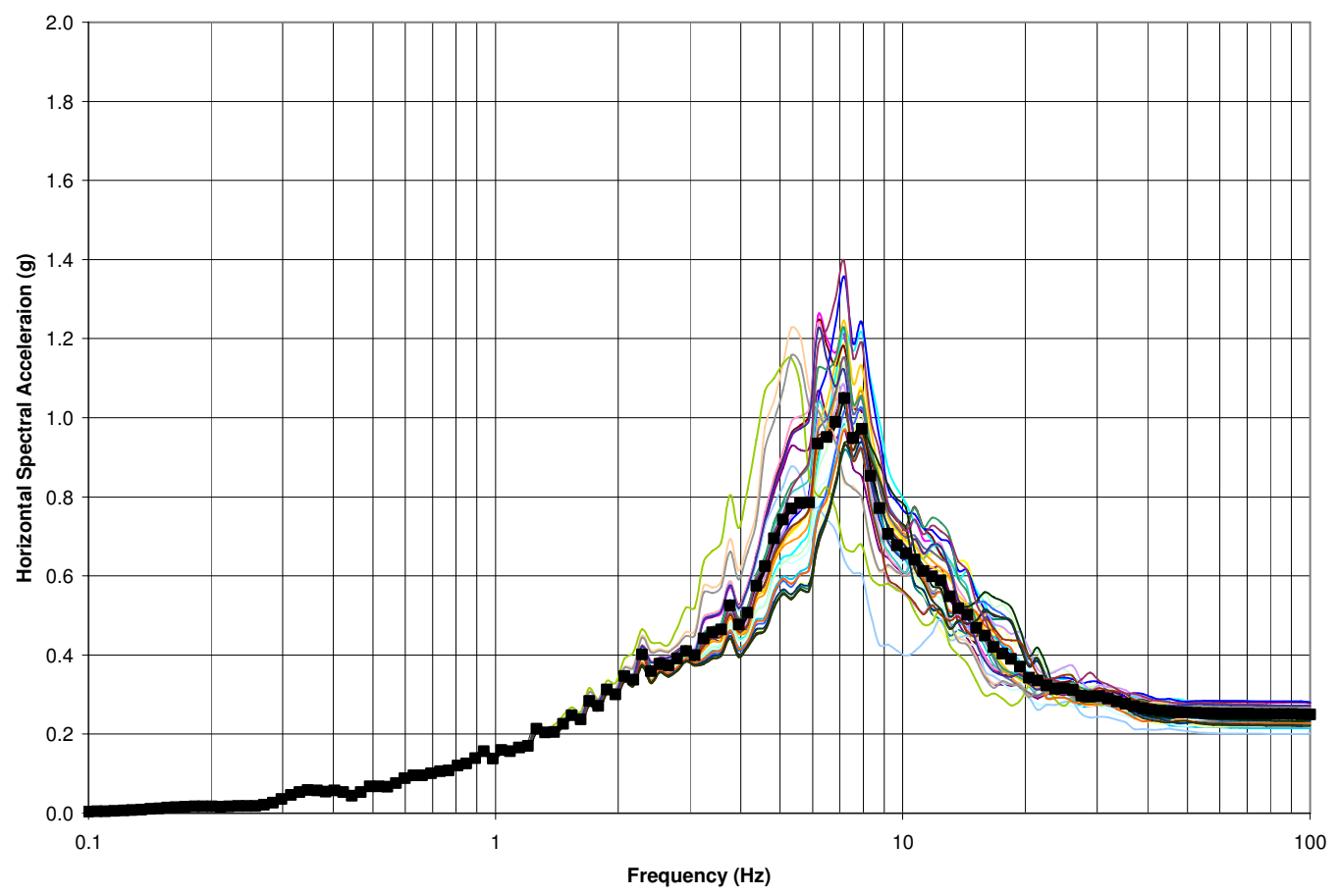

(b)

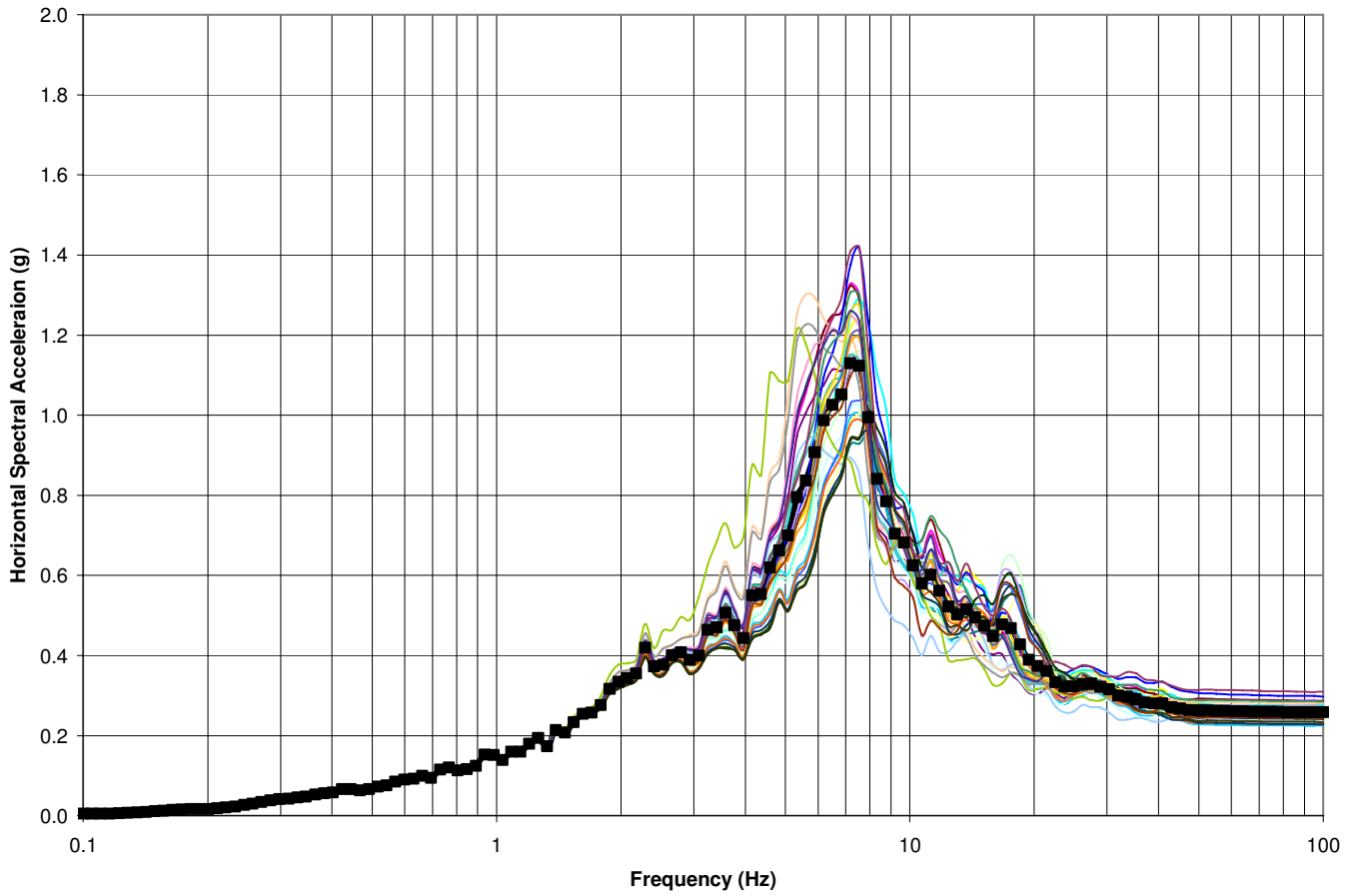

Figure 10. PC 3 (2,500 yr) mean (black jagged line) and 30 soil surface 5\% damped spectra (colored lines) for: (a) $\mathrm{H} 1$ and (b) $\mathrm{H} 2$ corresponding to random soil profiles with log normal distribution of $\mathrm{G}$. 
(a)

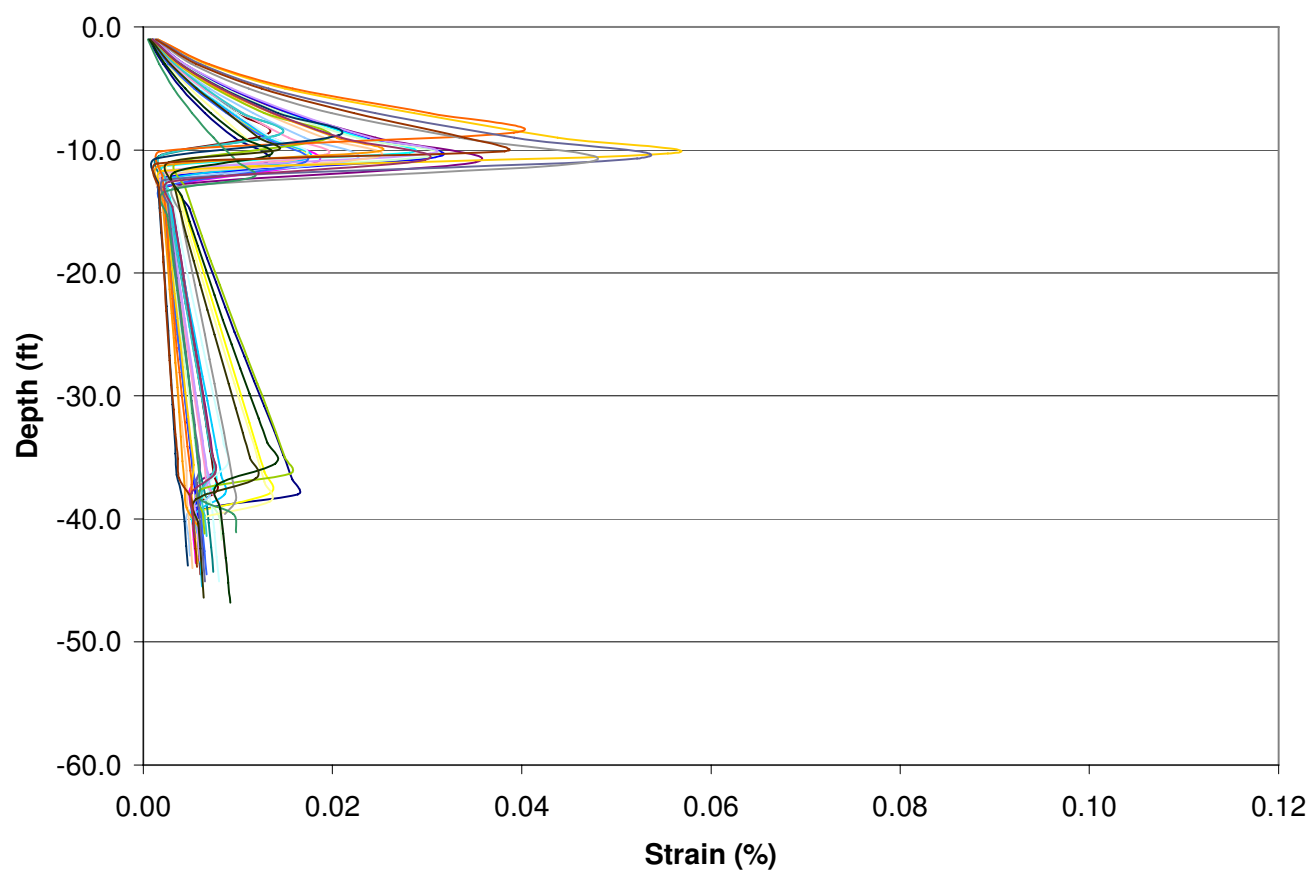

(b)

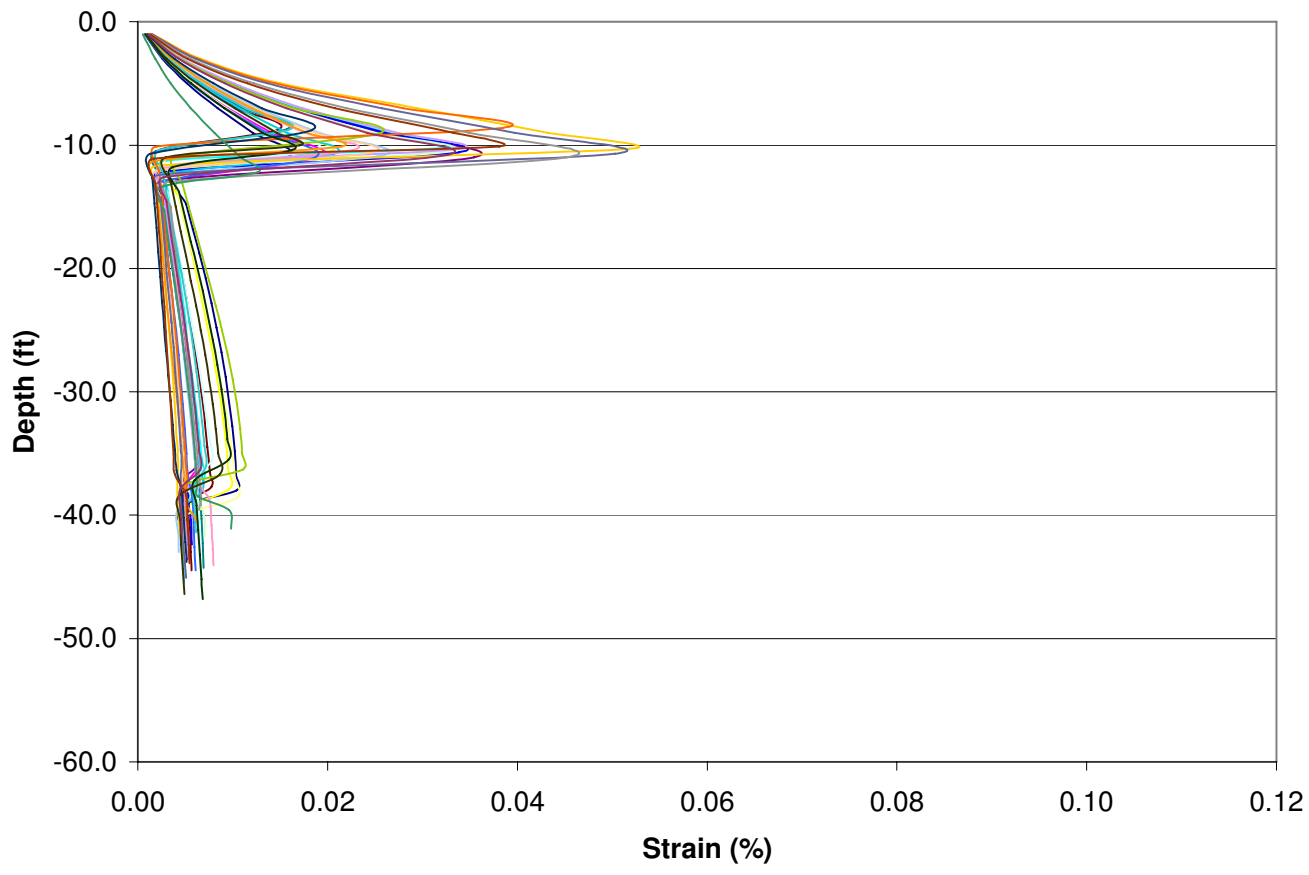

Figure 11. Strain as a function of depth corresponding to 30 random soil profiles with the normal distribution of $\mathrm{G}$ from the output of SHAKE2000 for: (a) H1 and (b) H2. 
(a)

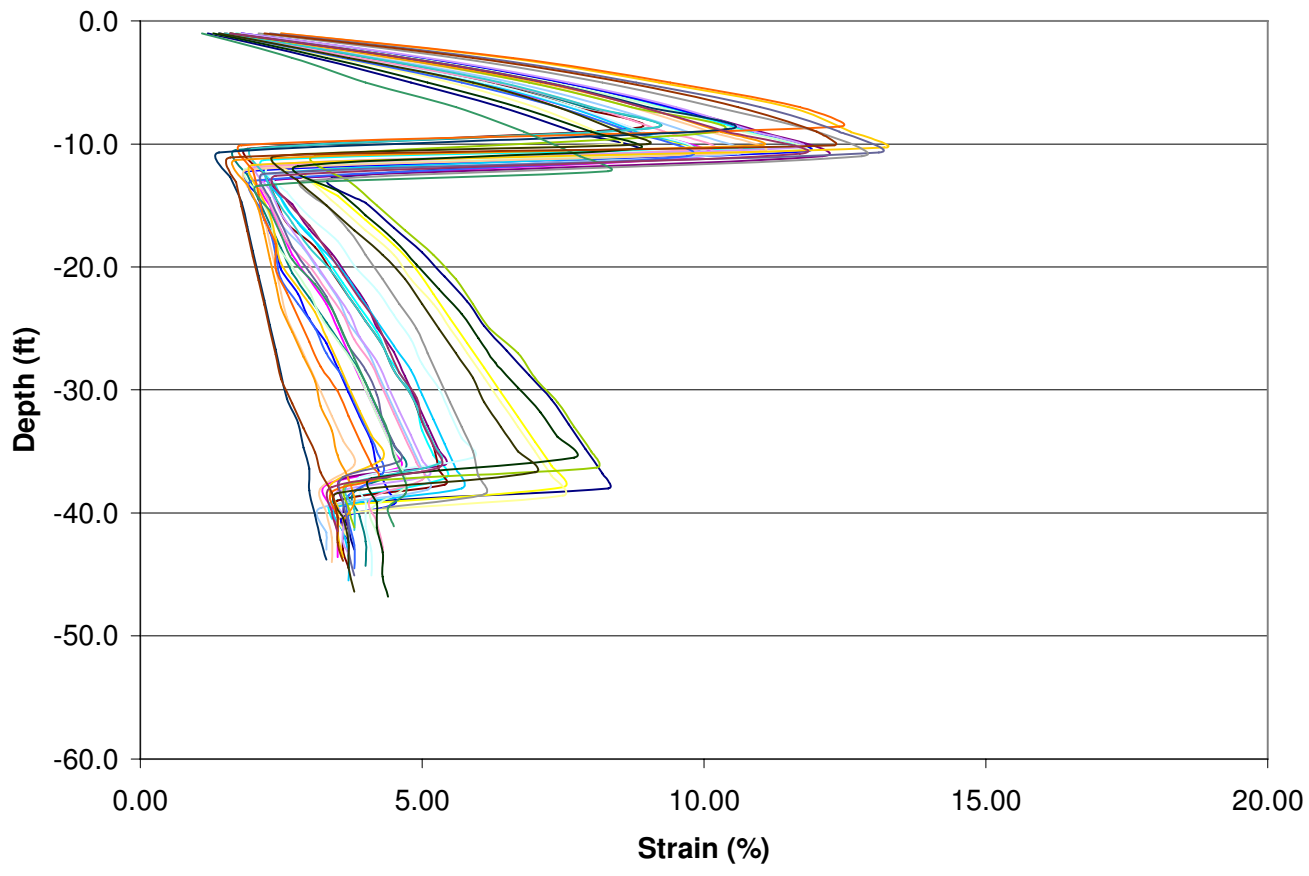

(b)

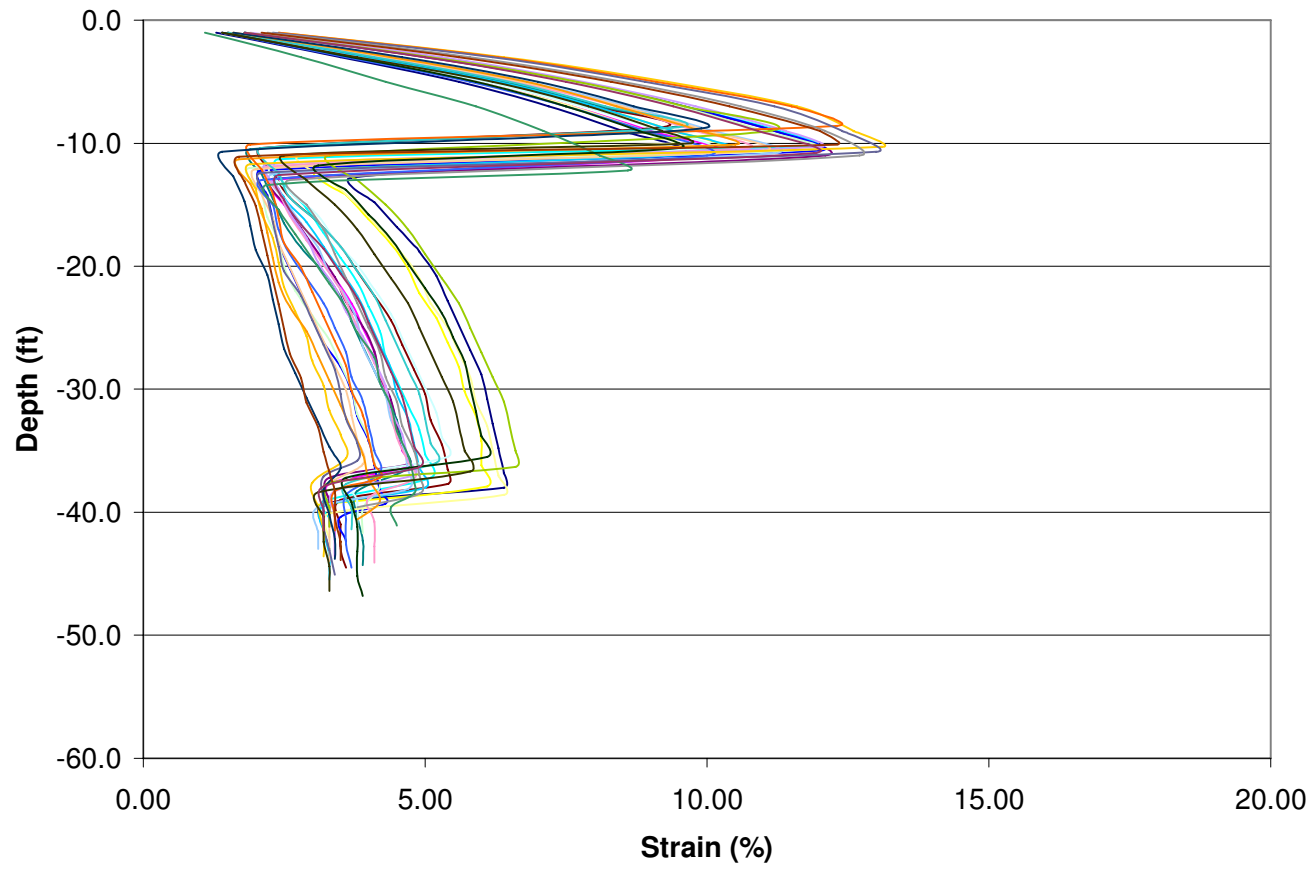

Figure 12. Damping as a function of depth corresponding to 30 random soil profiles with the normal distribution of G from the output of SHAKE2000 for: (a) H1 and (b) H2. 
(a)

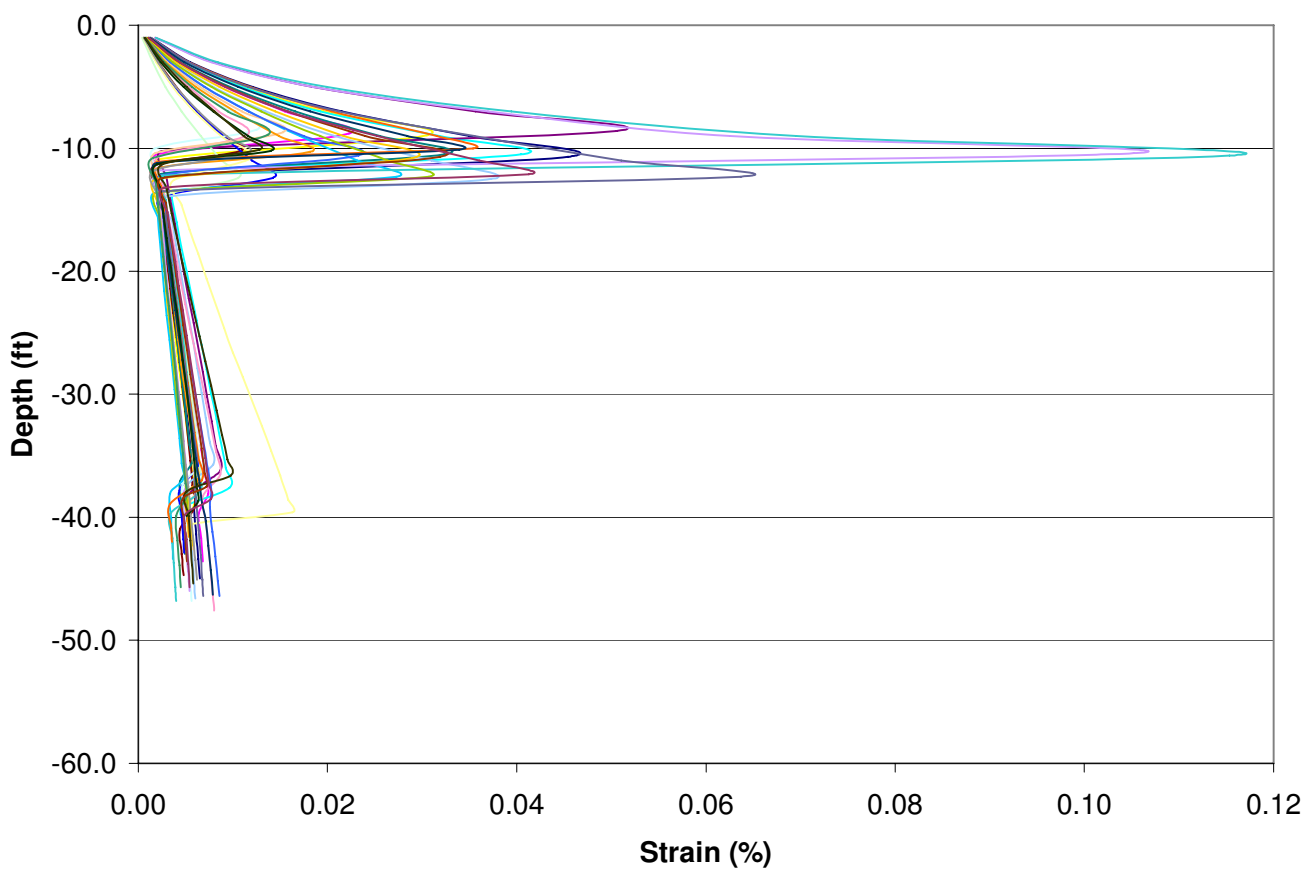

(b)

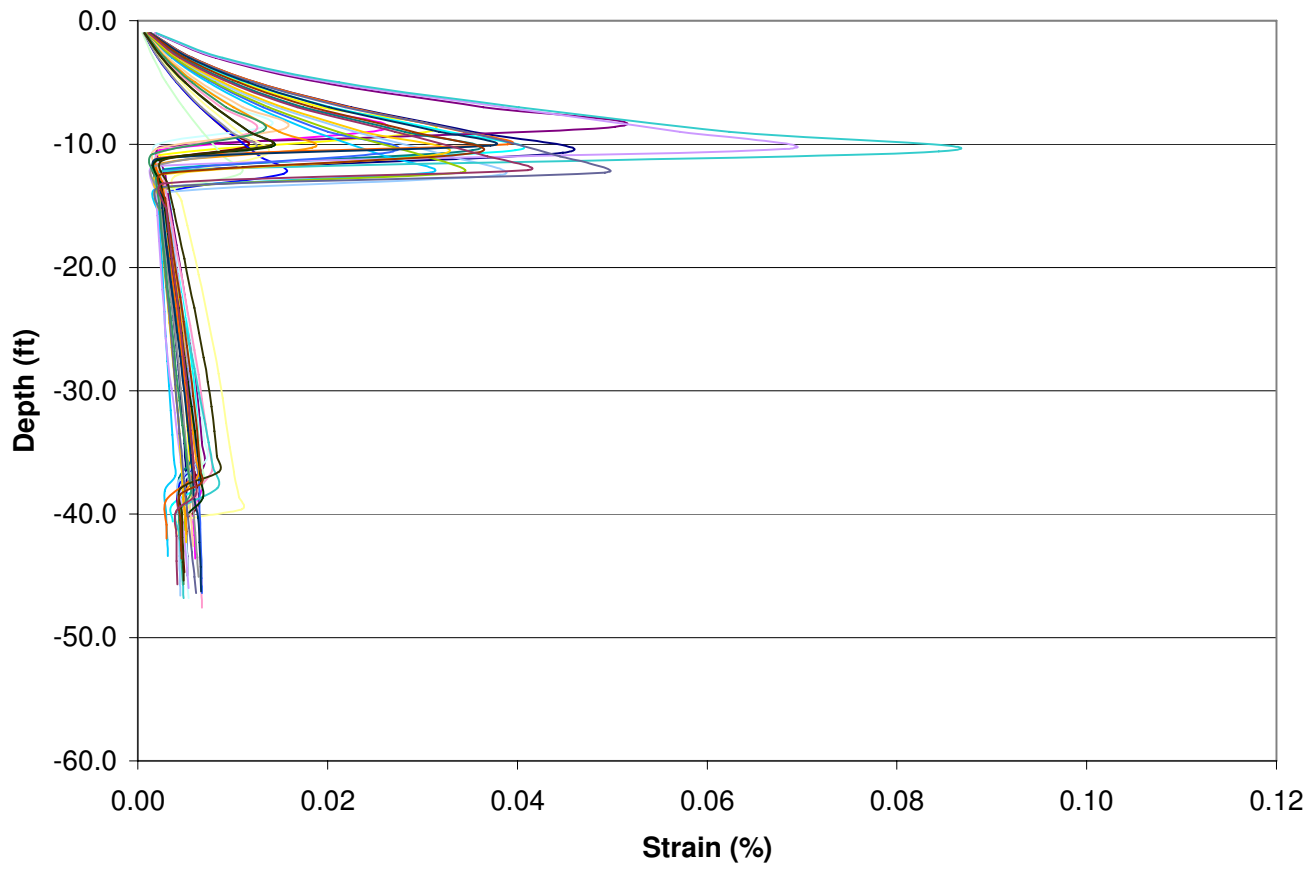

Figure 13. Strain as a function of depth corresponding to 30 random soil profiles with the log normal distribution of $\mathrm{G}$ from the output of SHAKE2000 for: (a) H1 and (b) H2. 
(a)

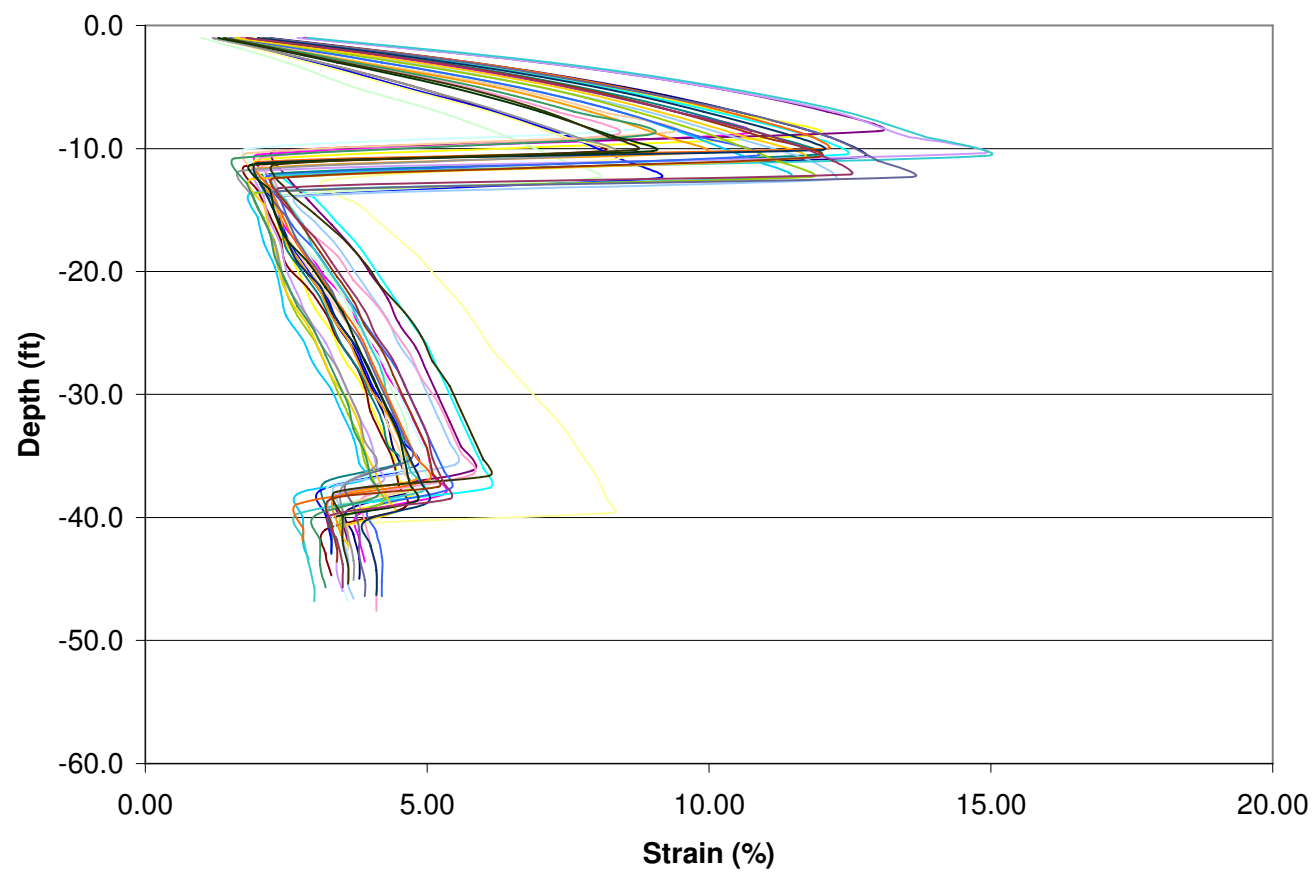

(b)

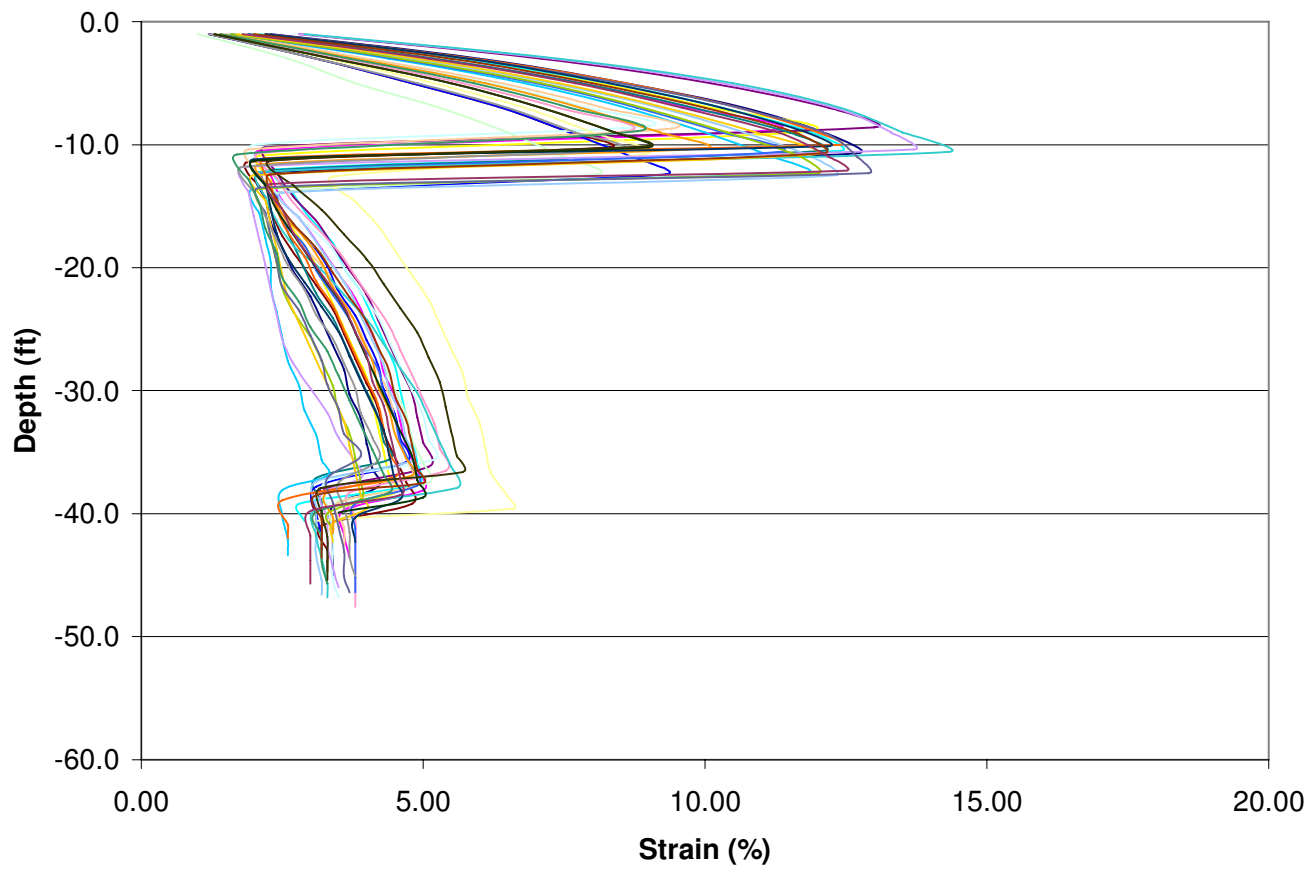

Figure 14. Damping as a function of depth corresponding to 30 random soil profiles with the log normal distribution of G from the output of SHAKE2000 for: (a) H1 and (b) H2. 
(a)

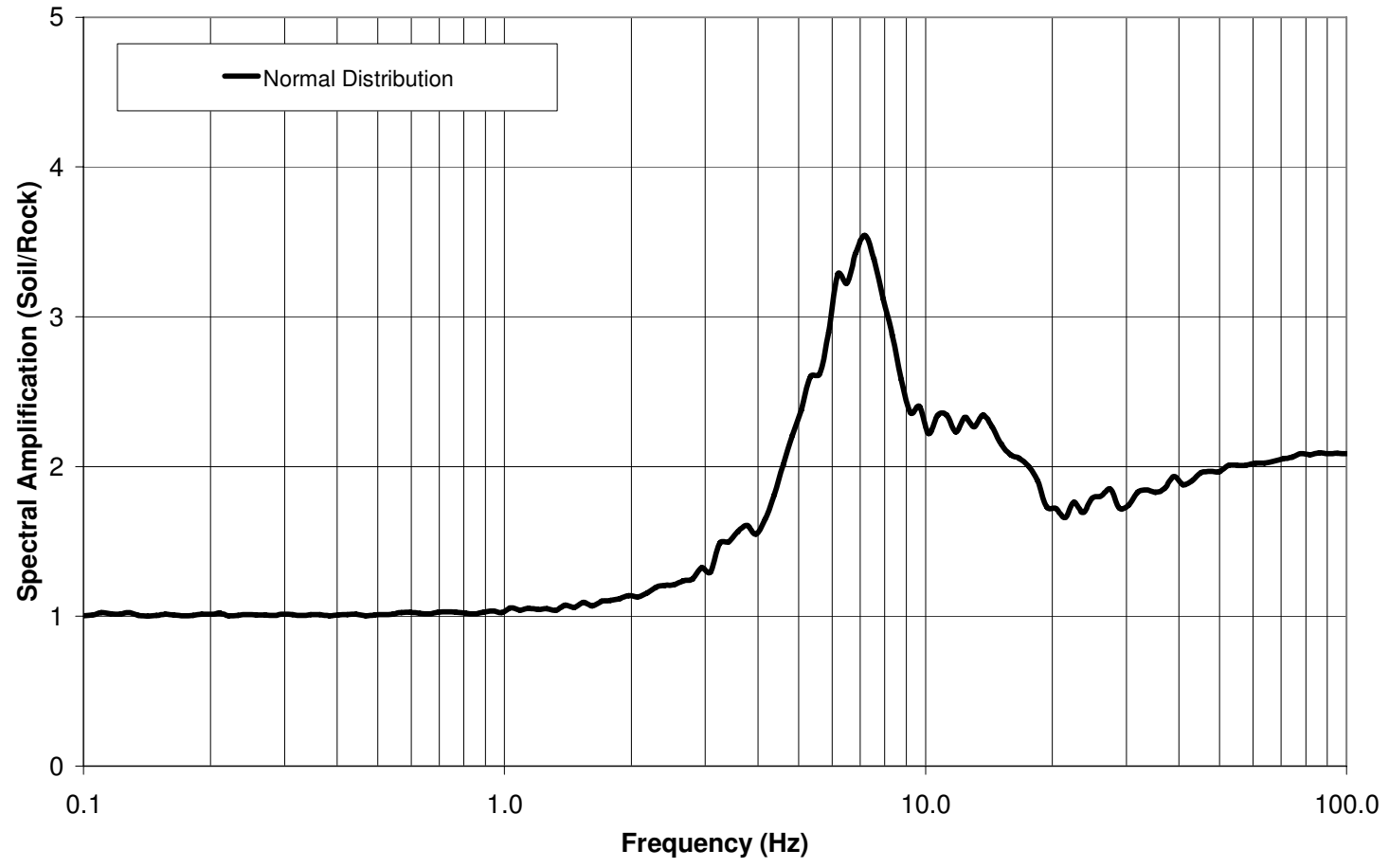

(b)

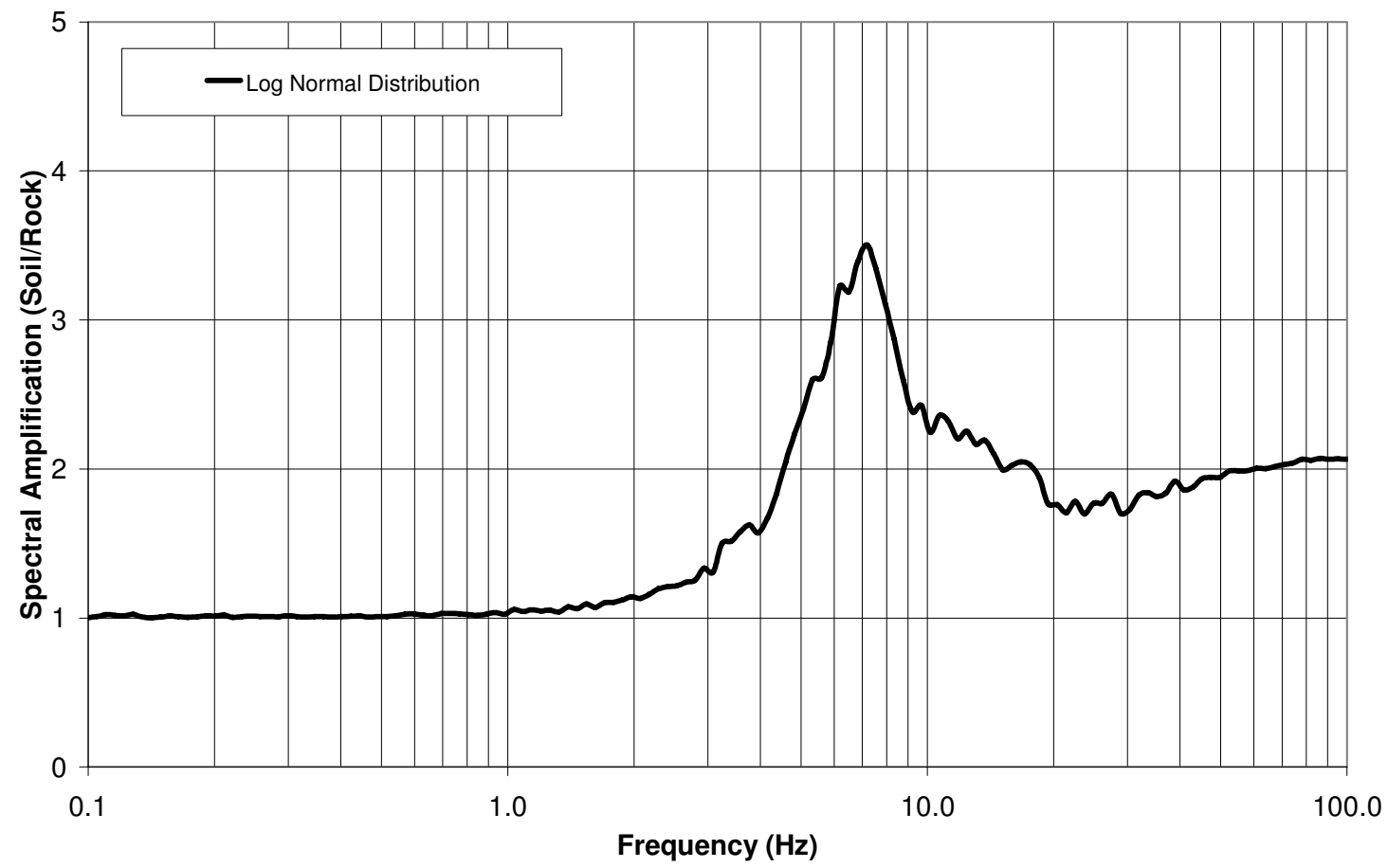

Figure 15. Spectral amplification factors as function of frequency of the mean soil surface spectra for: a) normal and b) $\log$ normal distributions of shear modulus. 


\subsection{Horizontal IWTU PC 3 Soil DBE 5\% Damped Spectrum}

\subsubsection{Comparison to IWTU SSI Spectrum}

The mean soil surface 5\% damped spectra from the two sets of random soil profiles were compared with each other and the IWTU SSI spectrum. The mean soil surface spectra for the two sets of random soil profiles with normal and log normal distributions of $\mathrm{G}$ have similar spectral peaks at $7.18 \mathrm{~Hz}$ with peak amplitudes of 1.1017 and $1.0892 \mathrm{~g}$, respectively. The mean spectral peaks are narrower and exceed the IWTU SSI spectrum by $30 \%$ (Figure 16).

From these comparisons, the exceedance of the mean spectral peaks by over $20 \%$ indicates that a site-specific DBE spectrum should be developed for IWTU. The increased spectral peaks of the mean soil surface spectra for the normal and log normal distributions over those computed by Payne (2006) are the result of:

- $\quad$ Using "Darendeli/Menq CU 40" in place of the EPRI (1993) degradation models used in Payne (2006).

- Smaller variations (or COV) of $\mathrm{G}$ within the sets of 30 random soil profiles for the rock and all soil layers.

- The lower starting Vs of $750 \mathrm{ft} / \mathrm{s}$ for Layer A (which is equivalent to the Upper Alluvial Soil layer with Vs of $971 \mathrm{ft} / \mathrm{s}$ in Payne 2006).

Sensitivity analyses were conducted using three additional degradation models and a new set of 30 random soil profiles with a larger COV with the log normal distribution. Results of the sensitivity analyses indicate the greatest contribution to producing spectral peaks greater than the IWTU SSI Spectrum is use of smaller COVs for rock and soil layers combined with the "Darendeli/Menq CU 40" degradation models for Layers A and B (see Appendix C).

\subsubsection{Development of the IWTU Mean DBE Spectrum}

The site-specific mean horizontal IWTU soil DBE 5\% damped spectrum was developed by setting the spectral peak amplitude, broadening the acceleration part of the spectrum, and setting others parts of the spectrum equivalent to the RTC/INTEC PC 3 Soil DBE 5\% damped spectrum. The DBE spectral peak amplitude was set to a value to envelop the spectral peaks of the mean soil surface spectra with normal and $\log$ normal distributions of $\mathrm{G}$ (Appendix A; Table A-2). This approach was recommended by the BRP since the mean soil surface spectral peaks are narrower than the RTC/INTEC PC 3 Soil DBE spectrum (Houston 2007a).

The RTC/INTEC PC 3 Soil DBE 5\% damped spectrum has regions of constant acceleration, velocity and displacement similar to the approach of Newmark and Hall (1978). The mean IWTU soil DBE spectrum was developed to be consistent with this approach. Figure 17 shows the mean IWTU PC 3 soil DBE 5\% damped spectrum compared with the RTC/INTEC PC 3 Soil DBE 5\% damped spectrum and mean soil surface spectra for the normal and log normal distributions of G.

The spectral accelerations and frequencies of the mean IWTU soil DBE spectrum were calculated using new values or were set equivalent to values of the RTC/INTEC PC 3 Soil DBE 5\% damped spectrum (Table 7). The constant acceleration of the mean IWTU soil DBE spectrum was set to $1.100 \mathrm{~g}$. The constant acceleration region was broadened by a factor of 1.5 from the frequency of $7.18 \mathrm{~Hz}$ of the mean soil spectral peaks, resulting in spectral acceleration corners of 4.8 and $10.8 \mathrm{~Hz}$. The spectral 
accelerations at frequencies from 10.8 to $25 \mathrm{~Hz}$ were calculated using log-log interpolation. Spectral accelerations and frequencies from 25 to $100 \mathrm{~Hz}$ were set equivalent to the RTC/INTEC PC 3 Soil DBE $5 \%$ damped spectrum. The peak ground acceleration of the mean IWTU soil DBE spectrum is $0.2538 \mathrm{~g}$ at $50-100 \mathrm{~Hz}$.

Spectral accelerations at frequencies from 0.208 and $4.8 \mathrm{~Hz}$ were calculated by determining the peak spectral velocity. The spectral velocity of $35.7964 \mathrm{~cm} / \mathrm{s}$ was calculated using the spectral acceleration of $1.1 \mathrm{~g}$ and the corner frequency of $4.8 \mathrm{~Hz}$. The frequency of $0.208 \mathrm{~Hz}$ was calculated using the peak spectral velocity and peak spectral displacement of $27.3477 \mathrm{~cm}$, which is equivalent to the peak spectral displacement of the RTC/INTEC PC 3 Soil DBE 5\% damped spectrum. Spectral accelerations and frequencies from 0.10 to $0.208 \mathrm{~Hz}$ are the same as those for the RTC/INTEC PC 3 Soil DBE 5\% damped spectrum (Table 7).

A review by the DNFSB recommended the IWTU project not use a mean DBE soil spectrum, but consider an $84^{\text {th }}$ percentile DBE soil spectrum for design purposes. Initially, the site-specific mean horizontal IWTU soil DBE 5\% damped spectrum was selected for design of the IWTU. The DNFSB raised concerns with the standard practice of generating and averaging randomized spectra for shallow soil sites. For shallow soil sites, large variations of Vs and soil column heights result in rapid shifts of spectral peaks at different frequencies (Payne 2006). As shown in Figure 10, several spectral peaks of individual soil spectra exceed the mean soil surface spectrum (from 5.5 to $7.2 \mathrm{~Hz}$ ). The DNFSB suggested that the IWTU site will respond to ground motions within a narrow frequency range since Vs and thickness of the soil deposit does not vary significantly. Further, they stated that at this time there is an absence of clear criteria to generate and judge the acceptability of random soil profiles and standard methods to produce a representative soil spectrum that accounts for the variability of randomizations in shallow soils. Thus, they recommended the IWTU project adopt an $84^{\text {th }}$ percentile DBE spectrum, which would account for the uncertainty in the soil profile randomizations and an artificially low average spectrum (Eggenberger 2008).

\subsubsection{Development of the IWTU $84^{\text {th }}$ Percentile DBE Spectrum}

The spectral accelerations (SAs) and frequencies of the $84^{\text {th }}$ percentile horizontal IWTU PC 3 soil DBE 5\% damped spectrum were calculated using new values or were set equivalent to values of the SAs, peak spectral velocity (SV), or peak spectral displacement (SD) of the mean IWTU PC 3 Soil DBE 5\% damped spectrum (Table 7). The following steps were taken to develop the $84^{\text {th }}$ percentile soil DBE spectrum (Table 8):

- $\quad$ SAs from 100 to $25 \mathrm{~Hz}$ of the $84^{\text {th }}$ percentile DBE spectrum (Table F-2) were set to the SAs of the mean IWTU PC 3 soil DBE 5\% damped spectrum (Table 7).

- $\quad$ The corner frequency of $10 \mathrm{~Hz}$ of the $84^{\text {th }}$ percentile DBE spectrum was selected so that SA levels could be extended to the peak SA of $1.250 \mathrm{~g}$ and still be consistent with the SAs of the mean IWTU PC 3 soil DBE 5\% damped spectrum.

- $\quad$ The SAs of the $84^{\text {th }}$ percentile DBE spectrum between the corner frequencies of 10 and $25 \mathrm{~Hz}$ were calculated using log-log linear interpolations.

- $\quad$ The SAs of the $84^{\text {th }}$ percentile DBE spectrum between $10 \mathrm{~Hz}$ to the SA-SV corner frequency of $5.455 \mathrm{~Hz}$ were set to the spectral peak of $1.250 \mathrm{~g}$ to envelop the $84^{\text {th }}$ percentile soil surface spectrum (Appendix A; Table A-2). 
- $\quad$ The low frequency (f) corner of $5.455 \mathrm{~Hz}$ for the constant SA was calculated by using $\mathrm{f}=(\mathrm{SA} * 981.45) /(\mathrm{SV} * 2 \pi)$; where $\mathrm{SA}$ is $1.250 \mathrm{~g}, \mathrm{SV}$ is $35.7964 \mathrm{~cm} / \mathrm{s}$ (peak $\mathrm{SV}$ of the mean IWTU PC 3 soil DBE 5\% damped spectrum in Table 7), $\mathrm{f}$ is in $\mathrm{Hz}$ (or 1/s), and 981.45 is the conversion factor from $\mathrm{cm} / \mathrm{s} / \mathrm{s}$ to $\mathrm{g}$.

- $\quad$ The SAs of the $84^{\text {th }}$ percentile DBE spectrum from 5.455 to $0.208 \mathrm{~Hz}$ were calculated using $\log$ - $\log$ linear interpolations to adjust for the new corner frequency of $5.455 \mathrm{~Hz}$ (Table F-2). Although these SAs were computed using log-log linear interpolation, the SAs of the $84^{\text {th }}$ percentile DBE spectrum from 4.0 to $0.208 \mathrm{~Hz}$ are the same as the mean IWTU PC 3 soil DBE 5\% damped spectrum (Table 7).

- The SAs of the $84^{\text {th }}$ percentile DBE spectrum from 0.208 to $0.1 \mathrm{~Hz}$ (Table F-2) were set to the same values as the mean IWTU PC 3 soil DBE 5\% damped spectrum for the peak SD of 27.3477 cm (Table 7).

The $84^{\text {th }}$ percentile horizontal IWTU PC 3 soil DBE 5\% damped spectrum was compared to the $84^{\text {th }}$ percentile soil surface spectrum, the 30 random soil surface spectra, and the mean IWTU PC 3 soil DBE 5\% damped spectrum. The $84^{\text {th }}$ percentile IWTU PC 3 soil DBE 5\% damped spectrum envelops the $84^{\text {th }}$ percentile soil surface spectrum. The corner frequencies of 10 and $5.455 \mathrm{~Hz}$ result in a narrower $84^{\text {th }}$ percentile DBE spectrum in the peak spectral acceleration region of the spectrum than for the mean IWTU PC 3 Soil DBE 5\% damped spectrum (Figure 18). Figure 19 shows the $84^{\text {th }}$ percentile IWTU PC 3 soil DBE 5\% damped spectrum envelops the majority of spectral peaks of the $\mathrm{H} 1$ and $\mathrm{H} 2$ soil surface spectra for the 30 soil profiles with the log normal distribution of shear modulus. Additionally, the $84^{\text {th }}$ percentile IWTU PC 3 soil DBE 5\% damped spectrum envelops the two- and three-layer soil profiles of the IWTU boreholes except for the larger spectral peaks of one borehole (Appendix A; Figure A-8). 
Table 7. Spectral accelerations, velocities, and displacements of the mean horizontal IWTU PC 3 (2,500 yr) Soil DBE 5\% damped spectrum.

\begin{tabular}{|c|c|c|c|}
\hline \multirow[b]{2}{*}{ Frequency $(\mathrm{Hz})$} & \multicolumn{3}{|c|}{ Mean Horizontal IWTU PC 3 Soil DBE 5\% Damped Spectrum } \\
\hline & Spectral Acceleration $(\mathrm{g})$ & Spectral Velocity $(\mathrm{cm} / \mathrm{s})^{\mathrm{a}}$ & Spectral Displacement $(\mathrm{cm})^{\mathrm{b}}$ \\
\hline 100.000 & 0.2538 & 0.3964 & 0.0006 \\
\hline 90.000 & 0.2538 & 0.4405 & 0.0008 \\
\hline 80.000 & 0.2538 & 0.4956 & 0.0010 \\
\hline 70.000 & 0.2538 & 0.5663 & 0.0013 \\
\hline 60.000 & 0.2538 & 0.6607 & 0.0018 \\
\hline 55.000 & 0.2538 & 0.7208 & 0.0021 \\
\hline 50.000 & 0.2538 & 0.7929 & 0.0025 \\
\hline 45.000 & 0.2647 & 0.9189 & 0.0032 \\
\hline 40.000 & 0.2775 & 1.0835 & 0.0043 \\
\hline 35.000 & 0.2927 & 1.3062 & 0.0059 \\
\hline 30.000 & 0.3113 & 1.6207 & 0.0086 \\
\hline 27.500 & 0.3223 & 1.8306 & 0.0106 \\
\hline 25.000 & 0.3348 & 2.0919 & 0.0133 \\
\hline 22.500 & 0.3887 & 2.6986 & 0.0191 \\
\hline 20.000 & 0.4593 & 3.5875 & 0.0285 \\
\hline 17.500 & 0.5550 & 4.9541 & 0.0451 \\
\hline 15.000 & 0.6906 & 7.1911 & 0.0763 \\
\hline 12.500 & 0.8942 & 11.1737 & 0.1423 \\
\hline 12.000 & 0.9474 & 12.3325 & 0.1636 \\
\hline 10.800 & 1.1000 & 15.9095 & 0.2345 \\
\hline 9.000 & 1.1000 & 19.0914 & 0.3376 \\
\hline 8.000 & 1.1000 & 21.4779 & 0.4273 \\
\hline 7.000 & 1.1000 & 24.5461 & 0.5581 \\
\hline 6.000 & 1.1000 & 28.6371 & 0.7596 \\
\hline 5.500 & 1.1000 & 31.2405 & 0.9040 \\
\hline 5.000 & 1.1000 & 34.3646 & 1.0939 \\
\hline 4.800 & 1.1000 & 35.7964 & 1.1869 \\
\hline 4.000 & 0.9167 & 35.7964 & 1.4243 \\
\hline 3.829 & 0.8775 & 35.7964 & 1.4878 \\
\hline 3.500 & 0.8021 & 35.7964 & 1.6278 \\
\hline 3.000 & 0.6875 & 35.7964 & 1.8991 \\
\hline
\end{tabular}


Table 7. Continued.

Mean Horizontal IWTU PC 3 Soil DBE 5\% Damped Spectrum

\begin{tabular}{|c|c|c|c|}
\hline Frequency $(\mathrm{Hz})$ & Spectral Acceleration (g) & Spectral Velocity $(\mathrm{cm} / \mathrm{s})^{\mathrm{a}}$ & Spectral Displacement $(\mathrm{cm})^{\mathrm{b}}$ \\
\hline 2.750 & 0.6302 & 35.7964 & 2.0717 \\
\hline 2.500 & 0.5729 & 35.7964 & 2.2789 \\
\hline 2.250 & 0.5156 & 35.7964 & 2.5321 \\
\hline 2.000 & 0.4583 & 35.7964 & 2.8486 \\
\hline 1.750 & 0.4010 & 35.7964 & 3.2555 \\
\hline 1.500 & 0.3438 & 35.7964 & 3.7981 \\
\hline 1.250 & 0.2865 & 35.7964 & 4.5577 \\
\hline 1.000 & 0.2292 & 35.7964 & 5.6972 \\
\hline 0.900 & 0.2063 & 35.7964 & 6.3302 \\
\hline 0.800 & 0.1833 & 35.7964 & 7.1215 \\
\hline 0.700 & 0.1604 & 35.7964 & 8.1388 \\
\hline 0.600 & 0.1375 & 35.7964 & 9.4953 \\
\hline 0.550 & 0.1260 & 35.7964 & 10.3585 \\
\hline 0.500 & 0.1146 & 35.7964 & 11.3944 \\
\hline 0.450 & 0.1031 & 35.7964 & 12.6604 \\
\hline 0.400 & 0.0917 & 35.7964 & 14.2429 \\
\hline 0.350 & 0.0802 & 35.7964 & 16.2777 \\
\hline 0.300 & 0.0688 & 35.7964 & 18.9906 \\
\hline 0.275 & 0.0630 & 35.7964 & 20.7170 \\
\hline 0.250 & 0.0573 & 35.7964 & 22.7887 \\
\hline 0.225 & 0.0516 & 35.7964 & 25.3208 \\
\hline 0.208 & 0.0477 & 35.7964 & 27.3477 \\
\hline 0.190 & 0.0397 & 32.6478 & 27.3477 \\
\hline 0.175 & 0.0337 & 30.0703 & 27.3477 \\
\hline 0.150 & 0.0248 & 25.7746 & 27.3477 \\
\hline 0.125 & 0.0172 & 21.4788 & 27.3477 \\
\hline 0.100 & 0.0110 & 17.1830 & 27.3477 \\
\hline
\end{tabular}

a. Computed using frequency (column 1) and SA (column 2) and equation: $\mathrm{SV}=\mathrm{SA} \bullet 981.45 / 2 \pi \mathrm{f}$; where $981.45 \mathrm{~cm} / \mathrm{s}^{2}$ is the factor to convert from $\mathrm{g}$.

b. Computed using frequency (column 1) and SV (column 3) and equation: $\mathrm{SD}=\mathrm{SV} / 2 \pi \mathrm{f}$. 
Table 8. Spectral accelerations, velocities, and displacements of the $84^{\text {th }}$ percentile horizontal IWTU PC 3 (2,500 yr) Soil DBE 5\% damped spectrum.

$84^{\text {th }}$ Percentile Horizontal IWTU PC 3 Soil DBE 5\% Damped Spectrum

\begin{tabular}{|c|c|c|c|}
\hline Frequency $(\mathrm{Hz})$ & Spectral Acceleration $(\mathrm{g})$ & Spectral Velocity $(\mathrm{cm} / \mathrm{s})^{\mathrm{a}}$ & Spectral Displacement $(\mathrm{cm})^{\mathrm{b}}$ \\
\hline 100.000 & 0.2538 & 0.3964 & 0.0006 \\
\hline 90.000 & 0.2538 & 0.4405 & 0.0008 \\
\hline 80.000 & 0.2538 & 0.4956 & 0.0010 \\
\hline 70.000 & 0.2538 & 0.5663 & 0.0013 \\
\hline 60.000 & 0.2538 & 0.6607 & 0.0018 \\
\hline 55.000 & 0.2538 & 0.7208 & 0.0021 \\
\hline 50.000 & 0.2538 & 0.7929 & 0.0025 \\
\hline 45.000 & 0.2647 & 0.9189 & 0.0032 \\
\hline 40.000 & 0.2775 & 1.0835 & 0.0043 \\
\hline 35.000 & 0.2927 & 1.3062 & 0.0059 \\
\hline 30.000 & 0.3113 & 1.6207 & 0.0086 \\
\hline 27.500 & 0.3223 & 1.8306 & 0.0106 \\
\hline 25.000 & 0.3348 & 2.0919 & 0.0133 \\
\hline 22.500 & 0.3896 & 2.7044 & 0.0191 \\
\hline 20.000 & 0.4614 & 3.6039 & 0.0287 \\
\hline 17.500 & 0.5591 & 4.9905 & 0.0454 \\
\hline 15.000 & 0.6978 & 7.2667 & 0.0771 \\
\hline 12.500 & 0.9069 & 11.3334 & 0.1443 \\
\hline 12.000 & 0.9618 & 12.5192 & 0.1660 \\
\hline 10.000 & 1.2500 & 19.5253 & 0.3108 \\
\hline 9.000 & 1.2500 & 21.6948 & 0.3836 \\
\hline 8.000 & 1.2500 & 24.4067 & 0.4856 \\
\hline 7.000 & 1.2500 & 27.8933 & 0.6342 \\
\hline 6.000 & 1.2500 & 32.5422 & 0.8632 \\
\hline 5.455 & 1.2500 & 35.7964 & 1.0445 \\
\hline 5.000 & 1.1458 & 35.7964 & 1.1394 \\
\hline 4.500 & 1.0313 & 35.7964 & 1.2660 \\
\hline 4.000 & 0.9167 & 35.7964 & 1.4243 \\
\hline 3.750 & 0.8594 & 35.7964 & 1.5192 \\
\hline 3.500 & 0.8021 & 35.7964 & 1.6278 \\
\hline 3.000 & 0.6875 & 35.7964 & 1.8991 \\
\hline
\end{tabular}


Table 8. Continued.

$84^{\text {th }}$ Percentile Horizontal IWTU PC 3 Soil DBE 5\% Damped Spectrum

\begin{tabular}{|c|c|c|c|}
\hline Frequency $(\mathrm{Hz})$ & Spectral Acceleration (g) & Spectral Velocity $(\mathrm{cm} / \mathrm{s})^{\mathrm{a}}$ & Spectral Displacement $(\mathrm{cm})^{\mathrm{b}}$ \\
\hline 2.750 & 0.6302 & 35.7964 & 2.0717 \\
\hline 2.500 & 0.5729 & 35.7964 & 2.2789 \\
\hline 2.250 & 0.5156 & 35.7964 & 2.5321 \\
\hline 2.000 & 0.4583 & 35.7964 & 2.8486 \\
\hline 1.750 & 0.4010 & 35.7964 & 3.2555 \\
\hline 1.500 & 0.3438 & 35.7964 & 3.7981 \\
\hline 1.250 & 0.2865 & 35.7964 & 4.5577 \\
\hline 1.000 & 0.2292 & 35.7964 & 5.6972 \\
\hline 0.900 & 0.2063 & 35.7964 & 6.3302 \\
\hline 0.800 & 0.1833 & 35.7964 & 7.1215 \\
\hline 0.700 & 0.1604 & 35.7964 & 8.1388 \\
\hline 0.600 & 0.1375 & 35.7964 & 9.4953 \\
\hline 0.550 & 0.1260 & 35.7964 & 10.3585 \\
\hline 0.500 & 0.1146 & 35.7964 & 11.3944 \\
\hline 0.450 & 0.1031 & 35.7964 & 12.6604 \\
\hline 0.400 & 0.0917 & 35.7964 & 14.2429 \\
\hline 0.350 & 0.0802 & 35.7964 & 16.2777 \\
\hline 0.300 & 0.0688 & 35.7964 & 18.9906 \\
\hline 0.275 & 0.0630 & 35.7964 & 20.7170 \\
\hline 0.250 & 0.0573 & 35.7964 & 22.7887 \\
\hline 0.225 & 0.0516 & 35.7964 & 25.3208 \\
\hline 0.208 & 0.0477 & 35.7964 & 27.3477 \\
\hline 0.190 & 0.0397 & 32.6478 & 27.3477 \\
\hline 0.175 & 0.0337 & 30.0703 & 27.3477 \\
\hline 0.150 & 0.0248 & 25.7746 & 27.3477 \\
\hline 0.125 & 0.0172 & 21.4788 & 27.3477 \\
\hline 0.100 & 0.0110 & 17.1830 & 27.3477 \\
\hline
\end{tabular}

a. Computed using frequency (column 1) and SA (column 2) and equation: $\mathrm{SV}=\mathrm{SA} \bullet 981.45 / 2 \pi \mathrm{f}$; where $981.45 \mathrm{~cm} / \mathrm{s}^{2}$ is the factor to convert from $\mathrm{g}$.

b. Computed using frequency (column 1) and SV (column 3) and equation: $\mathrm{SD}=\mathrm{SV} / 2 \pi \mathrm{f}$. 


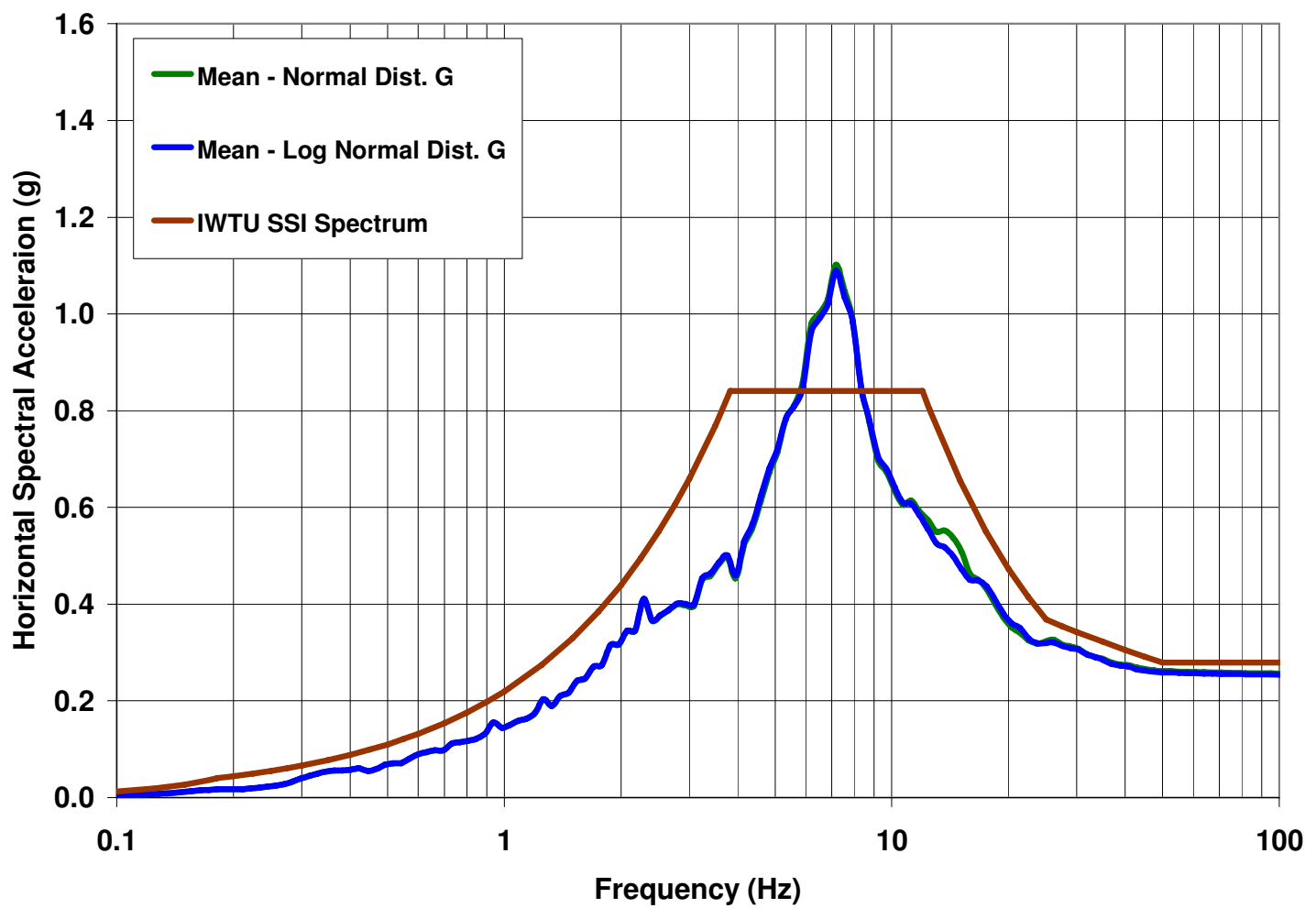

Figure 16. Horizontal PC 3 (2,500 yr) mean soil surface $5 \%$ damped spectra for the two sets of random soil profiles (log normal and normal distribution of $\mathrm{G})$. 


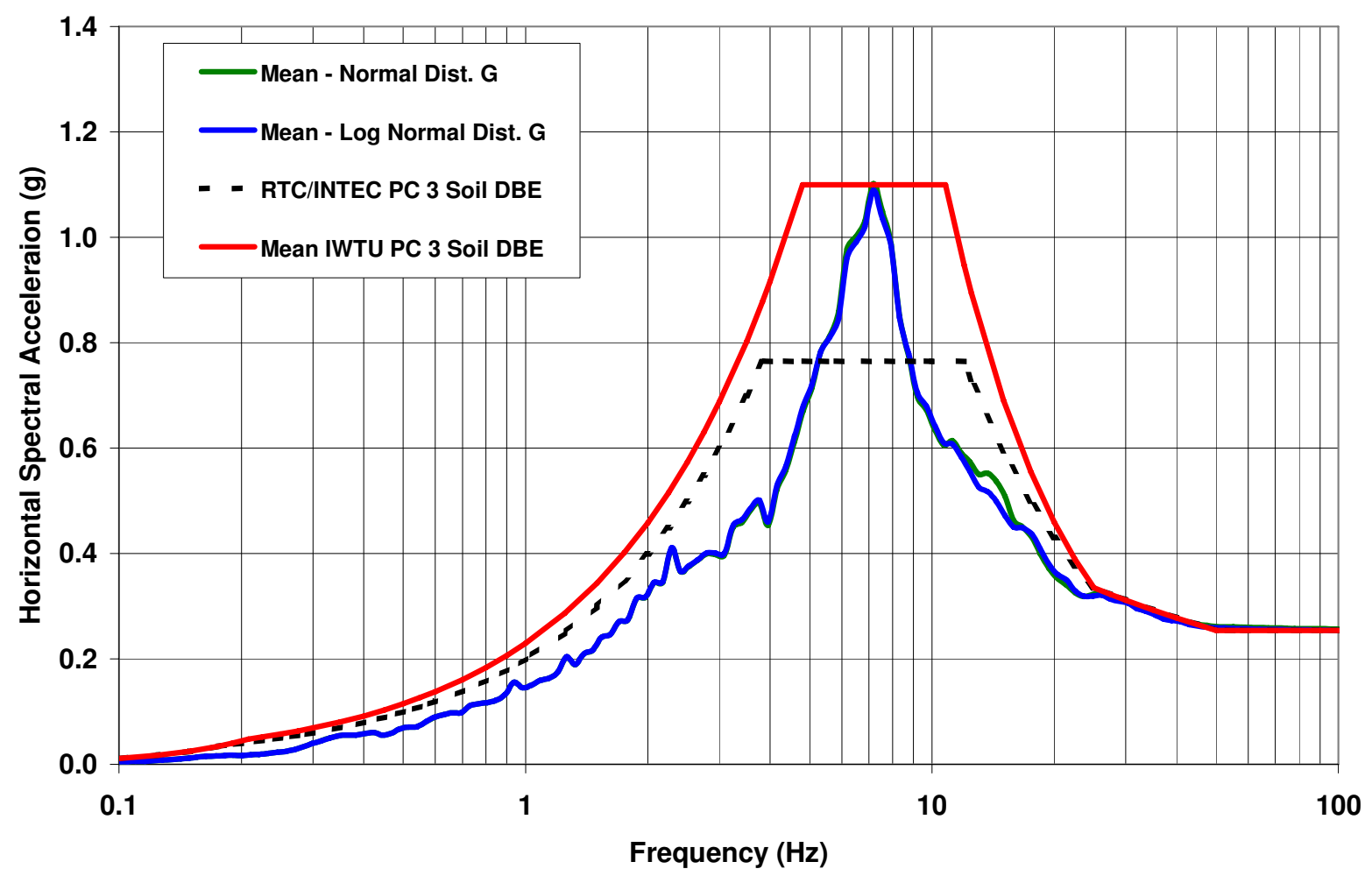

Figure 17. The mean horizontal IWTU PC 3 (2,500 yr) Soil DBE 5\% damped spectrum, RTC/INTEC PC 3 DBE spectrum, and mean soil surface spectra for the two sets of random soil profiles (log normal and normal distribution of $\mathrm{G})$. 


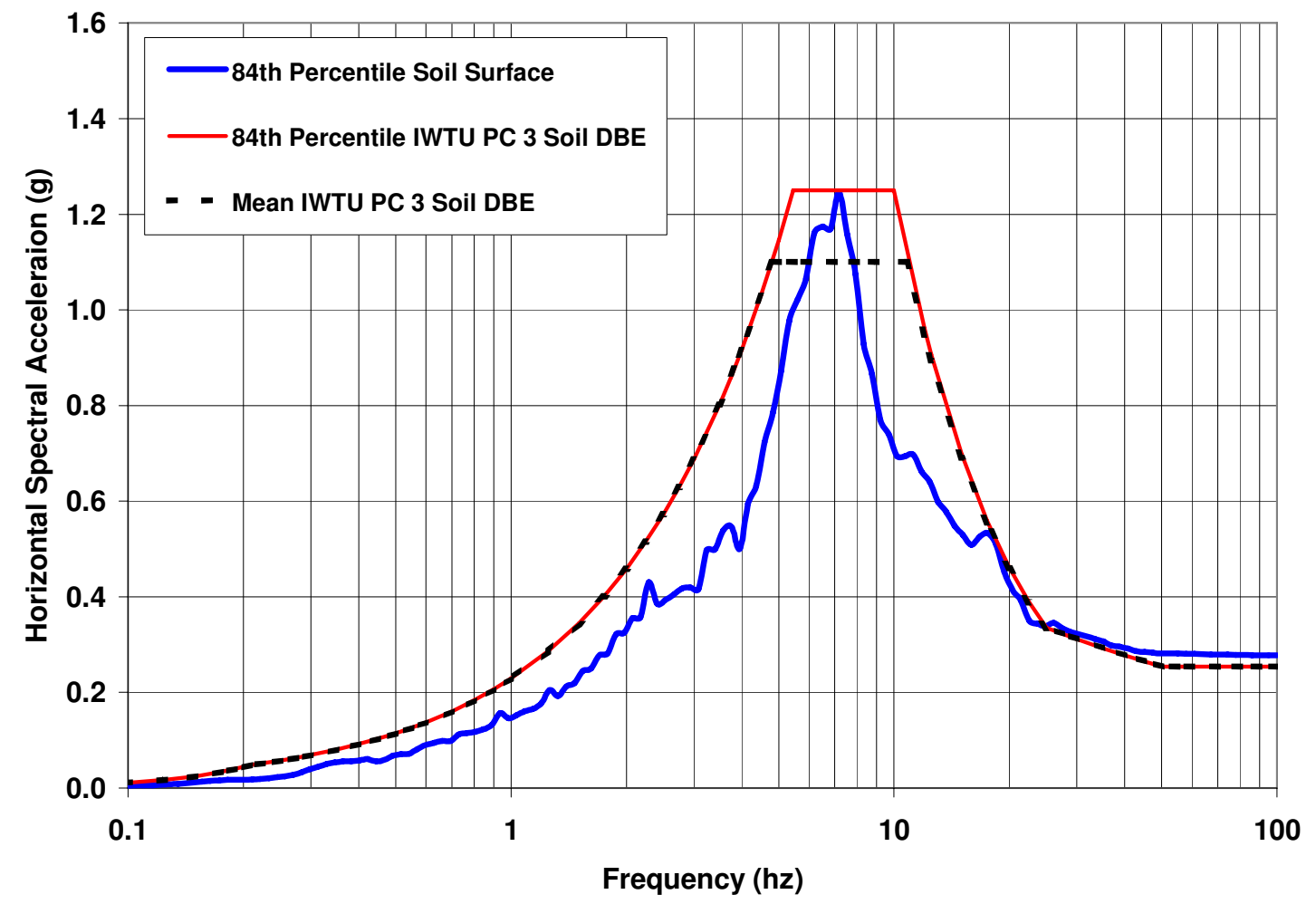

Figure 18. The $84^{\text {th }}$ percentile horizontal IWTU PC 3 (2,500 yr) Soil DBE 5\% damped spectrum, the mean IWTU PC 3 (2,500 yr) Soil DBE 5\% damped spectrum, and the $84^{\text {th }}$ percentile soil surface spectra for the 30 random soil profiles with the log normal distribution of shear modulus. 
(a)

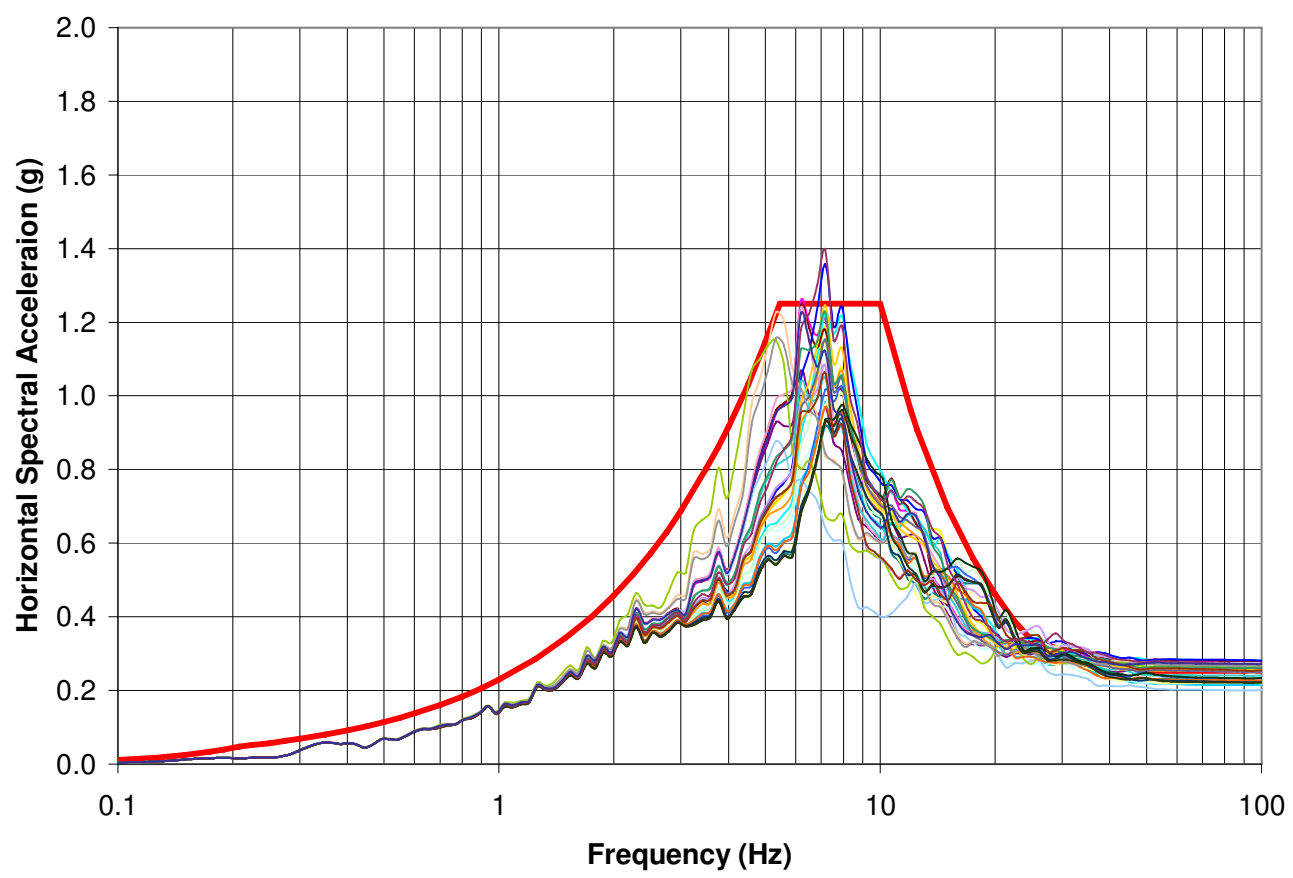

(b)

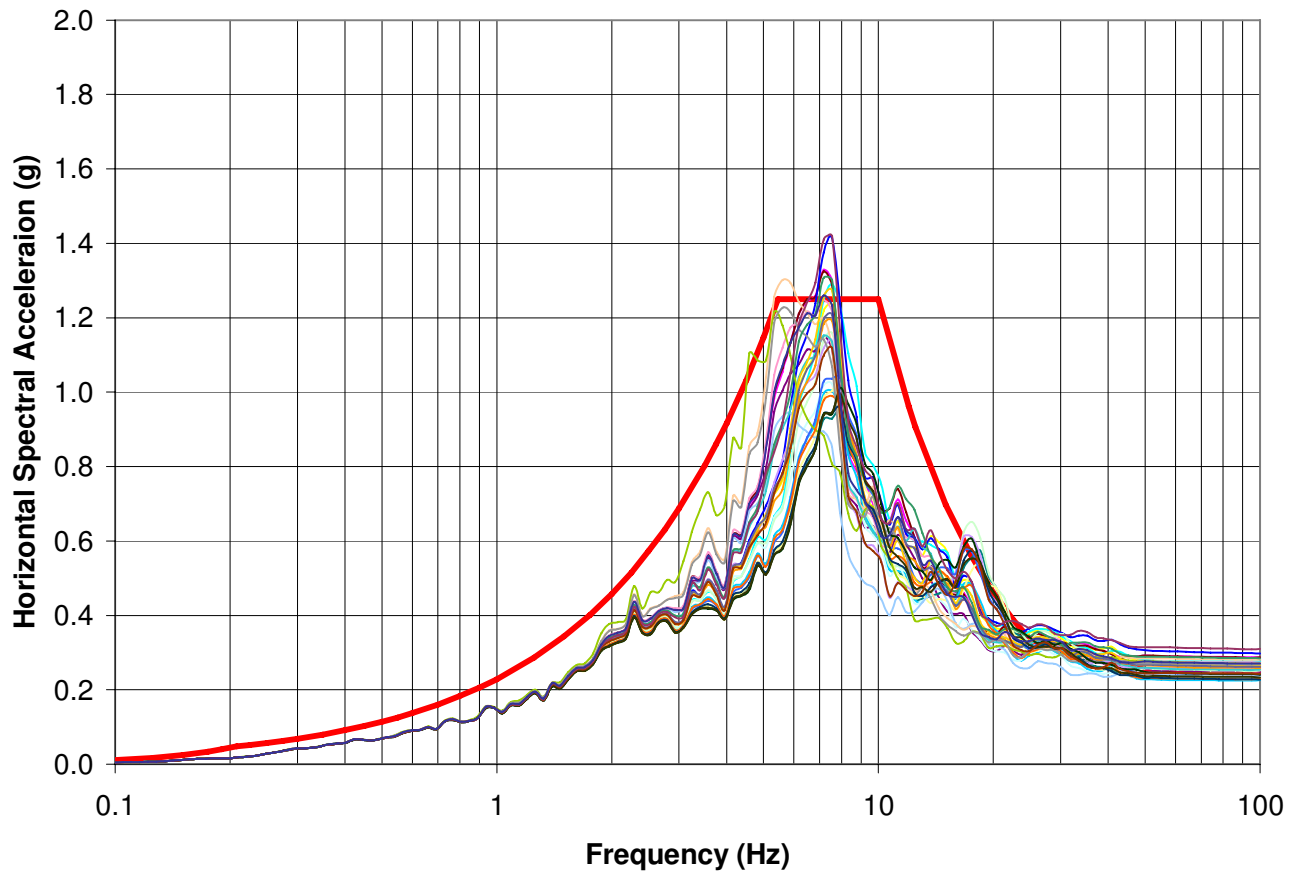

Figure 19. The $84^{\text {th }}$ percentile horizontal IWTU PC 3 (2,500 yr) soil DBE 5\% damped spectrum and individual soil surface spectra for the 30 random soil profiles with the log normal distribution of shear modulus for the (a) $\mathrm{H} 1$ and (b) $\mathrm{H} 2$ components. 


\section{Development of the Vertical Soil Design Spectra}

Vertical IWTU PC 3 Soil DBE 5\% damped spectra for the mean and $84^{\text {th }}$ percentile were developed using V/H spectral ratios appropriate for INL. Spectral accelerations of the mean and $8^{\text {th }}$ percentile horizontal IWTU PC 3 soil DBE 5\% damped spectra were multiplied by the V/H spectral ratios (Figure 9). The resulting vertical spectral curves was then enveloped to produce the vertical DBE spectrum with region of constant acceleration, velocity, and displacement. It was assumed that the $\mathrm{V} / \mathrm{H}$ spectral ratio developed for rock is also applicable for shallow soil conditions at IWTU. The V/H spectral ratio was developed with consideration of empirical ratios for rock and soil sites of less than $100 \mathrm{ft}$ (Abrahamson and Silva, 1997). Additionally, this same approach has been used to develop other DBE soil spectra at INL (URS Greiner Woodward-Clyde Federal Services et al. 1999; Payne 2006).

\subsection{Development of the Mean Vertical Soil DBE Spectrum}

Several steps were performed to develop the mean vertical IWTU soil DBE 5\% damped spectrum. First, SAs of the mean horizontal IWTU PC 3 Soil DBE spectrum were computed at the frequencies of the V/H spectral ratios (Table 9). Second, the SAs of the mean horizontal IWTU PC 3 soil DBE spectrum were multiplied by the V/H spectral ratios to produce a mean vertical spectral curve (Table 9). Third, SVs and SDs were calculated for the mean vertical spectral curve using Equations [4] and [5] to determine the SA levels and corner frequencies for the constant SA, SV, and SD parts of the DBE spectrum (Table 10).

$$
\begin{aligned}
& \mathrm{SV}(\mathrm{cm} / \mathrm{s})=(\mathrm{SA} * 981.45) / 2 \pi \mathrm{f} \\
& \mathrm{SD}(\mathrm{cm})=\mathrm{SV} / 2 \pi \mathrm{f}
\end{aligned}
$$

Finally, the following steps were used to construct the mean vertical IWTU PC 3 (2,500 yr) soil DBE 5\% damped spectrum using values in Table 10:

1. DBE SAs from 100 to $50 \mathrm{~Hz}$ were set to the SA of $0.1954 \mathrm{~g}$ of the vertical spectral curve.

2. The DBE SAs between frequencies of 50 and $25 \mathrm{~Hz}$ are from the vertical spectral curve for these frequencies.

3. The high frequency corner of $12.5 \mathrm{~Hz}$ for the DBE constant SA level was determined by selecting the frequency that resulted in SA (from a log-log linear interpolation) that closely matched the vertical spectral curve between $25 \mathrm{~Hz}$ and the high frequency SA corner.

4. The DBE constant SA was selected to be $0.9892 \mathrm{~g}$, which is the spectral peak of the vertical spectral curve.

5. The DBE peak SV was determined by choosing the maximum SV of $23.8762 \mathrm{~cm} / \mathrm{s}$ from the constant SV part of the vertical spectral curve. This value is $2 / 3$ the horizontal DBE SV.

6. The peak DBE SV, peak SA, and Equation [4] were used to compute the DBE low frequency corner of $0.6472 \mathrm{~Hz}$ for constant SA.

7. The DBE SAs from 0.208 and $0.1 \mathrm{~Hz}$ are the same as the vertical spectral curve. This portion of the $\mathrm{DBE}$ spectrum has a constant $\mathrm{SD}=18.2409 \mathrm{~cm}$ (or $2 / 3$ times the horizontal DBE SD).

The mean vertical IWTU soil DBE 5\% damped spectrum (Table 11) exceeds the spectral accelerations from frequencies of 4.8 to $10.8 \mathrm{~Hz}$. It closely matches the spectral accelerations of the vertical spectral 
curve at frequencies less than $4.8 \mathrm{~Hz}$ and greater than $15 \mathrm{~Hz}$. The mean vertical soil DBE spectrum slightly exceeds the mean horizontal soil DBE spectrum near12 Hz (Figure 18).

\subsection{Development of the $84^{\text {th }}$ Percentile Vertical Soil DBE Spectrum}

The $84^{\text {th }}$ percentile vertical IWTU PC 3 soil DBE 5\% damped spectrum was developed using the same general approach as for the mean vertical soil DBE spectrum (Section 3.1). The SAs of the $84^{\text {th }}$ percentile horizontal IWTU PC 3 Soil DBE spectrum were multiplied by the V/H spectral ratios to produce an $84^{\text {th }}$ percentile vertical spectral curve (Table 12). The following steps were taken to develop the $84^{\text {th }}$ percentile vertical IWTU PC 3 soil DBE 5\% damped spectrum (Table 13).

1. The SA of the $84^{\text {th }}$ percentile DBE spectrum from 25 to $100 \mathrm{~Hz}$ were set to the SA of the mean vertical IWTU PC 3 soil DBE 5\% damped spectrum (Table 10), since the same V/H spectral ratios were used.

2. The peak SA of the $84^{\text {th }}$ percentile DBE spectrum was set to $1.0875 \mathrm{~g}$ to envelop the peak SA of the vertical spectral curve (Table 12).

3. The corner frequency of $12 \mathrm{~Hz}$ was selected so that the SA levels $84^{\text {th }}$ percentile DBE spectrum (Table 13) could be extended to the peak SA of $1.0875 \mathrm{~g}$ and still be consistent with the SAs of the meqn vertical IWTU PC 3 soil DBE 5\% damped spectrum (Table 10).

4. SAs of the $84^{\text {th }}$ percentile DBE spectrum between the corner frequencies of 12 and $25 \mathrm{~Hz}$ were calculated using log-log linear interpolations.

5. Peak SAs of the $84^{\text {th }}$ percentile DBE spectrum were set to $1.0875 \mathrm{~g}$ for frequencies between $12 \mathrm{~Hz}$ and the SA-SV corner frequency of $7.115 \mathrm{~Hz}$, which was calculated using $\mathrm{f}=(\mathrm{SA} * 981.45) /(\mathrm{SV} * 2 \pi)$; where SA is $1.0875 \mathrm{~g}, \mathrm{SV}$ is $23.8762 \mathrm{~cm} / \mathrm{s}$ (peak SV of the vertical spectral curve in Table 12), $\mathrm{f}$ is in $\mathrm{Hz}$ (or $1 / \mathrm{s}$ ), and 981.45 is the conversion factor from $\mathrm{cm} / \mathrm{s} / \mathrm{s}$ to $\mathrm{g}$. The peak SV of $23.8762 \mathrm{~cm} / \mathrm{s}$ is the same as the mean vertical IWTU PC 3 soil DBE 5\% damped spectrum (Table 10).

6. SAs of the $84^{\text {th }}$ percentile DBE spectrum from 7.115 to $0.208 \mathrm{~Hz}$ were calculated using log-log linear interpolation. Although the SAs were computed using log-log linear interpolations, the SAs of the $84^{\text {th }}$ percentile DBE spectrum from 4.5 to $0.208 \mathrm{~Hz}$ (Table 13) are the same as the mean vertical IWTU PC 3 soil DBE 5\% damped spectrum (Table 10).

7. SAs of the $84^{\text {th }}$ percentile DBE spectrum from 0.208 to $0.1 \mathrm{~Hz}$ (Table 13) were set to the same values as the mean vertical IWTU PC 3 soil DBE 5\% damped spectrum for a peak SD of 18.2409 $\mathrm{cm}$ (Table 10).

The $84^{\text {th }}$ percentile vertical IWTU PC 3 soil DBE 5\% damped spectrum envelopes the $84^{\text {th }}$ percentile vertical spectral curve, with only a slight exceedance 16 to $25 \mathrm{~Hz}$. The $84^{\text {th }}$ percentile soil DBE spectrum has spectral accelerations the same as the $84^{\text {th }}$ percentile spectral curve at frequencies greater than $25 \mathrm{~Hz}$ and less than $4.8 \mathrm{~Hz}$. Additionally, spectral accelerations from 11 to $22 \mathrm{~Hz}$ of the $84^{\text {th }}$ percentile vertical soil DBE spectrum exceed those of the $84^{\text {th }}$ percentile horizontal soil DBE spectrum (Figure 21). 
Table 9. Calculation of the mean vertical IWTU PC 3 spectral curve.

\begin{tabular}{|c|c|c|c|}
\hline $\begin{array}{l}\text { Frequency } \\
(\mathrm{Hz})\end{array}$ & $\begin{array}{c}\text { Mean Horizontal IWTU PC } 3 \text { Soil } \\
\text { DBE Spectral Acceleration (g) }\end{array}$ & $\begin{array}{l}\text { Vertical/Horizontal } \\
\text { Spectral Ratio }\end{array}$ & $\begin{array}{c}\text { Mean Vertical Curve } \\
\text { Spectral Acceleration }(\mathrm{g})^{\text {a }}\end{array}$ \\
\hline 100.00 & 0.2538 & 0.7700 & 0.1954 \\
\hline 50.00 & 0.2538 & 0.7700 & 0.1954 \\
\hline 45.00 & 0.2647 & 0.8070 & 0.2136 \\
\hline 40.00 & 0.2775 & 0.8500 & 0.2358 \\
\hline 33.33 & 0.2984 & 0.8970 & 0.2677 \\
\hline 31.00 & 0.3072 & 0.9250 & 0.2842 \\
\hline 30.00 & 0.3113 & 0.9360 & 0.2913 \\
\hline 28.00 & 0.3200 & 0.9540 & 0.3053 \\
\hline 25.00 & 0.3348 & 0.9850 & 0.3298 \\
\hline 22.00 & 0.4013 & 1.0300 & 0.4133 \\
\hline 20.00 & 0.4593 & 1.0600 & 0.4869 \\
\hline 18.00 & 0.5333 & 1.0900 & 0.5813 \\
\hline 17.50 & 0.5550 & 1.0900 & 0.6050 \\
\hline 17.00 & 0.5783 & 1.0900 & 0.6304 \\
\hline 16.00 & 0.6302 & 1.0700 & 0.6743 \\
\hline 15.00 & 0.6906 & 1.0600 & 0.7320 \\
\hline 14.50 & 0.7245 & 1.0600 & 0.7680 \\
\hline 14.00 & 0.7615 & 1.0500 & 0.7996 \\
\hline 13.50 & 0.8018 & 1.0400 & 0.8338 \\
\hline 13.00 & 0.8458 & 1.0300 & 0.8712 \\
\hline 12.50 & 0.8942 & 1.0000 & 0.8942 \\
\hline 12.00 & 0.9474 & 0.9750 & 0.9237 \\
\hline 11.50 & 1.0063 & 0.9490 & 0.9550 \\
\hline 11.00 & 1.0718 & 0.9230 & 0.9892 \\
\hline 10.50 & 1.1000 & 0.8970 & 0.9867 \\
\hline 10.00 & 1.1000 & 0.8700 & 0.9570 \\
\hline 9.50 & 1.1000 & 0.8420 & 0.9262 \\
\hline 9.00 & 1.1000 & 0.8130 & 0.8943 \\
\hline 8.50 & 1.1000 & 0.7890 & 0.8679 \\
\hline 8.00 & 1.1000 & 0.7650 & 0.8415 \\
\hline 7.75 & 1.1000 & 0.7460 & 0.8206 \\
\hline 7.50 & 1.1000 & 0.7280 & 0.8008 \\
\hline
\end{tabular}


Table 9. Continued.

\begin{tabular}{|c|c|c|c|}
\hline $\begin{array}{l}\text { Frequency } \\
(\mathrm{Hz})\end{array}$ & $\begin{array}{c}\text { Mean Horizontal IWTU PC } 3 \text { Soil } \\
\text { DBE Spectral Acceleration (g) }\end{array}$ & $\begin{array}{l}\text { Vertical/Horizontal } \\
\text { Spectral Ratio }\end{array}$ & $\begin{array}{c}\text { Mean Vertical Curve } \\
\text { Spectral Acceleration }(\mathrm{g})^{\text {a }}\end{array}$ \\
\hline 7.25 & 1.1000 & 0.7090 & 0.7799 \\
\hline 7.00 & 1.1000 & 0.6900 & 0.7590 \\
\hline 6.75 & 1.1000 & 0.6850 & 0.7535 \\
\hline 6.50 & 1.1000 & 0.6790 & 0.7469 \\
\hline 6.25 & 1.1000 & 0.6730 & 0.7403 \\
\hline 6.00 & 1.1000 & 0.6670 & 0.7337 \\
\hline 5.500 & 1.1000 & 0.6670 & 0.7337 \\
\hline 5.000 & 1.1000 & 0.6670 & 0.7337 \\
\hline 4.800 & 1.1000 & 0.6670 & 0.7337 \\
\hline 4.000 & 0.9167 & 0.6670 & 0.6114 \\
\hline 3.829 & 0.8775 & 0.6670 & 0.5853 \\
\hline 3.500 & 0.8021 & 0.6670 & 0.5350 \\
\hline 3.000 & 0.6875 & 0.6670 & 0.4586 \\
\hline 2.750 & 0.6302 & 0.6670 & 0.4203 \\
\hline 2.500 & 0.5729 & 0.6670 & 0.3821 \\
\hline 2.250 & 0.5156 & 0.6670 & 0.3439 \\
\hline 2.000 & 0.4583 & 0.6670 & 0.3057 \\
\hline 1.750 & 0.4010 & 0.6670 & 0.2675 \\
\hline 1.500 & 0.3438 & 0.6670 & 0.2293 \\
\hline 1.250 & 0.2865 & 0.6670 & 0.1911 \\
\hline 1.000 & 0.2292 & 0.6670 & 0.1529 \\
\hline 0.900 & 0.2063 & 0.6670 & 0.1376 \\
\hline 0.800 & 0.1833 & 0.6670 & 0.1223 \\
\hline 0.700 & 0.1604 & 0.6670 & 0.1070 \\
\hline 0.600 & 0.1375 & 0.6670 & 0.0917 \\
\hline 0.550 & 0.1260 & 0.6670 & 0.0841 \\
\hline 0.500 & 0.1146 & 0.6670 & 0.0764 \\
\hline 0.450 & 0.1031 & 0.6670 & 0.0688 \\
\hline 0.400 & 0.0917 & 0.6670 & 0.0611 \\
\hline 0.350 & 0.0802 & 0.6670 & 0.0535 \\
\hline 0.300 & 0.0688 & 0.6670 & 0.0459 \\
\hline 0.275 & 0.0630 & 0.6670 & 0.0420 \\
\hline
\end{tabular}


Table 9. Continued.

\begin{tabular}{cccc}
$\begin{array}{c}\text { Frequency } \\
(\mathrm{Hz})\end{array}$ & $\begin{array}{c}\text { Mean Horizontal IWTU PC 3 Soil } \\
\text { DBE Spectral Acceleration }(\mathrm{g})\end{array}$ & $\begin{array}{c}\text { Vertical/Horizontal } \\
\text { Spectral Ratio }\end{array}$ & $\begin{array}{c}\text { Mean Vertical Curve } \\
\text { Spectral Acceleration }(\mathrm{g})^{\mathrm{a}}\end{array}$ \\
\hline 0.250 & 0.0573 & 0.6670 & 0.0382 \\
0.225 & 0.0516 & 0.6670 & 0.0344 \\
0.208 & 0.0477 & 0.6670 & 0.0318 \\
0.190 & 0.0397 & 0.6670 & 0.0265 \\
0.175 & 0.0337 & 0.6670 & 0.0225 \\
0.150 & 0.0248 & 0.6670 & 0.0165 \\
0.125 & 0.0172 & 0.6670 & 0.0115 \\
0.100 & 0.0110 & 0.6670 & 0.0073 \\
\hline
\end{tabular}

a. SA (column 4) calculated by multiplying horizontal SA (column 2) by V/H spectral ratio (column 3). 
Table 10. Spectral accelerations, velocities, displacements of the mean vertical IWTU PC 3 spectral curve.

\begin{tabular}{|c|c|c|c|}
\hline $\begin{array}{l}\text { Frequency } \\
(\mathrm{Hz})\end{array}$ & $\begin{array}{c}\text { Mean Vertical Curve } \\
\text { Spectral Acceleration }(\mathrm{g})\end{array}$ & $\begin{array}{c}\text { Mean Vertical Curve } \\
\text { Spectral Velocity }(\mathrm{cm} / \mathrm{s})^{\text {a }}\end{array}$ & $\begin{array}{c}\text { Mean Vertical Curve } \\
\text { Spectral Displacement }(\mathrm{cm})^{\mathrm{b}}\end{array}$ \\
\hline 100.000 & 0.1954 & 0.3053 & 0.0005 \\
\hline 50.000 & 0.1954 & 0.6105 & 0.0019 \\
\hline 45.000 & 0.2136 & 0.7415 & 0.0026 \\
\hline 40.000 & 0.2358 & 0.9210 & 0.0037 \\
\hline 33.330 & 0.2677 & 1.2546 & 0.0060 \\
\hline 31.000 & 0.2842 & 1.4319 & 0.0074 \\
\hline 30.000 & 0.2913 & 1.5170 & 0.0080 \\
\hline 28.000 & 0.3053 & 1.7029 & 0.0097 \\
\hline 25.000 & 0.3298 & 2.0605 & 0.0131 \\
\hline 22.000 & 0.4133 & 2.9347 & 0.0212 \\
\hline 20.000 & 0.4869 & 3.8027 & 0.0303 \\
\hline 18.000 & 0.5813 & 5.0445 & 0.0446 \\
\hline 17.500 & 0.6050 & 5.4000 & 0.0491 \\
\hline 17.000 & 0.6304 & 5.7920 & 0.0542 \\
\hline 16.000 & 0.6743 & 6.5831 & 0.0655 \\
\hline 15.000 & 0.7320 & 7.6226 & 0.0809 \\
\hline 14.500 & 0.7680 & 8.2735 & 0.0908 \\
\hline 14.000 & 0.7996 & 8.9210 & 0.1014 \\
\hline 13.500 & 0.8338 & 9.6480 & 0.1137 \\
\hline 13.000 & 0.8712 & 10.4679 & 0.1282 \\
\hline 12.500 & 0.8942 & 11.1737 & 0.1423 \\
\hline 12.000 & 0.9237 & 12.0242 & 0.1595 \\
\hline 11.500 & 0.9550 & 12.9717 & 0.1795 \\
\hline 11.000 & 0.9892 & 14.0474 & 0.2032 \\
\hline 10.500 & 0.9867 & 14.6786 & 0.2225 \\
\hline 10.000 & 0.9570 & 14.9486 & 0.2379 \\
\hline 9.500 & 0.9262 & 15.2289 & 0.2551 \\
\hline 9.000 & 0.8943 & 15.5213 & 0.2745 \\
\hline 8.500 & 0.8679 & 15.9492 & 0.2986 \\
\hline 8.000 & 0.8415 & 16.4306 & 0.3269 \\
\hline 7.750 & 0.8206 & 16.5393 & 0.3397 \\
\hline
\end{tabular}


Table 10. Continued.

\begin{tabular}{|c|c|c|c|}
\hline $\begin{array}{l}\text { Frequency } \\
(\mathrm{Hz})\end{array}$ & $\begin{array}{c}\text { Mean Vertical Curve } \\
\text { Spectral Acceleration }(\mathrm{g})\end{array}$ & $\begin{array}{c}\text { Mean Vertical Curve } \\
\text { Spectral Velocity }(\mathrm{cm} / \mathrm{s})^{\mathrm{a}}\end{array}$ & $\begin{array}{c}\text { Mean Vertical Curve } \\
\text { Spectral Displacement }(\mathrm{cm})^{\mathrm{b}}\end{array}$ \\
\hline 7.500 & 0.8008 & 16.6783 & 0.3539 \\
\hline 7.250 & 0.7799 & 16.8031 & 0.3689 \\
\hline 7.000 & 0.7590 & 16.9368 & 0.3851 \\
\hline 6.750 & 0.7535 & 17.4368 & 0.4111 \\
\hline 6.500 & 0.7469 & 17.9489 & 0.4395 \\
\hline 6.250 & 0.7403 & 18.5019 & 0.4711 \\
\hline 6.000 & 0.7337 & 19.1010 & 0.5067 \\
\hline 5.500 & 0.7337 & 20.8374 & 0.6030 \\
\hline 5.000 & 0.7337 & 22.9212 & 0.7296 \\
\hline 4.800 & 0.7337 & 23.8762 & 0.7917 \\
\hline 4.000 & 0.6114 & 23.8762 & 0.9500 \\
\hline 3.829 & 0.5853 & 23.8762 & 0.9924 \\
\hline 3.500 & 0.5350 & 23.8762 & 1.0857 \\
\hline 3.000 & 0.4586 & 23.8762 & 1.2667 \\
\hline 2.750 & 0.4203 & 23.8762 & 1.3818 \\
\hline 2.500 & 0.3821 & 23.8762 & 1.5200 \\
\hline 2.250 & 0.3439 & 23.8762 & 1.6889 \\
\hline 2.000 & 0.3057 & 23.8762 & 1.9000 \\
\hline 1.750 & 0.2675 & 23.8762 & 2.1714 \\
\hline 1.500 & 0.2293 & 23.8762 & 2.5333 \\
\hline 1.250 & 0.1911 & 23.8762 & 3.0400 \\
\hline 1.000 & 0.1529 & 23.8762 & 3.8000 \\
\hline 0.900 & 0.1376 & 23.8762 & 4.2222 \\
\hline 0.800 & 0.1223 & 23.8762 & 4.7500 \\
\hline 0.700 & 0.1070 & 23.8762 & 5.4286 \\
\hline 0.600 & 0.0917 & 23.8762 & 6.3334 \\
\hline 0.550 & 0.0841 & 23.8762 & 6.9091 \\
\hline 0.500 & 0.0764 & 23.8762 & 7.6000 \\
\hline 0.450 & 0.0688 & 23.8762 & 8.4445 \\
\hline 0.400 & 0.0611 & 23.8762 & 9.5000 \\
\hline 0.350 & 0.0535 & 23.8762 & 10.8572 \\
\hline 0.300 & 0.0459 & 23.8762 & 12.6667 \\
\hline
\end{tabular}


Table 10. Continued.

\begin{tabular}{|c|c|c|c|}
\hline $\begin{array}{l}\text { Frequency } \\
(\mathrm{Hz})\end{array}$ & $\begin{array}{c}\text { Mean Vertical Curve } \\
\text { Spectral Acceleration }(\mathrm{g}) \\
\end{array}$ & $\begin{array}{c}\text { Mean Vertical Curve } \\
\text { Spectral Velocity }(\mathrm{cm} / \mathrm{s})^{a}\end{array}$ & $\begin{array}{c}\text { Mean Vertical Curve } \\
\text { Spectral Displacement }(\mathrm{cm})^{\mathrm{b}}\end{array}$ \\
\hline 0.275 & 0.0420 & 23.8762 & 13.8182 \\
\hline 0.250 & 0.0382 & 23.8762 & 15.2001 \\
\hline 0.225 & 0.0344 & 23.8762 & 16.8890 \\
\hline 0.208 & 0.0318 & 23.8762 & 18.2409 \\
\hline 0.190 & 0.0265 & 21.7761 & 18.2409 \\
\hline 0.175 & 0.0225 & 20.0569 & 18.2409 \\
\hline 0.150 & 0.0165 & 17.1916 & 18.2409 \\
\hline 0.125 & 0.0115 & 14.3264 & 18.2409 \\
\hline 0.100 & 0.0073 & 11.4611 & 18.2409 \\
\hline
\end{tabular}


Table 11. Spectral accelerations, velocities, and displacements of the mean vertical IWTU PC 3 (2,500 yr) Soil DBE 5\% damped spectrum.

Mean Vertical IWTU PC 3 Soil DBE 5\% Damped Spectrum

Frequency $(\mathrm{Hz}) \quad$ Spectral Acceleration $(\mathrm{g}) \quad$ Spectral Velocity $(\mathrm{cm} / \mathrm{s})^{\mathrm{a}} \quad{\text { Spectral Displacement }(\mathrm{cm})^{\mathrm{b}}}^{\mathrm{b}}$

\begin{tabular}{|c|c|c|c|}
\hline 100.000 & 0.1954 & 0.3053 & 100.000 \\
\hline 50.000 & 0.1954 & 0.6105 & 50.000 \\
\hline 45.000 & 0.2136 & 0.7415 & 45.000 \\
\hline 40.000 & 0.2358 & 0.9210 & 40.000 \\
\hline 33.330 & 0.2677 & 1.2546 & 33.330 \\
\hline 31.000 & 0.2842 & 1.4319 & 31.000 \\
\hline 30.000 & 0.2913 & 1.5170 & 30.000 \\
\hline 28.000 & 0.3053 & 1.7029 & 28.000 \\
\hline 25.000 & 0.3298 & 2.0605 & 25.000 \\
\hline 22.000 & 0.4038 & 2.8673 & 22.000 \\
\hline 20.000 & 0.4697 & 3.6683 & 20.000 \\
\hline 18.000 & 0.5550 & 4.8166 & 18.000 \\
\hline 17.500 & 0.5804 & 5.1804 & 17.500 \\
\hline 17.000 & 0.6077 & 5.5835 & 17.000 \\
\hline 16.000 & 0.6689 & 6.5307 & 16.000 \\
\hline 15.000 & 0.7410 & 7.7163 & 15.000 \\
\hline 14.500 & 0.7819 & 8.4230 & 14.500 \\
\hline 14.000 & 0.8266 & 9.2227 & 14.000 \\
\hline 13.500 & 0.8756 & 10.1317 & 13.500 \\
\hline 13.000 & 0.9296 & 11.1699 & 13.000 \\
\hline 12.500 & 0.9892 & 12.3617 & 12.500 \\
\hline 12.000 & 0.9892 & 12.8768 & 12.000 \\
\hline 11.500 & 0.9892 & 13.4366 & 11.500 \\
\hline 11.000 & 0.9892 & 14.0474 & 11.000 \\
\hline 10.500 & 0.9892 & 14.7163 & 10.500 \\
\hline 10.000 & 0.9892 & 15.4521 & 10.000 \\
\hline 9.500 & 0.9892 & 16.2654 & 9.500 \\
\hline 9.000 & 0.9892 & 17.1691 & 9.000 \\
\hline 8.500 & 0.9892 & 18.1790 & 8.500 \\
\hline 8.000 & 0.9892 & 19.3152 & 8.000 \\
\hline 7.750 & 0.9892 & 19.9383 & 7.750 \\
\hline
\end{tabular}


Table 11. Continued.

Mean Vertical IWTU PC 3 Soil DBE 5\% Damped Spectrum

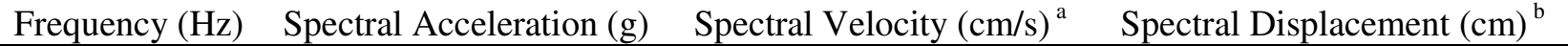

\begin{tabular}{|c|c|c|c|}
\hline 7.500 & 0.9892 & 20.6029 & 7.500 \\
\hline 7.250 & 0.9892 & 21.3133 & 7.250 \\
\hline 7.000 & 0.9892 & 22.0745 & 7.000 \\
\hline 6.750 & 0.9892 & 22.8921 & 6.750 \\
\hline 6.500 & 0.9892 & 23.7725 & 6.500 \\
\hline 6.472 & 0.9892 & 23.8762 & 6.472 \\
\hline 6.000 & 0.9171 & 23.8762 & 6.000 \\
\hline 5.500 & 0.8407 & 23.8762 & 5.500 \\
\hline 5.000 & 0.7643 & 23.8762 & 5.000 \\
\hline 4.800 & 0.7337 & 23.8762 & 4.800 \\
\hline 4.000 & 0.6114 & 23.8762 & 4.000 \\
\hline 3.829 & 0.5853 & 23.8762 & 3.829 \\
\hline 3.500 & 0.5350 & 23.8762 & 3.500 \\
\hline 3.000 & 0.4586 & 23.8762 & 3.000 \\
\hline 2.750 & 0.4203 & 23.8762 & 2.750 \\
\hline 2.500 & 0.3821 & 23.8762 & 2.500 \\
\hline 2.250 & 0.3439 & 23.8762 & 2.250 \\
\hline 2.000 & 0.3057 & 23.8762 & 2.000 \\
\hline 1.750 & 0.2675 & 23.8762 & 1.750 \\
\hline 1.500 & 0.2293 & 23.8762 & 1.500 \\
\hline 1.250 & 0.1911 & 23.8762 & 1.250 \\
\hline 1.000 & 0.1529 & 23.8762 & 1.000 \\
\hline 0.900 & 0.1376 & 23.8762 & 0.900 \\
\hline 0.800 & 0.1223 & 23.8762 & 0.800 \\
\hline 0.700 & 0.1070 & 23.8762 & 0.700 \\
\hline 0.600 & 0.0917 & 23.8762 & 0.600 \\
\hline 0.550 & 0.0841 & 23.8762 & 0.550 \\
\hline 0.500 & 0.0764 & 23.8762 & 0.500 \\
\hline 0.450 & 0.0688 & 23.8762 & 0.450 \\
\hline 0.400 & 0.0611 & 23.8762 & 0.400 \\
\hline 0.350 & 0.0535 & 23.8762 & 0.350 \\
\hline 0.300 & 0.0459 & 23.8762 & 0.300 \\
\hline
\end{tabular}


Table 11. Continued.

Mean Vertical IWTU PC 3 Soil DBE 5\% Damped Spectrum

Frequency $(\mathrm{Hz}) \quad$ Spectral Acceleration $(\mathrm{g}) \quad$ Spectral Velocity $(\mathrm{cm} / \mathrm{s})^{\mathrm{a}} \quad{\text { Spectral Displacement }(\mathrm{cm})^{\mathrm{b}}}^{\mathrm{b}}$

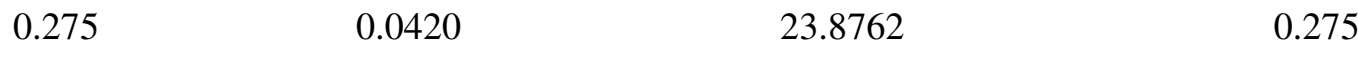

$\begin{array}{llll}0.250 & 0.0382 & 23.8762 & 0.250\end{array}$

$\begin{array}{llll}0.225 & 0.0344 & 23.8762 & 0.225\end{array}$

$\begin{array}{llll}0.208 & 0.0318 & 23.8762 & 0.208\end{array}$

$\begin{array}{llll}0.190 & 0.0265 & 21.7761 & 0.190\end{array}$

$\begin{array}{llll}0.175 & 0.0225 & 20.0569 & 0.175\end{array}$

$\begin{array}{llll}0.150 & 0.0165 & 0.150\end{array}$

$\begin{array}{llll}0.125 & 0.0115 & 14.3264 & 0.125\end{array}$

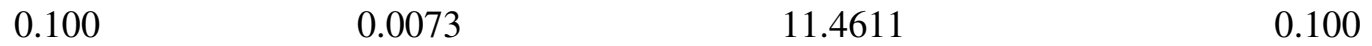

a. Computed using frequency (column 1) and SA (column 2) and Equation [4].

b. Computed using frequency (column 1) and SV (column 3) and Equation [5]. 
Table 12. Calculation of the $84^{\text {th }}$ percentile vertical IWTU PC 3 spectral curve.

\begin{tabular}{|c|c|c|c|}
\hline $\begin{array}{l}\text { Frequency } \\
(\mathrm{Hz})\end{array}$ & $\begin{array}{l}84^{\text {th }} \text { Percentile IWTU PC } 3 \text { Soil } \\
\text { DBE Spectral Acceleration }(\mathrm{g})\end{array}$ & $\begin{array}{l}\text { Vertical/Horizontal } \\
\text { Spectral Ratio }\end{array}$ & $\begin{array}{l}84^{\text {th }} \text { Percentile Vertical Curve } \\
\text { Spectral Acceleration }(\mathrm{g})^{\mathrm{a}}\end{array}$ \\
\hline 100.00 & 0.2538 & 0.7700 & 0.1954 \\
\hline 50.00 & 0.2538 & 0.7700 & 0.1954 \\
\hline 45.00 & 0.2647 & 0.8070 & 0.2136 \\
\hline 40.00 & 0.2775 & 0.8500 & 0.2358 \\
\hline 33.33 & 0.2984 & 0.8970 & 0.2677 \\
\hline 31.00 & 0.3072 & 0.9250 & 0.2842 \\
\hline 30.00 & 0.3113 & 0.9360 & 0.2913 \\
\hline 28.00 & 0.3200 & 0.9540 & 0.3053 \\
\hline 25.00 & 0.3348 & 0.9850 & 0.3298 \\
\hline 22.00 & 0.4023 & 1.0300 & 0.4144 \\
\hline 20.00 & 0.4614 & 1.0600 & 0.4891 \\
\hline 18.00 & 0.5369 & 1.0900 & 0.5852 \\
\hline 17.50 & 0.5591 & 1.0900 & 0.6094 \\
\hline 17.00 & 0.5829 & 1.0900 & 0.6354 \\
\hline 16.00 & 0.6360 & 1.0700 & 0.6805 \\
\hline 15.00 & 0.6978 & 1.0600 & 0.7397 \\
\hline 14.50 & 0.7327 & 1.0600 & 0.7766 \\
\hline 14.00 & 0.7706 & 1.0500 & 0.8091 \\
\hline 13.50 & 0.8119 & 1.0400 & 0.8444 \\
\hline 13.00 & 0.8572 & 1.0300 & 0.8829 \\
\hline 12.50 & 0.9069 & 1.0000 & 0.9069 \\
\hline 12.00 & 0.9618 & 0.9750 & 0.9377 \\
\hline 11.50 & 1.0225 & 0.9490 & 0.9703 \\
\hline 11.00 & 1.0899 & 0.9230 & 1.0060 \\
\hline 10.50 & 1.1653 & 0.8970 & 1.0453 \\
\hline 10.00 & 1.2500 & 0.8700 & 1.0875 \\
\hline 9.50 & 1.2500 & 0.8420 & 1.0525 \\
\hline 9.00 & 1.2500 & 0.8130 & 1.0163 \\
\hline 8.50 & 1.2500 & 0.7890 & 0.9863 \\
\hline 8.00 & 1.2500 & 0.7650 & 0.9563 \\
\hline 7.75 & 1.2500 & 0.7460 & 0.9325 \\
\hline 7.50 & 1.2500 & 0.7280 & 0.9100 \\
\hline
\end{tabular}


Table 12. Continued.

\begin{tabular}{|c|c|c|c|}
\hline $\begin{array}{l}\text { Frequency } \\
(\mathrm{Hz})\end{array}$ & $\begin{array}{l}84^{\text {th }} \text { Percentile IWTU PC } 3 \text { Soil } \\
\text { DBE Spectral Acceleration }(\mathrm{g})\end{array}$ & $\begin{array}{l}\text { Vertical/Horizontal } \\
\text { Spectral Ratio }\end{array}$ & $\begin{array}{l}84^{\text {th }} \text { Percentile Vertical Curve } \\
\text { Spectral Acceleration }(\mathrm{g})^{\mathrm{a}}\end{array}$ \\
\hline 7.25 & 1.2500 & 0.7090 & 0.8863 \\
\hline 7.00 & 1.2500 & 0.6900 & 0.8625 \\
\hline 6.75 & 1.2500 & 0.6850 & 0.8563 \\
\hline 6.50 & 1.2500 & 0.6790 & 0.8488 \\
\hline 6.25 & 1.2500 & 0.6730 & 0.8413 \\
\hline 6.00 & 1.2500 & 0.6670 & 0.8338 \\
\hline 5.455 & 1.2500 & 0.6670 & 0.8338 \\
\hline 5.000 & 1.1458 & 0.6670 & 0.7643 \\
\hline 4.500 & 1.0313 & 0.6670 & 0.6878 \\
\hline 4.000 & 0.9167 & 0.6670 & 0.6114 \\
\hline 3.750 & 0.8594 & 0.6670 & 0.5732 \\
\hline 3.500 & 0.8021 & 0.6670 & 0.5350 \\
\hline 3.000 & 0.6875 & 0.6670 & 0.4586 \\
\hline 2.750 & 0.6302 & 0.6670 & 0.4203 \\
\hline 2.500 & 0.5729 & 0.6670 & 0.3821 \\
\hline 2.250 & 0.5156 & 0.6670 & 0.3439 \\
\hline 2.000 & 0.4583 & 0.6670 & 0.3057 \\
\hline 1.750 & 0.4010 & 0.6670 & 0.2675 \\
\hline 1.500 & 0.3438 & 0.6670 & 0.2293 \\
\hline 1.250 & 0.2865 & 0.6670 & 0.1911 \\
\hline 1.000 & 0.2292 & 0.6670 & 0.1529 \\
\hline 0.900 & 0.2063 & 0.6670 & 0.1376 \\
\hline 0.800 & 0.1833 & 0.6670 & 0.1223 \\
\hline 0.700 & 0.1604 & 0.6670 & 0.1070 \\
\hline 0.600 & 0.1375 & 0.6670 & 0.0917 \\
\hline 0.550 & 0.1260 & 0.6670 & 0.0841 \\
\hline 0.500 & 0.1146 & 0.6670 & 0.0764 \\
\hline 0.450 & 0.1031 & 0.6670 & 0.0688 \\
\hline 0.400 & 0.0917 & 0.6670 & 0.0611 \\
\hline 0.350 & 0.0802 & 0.6670 & 0.0535 \\
\hline 0.300 & 0.0688 & 0.6670 & 0.0459 \\
\hline 0.275 & 0.0630 & 0.6670 & 0.0420 \\
\hline
\end{tabular}


Table 12. Continued.

\begin{tabular}{cccc}
\hline $\begin{array}{c}\text { Frequency } \\
(\mathrm{Hz})\end{array}$ & $\begin{array}{c}84^{\text {th }} \text { Percentile IWTU PC 3 Soil } \\
\text { DBE Spectral Acceleration }(\mathrm{g})\end{array}$ & $\begin{array}{c}\text { Vertical/Horizontal } \\
\text { Spectral Ratio }\end{array}$ & $\begin{array}{c}84^{\text {th }} \text { Percentile Vertical Curve } \\
\text { Spectral Acceleration }(\mathrm{g})^{\mathrm{a}}\end{array}$ \\
\hline 0.250 & 0.0573 & 0.6670 & 0.0382 \\
0.225 & 0.0516 & 0.6670 & 0.0344 \\
0.208 & 0.0477 & 0.6670 & 0.0318 \\
0.190 & 0.0397 & 0.6670 & 0.0265 \\
0.175 & 0.0337 & 0.6670 & 0.0225 \\
0.150 & 0.0248 & 0.6670 & 0.0165 \\
0.125 & 0.0172 & 0.6670 & 0.0115 \\
0.100 & 0.0110 & 0.6670 & 0.0073 \\
\hline
\end{tabular}

a. SA (column 4) calculated by multiplying horizontal SA (column 2) by V/H spectral ratio (column 3). 
Table 13. Spectral accelerations, velocities, and displacements of the $84^{\text {th }}$ percentile vertical IWTU PC 3 (2,500 yr) Soil DBE 5\% damped spectrum.

$84^{\text {th }}$ Percentile Vertical IWTU PC 3 Soil DBE 5\% Damped Spectrum

Frequency $(\mathrm{Hz}) \quad$ Spectral Acceleration $(\mathrm{g}) \quad$ Spectral Velocity $(\mathrm{cm} / \mathrm{s})^{\mathrm{a}} \quad{\text { Spectral Displacement }(\mathrm{cm})^{\mathrm{b}}}^{\mathrm{b}}$

\begin{tabular}{|c|c|c|c|}
\hline 100.000 & 0.1954 & 0.3053 & 0.0005 \\
\hline 50.000 & 0.1954 & 0.6105 & 0.0019 \\
\hline 45.000 & 0.2136 & 0.7415 & 0.0026 \\
\hline 40.000 & 0.2358 & 0.9210 & 0.0037 \\
\hline 33.330 & 0.2677 & 1.2546 & 0.0060 \\
\hline 31.000 & 0.2842 & 1.4319 & 0.0074 \\
\hline 30.000 & 0.2913 & 1.5170 & 0.0080 \\
\hline 28.000 & 0.3053 & 1.7029 & 0.0097 \\
\hline 25.000 & 0.3298 & 2.0605 & 0.0131 \\
\hline 22.000 & 0.4060 & 2.8823 & 0.0209 \\
\hline 20.000 & 0.4740 & 3.7019 & 0.0295 \\
\hline 18.000 & 0.5625 & 4.8817 & 0.0432 \\
\hline 17.500 & 0.5889 & 5.2565 & 0.0478 \\
\hline 17.000 & 0.6173 & 5.6722 & 0.0531 \\
\hline 16.000 & 0.6813 & 6.6510 & 0.0662 \\
\hline 15.000 & 0.7566 & 7.8791 & 0.0836 \\
\hline 14.500 & 0.7995 & 8.6127 & 0.0945 \\
\hline 14.000 & 0.8464 & 9.4440 & 0.1074 \\
\hline 13.500 & 0.8980 & 10.3902 & 0.1225 \\
\hline 13.000 & 0.9548 & 11.4726 & 0.1405 \\
\hline 12.500 & 1.0177 & 12.7170 & 0.1619 \\
\hline 12.000 & 1.0875 & 14.1559 & 0.1877 \\
\hline 11.500 & 1.0875 & 14.7713 & 0.2044 \\
\hline 11.000 & 1.0875 & 15.4428 & 0.2234 \\
\hline 10.500 & 1.0875 & 16.1781 & 0.2452 \\
\hline 10.000 & 1.0875 & 16.9870 & 0.2704 \\
\hline 9.500 & 1.0875 & 17.8811 & 0.2996 \\
\hline 9.000 & 1.0875 & 18.8745 & 0.3338 \\
\hline 8.500 & 1.0875 & 19.9847 & 0.3742 \\
\hline 8.000 & 1.0875 & 21.2338 & 0.4224 \\
\hline 7.750 & 1.0875 & 21.9188 & 0.4501 \\
\hline
\end{tabular}


Table 13. Continued.

$84^{\text {th }}$ Percentile Vertical IWTU PC 3 Soil DBE 5\% Damped Spectrum

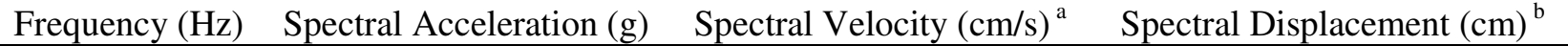

\begin{tabular}{|c|c|c|c|}
\hline 7.500 & 1.0875 & 22.6494 & 0.4806 \\
\hline 7.115 & 1.0875 & 23.8762 & 0.5341 \\
\hline 7.000 & 1.0700 & 23.8762 & 0.5429 \\
\hline 6.750 & 1.0318 & 23.8762 & 0.5630 \\
\hline 6.500 & 0.9936 & 23.8762 & 0.5846 \\
\hline 6.250 & 0.9553 & 23.8762 & 0.6080 \\
\hline 6.000 & 0.9171 & 23.8762 & 0.6333 \\
\hline 5.500 & 0.8407 & 23.8762 & 0.6909 \\
\hline 5.000 & 0.7643 & 23.8762 & 0.7600 \\
\hline 4.500 & 0.6878 & 23.8762 & 0.8444 \\
\hline 4.000 & 0.6114 & 23.8762 & 0.9500 \\
\hline 3.750 & 0.5732 & 23.8762 & 1.0133 \\
\hline 3.500 & 0.5350 & 23.8762 & 1.0857 \\
\hline 3.000 & 0.4586 & 23.8762 & 1.2667 \\
\hline 2.750 & 0.4203 & 23.8762 & 1.3818 \\
\hline 2.500 & 0.3821 & 23.8762 & 1.5200 \\
\hline 2.250 & 0.3439 & 23.8762 & 1.6889 \\
\hline 2.000 & 0.3057 & 23.8762 & 1.9000 \\
\hline 1.750 & 0.2675 & 23.8762 & 2.1714 \\
\hline 1.500 & 0.2293 & 23.8762 & 2.5333 \\
\hline 1.250 & 0.1911 & 23.8762 & 3.0400 \\
\hline 1.000 & 0.1529 & 23.8762 & 3.8000 \\
\hline 0.900 & 0.1376 & 23.8762 & 4.2222 \\
\hline 0.800 & 0.1223 & 23.8762 & 4.7500 \\
\hline 0.700 & 0.1070 & 23.8762 & 5.4286 \\
\hline 0.600 & 0.0917 & 23.8762 & 6.3334 \\
\hline 0.550 & 0.0841 & 23.8762 & 6.9091 \\
\hline 0.500 & 0.0764 & 23.8762 & 7.6000 \\
\hline 0.450 & 0.0688 & 23.8762 & 8.4445 \\
\hline 0.400 & 0.0611 & 23.8762 & 9.5000 \\
\hline 0.350 & 0.0535 & 23.8762 & 10.8572 \\
\hline 0.300 & 0.0459 & 23.8762 & 12.6667 \\
\hline
\end{tabular}


Table 13. Continued.

$84^{\text {th }}$ Percentile Vertical IWTU PC 3 Soil DBE 5\% Damped Spectrum

Frequency $(\mathrm{Hz}) \quad$ Spectral Acceleration $(\mathrm{g}) \quad$ Spectral Velocity $(\mathrm{cm} / \mathrm{s})^{\mathrm{a}} \quad{\text { Spectral Displacement }(\mathrm{cm})^{\mathrm{b}}}^{\mathrm{b}}$

$\begin{array}{llll}0.275 & 0.0420 & 23.8762 & 13.8182\end{array}$

$\begin{array}{llll}0.250 & 0.0382 & 23.8762 & 15.2001\end{array}$

$\begin{array}{lll}0.225 & 0.0344 & 23.8762\end{array}$

$\begin{array}{llll}0.208 & 0.0318 & 23.8762 & 18.2409\end{array}$

$\begin{array}{llll}0.190 & 0.0265 & 21.7761 & 18.2409\end{array}$

$\begin{array}{llll}0.175 & 0.0225 & 20.0569 & 18.2409\end{array}$

$\begin{array}{llll}0.150 & 0.0165 & 17.1916 & 18.2409\end{array}$

$\begin{array}{llll}0.125 & 0.0115 & 14.3264 & 18.2409\end{array}$

$\begin{array}{llll}0.100 & 0.0073 & 11.4611 & 18.2409\end{array}$

a. Computed using frequency (column 1) and SA (column 2) and Equation [4].

b. Computed using frequency (column 1) and SV (column 3) and Equation [5]. 


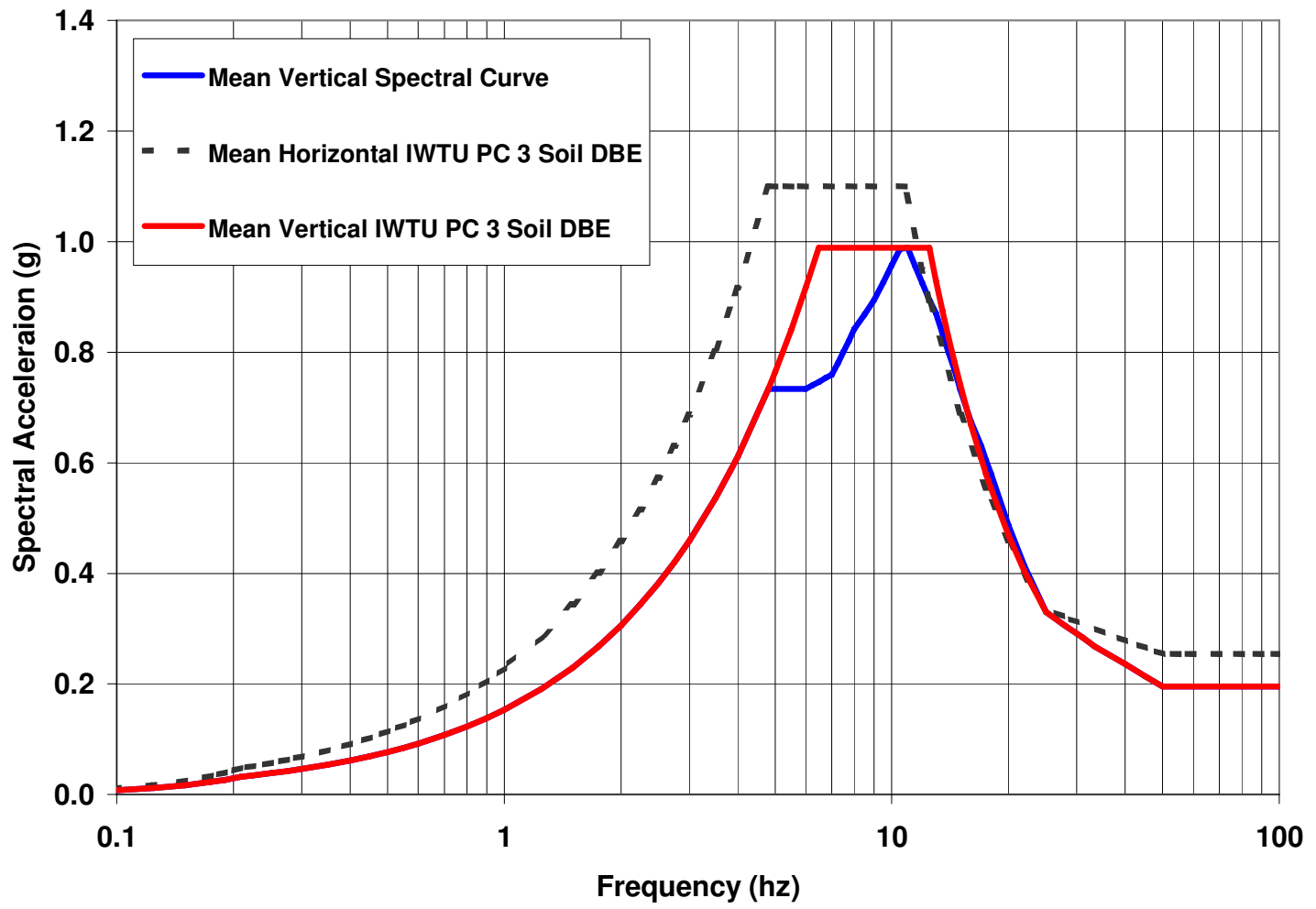

Figure 20. The mean vertical and horizontal IWTU PC 3 Soil DBE 5\% damped spectra and the mean vertical spectral curve. 


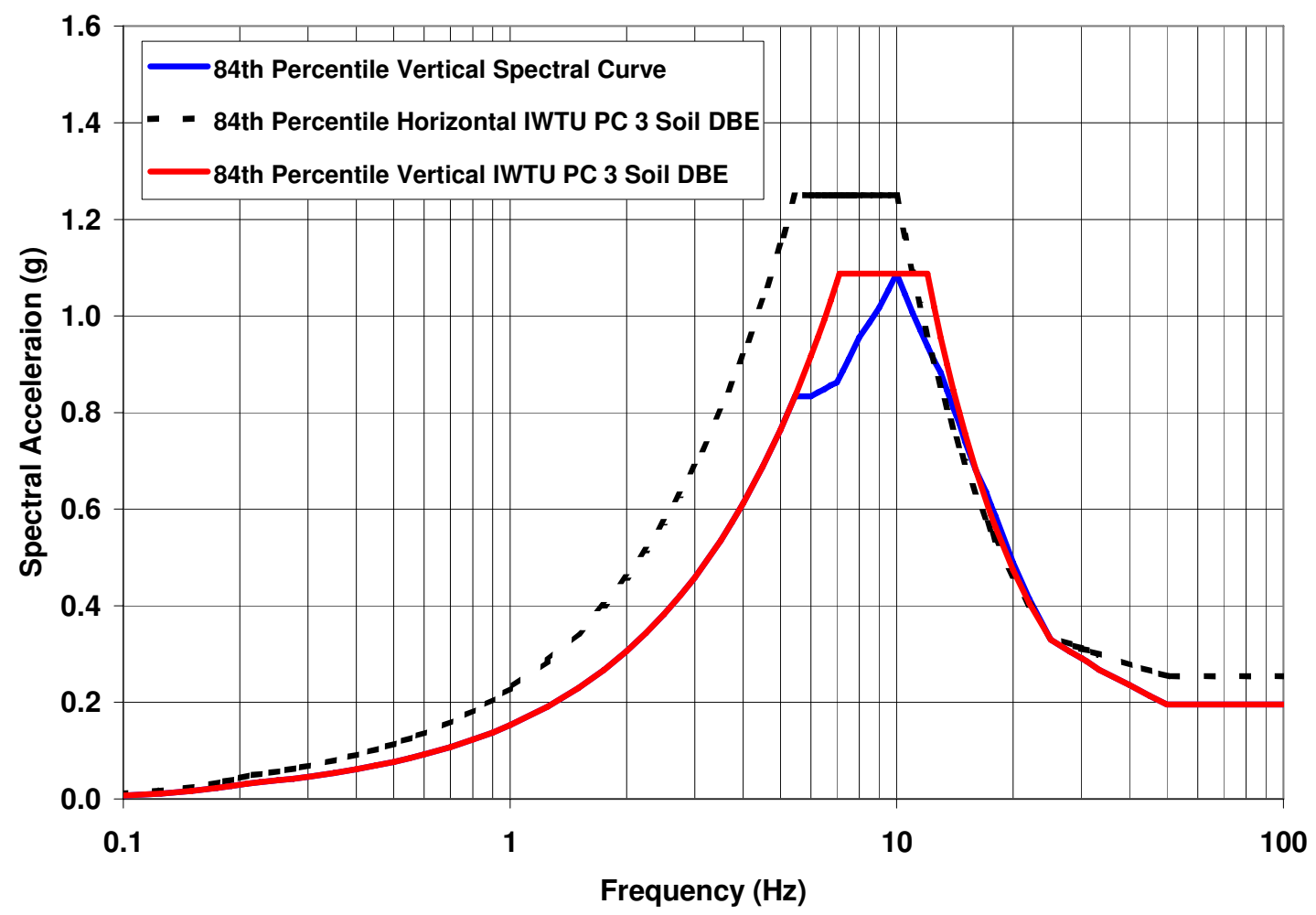

Figure 21. The $84^{\text {th }}$ percentile vertical and horizontal IWTU PC 3 Soil DBE 5\% damped spectra and the $84^{\text {th }}$ percentile vertical spectral curve. 


\section{Development of Soil DBE Time Histories}

Horizontal and vertical time histories were developed to match their respective IWTU PC $3(2,500$ yr) Soil DBE 5\% damped spectra. The process used to generate time histories to match a target spectrum was consistent with the recommendations in NUREG/CR-6728 (NRC 2001) and ASCE/SEI 43-05 (ASCE 2005). The horizontal and vertical IWTU PC 3 Soil DBE 5\% damped spectra (listed in Tables 8 and 13) were increased to 300 frequency points for the frequency range from 0.1 to $100 \mathrm{~Hz}$.

The horizontal time histories were selected from the output of the site response analyses. The acceleration time histories for the $\mathrm{H} 1$ and $\mathrm{H} 2$ components are from the output of SHAKE2000 for the base case soil profiles of the log normal distribution of $\mathrm{G}$. These time histories were selected as seeds because they generally have spectral peaks within the range of the soil DBE spectral acceleration level. The vertical rock DBE time history (Figure 5) was used as a seed to compute the vertical soil DBE time history.

Two programs RSPM02 and BLINE02 were used to perform the spectral matches of the seed time history to the target soil DBE spectra (Abrahamson 1993; 1996). The RSPM02 program was used to modify the acceleration time history to match the target spectrum and the BLINE02 program was used to

make baseline corrections. After each spectral match using RSPM02, the soil time history was baseline corrected using BLINE02. The corrected acceleration time history from BLINE02 was used as input to the next iteration with the RSPM02 program. The computed time history and target acceleration spectrum were visually examined to determine the minimum number of iterations. The horizontal and vertical starting time history, target, and final time history spectral matches are shown in Appendix D.

The mean and $84^{\text {th }}$ percentile horizontal and vertical IWTU PC 3 soil DBE time histories were matched to spectral frequencies from 0.3 to $100 \mathrm{~Hz}$. Over this frequency range, the spectra computed for the horizontal and vertical soil DBE time histories relative to their corresponding DBE target spectrum meet the acceptance criteria in NUREG/CR-6728 and ASCE/SEI 43-05. Although the criteria recommend spectral matches to $0.2 \mathrm{~Hz}$, the displacement regions of the horizontal DBE spectrum was set to $27.3 \mathrm{~cm}$ (or 10.7 inches) as discussed in Payne (2006). The spectral matches are considered acceptable considering the conservatism in the displacement levels of the horizontal and vertical DBE spectra (per. Comm. Carl Costantino 2007). The $84^{\text {th }}$ percentile horizontal and vertical IWTU PC 3 soil DBE acceleration, velocity, and displacement time histories are shown in Figures 22, 23, and 24. The mean soil DBE time histories and all arias intensity plots are shown in Appendix B. Arias intensity plots of the soil DBE time histories show smooth curves. 

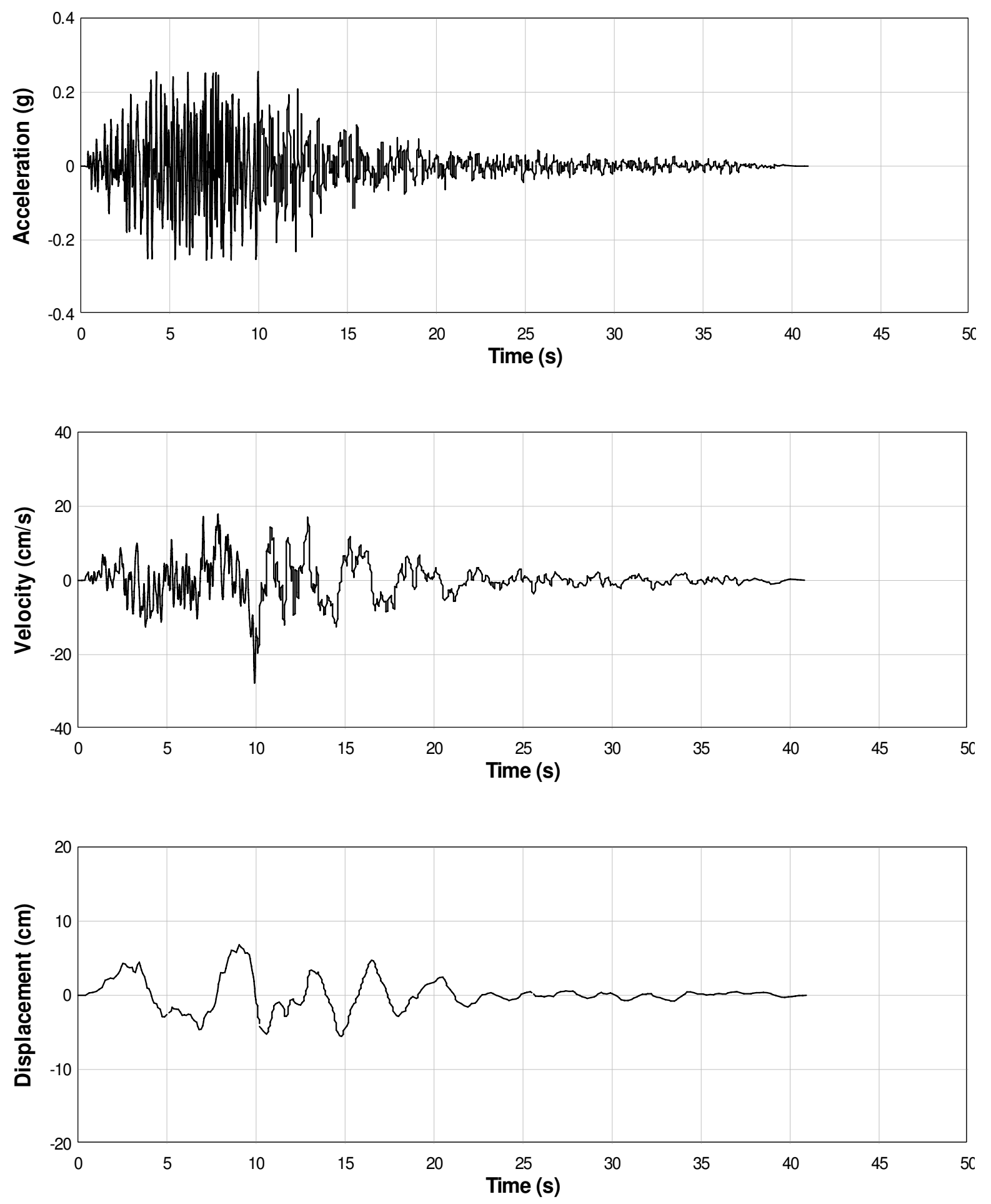

Figure 22. $84^{\text {th }}$ percentile IWTU PC 3 (2,500 yr) soil DBE time histories for the horizontal 1 component. 

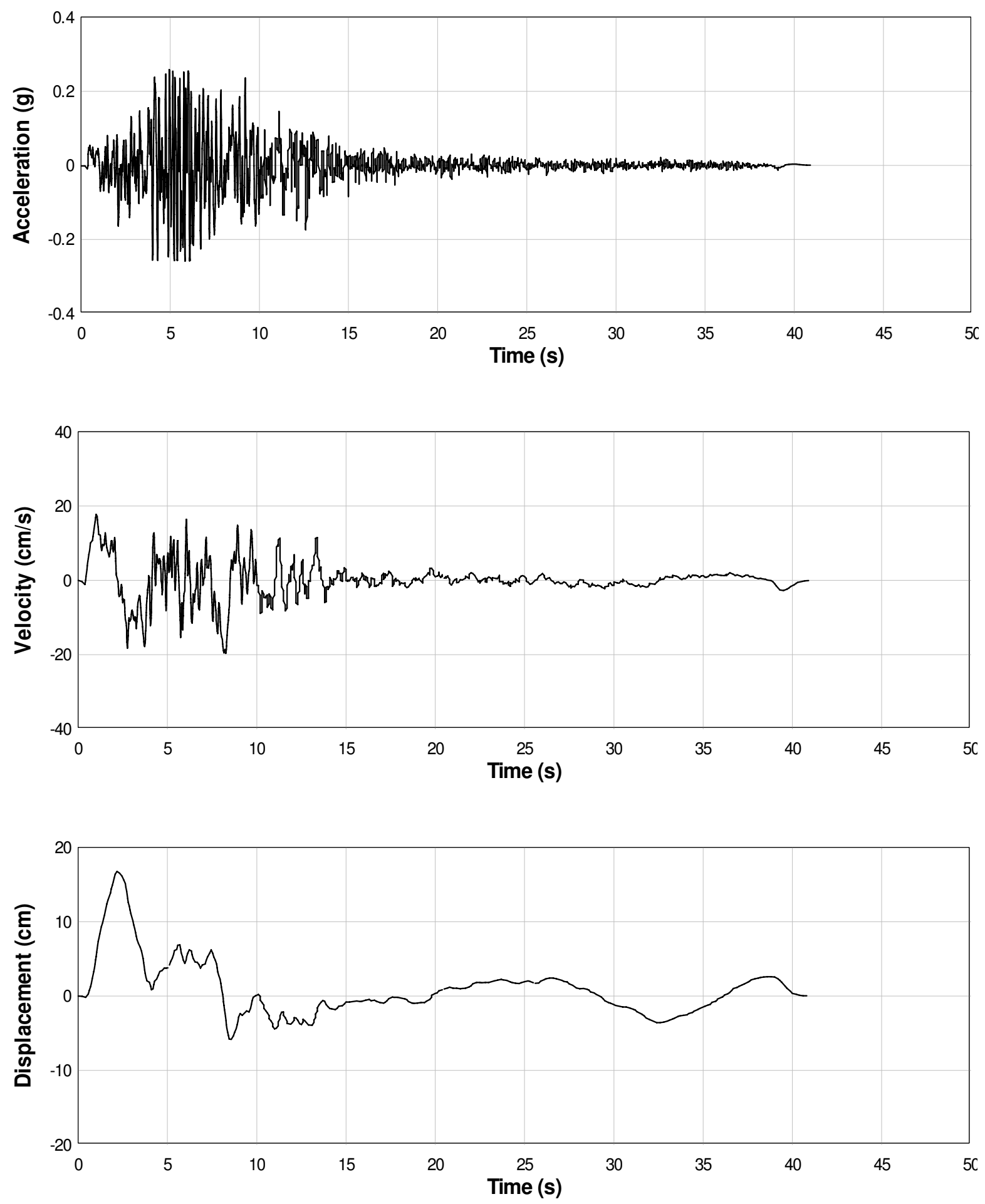

Figure 23. $84^{\text {th }}$ percentile IWTU PC 3 (2,500 yr soil DBE time histories for the horizontal 2 component. 

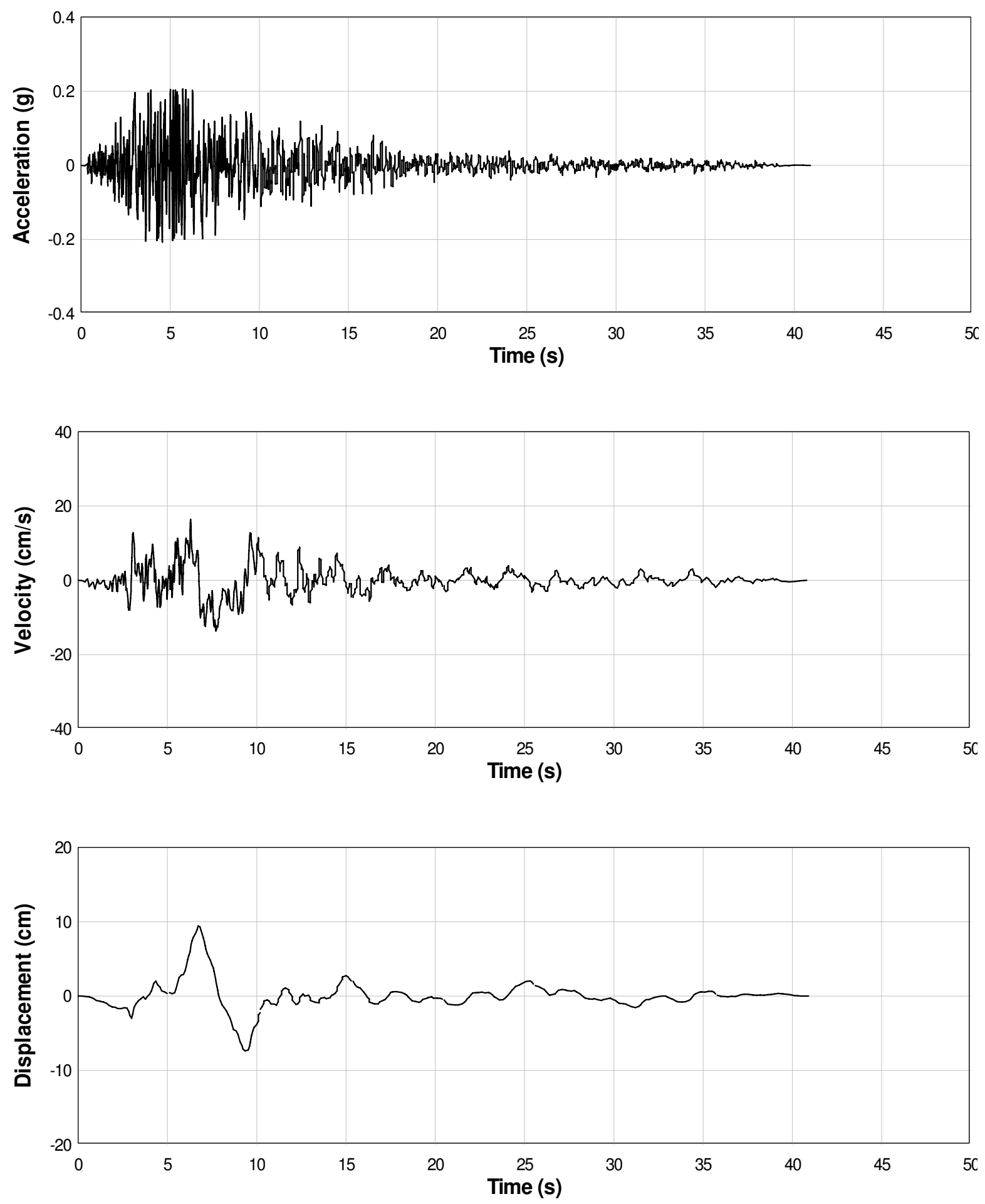

Figure 24. $84^{\text {th }}$ percentile IWTU PC $3(2,500 \mathrm{yr})$ soil DBE time histories for the vertical component. 


\section{Strain-compatible Soil Properties}

Strain-compatible soil properties were computed for the horizontal and vertical IWTU Soil DBE 5\% damped spectra and corresponding time histories. The best estimate, lower bound, and upper bound strain-compatible Vs, Vp, and damping were calculated for soil and rock as a function of depth. The strain-compatible soil properties for Vs and damping were calculated using iterated Vs and damping for soil profiles from the output of SHAKE2000. Low-strain Vp for soil and rock were calculated using Vs of the soil profiles used as input to SHAKE2000. Soil profiles for the log normal distribution of shear modulus were used for the calculations of the strain-compatible soil properties (Houston 2007a). Vs and $\mathrm{Vp}$ soil properties were calculated for the depth profile consistent with computations of SHAKE2000 iterated soil profile layers at depths of $1,3,5,7 \ldots 43 \mathrm{ft}$.

Strain-compatible soil properties for Vs and damping were calculated based on ratios of Vs for soil profiles from the output of SHAKE2000 to Vs for input soil profiles to SHAKE2000 as a function of depth. This approach was recommended (Per. Comm. Carl Costantino 2007) in place of computing the best estimate, upper bound, and lower bound iterated Vs and damping for a log normal distribution as first recommended by the BRP (Houston 2007a). Best estimate, upper bound, and lower bound iterated Vs and damping as function of depth for the log normal distribution resulted in anomalously high values for the upper bound at depths that cross the boundary between Layers A and B. The reason for high upper-bound values is the iterated Vs and damping at depths that cross this boundary do not have log normal distributions. The distributions are bimodal and result from sampling iterated Vs and damping in both Layers A and B at the profile depths of 11 and $13 \mathrm{ft}$. Vs of Layers A and B are different and do not overlap due to small COVs. Appendix E shows the bimodal distributions for these layers.

The low-strain Vp soil and rock properties were calculated using the log normal distribution of Vs of the input soil profiles to SHAKE2000 (Figure 2b). Kleinfelder, Inc. (2007a) computed average Poisson's ratios from seismic velocities measured in soil and rock layers at the IWTU. Average Poisson's ratios and Vs were used to calculate the low-strain mean, upper bound, and lower bound Vp.

\subsection{Iterated Shear Wave Velocity and Damping Calculations}

Iterated Vs and damping values were calculated based on ratios of the output to input Vs soil profiles for SHAKE2000. First, the shear modulus of the last iteration soil profile of SHAKE2000 and average density of each soil layer were used to compute the corresponding iterated Vs. The shear modulus of the input soil profile to SHAKE2000 and average density of each soil layer were used to calculate the corresponding input Vs.

Second, ratios of Vs for SHAKE2000 output soil profiles to the Vs for SHAKE2000 input soil profiles were calculated at depths that correspond to the iterated soil profile depths calculated by SHAKE2000. The input soil profiles to SHAKE2000 were divided into $2 \mathrm{ft}$ sub-layers so the output soil properties were calculated in the middle of the sub-layers at depths of $1,3,5,7$...etc to depths less than $47 \mathrm{ft}$. The maximum depth of the soil profile for iterated Vs and damping was set to $43 \mathrm{ft}$, which is close to the average depth $42.9 \mathrm{ft}$ of the borehole soil column heights (Kleinfelder, Inc. 2007a). Iterated Vs of SHAKE2000 input and output files were sorted at $\pm 1 \mathrm{ft}$ of the depths $1,3,5,7 \ldots 41 \mathrm{ft}$. Vs at depths between 42 and $47 \mathrm{ft}$ were grouped with the soil profile depth of $43 \mathrm{ft}$. Ratios of the output to input Vs were then calculated at the soil profile depths by matching soil profile file names.

Third, the best estimate (or mean), lower bound (or minus one-sigma), and upper bound (or plus one-sigma) were calculated for each ratio. Vs for each soil layer of the base case soil profile listed in Table 4 were assigned to the depth profile consistent with each soil layer's thickness. To compute iterated 
Vs as function of depth, the best estimate, lower bound, and upper bound ratios were multiplied by the Vs assigned to each depth (Table 14).

Fourth, corresponding damping values were calculated using the best estimate, lower bound, and upper bound ratios and the "Darendeli/Menq CU 40" shear modulus reduction curves. G/G $\mathrm{GAX}_{\text {can be }}$ obtained from:

$$
\frac{G}{G_{M A X}}=\left(\frac{V_{\text {iterated }}}{V_{\text {low_strain }}}\right)^{2}
$$

The squared-ratios for the best estimate, lower bound, and upper bound were used to select the range of $\mathrm{G} / \mathrm{G}_{\mathrm{MAX}}$ values of the shear modulus reduction curve appropriate for that layer's depth (see Section 2.2.2). A linear interpolation was used over that range to determine the corresponding percent strain. The percent strain was then used to select the range of damping values for the corresponding damping ratio curve. A linear interpolation was then used to calculate the damping value (Table 15).

\subsection{Low-strain Compressional Wave Velocity Calculations}

The low-strain Vp soil and rock properties were calculated using the input soil profiles to SHAKE2000. The shear modulus of each soil layer was sorted for depths of 1, 3, 5, $7 \ldots 43 \mathrm{ft}$ as discussed in Section 5.1. The best estimate (or mean), lower bound (or minus one-sigma), and upper bound (or plus one-sigma) shear modulus of each soil profile depth and the rock layer were calculated for the log normal distribution. Low-strain Vs were calculated using the average density and best estimate, lower bound, and upper bound shear modulus for each soil layer and the rock layer. Average Poisson's ratios and low-strain Vs were used to calculate the low-strain mean, lower bound, and upper bound Vp (Table 16). Vp was calculated using Equation [7]:

$\mathrm{Vp}=\mathrm{Vs} * \operatorname{SQRT}((2 *(1-v) /(1-2 v))$ 
Table 14. Calculations of iterated best estimate, lower bound, and upper bound shear wave velocities as function of depth.

\begin{tabular}{|c|c|c|c|c|c|c|c|}
\hline \multirow[b]{2}{*}{ Depth (ft) } & \multirow[b]{2}{*}{$\begin{array}{c}\text { Median Vs } \\
(\mathrm{ft} / \mathrm{s})^{\mathrm{a}}\end{array}$} & \multicolumn{3}{|c|}{ Ratio (Vs iterated/low-strain Vs) } & \multicolumn{3}{|c|}{ Iterated Vs $(\mathrm{ft} / \mathrm{s})^{\mathrm{b}}$} \\
\hline & & Lower Bound & Best Estimate & Upper Bound & Lower Bound & Best Estimate & Upper Bound \\
\hline 1 & 750 & 0.8980 & 0.9187 & 0.9393 & 674 & 689 & 704 \\
\hline 3 & 750 & 0.7586 & 0.8063 & 0.8541 & 569 & 605 & 641 \\
\hline 5 & 750 & 0.6504 & 0.7160 & 0.7815 & 488 & 537 & 586 \\
\hline 7 & 750 & 0.5650 & 0.6428 & 0.7205 & 424 & 482 & 540 \\
\hline 9 & 750 & 0.4884 & 0.5915 & 0.6945 & 366 & 444 & 521 \\
\hline 11 & 750 & 0.5058 & 0.7014 & 0.8970 & 379 & 526 & 673 \\
\hline 13 & 1540 & 0.6851 & 0.8346 & 0.9842 & 1055 & 1285 & 1516 \\
\hline 15 & 1540 & 0.8823 & 0.8963 & 0.9102 & 1359 & 1380 & 1402 \\
\hline 17 & 1540 & 0.8704 & 0.8874 & 0.9044 & 1340 & 1367 & 1393 \\
\hline 19 & 1540 & 0.8585 & 0.8780 & 0.8975 & 1322 & 1352 & 1382 \\
\hline 21 & 1540 & 0.8473 & 0.8687 & 0.8900 & 1305 & 1338 & 1371 \\
\hline 23 & 1540 & 0.8372 & 0.8596 & 0.8821 & 1289 & 1324 & 1358 \\
\hline 25 & 1540 & 0.8279 & 0.8512 & 0.8746 & 1275 & 1311 & 1347 \\
\hline 27 & 1540 & 0.8194 & 0.8434 & 0.8673 & 1262 & 1299 & 1336 \\
\hline 29 & 1540 & 0.8115 & 0.8360 & 0.8604 & 1250 & 1287 & 1325 \\
\hline 31 & 1540 & 0.8043 & 0.8292 & 0.8542 & 1239 & 1277 & 1315 \\
\hline 33 & 1540 & 0.7977 & 0.8231 & 0.8485 & 1228 & 1268 & 1307 \\
\hline 35 & 1540 & 0.7924 & 0.8178 & 0.8433 & 1220 & 1259 & 1299 \\
\hline 37 & 1540 & 0.7791 & 0.8374 & 0.8956 & 1200 & 1290 & 1379 \\
\hline 39 & 1550 & 0.8310 & 0.9004 & 0.9698 & 1288 & 1396 & 1503 \\
\hline
\end{tabular}


Table 14. Continued.

\begin{tabular}{|c|c|c|c|c|c|c|c|}
\hline \multirow[b]{2}{*}{ Depth (ft) } & \multirow[b]{2}{*}{$\begin{array}{c}\text { Median Vs } \\
(\mathrm{ft} / \mathrm{s})^{\mathrm{a}}\end{array}$} & \multicolumn{3}{|c|}{ Ratio (Vs iterated/low-strain Vs) } & \multicolumn{3}{|c|}{ Iterated Vs $(\mathrm{ft} / \mathrm{s})^{\mathrm{b}}$} \\
\hline & & Lower Bound & Best Estimate & Upper Bound & Lower Bound & Best Estimate & Upper Bound \\
\hline 41 & 1550 & 0.9323 & 0.9432 & 0.9541 & 1445 & 1462 & 1479 \\
\hline 43 & 1550 & 0.9261 & 0.9377 & 0.9493 & 1435 & 1453 & 1471 \\
\hline
\end{tabular}


Table 15. Calculations of the best estimate, lower bound, and upper bound damping.

\begin{tabular}{|c|c|c|c|c|c|c|c|c|c|c|c|}
\hline \multirow{3}{*}{$\begin{array}{l}\text { Degradation } \\
\text { Model }\end{array}$} & \multirow{3}{*}{$\begin{array}{c}\text { Squared } \\
\text { Vs } \\
\text { Ratio }^{\mathrm{a}}\end{array}$} & \multicolumn{4}{|c|}{ Shear Modulus Reduction Curve Values } & \multirow{3}{*}{$\begin{array}{c}\% \\
\text { Strain }^{\mathrm{b}}\end{array}$} & \multicolumn{4}{|c|}{ Damping Ratio Curve Values } & \multirow{3}{*}{$\begin{array}{l}\text { Corresponding } \\
\text { Damping }(\%)^{\mathrm{c}}\end{array}$} \\
\hline & & \multicolumn{2}{|c|}{$\mathrm{G} / \mathrm{G}_{\mathrm{MAX}}$} & \multicolumn{2}{|c|}{$\%$ Strain } & & \multicolumn{2}{|c|}{ Damping (\%) } & \multicolumn{2}{|c|}{$\%$ Strain } & \\
\hline & & $\mathrm{Y} 1$ & $\mathrm{Y} 2$ & $\mathrm{X} 1$ & $\mathrm{X} 1$ & & Y1 & $\mathrm{Y} 2$ & $\mathrm{X} 1$ & $\mathrm{X} 1$ & \\
\hline \multicolumn{12}{|l|}{ Lower Bound } \\
\hline $\begin{array}{c}\mathrm{D} / \mathrm{M} \mathrm{CU} 40 \\
5 \mathrm{ft}\end{array}$ & 0.8064 & 0.76 & 0.85 & 0.002 & 0.001 & 0.0015 & 2.8 & 1.6 & 0.002 & 0.001 & 2.2 \\
\hline $\begin{array}{c}\mathrm{D} / \mathrm{M} \mathrm{CU} 40 \\
5 \mathrm{ft}\end{array}$ & 0.5754 & 0.47 & 0.61 & 0.010 & 0.005 & 0.0062 & 7.8 & 5.3 & 0.010 & 0.005 & 5.9 \\
\hline $\begin{array}{c}\mathrm{D} / \mathrm{M} \mathrm{CU} 40 \\
5 \mathrm{ft}\end{array}$ & 0.4231 & 0.34 & 0.47 & 0.020 & 0.010 & 0.0136 & 10.4 & 7.8 & 0.020 & 0.010 & 8.7 \\
\hline $\begin{array}{c}\text { D/M CU } 40 \\
5 \mathrm{ft}\end{array}$ & 0.3193 & 0.27 & 0.34 & 0.030 & 0.020 & 0.0230 & 11.7 & 10.4 & 0.030 & 0.020 & 10.8 \\
\hline $\begin{array}{c}\mathrm{D} / \mathrm{M} \mathrm{CU} 40 \\
5 \mathrm{ft}\end{array}$ & 0.2386 & 0.20 & 0.27 & 0.050 & 0.030 & 0.0390 & 13.1 & 11.7 & 0.050 & 0.030 & 12.3 \\
\hline $\begin{array}{c}\mathrm{D} / \mathrm{M} \mathrm{CU} 40 \\
5 \mathrm{ft}\end{array}$ & 0.2558 & 0.20 & 0.27 & 0.050 & 0.030 & 0.0340 & 13.1 & 11.7 & 0.050 & 0.030 & 12.0 \\
\hline $\begin{array}{c}\mathrm{D} / \mathrm{M} \mathrm{CU} 40 \\
25 \mathrm{ft}\end{array}$ & 0.4693 & 0.43 & 0.58 & 0.020 & 0.010 & 0.0174 & 9.2 & 6.2 & 0.020 & 0.010 & 8.4 \\
\hline $\begin{array}{c}\mathrm{D} / \mathrm{M} \mathrm{CU} 40 \\
25 \mathrm{ft}\end{array}$ & 0.7785 & 0.72 & 0.80 & 0.005 & 0.003 & 0.0035 & 3.8 & 2.5 & 0.005 & 0.003 & 2.8 \\
\hline $\begin{array}{c}\mathrm{D} / \mathrm{M} \mathrm{CU} 40 \\
25 \mathrm{ft}\end{array}$ & 0.7576 & 0.72 & 0.80 & 0.005 & 0.003 & 0.0041 & 3.8 & 2.5 & 0.005 & 0.003 & 3.2 \\
\hline $\begin{array}{c}\mathrm{D} / \mathrm{M} \mathrm{CU} 40 \\
25 \mathrm{ft}\end{array}$ & 0.7370 & 0.72 & 0.80 & 0.005 & 0.003 & 0.0046 & 3.8 & 2.5 & 0.005 & 0.003 & 3.5 \\
\hline $\begin{array}{c}\mathrm{D} / \mathrm{M} \mathrm{CU} 40 \\
25 \mathrm{ft}\end{array}$ & 0.7180 & 0.58 & 0.72 & 0.010 & 0.005 & 0.0051 & 6.2 & 3.8 & 0.010 & 0.005 & 3.8 \\
\hline $\begin{array}{c}\text { D/M CU } 40 \\
25 \mathrm{ft}\end{array}$ & 0.7008 & 0.58 & 0.72 & 0.010 & 0.005 & 0.0057 & 6.2 & 3.8 & 0.010 & 0.005 & 4.1 \\
\hline
\end{tabular}


Table 15. Continued.

\begin{tabular}{|c|c|c|c|c|c|c|c|c|c|c|c|}
\hline \multirow{3}{*}{$\begin{array}{l}\text { Degradation } \\
\text { Model }\end{array}$} & \multirow{3}{*}{$\begin{array}{c}\text { Squared } \\
\text { Vs } \\
\text { Ratio }^{\mathrm{a}}\end{array}$} & \multicolumn{4}{|c|}{ Shear Modulus Reduction Curve Values } & \multirow{3}{*}{$\begin{array}{c}\% \\
\text { Strain }^{\mathrm{b}}\end{array}$} & \multicolumn{4}{|c|}{ Damping Ratio Curve Values } & \multirow{3}{*}{$\begin{array}{l}\text { Corresponding } \\
\text { Damping }(\%)^{\mathrm{c}}\end{array}$} \\
\hline & & \multicolumn{2}{|c|}{$\mathrm{G} / \mathrm{G}_{\mathrm{MAX}}$} & \multicolumn{2}{|c|}{$\%$ Strain } & & \multicolumn{2}{|c|}{ Damping (\%) } & \multicolumn{2}{|c|}{ \% Strain } & \\
\hline & & Y1 & $\mathrm{Y} 2$ & $\mathrm{X} 1$ & $\mathrm{X} 1$ & & $\mathrm{Y} 1$ & $\mathrm{Y} 2$ & $\mathrm{X} 1$ & $\mathrm{X} 1$ & \\
\hline $\begin{array}{c}\text { D/M CU } 40 \\
25 \mathrm{ft}\end{array}$ & 0.6854 & 0.58 & 0.72 & 0.010 & 0.005 & 0.0062 & 6.2 & 3.8 & 0.010 & 0.005 & 4.4 \\
\hline $\begin{array}{c}\mathrm{D} / \mathrm{M} \mathrm{CU} 40 \\
25 \mathrm{ft}\end{array}$ & 0.6714 & 0.58 & 0.72 & 0.010 & 0.005 & 0.0067 & 6.2 & 3.8 & 0.010 & 0.005 & 4.6 \\
\hline $\begin{array}{c}\mathrm{D} / \mathrm{M} \mathrm{CU} 40 \\
25 \mathrm{ft}\end{array}$ & 0.6585 & 0.58 & 0.72 & 0.010 & 0.005 & 0.0072 & 6.2 & 3.8 & 0.010 & 0.005 & 4.9 \\
\hline $\begin{array}{c}\mathrm{D} / \mathrm{M} \mathrm{CU} 40 \\
25 \mathrm{ft}\end{array}$ & 0.6469 & 0.58 & 0.72 & 0.010 & 0.005 & 0.0076 & 6.2 & 3.8 & 0.010 & 0.005 & 5.1 \\
\hline $\begin{array}{c}\mathrm{D} / \mathrm{M} \mathrm{CU} 40 \\
25 \mathrm{ft}\end{array}$ & 0.6363 & 0.58 & 0.72 & 0.010 & 0.005 & 0.0080 & 6.2 & 3.8 & 0.010 & 0.005 & 5.2 \\
\hline $\begin{array}{c}\mathrm{D} / \mathrm{M} \mathrm{CU} 40 \\
25 \mathrm{ft}\end{array}$ & 0.6279 & 0.58 & 0.72 & 0.010 & 0.005 & 0.0083 & 6.2 & 3.8 & 0.010 & 0.005 & 5.4 \\
\hline $\begin{array}{c}\text { D/M CU } 40 \\
25 \mathrm{ft}\end{array}$ & 0.6071 & 0.58 & 0.72 & 0.010 & 0.005 & 0.0090 & 6.2 & 3.8 & 0.010 & 0.005 & 5.7 \\
\hline V\&D PI 15 & 0.6906 & 0.637 & 0.819 & 0.03162 & 0.01000 & 0.0253 & 7.8 & 4.5 & 0.03162 & 0.01000 & 6.8 \\
\hline V\&D PI 15 & 0.8691 & 0.819 & 0.935 & 0.01000 & 0.00316 & 0.0070 & 4.5 & 2.6 & 0.01000 & 0.00316 & 3.7 \\
\hline V\&D PI 15 & 0.8577 & 0.819 & 0.935 & 0.01000 & 0.00316 & 0.0077 & 4.5 & 2.6 & 0.01000 & 0.00316 & 3.9 \\
\hline Best Estimate & & & & & & & & & & & \\
\hline $\begin{array}{c}\text { D/M CU } 40 \\
5 \mathrm{ft}\end{array}$ & 0.8439 & 0.76 & 0.85 & 0.0020 & 0.0010 & 0.0011 & 2.8 & 1.6 & 0.0020 & 0.0010 & 1.7 \\
\hline $\begin{array}{c}\text { D/M CU } 40 \\
5 \mathrm{ft}\end{array}$ & 0.6501 & 0.61 & 0.70 & 0.0050 & 0.0030 & 0.0041 & 5.3 & 3.8 & 0.0050 & 0.0030 & 4.6 \\
\hline $\begin{array}{c}\mathrm{D} / \mathrm{M} \mathrm{CU} 40 \\
5 \mathrm{ft} \\
\end{array}$ & 0.5126 & 0.47 & 0.61 & 0.0100 & 0.0050 & 0.0085 & 7.8 & 5.3 & 0.0100 & 0.0050 & 7.0 \\
\hline
\end{tabular}


Table 15. Continued.

\begin{tabular}{|c|c|c|c|c|c|c|c|c|c|c|c|}
\hline \multirow{3}{*}{$\begin{array}{c}\text { Degradation } \\
\text { Model }\end{array}$} & \multirow{3}{*}{$\begin{array}{c}\text { Squared } \\
\text { Vs } \\
\text { Ratio }^{\mathrm{a}}\end{array}$} & \multicolumn{4}{|c|}{ Shear Modulus Reduction Curve Values } & \multirow{3}{*}{$\begin{array}{c}\% \\
\text { Strain }^{\mathrm{b}}\end{array}$} & \multicolumn{4}{|c|}{ Damping Ratio Curve Values } & \multirow{3}{*}{$\begin{array}{l}\text { Corresponding } \\
\text { Damping }(\%)^{\mathrm{c}}\end{array}$} \\
\hline & & \multicolumn{2}{|c|}{$\mathrm{G} / \mathrm{G}_{\mathrm{MAX}}$} & \multicolumn{2}{|c|}{$\%$ Strain } & & \multicolumn{2}{|c|}{ Damping (\%) } & \multicolumn{2}{|c|}{$\%$ Strain } & \\
\hline & & Y1 & $\mathrm{Y} 2$ & $\mathrm{X} 1$ & $\mathrm{X} 1$ & & $\mathrm{Y} 1$ & $\mathrm{Y} 2$ & $\mathrm{X} 1$ & $\mathrm{X} 1$ & \\
\hline $\begin{array}{c}\mathrm{D} / \mathrm{M} \mathrm{CU} 40 \\
5 \mathrm{ft}\end{array}$ & 0.4132 & 0.34 & 0.47 & 0.0200 & 0.0100 & 0.0144 & 10.4 & 7.8 & 0.0200 & 0.0100 & 8.9 \\
\hline $\begin{array}{c}\mathrm{D} / \mathrm{M} \mathrm{CU} 40 \\
5 \mathrm{ft}\end{array}$ & 0.3498 & 0.34 & 0.47 & 0.0200 & 0.0100 & 0.0192 & 10.4 & 7.8 & 0.0200 & 0.0100 & 10.2 \\
\hline $\begin{array}{c}\mathrm{D} / \mathrm{M} \mathrm{CU} 40 \\
5 \mathrm{ft}\end{array}$ & 0.4920 & 0.47 & 0.61 & 0.0100 & 0.0050 & 0.0092 & 7.8 & 5.3 & 0.0100 & 0.0050 & 7.4 \\
\hline $\begin{array}{c}\mathrm{D} / \mathrm{M} \mathrm{CU} 40 \\
25 \mathrm{ft}\end{array}$ & 0.6966 & 0.58 & 0.72 & 0.0100 & 0.0050 & 0.0058 & 6.2 & 3.8 & 0.0100 & 0.0050 & 4.2 \\
\hline $\begin{array}{c}\mathrm{D} / \mathrm{M} \mathrm{CU} 40 \\
25 \mathrm{ft}\end{array}$ & 0.8033 & 0.80 & 0.85 & 0.0030 & 0.0020 & 0.0029 & 2.5 & 1.8 & 0.0030 & 0.0020 & 2.5 \\
\hline $\begin{array}{c}\mathrm{D} / \mathrm{M} \mathrm{CU} 40 \\
25 \mathrm{ft}\end{array}$ & 0.7875 & 0.72 & 0.80 & 0.0050 & 0.0030 & 0.0033 & 3.8 & 2.5 & 0.0050 & 0.0030 & 2.7 \\
\hline $\begin{array}{c}\mathrm{D} / \mathrm{M} \mathrm{CU} 40 \\
25 \mathrm{ft}\end{array}$ & 0.7708 & 0.72 & 0.80 & 0.0050 & 0.0030 & 0.0037 & 3.8 & 2.5 & 0.0050 & 0.0030 & 3.0 \\
\hline $\begin{array}{c}\mathrm{D} / \mathrm{M} \mathrm{CU} 40 \\
25 \mathrm{ft}\end{array}$ & 0.7546 & 0.72 & 0.80 & 0.0050 & 0.0030 & 0.0041 & 3.8 & 2.5 & 0.0050 & 0.0030 & 3.2 \\
\hline $\begin{array}{c}\mathrm{D} / \mathrm{M} \mathrm{CU} 40 \\
25 \mathrm{ft}\end{array}$ & 0.7390 & 0.72 & 0.80 & 0.0050 & 0.0030 & 0.0045 & 3.8 & 2.5 & 0.0050 & 0.0030 & 3.5 \\
\hline $\begin{array}{c}\mathrm{D} / \mathrm{M} \mathrm{CU} 40 \\
25 \mathrm{ft}\end{array}$ & 0.7246 & 0.72 & 0.80 & 0.0050 & 0.0030 & 0.0049 & 3.8 & 2.5 & 0.0050 & 0.0030 & 3.7 \\
\hline $\begin{array}{c}\mathrm{D} / \mathrm{M} \mathrm{CU} 40 \\
25 \mathrm{ft}\end{array}$ & 0.7113 & 0.58 & 0.72 & 0.0100 & 0.0050 & 0.0053 & 6.2 & 3.8 & 0.0100 & 0.0050 & 3.9 \\
\hline $\begin{array}{c}\mathrm{D} / \mathrm{M} \mathrm{CU} 40 \\
25 \mathrm{ft}\end{array}$ & 0.6988 & 0.58 & 0.72 & 0.0100 & 0.0050 & 0.0058 & 6.2 & 3.8 & 0.0100 & 0.0050 & 4.2 \\
\hline $\begin{array}{c}\mathrm{D} / \mathrm{M} \mathrm{CU} 40 \\
25 \mathrm{ft}\end{array}$ & 0.6876 & 0.58 & 0.72 & 0.0100 & 0.0050 & 0.0062 & 6.2 & 3.8 & 0.0100 & 0.0050 & 4.4 \\
\hline
\end{tabular}


Table 15. Continued.

\begin{tabular}{|c|c|c|c|c|c|c|c|c|c|c|c|}
\hline \multirow{3}{*}{$\begin{array}{l}\text { Degradation } \\
\text { Model }\end{array}$} & \multirow{3}{*}{$\begin{array}{c}\text { Squared } \\
\text { Vs } \\
\text { Ratio }^{\mathrm{a}}\end{array}$} & \multicolumn{4}{|c|}{ Shear Modulus Reduction Curve Values } & \multirow{3}{*}{$\begin{array}{c}\% \\
\text { Strain }^{\mathrm{b}} \\
\end{array}$} & \multicolumn{4}{|c|}{ Damping Ratio Curve Values } & \multirow{3}{*}{$\begin{array}{l}\text { Corresponding } \\
\text { Damping }(\%)^{\mathrm{c}}\end{array}$} \\
\hline & & \multicolumn{2}{|c|}{$\mathrm{G} / \mathrm{G}_{\mathrm{MAX}}$} & \multicolumn{2}{|c|}{$\%$ Strain } & & \multicolumn{2}{|c|}{ Damping (\%) } & \multicolumn{2}{|c|}{$\%$ Strain } & \\
\hline & & Y1 & $\mathrm{Y} 2$ & $\mathrm{X} 1$ & $\mathrm{X} 1$ & & $\mathrm{Y} 1$ & $\mathrm{Y} 2$ & $\mathrm{X} 1$ & $\mathrm{X} 1$ & \\
\hline D/M CU 40 & & & & & & & & & & & \\
\hline $25 \mathrm{ft}$ & 0.6775 & 0.58 & 0.72 & 0.0100 & 0.0050 & 0.0065 & 6.2 & 3.8 & 0.0100 & 0.0050 & 4.5 \\
\hline D/M CU 40 & & & & & & & & & & & \\
\hline $25 \mathrm{ft}$ & 0.6688 & 0.58 & 0.72 & 0.0100 & 0.0050 & 0.0068 & 6.2 & 3.8 & 0.0100 & 0.0050 & 4.7 \\
\hline D/M CU 40 & & & & & & & & & & & \\
\hline $25 \mathrm{ft}$ & 0.7012 & 0.58 & 0.72 & 0.0100 & 0.0050 & 0.0057 & 6.2 & 3.8 & 0.0100 & 0.0050 & 4.1 \\
\hline V\&D PI 15 & 0.8108 & 0.819 & 0.935 & 0.01000 & 0.00316 & 0.0105 & 4.5 & 2.6 & 0.01000 & 0.00316 & 4.6 \\
\hline V\&D PI 15 & 0.8896 & 0.819 & 0.935 & 0.01000 & 0.00316 & 0.0058 & 4.5 & 2.6 & 0.01000 & 0.00316 & 3.3 \\
\hline V\&D PI 15 & 0.8792 & 0.819 & 0.935 & 0.01000 & 0.00316 & 0.0064 & 4.5 & 2.6 & 0.01000 & 0.00316 & 3.5 \\
\hline Upper Bound & & & & & & & & & & & \\
\hline $\begin{array}{c}\mathrm{D} / \mathrm{M} \mathrm{CU} 40 \\
5 \mathrm{ft}\end{array}$ & 0.8823 & 0.85 & 0.91 & 0.0010 & 0.0005 & 0.0007 & 1.6 & 1.0 & 0.0010 & 0.0005 & 1.3 \\
\hline $\begin{array}{c}\mathrm{D} / \mathrm{M} \mathrm{CU} 40 \\
5 \mathrm{ft}\end{array}$ & 0.7294 & 0.70 & 0.76 & 0.0030 & 0.0020 & 0.0025 & 3.8 & 2.8 & 0.0030 & 0.0020 & 3.3 \\
\hline $\begin{array}{c}\mathrm{D} / \mathrm{M} \mathrm{CU} 40 \\
5 \mathrm{ft}\end{array}$ & 0.6107 & 0.61 & 0.70 & 0.0050 & 0.0030 & 0.0050 & 5.3 & 3.8 & 0.0050 & 0.0030 & 5.3 \\
\hline $\begin{array}{c}\mathrm{D} / \mathrm{M} \mathrm{CU} 40 \\
5 \mathrm{ft}\end{array}$ & 0.5191 & 0.47 & 0.61 & 0.0100 & 0.0050 & 0.0082 & 7.8 & 5.3 & 0.0100 & 0.0050 & 6.9 \\
\hline $\begin{array}{c}\mathrm{D} / \mathrm{M} \mathrm{CU} 40 \\
5 \mathrm{ft}\end{array}$ & 0.4823 & 0.47 & 0.61 & 0.0100 & 0.0050 & 0.0096 & 7.8 & 5.3 & 0.0100 & 0.0050 & 7.6 \\
\hline $\begin{array}{c}\mathrm{D} / \mathrm{M} \mathrm{CU} 40 \\
5 \mathrm{ft}\end{array}$ & 0.8046 & 0.76 & 0.85 & 0.0020 & 0.0010 & 0.0015 & 2.8 & 1.6 & 0.0020 & 0.0010 & 2.2 \\
\hline $\begin{array}{c}\mathrm{D} / \mathrm{M} \mathrm{CU} 40 \\
25 \mathrm{ft} \\
\end{array}$ & 0.9686 & 0.95 & 0.97 & 0.0005 & 0.0003 & 0.0003 & 0.6 & 0.4 & 0.0005 & 0.0003 & 0.4 \\
\hline
\end{tabular}


Table 15. Continued.

\begin{tabular}{|c|c|c|c|c|c|c|c|c|c|c|c|}
\hline \multirow{3}{*}{$\begin{array}{c}\text { Degradation } \\
\text { Model }\end{array}$} & \multirow{3}{*}{$\begin{array}{c}\text { Squared } \\
\text { Vs } \\
\text { Ratio }^{\mathrm{a}}\end{array}$} & \multicolumn{4}{|c|}{ Shear Modulus Reduction Curve Values } & \multirow{3}{*}{$\begin{array}{c}\% \\
\text { Strain }^{\mathrm{b}}\end{array}$} & \multicolumn{4}{|c|}{ Damping Ratio Curve Values } & \multirow{3}{*}{$\begin{array}{l}\text { Corresponding } \\
\text { Damping }(\%)^{\mathrm{c}}\end{array}$} \\
\hline & & \multicolumn{2}{|c|}{$\mathrm{G} / \mathrm{G}_{\mathrm{MAX}}$} & \multicolumn{2}{|c|}{$\%$ Strain } & & \multicolumn{2}{|c|}{ Damping (\%) } & \multicolumn{2}{|c|}{$\%$ Strain } & \\
\hline & & Y1 & $\mathrm{Y} 2$ & $\mathrm{X} 1$ & $\mathrm{X} 1$ & & $\mathrm{Y} 1$ & $\mathrm{Y} 2$ & $\mathrm{X} 1$ & $\mathrm{X} 1$ & \\
\hline $\begin{array}{c}\mathrm{D} / \mathrm{M} \mathrm{CU} 40 \\
25 \mathrm{ft}\end{array}$ & 0.8285 & 0.80 & 0.85 & 0.0030 & 0.0020 & 0.0024 & 2.5 & 1.8 & 0.0030 & 0.0020 & 2.1 \\
\hline $\begin{array}{c}\mathrm{D} / \mathrm{M} \mathrm{CU} 40 \\
25 \mathrm{ft}\end{array}$ & 0.8180 & 0.80 & 0.85 & 0.0030 & 0.0020 & 0.0026 & 2.5 & 1.8 & 0.0030 & 0.0020 & 2.2 \\
\hline $\begin{array}{c}\mathrm{D} / \mathrm{M} \mathrm{CU} 40 \\
25 \mathrm{ft}\end{array}$ & 0.8054 & 0.80 & 0.85 & 0.0030 & 0.0020 & 0.0029 & 2.5 & 1.8 & 0.0030 & 0.0020 & 2.4 \\
\hline $\begin{array}{c}\mathrm{D} / \mathrm{M} \mathrm{CU} 40 \\
25 \mathrm{ft}\end{array}$ & 0.7921 & 0.72 & 0.80 & 0.0050 & 0.0030 & 0.0032 & 3.8 & 2.5 & 0.0050 & 0.0030 & 2.6 \\
\hline $\begin{array}{c}\mathrm{D} / \mathrm{M} \mathrm{CU} 40 \\
25 \mathrm{ft}\end{array}$ & 0.7781 & 0.72 & 0.80 & 0.0050 & 0.0030 & 0.0035 & 3.8 & 2.5 & 0.0050 & 0.0030 & 2.9 \\
\hline $\begin{array}{c}\mathrm{D} / \mathrm{M} \mathrm{CU} 40 \\
25 \mathrm{ft}\end{array}$ & 0.7649 & 0.72 & 0.80 & 0.0050 & 0.0030 & 0.0039 & 3.8 & 2.5 & 0.0050 & 0.0030 & 3.1 \\
\hline $\begin{array}{c}\mathrm{D} / \mathrm{M} \mathrm{CU} 40 \\
25 \mathrm{ft}\end{array}$ & 0.7523 & 0.72 & 0.80 & 0.0050 & 0.0030 & 0.0042 & 3.8 & 2.8 & 0.0050 & 0.0030 & 3.4 \\
\hline $\begin{array}{c}\mathrm{D} / \mathrm{M} \mathrm{CU} 40 \\
25 \mathrm{ft}\end{array}$ & 0.7403 & 0.72 & 0.80 & 0.0050 & 0.0030 & 0.0045 & 3.8 & 2.8 & 0.0050 & 0.0030 & 3.5 \\
\hline $\begin{array}{c}\mathrm{D} / \mathrm{M} \mathrm{CU} 40 \\
25 \mathrm{ft}\end{array}$ & 0.7296 & 0.72 & 0.80 & 0.0050 & 0.0030 & 0.0048 & 3.8 & 2.8 & 0.0050 & 0.0030 & 3.7 \\
\hline $\begin{array}{c}\mathrm{D} / \mathrm{M} \mathrm{CU} 40 \\
25 \mathrm{ft}\end{array}$ & 0.7200 & 0.72 & 0.80 & 0.0050 & 0.0030 & 0.0050 & 3.8 & 2.8 & 0.0050 & 0.0030 & 3.8 \\
\hline $\begin{array}{c}\mathrm{D} / \mathrm{M} \mathrm{CU} 40 \\
25 \mathrm{ft}\end{array}$ & 0.7111 & 0.58 & 0.72 & 0.0100 & 0.0050 & 0.0053 & 3.8 & 2.8 & 0.0100 & 0.0050 & 2.9 \\
\hline $\begin{array}{c}\mathrm{D} / \mathrm{M} \mathrm{CU} 40 \\
25 \mathrm{ft}\end{array}$ & 0.8021 & 0.80 & 0.85 & 0.0030 & 0.0020 & 0.0030 & 2.5 & 1.8 & 0.0030 & 0.0020 & 2.5 \\
\hline
\end{tabular}


Table 15. Continued.

\begin{tabular}{|c|c|c|c|c|c|c|c|c|c|c|c|}
\hline \multirow{3}{*}{$\begin{array}{l}\text { Degradation } \\
\text { Model }\end{array}$} & \multirow{3}{*}{$\begin{array}{c}\text { Squared } \\
\text { Vs } \\
\text { Ratio }^{\mathrm{a}}\end{array}$} & \multicolumn{4}{|c|}{ Shear Modulus Reduction Curve Values } & \multirow{3}{*}{$\begin{array}{c}\% \\
\text { Strain }^{\mathrm{b}}\end{array}$} & \multicolumn{4}{|c|}{ Damping Ratio Curve Values } & \multirow{3}{*}{$\begin{array}{l}\text { Corresponding } \\
\text { Damping }(\%)^{\mathrm{c}}\end{array}$} \\
\hline & & \multicolumn{2}{|c|}{$\mathrm{G} / \mathrm{G}_{\mathrm{MAX}}$} & \multicolumn{2}{|c|}{$\%$ Strain } & & \multicolumn{2}{|c|}{ Damping $(\%)$} & \multicolumn{2}{|c|}{$\%$ Strain } & \\
\hline & & Y1 & Y2 & $\mathrm{X} 1$ & $\mathrm{X} 1$ & & Y1 & $\mathrm{Y} 2$ & $\mathrm{X} 1$ & $\mathrm{X} 1$ & \\
\hline V\&D PI 15 & 0.9406 & 0.935 & 0.994 & 0.00316 & 0.00100 & 0.0030 & 2.6 & 1.6 & 0.0032 & 0.0010 & 2.5 \\
\hline V\&D PI 15 & 0.9102 & 0.819 & 0.935 & 0.01000 & 0.00316 & 0.0046 & 4.5 & 2.6 & 0.0100 & 0.0032 & 3.0 \\
\hline V\&D PI 15 & 0.9011 & 0.819 & 0.935 & 0.01000 & 0.00316 & 0.0052 & 4.5 & 2.6 & 0.0100 & 0.0032 & 3.2 \\
\hline \multicolumn{12}{|c|}{ a. Equal to $\mathrm{G} / \mathrm{G}_{\mathrm{MAX}}$, see Equation [6]. } \\
\hline \multicolumn{12}{|c|}{ b. Computed using a linear interpolation of shear modulus reduction curve values. } \\
\hline \multicolumn{12}{|c|}{ c. Computed for the percent strain value in column 7 and linear interpolation of the damping ratio curve values. } \\
\hline d. Squared rat & ceeds $\mathrm{C}$ & so da & g value & to 0.4 for $\mathrm{p}$ & rcent strai & 0.0001 & les & & & & \\
\hline
\end{tabular}


Table 16. Calculations of the best estimate, lower bound, and upper bound low-strain compressional wave velocities.

\begin{tabular}{|c|c|c|c|c|c|c|c|c|c|c|c|}
\hline \multirow[b]{2}{*}{ Layer } & \multirow{2}{*}{$\begin{array}{l}\text { Poisson's } \\
\text { Ratio }^{\mathrm{a}}\end{array}$} & \multirow{2}{*}{$\begin{array}{l}\text { Depth } \\
\text { (ft) }\end{array}$} & \multicolumn{3}{|c|}{$\begin{array}{l}\text { Input Soil Profile } \\
\text { Shear Modulus (ksf) }\end{array}$} & \multicolumn{3}{|c|}{$\begin{array}{c}\text { Low-strain } \\
\text { Shear Wave Velocity }(\mathrm{ft} / \mathrm{s})^{\mathrm{c}}\end{array}$} & \multicolumn{3}{|c|}{ 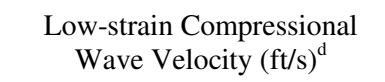 } \\
\hline & & & $\begin{array}{l}\text { Lower } \\
\text { Bound }\end{array}$ & $\begin{array}{c}\text { Best } \\
\text { Estimate } \\
\end{array}$ & $\begin{array}{l}\text { Upper } \\
\text { Bound } \\
\end{array}$ & $\begin{array}{l}\text { Lower } \\
\text { Bound }\end{array}$ & $\begin{array}{c}\text { Best } \\
\text { Estimate } \\
\end{array}$ & $\begin{array}{l}\text { Upper } \\
\text { Bound }\end{array}$ & $\begin{array}{l}\text { Lower } \\
\text { Bound }\end{array}$ & $\begin{array}{c}\text { Best } \\
\text { Estimate }\end{array}$ & $\begin{array}{l}\text { Upper } \\
\text { Bound }\end{array}$ \\
\hline A & 0.23 & 1 & 1703.9 & 2192.1 & 2820.3 & 681.6 & 773.1 & 876.9 & 1151.0 & 1305.5 & 1480.8 \\
\hline $\mathrm{A}$ & 0.23 & 3 & 1703.9 & 2192.1 & 2820.3 & 681.6 & 773.1 & 876.9 & 1151.0 & 1305.5 & 1480.8 \\
\hline A & 0.23 & 5 & 1703.9 & 2192.1 & 2820.3 & 681.6 & 773.1 & 876.9 & 1151.0 & 1305.5 & 1480.8 \\
\hline $\mathrm{A}$ & 0.23 & 7 & 1703.9 & 2192.1 & 2820.3 & 681.6 & 773.1 & 876.9 & 1151.0 & 1305.5 & 1480.8 \\
\hline $\mathrm{A}$ & 0.23 & 9 & 1703.9 & 2192.1 & 2820.3 & 681.6 & 773.1 & 876.9 & 1151.0 & 1305.5 & 1480.8 \\
\hline $\mathrm{A}$ & 0.23 & 11 & 1576.3 & 3108.2 & 6128.9 & 655.5 & 920.5 & 1292.6 & 1107.1 & 1554.5 & 2182.9 \\
\hline A & 0.23 & 13 & 3702.1 & 6869.6 & 12747.2 & 1004.6 & 1368.5 & 1864.2 & 1696.6 & 2311.1 & 3148.1 \\
\hline B & 0.33 & 15 & 8341.2 & 9543.3 & 10918.8 & 1465.2 & 1567.2 & 1676.3 & 2908.7 & 3111.2 & 3327.9 \\
\hline B & 0.33 & 17 & 8341.2 & 9543.3 & 10918.8 & 1465.2 & 1567.2 & 1676.3 & 2908.7 & 3111.2 & 3327.9 \\
\hline B & 0.33 & 19 & 8341.2 & 9543.3 & 10918.8 & 1465.2 & 1567.2 & 1676.3 & 2908.7 & 3111.2 & 3327.9 \\
\hline B & 0.33 & 21 & 8341.2 & 9543.3 & 10918.8 & 1465.2 & 1567.2 & 1676.3 & 2908.7 & 3111.2 & 3327.9 \\
\hline B & 0.33 & 23 & 8341.2 & 9543.3 & 10918.8 & 1465.2 & 1567.2 & 1676.3 & 2908.7 & 3111.2 & 3327.9 \\
\hline B & 0.33 & 25 & 8341.2 & 9543.3 & 10918.8 & 1465.2 & 1567.2 & 1676.3 & 2908.7 & 3111.2 & 3327.9 \\
\hline B & 0.33 & 27 & 8341.2 & 9543.3 & 10918.8 & 1465.2 & 1567.2 & 1676.3 & 2908.7 & 3111.2 & 3327.9 \\
\hline B & 0.33 & 29 & 8341.2 & 9543.3 & 10918.8 & 1465.2 & 1567.2 & 1676.3 & 2908.7 & 3111.2 & 3327.9 \\
\hline $\mathrm{C}$ & 0.33 & 31 & 8341.2 & 9543.3 & 10918.8 & 1459.3 & 1561.0 & 1669.7 & 2897.1 & 3098.9 & 3314.7 \\
\hline $\mathrm{C}$ & 0.33 & 33 & 8341.2 & 9543.3 & 10918.8 & 1459.3 & 1561.0 & 1669.7 & 2897.1 & 3098.9 & 3314.7 \\
\hline $\mathrm{C}$ & 0.33 & 35 & 8341.2 & 9543.3 & 10918.8 & 1459.3 & 1561.0 & 1669.7 & 2897.1 & 3098.9 & 3314.7 \\
\hline $\mathrm{C}$ & 0.33 & 37 & 8367.5 & 9525.9 & 10844.6 & 1461.6 & 1559.5 & 1664.0 & 2901.7 & 3096.0 & 3303.4 \\
\hline $\mathrm{C}$ & 0.33 & 39 & 8331.7 & 9712.9 & 11323.2 & 1458.5 & 1574.8 & 1700.3 & 2895.5 & 3126.3 & 3375.5 \\
\hline $\mathrm{C}$ & 0.33 & 41 & 8410.1 & 9559.3 & 10865.6 & 1465.3 & 1562.3 & 1665.6 & 2909.1 & 3101.5 & 3306.6 \\
\hline
\end{tabular}


Table 16. Continued.

\begin{tabular}{|c|c|c|c|c|c|c|c|c|c|c|c|}
\hline \multirow[b]{2}{*}{ Layer } & \multirow{2}{*}{$\begin{array}{l}\text { Poisson's } \\
\text { Ratio }^{\mathrm{a}}\end{array}$} & \multirow{2}{*}{$\begin{array}{l}\text { Depth } \\
\text { (ft) }\end{array}$} & \multicolumn{3}{|c|}{$\begin{array}{l}\text { Input Soil Profile } \\
\text { Shear Modulus (ksf) }\end{array}$} & \multicolumn{3}{|c|}{$\begin{array}{c}\text { Low-strain } \\
\text { Shear Wave Velocity }(\mathrm{ft} / \mathrm{s})^{\mathrm{c}}\end{array}$} & \multicolumn{3}{|c|}{$\begin{array}{l}\text { Low-strain Compressional } \\
\text { Wave Velocity }(\mathrm{ft} / \mathrm{s})^{\mathrm{d}}\end{array}$} \\
\hline & & & $\begin{array}{l}\text { Lower } \\
\text { Bound }\end{array}$ & $\begin{array}{c}\text { Best } \\
\text { Estimate } \\
\end{array}$ & $\begin{array}{l}\text { Upper } \\
\text { Bound }\end{array}$ & $\begin{array}{l}\text { Lower } \\
\text { Bound }\end{array}$ & $\begin{array}{c}\text { Best } \\
\text { Estimate }\end{array}$ & $\begin{array}{l}\text { Upper } \\
\text { Bound }\end{array}$ & $\begin{array}{l}\text { Lower } \\
\text { Bound }\end{array}$ & $\begin{array}{c}\text { Best } \\
\text { Estimate }\end{array}$ & $\begin{array}{l}\text { Upper } \\
\text { Bound }\end{array}$ \\
\hline $\mathrm{C}$ & 0.33 & 43 & 8286.7 & 9615.1 & 11156.3 & 1454.6 & 1566.8 & 1687.7 & 2887.6 & 3110.5 & 3350.5 \\
\hline $\mathrm{D}$ & 0.31 & NA & 60782.1 & 81854.9 & 110233.4 & 3495.9 & 4056.8 & 4707.8 & 6661.9 & 7731.0 & 8971.6 \\
\hline \multicolumn{12}{|c|}{$\begin{array}{l}\text { a. Kleinfelder, Inc. (2007a). } \\
\text { b. Calculated using log normal distribution of the shear modulus in soil profiles from Figure } 2 \mathrm{~b} \text {. } \\
\text { c. Calculated using shear modulus and average density of the layer. } \\
\text { d. Calculated using the low-strain Vs and Poisson's ratio. }\end{array}$} \\
\hline
\end{tabular}




\section{Recommendations for Use of IWTU PC 3 Soil DBE}

Site-specific site response analyses were conducted to determine the horizontal and vertical IWTU PC 3 (2,500 yr) Soil DBE 5\% damped spectra, corresponding time histories, and strain-compatible soil properties. The soil DBE parameters were developed for use in SSI analyses of the IWTU. Base case soil profiles were developed for three soil layers above basalt bedrock. Measured Vs and densities were used to compute the shear modulus and its variability for the alluvial soil (Layers A and B), clay (Layer C), and rock (Layer D) layers (Tables 3 and 4). Thirty random soil profiles were generated for normal and log normal distributions of shear modulus (Figure 2).

For the site response analyses, two horizontal INTEC/RTC/RWM/PBF PC 3 DBE acceleration time histories were propagated through the two sets of 30 random soil profiles. Strain-dependent soil properties were determined from shear modulus reduction and damping curves (Figures 6, 7, and 8) appropriate for alluvial soil layers ("Darendeli/Menq CU 40"; Pyke 2007) and the clay layer ("PI 15"; Vucetic and Dobry 1991). SHAKE2000 was used to generate horizontal soil surface spectra for the two sets of 30 random soil profiles. The mean spectral peaks of the two sets of 30 random profiles with the normal and log normal distributions exceed the IWTU SSI Spectrum by $30 \%$ (Figure 16).

Two approaches were considered for developing the horizontal and vertical design spectrum. The first approach developed the mean horizontal and vertical IWTU PC 3 soil DBE 5\% damped spectra, and the second, the $84^{\text {th }}$ percentile horizontal and vertical IWTU PC 3 soil DBE 5\% damped spectra. Both soil DBE spectra were developed using the 30 soil surface spectra of the soil profiles with the log normal distribution of shear modulus. The mean horizontal IWTU PC 3 Soil DBE 5\% damped spectrum was determined by setting the spectral peak acceleration to $1.100 \mathrm{~g}$ then broadening mean spectral peak at 7.18 $\mathrm{Hz}$ by a factor of 1.5 (Figure 17). For the $84^{\text {th }}$ percentile soil DBE spectrum, the spectral peak acceleration was set to $1.250 \mathrm{~g}$ to envelop the spectral peak of an $84^{\text {th }}$ percentile soil surface spectrum and the most of the spectral peaks of the 30 soil surface spectra of the log normal distribution of shear modulus (Figure 19). The PGA, peak spectral velocity, and peak spectral displacement of the $84^{\text {th }}$ percentile soil DBE spectrum were kept the same as the mean soil DBE spectrum (Figure 17). The mean and $84^{\text {th }}$ percentile vertical IWTU PC 3 Soil DBE 5\% damped spectra were calculated by multiplying the spectral accelerations of their respective horizontal soil $\mathrm{DBE}$ spectrum by $\mathrm{V} / \mathrm{H}$ spectral ratios appropriate for INL (Figures 20 and 21).

Based on recommendations of the DNFSB, the IWTU project adopted the $84^{\text {th }}$ percentile horizontal and vertical PC 3 Soil DBE 5\% damped spectra for design purposes. Acceleration, velocity, and displacement time histories were developed to match their respective DBE target spectra for spectral frequencies from 0.3 to $25 \mathrm{~Hz}$ (Figures 22, 23, and 24). Over this frequency range, the spectra computed for the horizontal and vertical soil DBE time histories relative to their corresponding DBE target spectrum meet the acceptance criteria in NUREG/CR-6728 and ASCE/SEI 43-05.

Strain-compatible soil properties were calculated for the horizontal and vertical soil DBE spectra and corresponding time histories. Iterated Vs and damping were calculated based on ratios of the iterated Vs to the low-strain Vs. The ratios were used with the base case soil profile Vs to calculate the best estimate, lower bound, and upper bound iterated Vs (Table 14). The squared ratios were then used with the corresponding shear modulus reduction and damping curves to determine the best estimate, lower bound, and upper bound damping values (Table 15). Low-strain Vp were calculated using the low-strain Vs and Poisson's ratios measured at the IWTU site (Table 16).

The $84^{\text {th }}$ percentile horizontal and vertical IWTU PC 3 (2,500 yr) Soil DBE 5\% damped spectra and corresponding time histories can be used for seismic analysis of the IWTU. Strain-compatible soil properties for SSI analyses at IWTU are listed in Tables 17 and 18 and shown in Figures 27 and 28. The 
strain-compatible soil properties can be used in SSI analyses with the $84^{\text {th }}$ percentile IWTU PC $3(2,500$ yr) Soil DBE 5\% damped spectra and corresponding time histories. For SSI analyses, the iterated soil properties should consider the following guidance:

- $\quad$ Low-strain damping values should be calculated from the damping curves used in the site response analyses for each soil layer listed in Tables 4, 5, and 6.

- Iterated soil properties should be used without any further iteration or additional deconvolution analyses of the design soil DBE time histories. 
Table 17. Iterated shear wave velocities and corresponding damping values for IWTU PC 3 Soil DBE.

\begin{tabular}{|c|c|c|c|c|c|c|c|}
\hline \multirow[b]{2}{*}{ Layer } & \multirow[b]{2}{*}{$\begin{array}{c}\text { Depth } \\
\text { (ft) }\end{array}$} & \multicolumn{3}{|c|}{ Iterated Shear Wave Velocity (ft/s) } & \multicolumn{3}{|c|}{ Corresponding Damping (\%) } \\
\hline & & $\begin{array}{l}\text { Lower } \\
\text { Bound }\end{array}$ & $\begin{array}{c}\text { Best } \\
\text { Estimate }\end{array}$ & $\begin{array}{l}\text { Upper } \\
\text { Bound }\end{array}$ & $\begin{array}{l}\text { Lower } \\
\text { Bound }\end{array}$ & $\begin{array}{c}\text { Best } \\
\text { Estimate }\end{array}$ & $\begin{array}{l}\text { Upper } \\
\text { Bound }\end{array}$ \\
\hline A & 1 & 674 & 689 & 704 & 2.2 & 1.7 & 1.3 \\
\hline A & 3 & 569 & 605 & 641 & 5.9 & 4.6 & 3.3 \\
\hline A & 5 & 488 & 537 & 586 & 8.7 & 7.0 & 5.3 \\
\hline A & 7 & 424 & 482 & 540 & 10.8 & 8.9 & 6.9 \\
\hline A & 9 & 366 & 444 & 521 & 12.3 & 10.2 & 7.6 \\
\hline A & 11 & 379 & 526 & 673 & 12.0 & 7.4 & 2.2 \\
\hline A & 13 & 1055 & 1285 & 1516 & 8.4 & 4.2 & 0.4 \\
\hline B & 15 & 1359 & 1380 & 1402 & 2.8 & 2.5 & 2.1 \\
\hline B & 17 & 1340 & 1367 & 1393 & 3.2 & 2.7 & 2.2 \\
\hline B & 19 & 1322 & 1352 & 1382 & 3.5 & 3.0 & 2.4 \\
\hline B & 21 & 1305 & 1338 & 1371 & 3.8 & 3.2 & 2.6 \\
\hline B & 23 & 1289 & 1324 & 1358 & 4.1 & 3.5 & 2.9 \\
\hline B & 25 & 1275 & 1311 & 1347 & 4.4 & 3.7 & 3.1 \\
\hline B & 27 & 1262 & 1299 & 1336 & 4.6 & 3.9 & 3.4 \\
\hline B & 29 & 1250 & 1287 & 1325 & 4.9 & 4.2 & 3.5 \\
\hline B & 31 & 1239 & 1277 & 1315 & 5.1 & 4.4 & 3.7 \\
\hline $\mathrm{C}$ & 33 & 1228 & 1268 & 1307 & 5.2 & 4.5 & 3.8 \\
\hline $\mathrm{C}$ & 35 & 1220 & 1259 & 1299 & 5.4 & 4.7 & 2.9 \\
\hline $\mathrm{C}$ & 37 & 1200 & 1290 & 1379 & 5.7 & 4.1 & 2.5 \\
\hline $\mathrm{C}$ & 39 & 1288 & 1396 & 1503 & 6.8 & 4.6 & 2.5 \\
\hline $\mathrm{C}$ & 41 & 1445 & 1462 & 1479 & 3.7 & 3.3 & 3.0 \\
\hline $\mathrm{C}$ & 43 & 1435 & 1453 & 1471 & 3.9 & 3.5 & 3.2 \\
\hline $\mathrm{D}^{\mathrm{a}}$ & NA & 3496 & 4057 & 4708 & NA & NA & NA \\
\hline
\end{tabular}


Table 18. Low-strain compressional wave velocities for IWTU PC 3 Soil DBE.

Low-strain Compressional Wave Velocity (ft/s)

\begin{tabular}{|c|c|c|c|c|}
\hline Layer & Depth (ft) & Lower Bound & Best Estimate & Upper Bound \\
\hline A & 1 & 1151.0 & 1305.5 & 1480.8 \\
\hline A & 3 & 1151.0 & 1305.5 & 1480.8 \\
\hline A & 5 & 1151.0 & 1305.5 & 1480.8 \\
\hline A & 7 & 1151.0 & 1305.5 & 1480.8 \\
\hline A & 9 & 1151.0 & 1305.5 & 1480.8 \\
\hline A & 11 & 1107.1 & 1554.5 & 2182.9 \\
\hline A & 13 & 1696.6 & 2311.1 & 3148.1 \\
\hline B & 15 & 2908.7 & 3111.2 & 3327.9 \\
\hline B & 17 & 2908.7 & 3111.2 & 3327.9 \\
\hline B & 19 & 2908.7 & 3111.2 & 3327.9 \\
\hline B & 21 & 2908.7 & 3111.2 & 3327.9 \\
\hline B & 23 & 2908.7 & 3111.2 & 3327.9 \\
\hline B & 25 & 2908.7 & 3111.2 & 3327.9 \\
\hline B & 27 & 2908.7 & 3111.2 & 3327.9 \\
\hline B & 29 & 2908.7 & 3111.2 & 3327.9 \\
\hline B & 31 & 2897.1 & 3098.9 & 3314.7 \\
\hline $\mathrm{C}$ & 33 & 2897.1 & 3098.9 & 3314.7 \\
\hline $\mathrm{C}$ & 35 & 2897.1 & 3098.9 & 3314.7 \\
\hline $\mathrm{C}$ & 37 & 2901.7 & 3096.0 & 3303.4 \\
\hline $\mathrm{C}$ & 39 & 2895.5 & 3126.3 & 3375.5 \\
\hline $\mathrm{C}$ & 41 & 2909.1 & 3101.5 & 3306.6 \\
\hline $\mathrm{C}$ & 43 & 2887.6 & 3110.5 & 3350.5 \\
\hline $\mathrm{D}$ & NA & 6661.9 & 7731.0 & 8971.6 \\
\hline
\end{tabular}




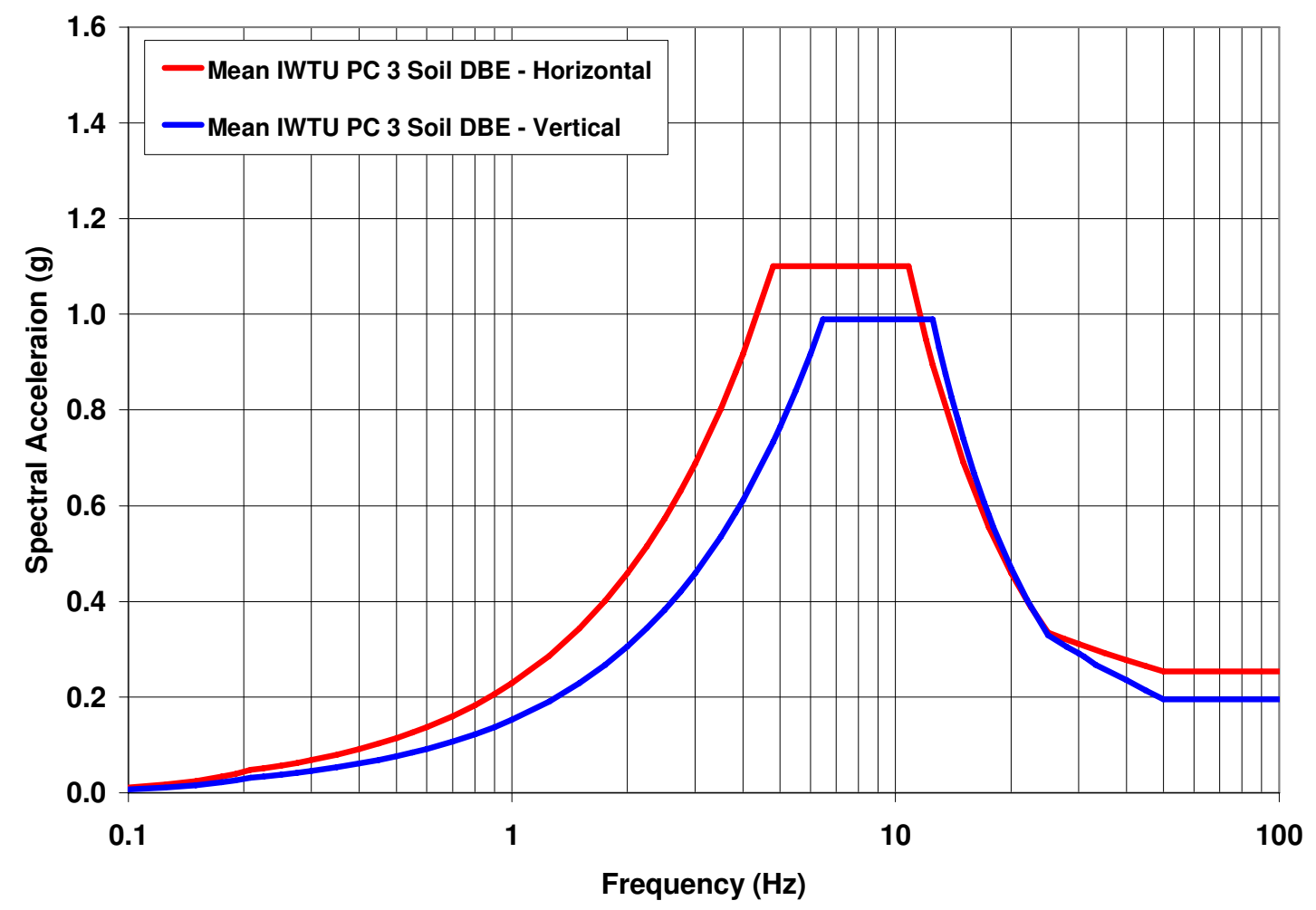

Figure 25. The mean horizontal and vertical IWTU PC 3 (2,500 yr) Soil DBE 5\% damped spectra. 


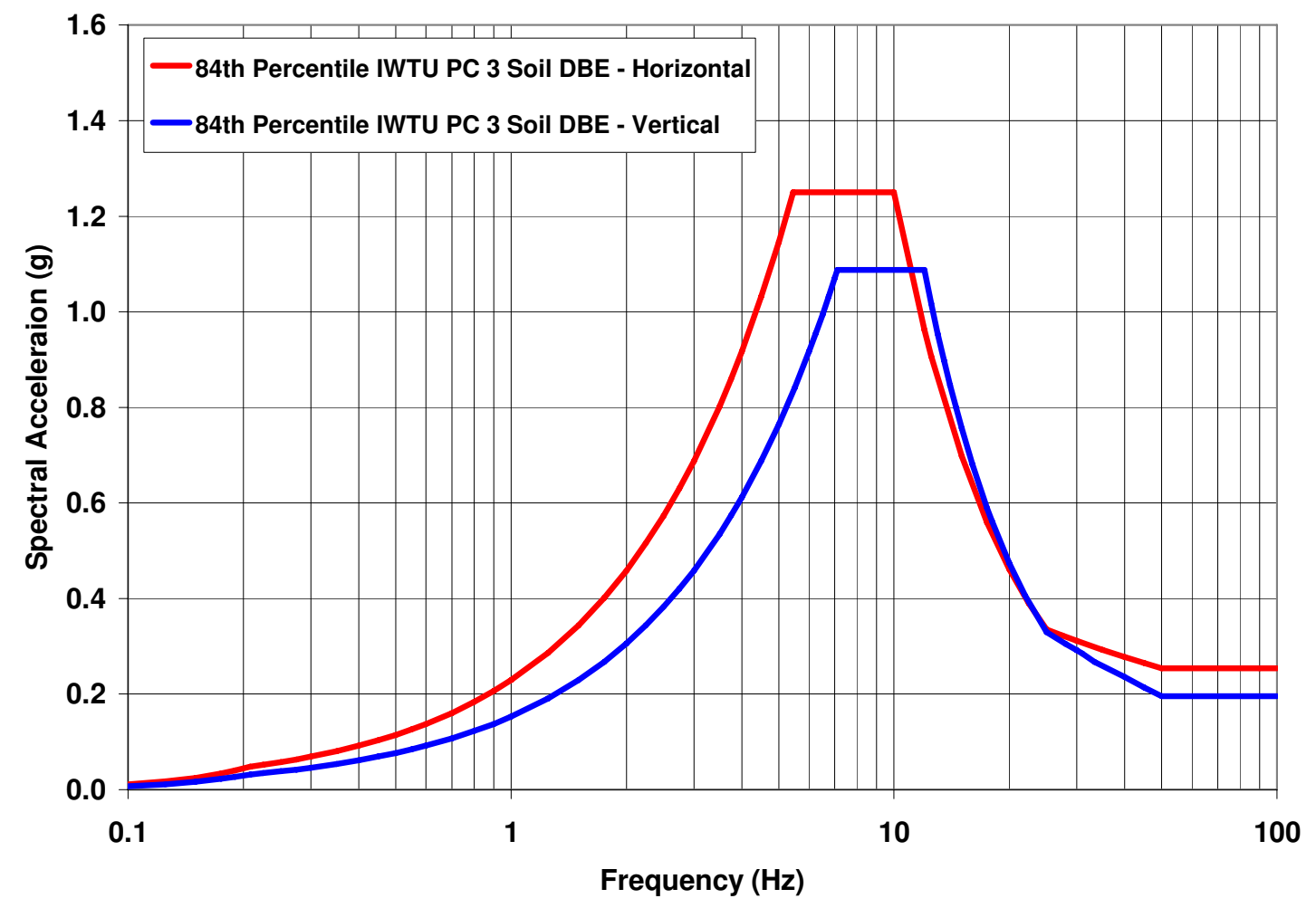

Figure 26. The $84^{\text {th }}$ percentile horizontal and vertical IWTU PC 2 (2,500 yr) Soil DBE 5\% damped spectra. 
(a)

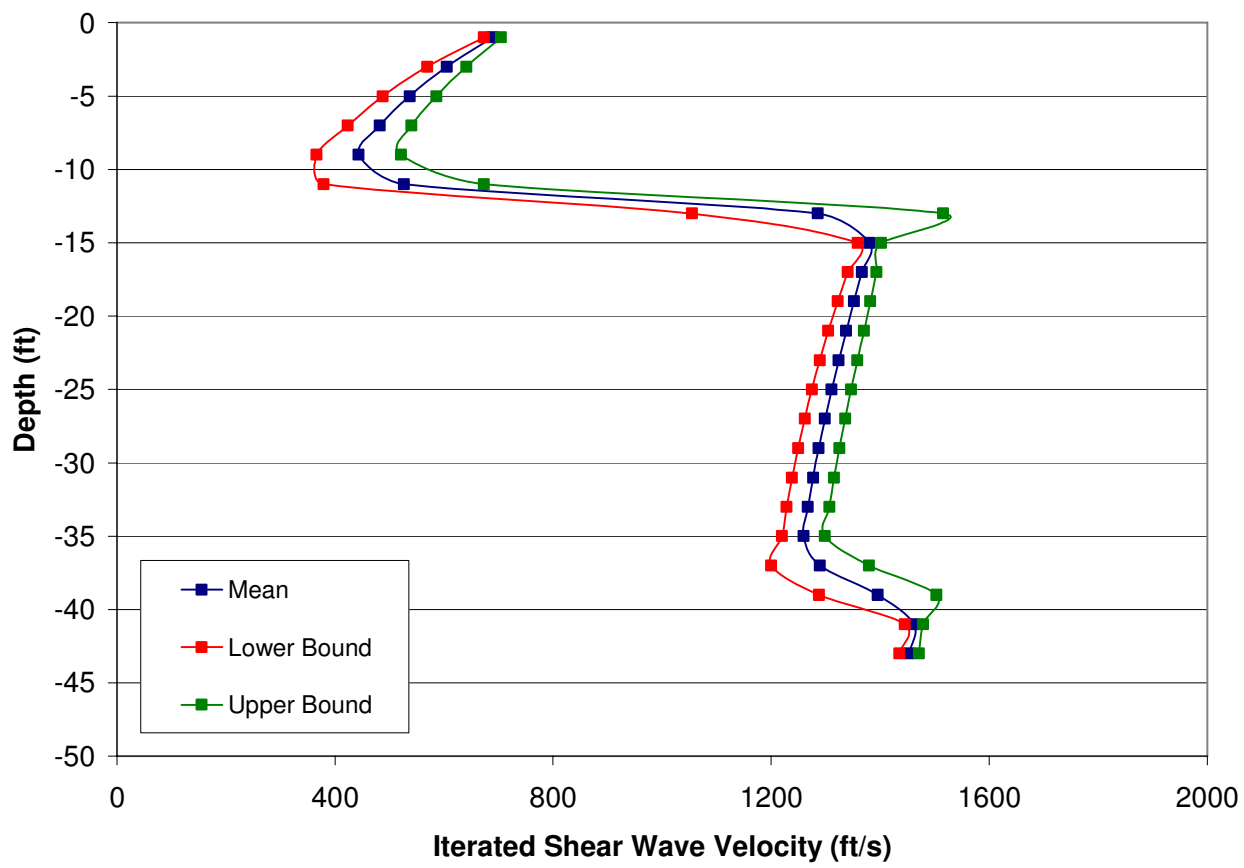

(b)

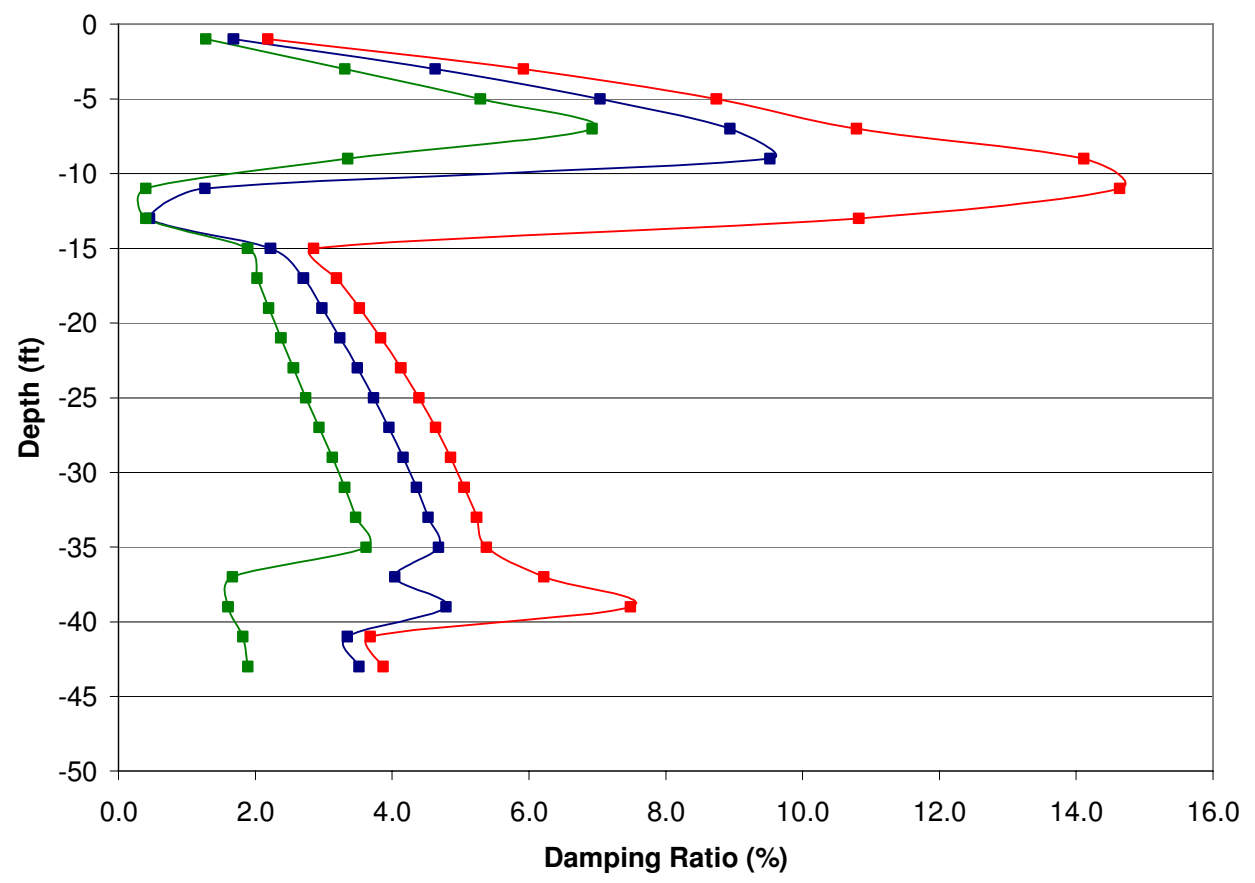

Figure 27. Best estimate, lower bound, and upper bound soil a) iterated shear wave velocities and b) corresponding damping ratios for the horizontal IWTU PC 3 Soil DBE spectra and time histories (rock values are not plotted). 


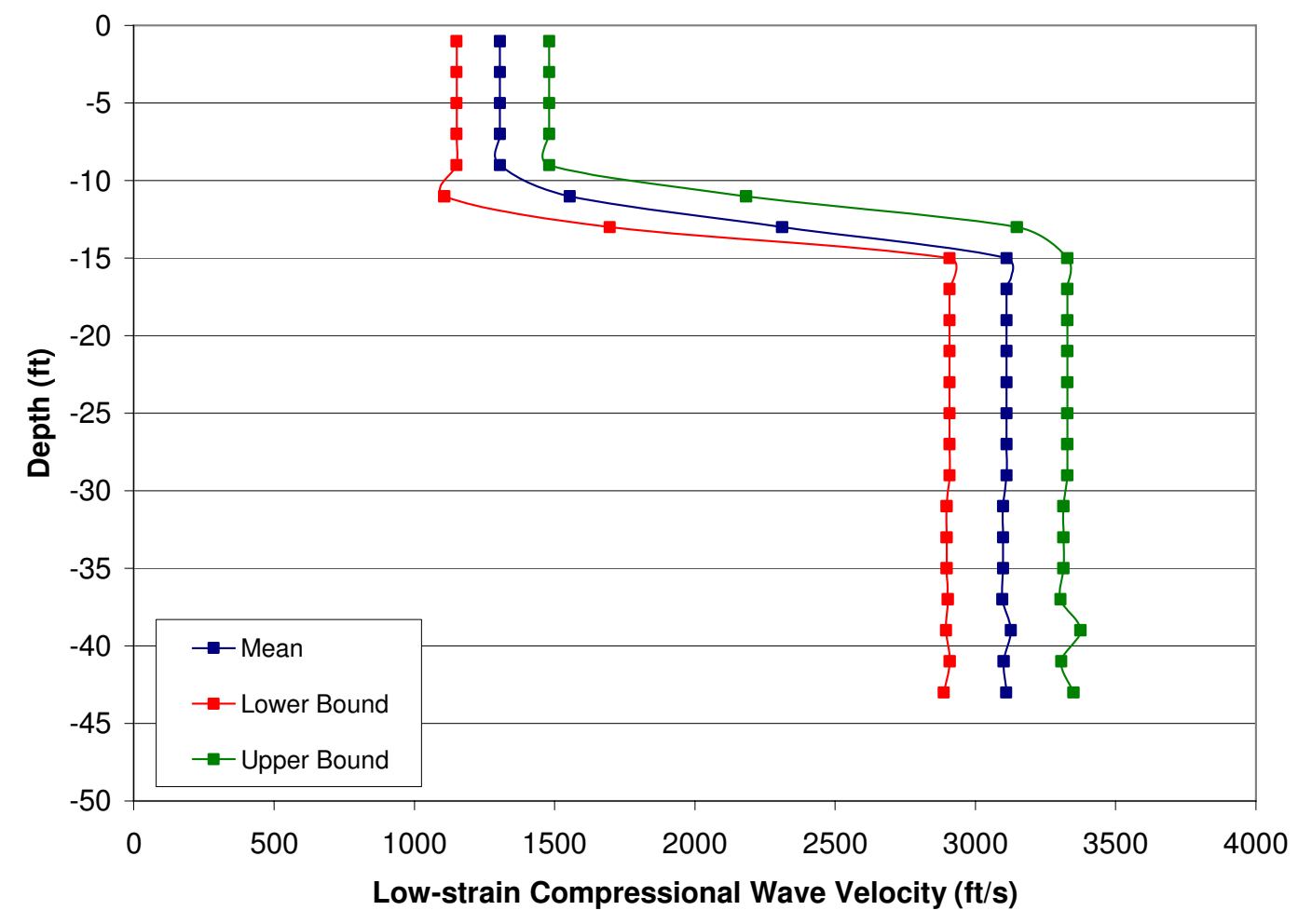

Figure 28. Low-strain compressional wave velocities of the soils for the vertical IWTU PC 3 Soil DBE spectra and corresponding time history (rock values are not plotted). 


\section{References}

Abrahamson, N. A., 1993, RSPMATCH FORTRAN computer program in Validation Manual RSPM Version 99 with Amendments, March 21, 1999.

Abrahamson, N. A., 1996, BASELINE FORTRAN computer program in Validation Manual RSPM Version 99 with Amendments, March 21, 1999.

Abrahamson, N. A. and W. J. Silva (1997), Empirical response spectral attenuation relations for shallow crustal earthquakes, Seismological Research Letters, v. 68, p. 94-127.

ASCE (2000), Seismic Analysis of Safety-Related Nuclear Structures and Commentary, American Society of Civil Engineers Standard 4-98.

ASCE (2005), Seismic design criteria for structures, systems, and components in nuclear facilities, America Society of the Civil Engineers ASCE/SEI 43-05.

Brott, C. A., D. D. Blackwell, and J. P. Ziagos (1981), Thermal and tectonic implications of heat flow in the eastern Snake River Plain, Idaho, Journal of Geophysical Research, v. 86, p. 11709-11734.

CWI (2007), Integrated Waste Treatment Unit record of telephone conference, CH2M Hill Washington Group, Idaho (CWI) Project Number 25051, March 23, 2007.

Dames and Moore (1976), Soils/foundation investigation New Waste Calcining Facility, INEL, report submitted to the Energy Research and Development Administration.

Dames and Moore (1977), Report of foundation investigation Flourinel and Fuel Storage Facilities, Chemical Processing Plant, Idaho Falls, Idaho, report submitted to the Energy Research and Development Administration.

Darendeli, M. B. (2001), Development of a new family of normalized modulus reduction and material damping curves, Ph.D. Dissertation, University of Texas at Austin, Texas.

Deng, N. and Ostadan, F. (2000), Theoretical and user's manual for SHAKE2000, Bechtel National Inc., San Francisco, California, January.

DOE (2002a), Natural Phenomena Hazards Design and Evaluation Criteria for Department of Energy Facilities, U.S. Department of Energy, DOE Standard, DOE-STD-1020-2002.

DOE (2002b), Natural Phenomena Hazards Assessment Criteria, U.S. Department of Energy, DOE Standard, DOE-STD-1023-2002.

EDF-5255 (2004), Computer Codes Used to Develop Soil Design Basis Earthquake (DBE) Parameters for TRA, Engineering Design File, Bechtel BWXT, Idaho, Idaho Falls, Idaho, Revision 0.

EDF-7903 (2007), Quality assurance requirements for developing soil design basis earthquake (DBE) parameters for IWTU, April.

EDF-7905 (2007), Development of soil design basis earthquake (DBE) parameters for IWTU, July. 
EG\&G Idaho Inc. (1984a), Report of the geotechnical investigation for the $7^{\text {th }}$ Bin Set at the Chemical Processing Plant, INEL, August.

EG\&G Idaho Inc. (1984b), Report of the geotechnical investigation for the Fuel Reprocessing Restoration Project at the Chemical Processing Plant, INEL, February.

Eggenberger, A. J. (2008), Letter report from A. J. Eggenberger, Defense Nuclear Facilities Safety Board, to J. A. Rispoli, Assistant Secretary for Environmental Management, U.S. Department of Energy dated May 1, 2008, with attachment of Staff Issue Report "Summary of Structural Design Reviews for Integrated Waste Treatment Unit”, dated March 19, 2008, 6 p.

EPRI (1993), Guidelines for determining design basis ground motions, Volume 1: Method and guidelines for estimating earthquake ground motion in eastern North America, prepared by Electric Power Research Institute, EPRI TR-102293, Project 3302, November.

Golder Associates Inc. (1992), High Level Waste Tank Farm Replacement project geotechnical investigation, prepared for Westinghouse Idaho Nuclear Company, Idaho Falls, Idaho, November.

Hull, L. C. (1989), Conceptual model and description of the affected environment for the TRA Warm Waste Pond (Waste Management Unit TRA-03), EG\&G Idaho Inc. Informal Report EGG-ER8644 , October.

Houston, T., R. Lee, C. Costantino, R. Creed, W. Lettis, and R. Pyke (2006), Blue-Ribbon-Panel review of the Performance Category-3 Design-Basis-Earthquake Parameters at the Integrated Waste Treatment Unit, Los Alamos National Laboratories Report LA-UR-06-6145, August 23, 2006.

Houston, T. (2007a), Summary of meeting between the Blue Ribbon Panel and IWTU Project, Memorandam D5-07-55 dated June 11, 2007 from Los Alamos National Laboratory to William Landman at CH2M Hill Washington Group, Idaho, (CWI) Project Number 25051.

Houston, T. (2007b), Summary of meeting between the Blue Ribbon Panel and IWTU Project, Memorandam D5-07-75 dated October 17, 2007 from Los Alamos National Laboratory to William Landman at CH2M Hill Washington Group, Idaho, (CWI) Project Number 25051.

ICP Architectural Engineering Standards (2007), Document ID STD-116, Revision 36, March 13, 2007.

Kleinfelder, Inc. (2007a). Geotechnical investigation Integrated Waste Treatment Unit (IWTU), Idaho National Laboratory, Kleinfelder Project No. 76388, Rev. 0. Prepared for CH2M Hill Washington Group, Idaho, LLC (CWI) Project Number 25051, June.

Kleinfelder, Inc. (2007b), Email transmittal of files "Layer Thickness.xls 04/03/2007 11:50 AM" and "D1 \& D2 Average Properties.pdf 04/03/2007 11:50 AM" from Jed Stoken to Suzette Payne, April 3, 2007.

Kuntz, M. A., H. R. Covington, and L. J. Schorr (1992), An overview of basaltic volcanism of the eastern Snake River Plain, Idaho, in Regional Geology of Eastern Idaho and Western Wyoming, Link, P. K. Kuntz, M. A., and Platt, L. B. editors, Geol. Soc. Am. Memoir 179, 227-267.

McQuarrie, N., and D.W. Rodgers (1998), Subsidence of a volcanic basin by flexure and lower crustal flow: The eastern Snake River Plain, Idaho: Tectonics, v. 17, no. 2, p. 203-220. 
Menq, F. Y. (2003), Dynamic properties of sandy and gravelly soils, Ph.D. Dissertation, University of Texas at Austin, Texas.

MSE Technology Applications, Inc. (2006), Final report - Subsurface investigation for the Integrated Waste Treatment Unit at the Idaho Nuclear Technology and Engineering Center, submitted to CH2M Hill Washington Group, Idaho, report number MSE-95 rev. 01, January.

Newmark, N.M. and W.J. Hall (1978), Development of Criteria for Seismic Review of Selected Nuclear Power Plants, Office of Nuclear Reactor Regulation, U.S. Nuclear Regulatory Commission, Washington, DC, NUREG/CR-0098.

Northern Engineering and Testing Inc. (1987), SIS geotechnical evaluation Idaho Chemical Processing Plant, INEL, report prepared for Westinghouse Idaho Nuclear Company, June.

Payne, S. J. (2006), Development of soil design basis earthquake (DBE) parameters for moderate and high hazard facilities at RTC, Battelle Energy Alliance, External Report INEEL/EXT-03-00942, Revision 2.

Payne S. J., Gorman, V. W., Jensen, S. A., Nitzel, M. E., Russell, M. J., and Smith R. P. (2002), Development of probabilistic design basis earthquake (DBE) parameters for moderate and high hazard facilities at INEEL, Bechtel BWXT Idaho, LLC. External Report INEEL/EXT-99-000775, Final Report, Rev 2, June, 101 pp.

Pierce, K.L. and Morgan, L.A. (1992), The track of the Yellowstone hot spot: Volcanism, faulting, and uplift, in P.K. Link et al., editors, Regional Geology of Eastern Idaho and Western Wyoming: Geological Society of America Memoir 179, 1-54.

Reilinger, R.E., G. P. Citron, and L. D. Brown (1977). Recent vertical crustal movements from precise leveling data in southwest Montana, western Yellowstone National Park, and the Snake River Plain, Journal of Geophysical Research, v. 82, p. 5349-5359.

Pyke, Robert (2007), Email transmittal of files "INLgravel.pdf 03/25/2007 10:25 PM", "gravel1.txt 03/26/2007 7:35 AM", and "gravel2.txt 03/26/2007 7:35 AM" from Robert Pyke to Suzette Payne, March 25, 2007.

Pyke, Robert (2006), Email transmittal of files "gravels.pdf 05/10/2006 9:22 PM", "g01.txt 05/11/2006 7:29 AM", “g02.txt 05/11/2006 7:30 AM", “g03.txt 05/11/2006 7:29 AM", and "INLdynprops.doc 05/10/2006 9:22 PM" from Robert Pyke to Suzette Payne, May 11, 2006.

Scott, W. E. (1982), Surficial Geologic Map of the Eastern Snake River Plain and Adjacent Areas, U.S. Geological Survey Map I-1372, scale 1:250,000.

Structural Dynamics Engineering (2000a), Seismic Evaluation and Upgrade of Building CPP-651, SPRand -- A Computer Program to Randomize Subsurface Soil Profiles for SHAKE 91 Input, Bechtel BWXT Idaho, LLC. Calculation Sheet SDE-99-05-06-C-003, Rev. 1, September 5, 2000.

Structural Dynamics Engineering (2000b), Seismic Evaluation and Upgrade of Building CPP-651, Building CPP-651 Soil Properties, Shear and Compression Wave Velocities, Bechtel BWXT Idaho, LLC. Calculation Sheet SDE-99-05-06-C-004, Rev. 1, September 14, 2000. 
URS Greiner Woodward-Clyde Federal Services, Geomatrix Consultants, and Pacific Engineering and Analysis (1999), Final Report: Development of Design Basis Earthquake Parameters for TMI-2 Independent Spent Fuel Storage Installation at the INEEL, Bechtel BWXT Idaho, LLC. External Report INEEL/EXT-99-00619, November.

Vucetic, M. and R. Dobry (1991), Effect of soil plasticity on cyclic response, Journal of Geotechnical Engineeing, v. 117, no. 1, p. 89-107. 
(Intentionally Blank) 


\section{Appendix A \\ Individual Borehole Soil Surface Spectra}


(Intentionally Blank) 


\section{Appendix A \\ Individual Borehole Soil Surface Spectra}

\section{Borehole Soil Profiles}

Eight individual soil profiles were developed for IWTU boreholes with Vs measurements, these soil profiles were used as input to SHAKE2000. The soil profiles are referred to as B-31, B-33, B-34, B34/B-35, B-37, B-38, B-39, and B-41. Both two- and three-layer soil profiles were developed (Table A1). Two-layer soil profiles were developed for boreholes B-31, B-34, B-34/B-35, and B-41 because Vs was not measured in the $2.3 \mathrm{ft}$ or less thicknesses of Layer $\mathrm{C}$. The thickness of Layer B was extended to the depth of the top of bedrock, which means the thicknesses of Layer B exceed those listed in Table 1 for these boreholes. Three-layer soil profiles were developed for boreholes B-33, B-37, B-38 and B-39. The thicknesses (7.0-8.0 ft) of Layer $\mathrm{C}$ in these boreholes appear to be sufficient to acquire Vs measurements (Table 1). Borehole B-34/B-35 includes the Vs measured in B-35 for basalt. The Vs of the soil layers in B-34 (and layer dimension parameters) were combined with the Vs of the basalt rock layer $\mathrm{D}_{2}$ in B-35 (Kleinfelder, Inc. 2007a). This approach was taken since the Vs measurements in B-34 for $\mathrm{D}_{1}$ were suspect due to poor coupling of the casing. Vs measurements were then taken in B-35 to assess the reason for the suspect measurements in B-34. A soil profile was not developed for the cross-hole Vs measurements (B-34) since the Vs measurement for Layer A was excluded to due to frozen ground. For the individual soil profiles, borehole Vs measurements were used with average densities of each layer to calculate corresponding $\mathrm{G}$ as discussed in Section 2.1.3.3. Layer dimension parameters were obtained from Table 1 (with the exceptions discussed above). Figure A-1 shows the two- and three-layer soil profiles that were developed for the IWTU boreholes listed in Table A-1. The three-layer soil profiles were compared to the sets of 30 soil profiles generated for the normal and log normal distributions of G. Figure A-2 shows a reasonable match to the sets of 30 random soil profiles for the normal and log normal distributions of $\mathrm{G}$.

\section{Soil Surface Spectra}

Soil surface spectra were calculated for the boreholes following the steps in Section 2.2. Two horizontal soil surface spectra were produced for each borehole (Figures A-3 and A-4). The individual borehole soil surface spectra are similar to the random soil surface spectra for the two sets of 30 random soil profiles. Figure A-5 shows the individual borehole soil surface spectra and the horizontal 1 (H1) and horizontal 2 (H2) components of soil surface spectra for the 30 random soil profiles with the log normal distribution of G. These two comparisons indicate the soil surface spectra of the individual borehole soil profiles are within the two sets of 30 random soil surface spectra.

The individual soil surface spectra were also compared to the mean and $84^{\text {th }}$ percentile soil surface spectra of the 30 random soil profiles with the log normal distribution of shear modulus (Table A-2) and the $84^{\text {th }}$ percentile PC 3 soil DBE 5\% damped spectrum. The spectral peak of the mean soil surface spectrum envelops the spectral peaks of the soil surface spectra for the two-layer soil profiles except for one borehole, B-31 (Figure A-6). For the three-layer soil profiles, the spectral peak of the mean soil surface spectrum only envelops the spectral peak of one borehole, B-39 (Figure A-7). The $84^{\text {th }}$ percentile soil surface spectrum envelops all two-layer soil profiles, except at $10 \mathrm{~Hz}$ for borehole B-34 due to a frequency shift in its spectral peak, and the spectral peak of borehole B-31 for the $\mathrm{H} 2$ component (Figure A-6). Only two spectral peaks for boreholes B-37 and B-38 exceed the $84^{\text {th }}$ percentile soil surface spectrum (Figure A-7). The $84^{\text {th }}$ percentile horizontal soil DBE 5\% damped spectrum envelops the soil surface spectra of the two-layer and three-layer borehole soil profiles except for larger spectral peaks of B-38 (Figure A-8). 
Table A-1. Individual soil profiles for IWTU boreholes.

\begin{tabular}{|c|c|c|c|c|c|c|}
\hline $\begin{array}{c}\text { Soil Profile } \\
\text { Name }\end{array}$ & Layer & Thickness (ft) & Depth $(\mathrm{ft})$ & Density (kcf) & Vs $(\mathrm{ft} / \mathrm{s})$ & $\mathrm{G}(\mathrm{kcf})$ \\
\hline \multirow[t]{3}{*}{ B-31 } & A & 10.0 & 10.0 & 0.1184 & 750 & 2070 \\
\hline & $\mathrm{B}$ & 30.0 & 40.0 & 0.1248 & 1510 & 8845 \\
\hline & $\mathrm{D}$ & Half-space & & 0.1599 & 4240 & 89357 \\
\hline \multirow[t]{4}{*}{ B-33 } & $\mathrm{A}$ & 11.0 & 11.0 & 0.1184 & 730 & 1961 \\
\hline & $\mathrm{B}$ & 25.5 & 36.5 & 0.1248 & 1570 & 9562 \\
\hline & $\mathrm{C}$ & 7.0 & 43.5 & 0.1257 & 1560 & 9509 \\
\hline & $\mathrm{D}$ & Half-space & & 0.1599 & 3610 & 64776 \\
\hline \multirow[t]{3}{*}{ B-34 } & A & 10.0 & 10.0 & 0.1184 & 900 & 2981 \\
\hline & $\mathrm{B}$ & 31.0 & 41.0 & 0.1248 & 1780 & 12291 \\
\hline & $\mathrm{D}$ & Half-space & & 0.1599 & 3390 & 57121 \\
\hline \multirow[t]{3}{*}{ B-34/B-35 } & A & 10.0 & 10.0 & 0.1184 & 900 & 2981 \\
\hline & B & 31.0 & 41.0 & 0.1248 & 1780 & 12291 \\
\hline & $\mathrm{D}$ & Half-space & & 0.1599 & 4010 & 79926 \\
\hline \multirow[t]{4}{*}{ B-37 } & $\mathrm{A}$ & 12.0 & 12.0 & 0.1184 & 750 & 2070 \\
\hline & $\mathrm{B}$ & 27.0 & 39.0 & 0.1248 & 1690 & 11080 \\
\hline & $\mathrm{C}$ & 8.0 & 47.0 & 0.1257 & 1330 & 6912 \\
\hline & $\mathrm{D}$ & Half-space & & 0.1599 & 4820 & 115476 \\
\hline \multirow[t]{4}{*}{ B-38 } & A & 9.0 & 9.0 & 0.1184 & 670 & 1652 \\
\hline & B & 27.6 & 36.6 & 0.1248 & 1590 & 9807 \\
\hline & $\mathrm{C}$ & 7.4 & 44.0 & 0.1257 & 1570 & 9631 \\
\hline & $\mathrm{D}$ & Half-space & & 0.1599 & 4600 & 105175 \\
\hline \multirow[t]{4}{*}{ B-39 } & A & 10.0 & 10.0 & 0.1184 & 910 & 3048 \\
\hline & B & 27.0 & 37.0 & 0.1248 & 1360 & 7175 \\
\hline & $\mathrm{C}$ & 8.0 & 45.0 & 0.1257 & 1540 & 9267 \\
\hline & $\mathrm{D}$ & Half-space & & 0.1599 & 3750 & 69897 \\
\hline
\end{tabular}


Table A-1. Continued.

\begin{tabular}{ccccccc}
$\begin{array}{c}\text { Soil Profile } \\
\text { Name }\end{array}$ & Layer & Thickness (ft) & Depth (ft) & Density (kcf) & Vs (ft/s) & G (kcf) \\
\cline { 1 - 4 } B-41 & A & 10.0 & 10.0 & 0.1184 & 890 & 2915 \\
& B & 33.5 & 43.5 & 0.1248 & 1480 & 8497 \\
& D & Half-space & & 0.1599 & 4170 & 86431 \\
\multicolumn{2}{l}{ a. The same layer dimensions as B-34 but uses B-35 Vs to calculate G for Layer D (see discussion in text). } \\
\hline
\end{tabular}


Table A-2. Spectral accelerations of the mean and $84^{\text {th }}$ percentile horizontal soil surface spectrum of the random soil profiles with the normal and log normal distribution of shear modulus.

\begin{tabular}{|c|c|c|c|}
\hline \multirow[b]{2}{*}{ Frequency $(\mathrm{Hz})$} & \multicolumn{3}{|c|}{ Spectral Accelerations (g) } \\
\hline & $\begin{array}{l}\text { Mean - Normal } \\
\text { Distribution }\end{array}$ & $\begin{array}{c}\text { Mean - Log Normal } \\
\text { Distribution }\end{array}$ & $\begin{array}{c}84^{\text {th }} \text { Percentile }- \text { Log Normal } \\
\text { Distribution }\end{array}$ \\
\hline 100.000 & 0.2565 & 0.2539 & 0.2773 \\
\hline 95.152 & 0.2568 & 0.2543 & 0.2774 \\
\hline 90.539 & 0.2569 & 0.2544 & 0.2775 \\
\hline 86.149 & 0.2571 & 0.2546 & 0.2778 \\
\hline 81.973 & 0.2574 & 0.2548 & 0.2780 \\
\hline 77.999 & 0.2577 & 0.2551 & 0.2783 \\
\hline 74.217 & 0.2580 & 0.2554 & 0.2787 \\
\hline 70.619 & 0.2584 & 0.2557 & 0.2790 \\
\hline 67.195 & 0.2587 & 0.2560 & 0.2793 \\
\hline 63.937 & 0.2591 & 0.2564 & 0.2797 \\
\hline 60.838 & 0.2595 & 0.2567 & 0.2801 \\
\hline 57.888 & 0.2600 & 0.2572 & 0.2806 \\
\hline 55.082 & 0.2605 & 0.2577 & 0.2811 \\
\hline 52.411 & 0.2612 & 0.2586 & 0.2816 \\
\hline 49.870 & 0.2616 & 0.2588 & 0.2815 \\
\hline 47.452 & 0.2630 & 0.2597 & 0.2827 \\
\hline 45.152 & 0.2654 & 0.2622 & 0.2842 \\
\hline 42.963 & 0.2688 & 0.2651 & 0.2858 \\
\hline 40.880 & 0.2735 & 0.2705 & 0.2917 \\
\hline 38.898 & 0.2752 & 0.2728 & 0.2958 \\
\hline 37.012 & 0.2789 & 0.2764 & 0.2982 \\
\hline 35.218 & 0.2861 & 0.2839 & 0.3062 \\
\hline 33.510 & 0.2907 & 0.2904 & 0.3116 \\
\hline 31.886 & 0.2966 & 0.2958 & 0.3173 \\
\hline 30.340 & 0.3080 & 0.3058 & 0.3217 \\
\hline 28.869 & 0.3126 & 0.3093 & 0.3269 \\
\hline 27.469 & 0.3166 & 0.3134 & 0.3345 \\
\hline 26.138 & 0.3267 & 0.3209 & 0.3450 \\
\hline 24.870 & 0.3226 & 0.3192 & 0.3387 \\
\hline 23.665 & 0.3182 & 0.3192 & 0.3435 \\
\hline
\end{tabular}


Table A-2. Continued.

\begin{tabular}{|c|c|c|c|}
\hline \multirow[b]{2}{*}{ Frequency $(\mathrm{Hz})$} & \multicolumn{3}{|c|}{ Spectral Accelerations (g) } \\
\hline & $\begin{array}{l}\text { Mean - Normal } \\
\text { Distribution }\end{array}$ & $\begin{array}{c}\text { Mean - Log Normal } \\
\text { Distribution }\end{array}$ & $\begin{array}{c}84^{\text {th }} \text { Percentile }- \text { Log Normal } \\
\text { Distribution }\end{array}$ \\
\hline 22.517 & 0.3252 & 0.3288 & 0.3504 \\
\hline 21.426 & 0.3402 & 0.3500 & 0.3920 \\
\hline 20.387 & 0.3520 & 0.3600 & 0.4139 \\
\hline 19.399 & 0.3724 & 0.3804 & 0.4518 \\
\hline 18.458 & 0.4004 & 0.4091 & 0.5096 \\
\hline 17.563 & 0.4315 & 0.4368 & 0.5331 \\
\hline 16.712 & 0.4504 & 0.4486 & 0.5249 \\
\hline 15.902 & 0.4623 & 0.4501 & 0.5083 \\
\hline 15.131 & 0.5087 & 0.4723 & 0.5288 \\
\hline 14.397 & 0.5369 & 0.4990 & 0.5485 \\
\hline 13.699 & 0.5526 & 0.5172 & 0.5773 \\
\hline 13.035 & 0.5501 & 0.5261 & 0.5989 \\
\hline 12.403 & 0.5736 & 0.5556 & 0.6404 \\
\hline 11.802 & 0.5911 & 0.5834 & 0.6620 \\
\hline 11.229 & 0.6140 & 0.6074 & 0.6975 \\
\hline 10.685 & 0.6055 & 0.6101 & 0.6937 \\
\hline 10.167 & 0.6349 & 0.6421 & 0.6944 \\
\hline 9.674 & 0.6733 & 0.6802 & 0.7404 \\
\hline 9.205 & 0.6980 & 0.7053 & 0.7697 \\
\hline 8.759 & 0.7752 & 0.7792 & 0.8656 \\
\hline 8.334 & 0.8498 & 0.8473 & 0.9288 \\
\hline 7.930 & 0.9867 & 0.9834 & 1.0753 \\
\hline 7.546 & 1.0493 & 1.0358 & 1.1591 \\
\hline 7.180 & 1.1017 & 1.0892 & 1.2461 \\
\hline 6.832 & 1.0305 & 1.0203 & 1.1701 \\
\hline 6.501 & 1.0014 & 0.9906 & 1.1743 \\
\hline 6.185 & 0.9781 & 0.9611 & 1.1608 \\
\hline 5.886 & 0.8587 & 0.8459 & 1.0654 \\
\hline 5.600 & 0.8115 & 0.8099 & 1.0223 \\
\hline 5.329 & 0.7832 & 0.7831 & 0.9775 \\
\hline 5.070 & 0.7146 & 0.7212 & 0.8719 \\
\hline
\end{tabular}


Table A-2. Continued.

\begin{tabular}{|c|c|c|c|}
\hline \multirow[b]{2}{*}{ Frequency $(\mathrm{Hz})$} & \multicolumn{3}{|c|}{ Spectral Accelerations (g) } \\
\hline & $\begin{array}{l}\text { Mean - Normal } \\
\text { Distribution }\end{array}$ & $\begin{array}{c}\text { Mean - Log Normal } \\
\text { Distribution }\end{array}$ & $\begin{array}{c}84^{\text {th }} \text { Percentile }- \text { Log Normal } \\
\text { Distribution }\end{array}$ \\
\hline 4.825 & 0.6713 & 0.6796 & 0.7848 \\
\hline 4.591 & 0.6125 & 0.6227 & 0.7234 \\
\hline 4.368 & 0.5577 & 0.5649 & 0.6328 \\
\hline 4.156 & 0.5215 & 0.5289 & 0.5945 \\
\hline 3.955 & 0.4533 & 0.4602 & 0.5000 \\
\hline 3.763 & 0.4961 & 0.5007 & 0.5466 \\
\hline 3.581 & 0.4822 & 0.4862 & 0.5384 \\
\hline 3.407 & 0.4586 & 0.4638 & 0.4990 \\
\hline 3.242 & 0.4498 & 0.4535 & 0.4969 \\
\hline 3.085 & 0.3961 & 0.3997 & 0.4162 \\
\hline 2.935 & 0.3974 & 0.4005 & 0.4193 \\
\hline 2.793 & 0.3995 & 0.4010 & 0.4173 \\
\hline 2.657 & 0.3876 & 0.3880 & 0.4043 \\
\hline 2.529 & 0.3757 & 0.3771 & 0.3933 \\
\hline 2.406 & 0.3658 & 0.3665 & 0.3855 \\
\hline 2.289 & 0.4102 & 0.4111 & 0.4304 \\
\hline 2.178 & 0.3452 & 0.3464 & 0.3570 \\
\hline 2.073 & 0.3446 & 0.3452 & 0.3553 \\
\hline 1.972 & 0.3166 & 0.3172 & 0.3249 \\
\hline 1.877 & 0.3144 & 0.3149 & 0.3210 \\
\hline 1.786 & 0.2742 & 0.2742 & 0.2814 \\
\hline 1.699 & 0.2704 & 0.2706 & 0.2777 \\
\hline 1.617 & 0.2461 & 0.2464 & 0.2497 \\
\hline 1.538 & 0.2405 & 0.2408 & 0.2445 \\
\hline 1.464 & 0.2164 & 0.2169 & 0.2194 \\
\hline 1.393 & 0.2097 & 0.2099 & 0.2126 \\
\hline 1.325 & 0.1892 & 0.1894 & 0.1921 \\
\hline 1.261 & 0.2036 & 0.2037 & 0.2054 \\
\hline 1.200 & 0.1748 & 0.1749 & 0.1770 \\
\hline 1.142 & 0.1630 & 0.1631 & 0.1652 \\
\hline 1.086 & 0.1587 & 0.1589 & 0.1611 \\
\hline
\end{tabular}


Table A-2. Continued.

\begin{tabular}{|c|c|c|c|}
\hline \multirow[b]{2}{*}{ Frequency $(\mathrm{Hz})$} & \multicolumn{3}{|c|}{ Spectral Accelerations (g) } \\
\hline & $\begin{array}{l}\text { Mean - Normal } \\
\text { Distribution }\end{array}$ & $\begin{array}{c}\text { Mean - Log Normal } \\
\text { Distribution }\end{array}$ & $\begin{array}{c}84^{\text {th }} \text { Percentile }- \text { Log Normal } \\
\text { Distribution }\end{array}$ \\
\hline 1.034 & 0.1499 & 0.1499 & 0.1522 \\
\hline 0.984 & 0.1446 & 0.1447 & 0.1457 \\
\hline 0.936 & 0.1554 & 0.1554 & 0.1565 \\
\hline 0.891 & 0.1317 & 0.1318 & 0.1324 \\
\hline 0.847 & 0.1214 & 0.1215 & 0.1223 \\
\hline 0.806 & 0.1172 & 0.1172 & 0.1176 \\
\hline 0.767 & 0.1144 & 0.1144 & 0.1151 \\
\hline 0.730 & 0.1111 & 0.1111 & 0.1119 \\
\hline 0.695 & 0.0976 & 0.0977 & 0.0987 \\
\hline 0.661 & 0.0977 & 0.0977 & 0.0984 \\
\hline 0.629 & 0.0939 & 0.0939 & 0.0942 \\
\hline 0.598 & 0.0891 & 0.0891 & 0.0897 \\
\hline 0.569 & 0.0807 & 0.0807 & 0.0813 \\
\hline 0.542 & 0.0712 & 0.0712 & 0.0716 \\
\hline 0.516 & 0.0703 & 0.0702 & 0.0704 \\
\hline 0.491 & 0.0673 & 0.0673 & 0.0674 \\
\hline 0.467 & 0.0587 & 0.0587 & 0.0588 \\
\hline 0.444 & 0.0553 & 0.0553 & 0.0555 \\
\hline 0.423 & 0.0601 & 0.0601 & 0.0603 \\
\hline 0.402 & 0.0577 & 0.0577 & 0.0579 \\
\hline 0.383 & 0.0554 & 0.0554 & 0.0556 \\
\hline 0.364 & 0.0557 & 0.0557 & 0.0559 \\
\hline 0.346 & 0.0537 & 0.0537 & 0.0537 \\
\hline 0.330 & 0.0496 & 0.0496 & 0.0498 \\
\hline 0.314 & 0.0444 & 0.0444 & 0.0445 \\
\hline 0.298 & 0.0392 & 0.0392 & 0.0393 \\
\hline 0.284 & 0.0329 & 0.0330 & 0.0331 \\
\hline 0.270 & 0.0276 & 0.0276 & 0.0277 \\
\hline 0.257 & 0.0243 & 0.0243 & 0.0244 \\
\hline 0.245 & 0.0224 & 0.0224 & 0.0225 \\
\hline 0.233 & 0.0203 & 0.0203 & 0.0204 \\
\hline
\end{tabular}


Table A-2. Continued.

\begin{tabular}{cccc}
\hline & \multicolumn{3}{c}{ Spectral Accelerations $(\mathrm{g})$} \\
\cline { 2 - 4 } Frequency $(\mathrm{Hz})$ & $\begin{array}{c}\text { Mean - Normal } \\
\text { Distribution }\end{array}$ & $\begin{array}{c}\text { Mean }- \text { Log Normal } \\
\text { Distribution }\end{array}$ & $\begin{array}{c}\text { 84 } \\
\text { th }\end{array}$ \\
\hline 0.221 & 0.0187 & 0.0187 & 0.0188 \\
0.211 & 0.0176 & 0.0176 & 0.0177 \\
0.201 & 0.0166 & 0.0166 & 0.0167 \\
0.191 & 0.0168 & 0.0168 & 0.0169 \\
0.182 & 0.0166 & 0.0166 & 0.0167 \\
0.173 & 0.0158 & 0.0158 & 0.0159 \\
0.164 & 0.0147 & 0.0147 & 0.0147 \\
0.156 & 0.0134 & 0.0134 & 0.0134 \\
0.149 & 0.0119 & 0.0119 & 0.0119 \\
0.142 & 0.0103 & 0.0103 & 0.0103 \\
0.135 & 0.0089 & 0.0089 & 0.0089 \\
0.128 & 0.0076 & 0.0076 & 0.0077 \\
0.122 & 0.0066 & 0.0066 & 0.0066 \\
0.116 & 0.0058 & 0.0058 & 0.0058 \\
0.110 & 0.0054 & 0.0054 & 0.0054 \\
0.105 & 0.0049 & 0.0049 & 0.0049 \\
0.100 & 0.0044 & 0.0044 & 0.0044 \\
\hline
\end{tabular}


(a)

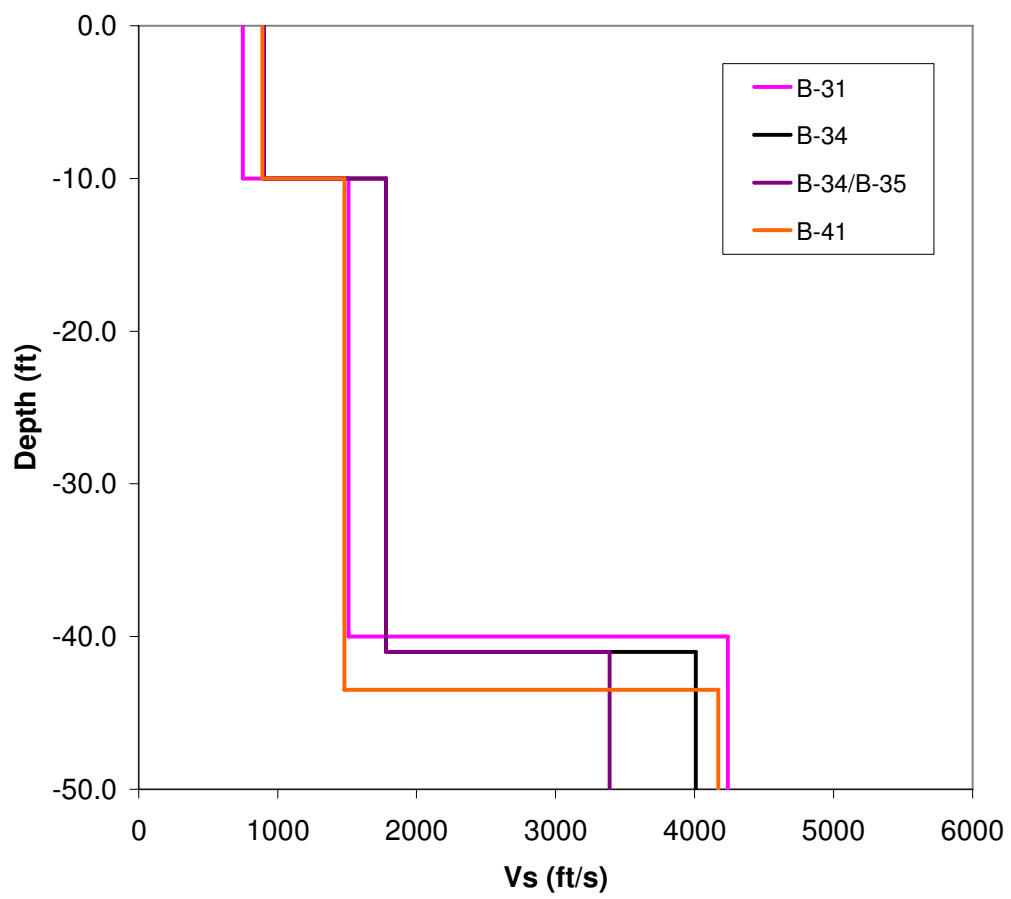

(b)

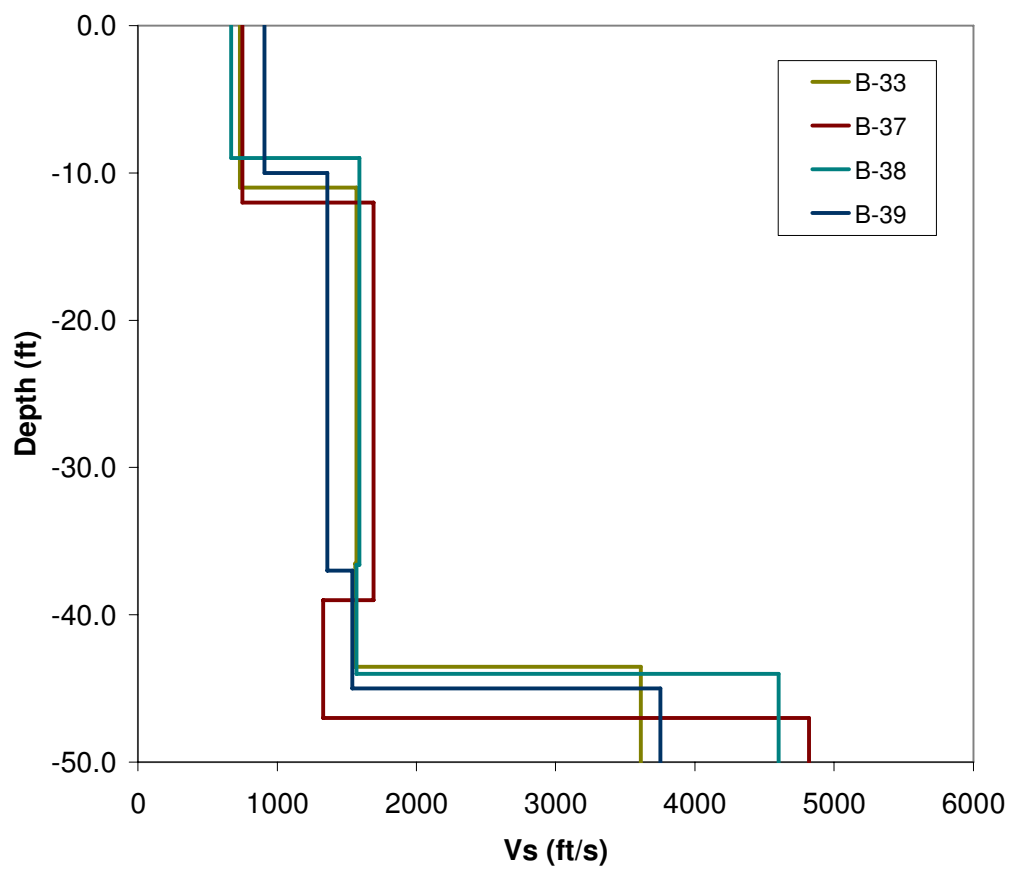

Figure A-1. Individual soil profiles for IWTU boreholes: (a) two-soil layers and (b) three-soil layers. 
(a)

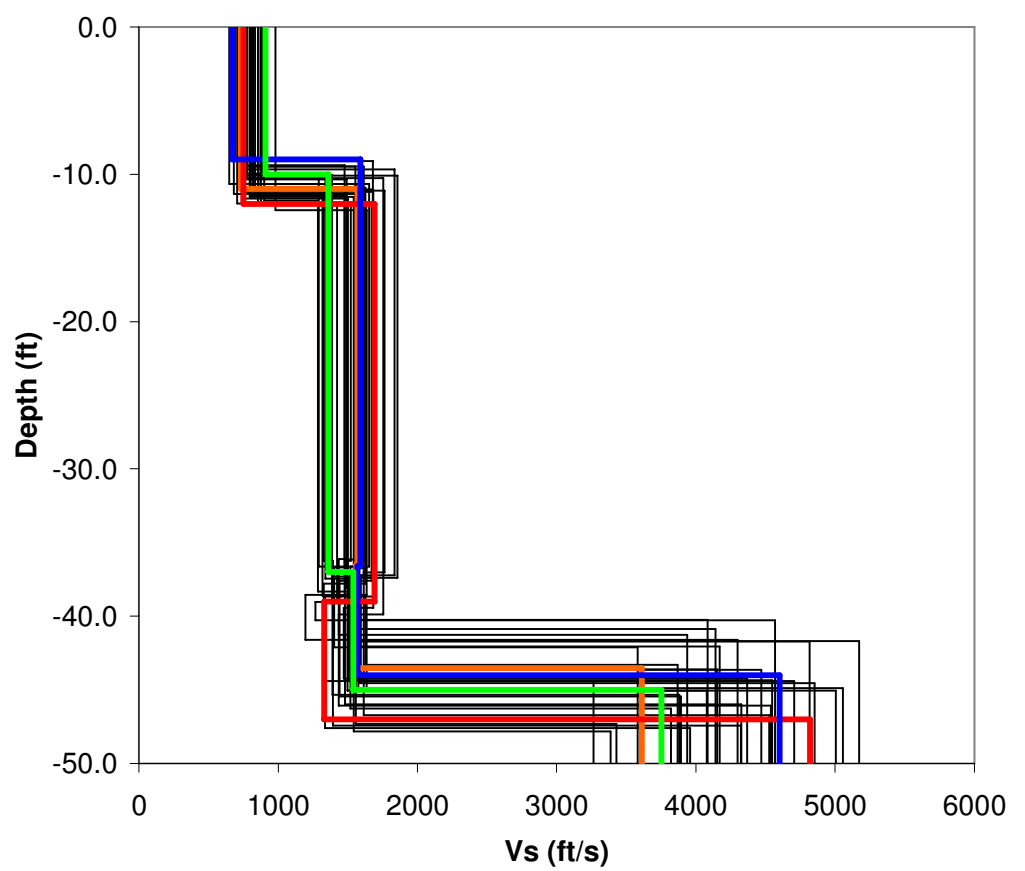

(b)

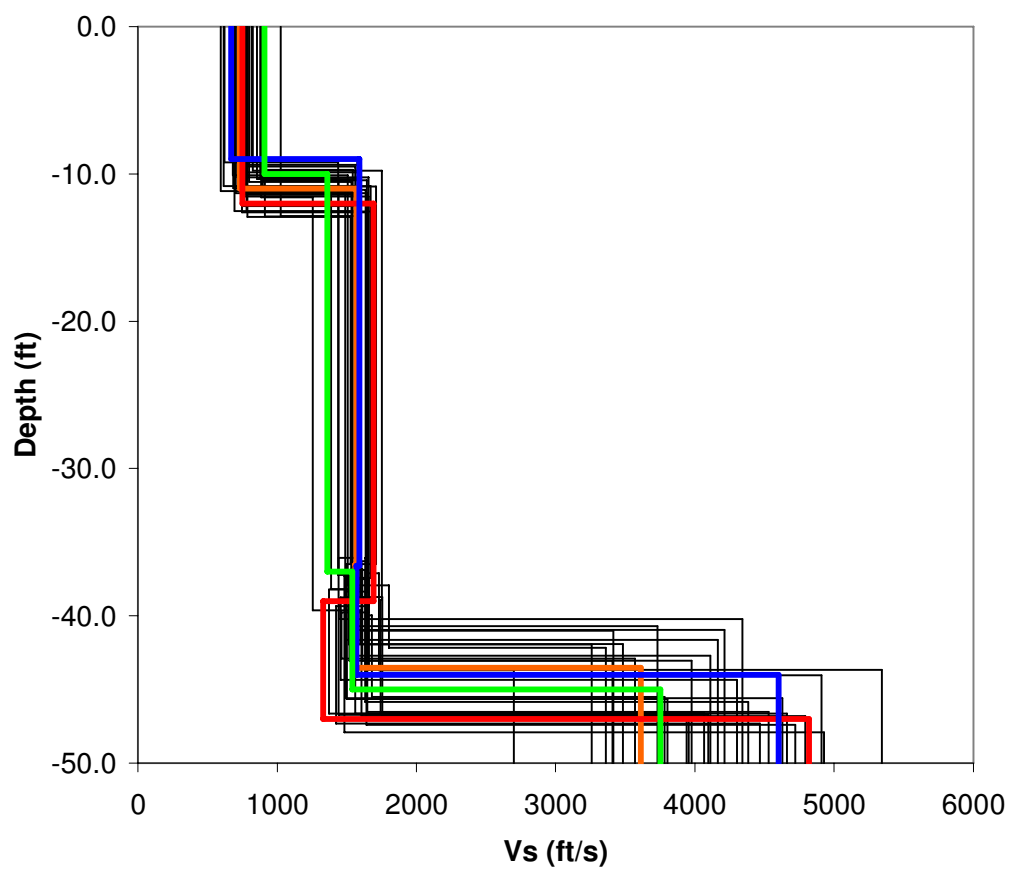

Figure A-2. Plot of individual soil profiles for IWTU boreholes and thirty random soil profiles (thin black lines) for the: (a) normal and (b) log normal distributions of shear modulus. The three-layer soil profiles are shown for boreholes: B-33 (orange); B-37 (red); B-38 (blue); and B-39 (green). 
(a)

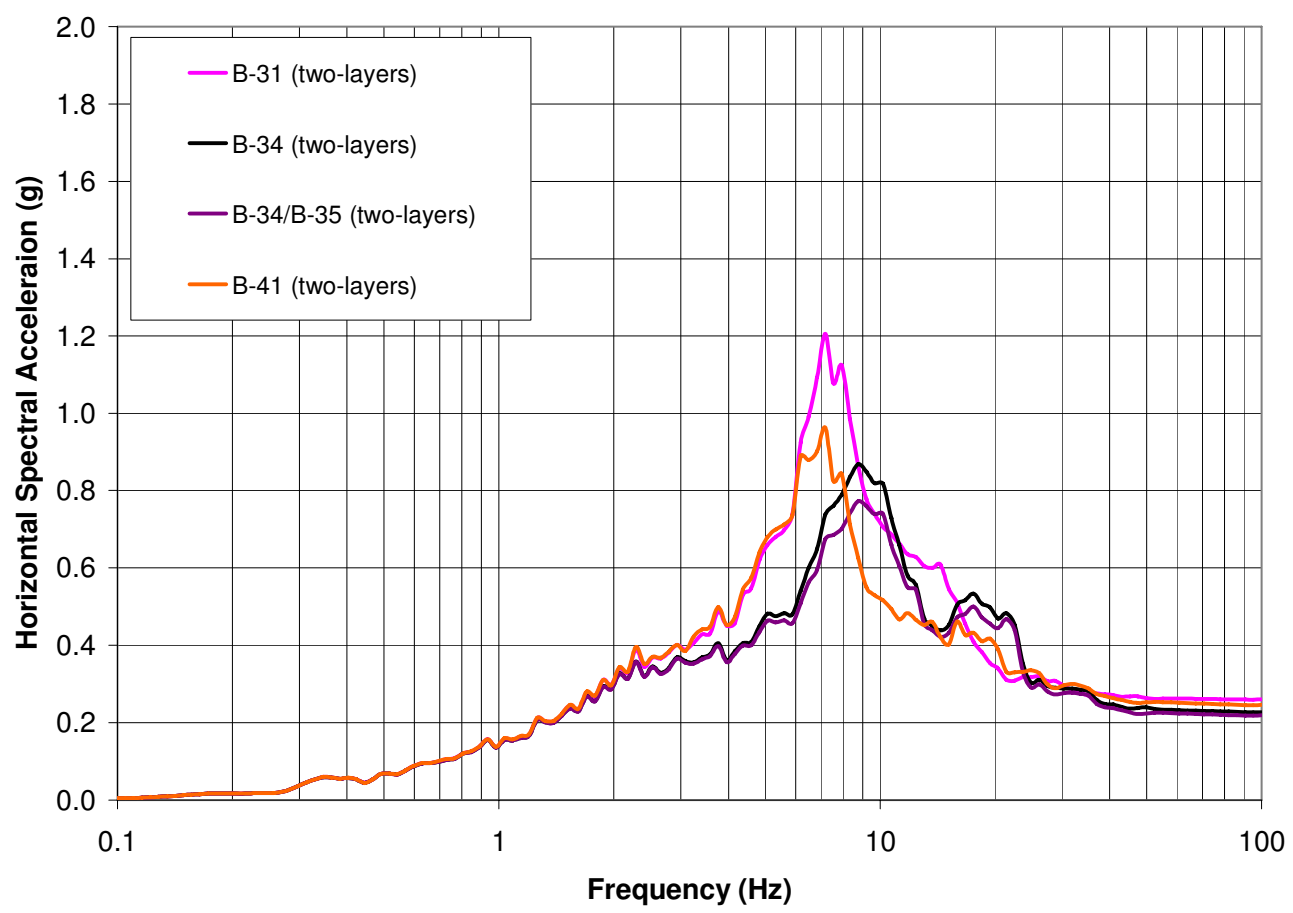

(b)

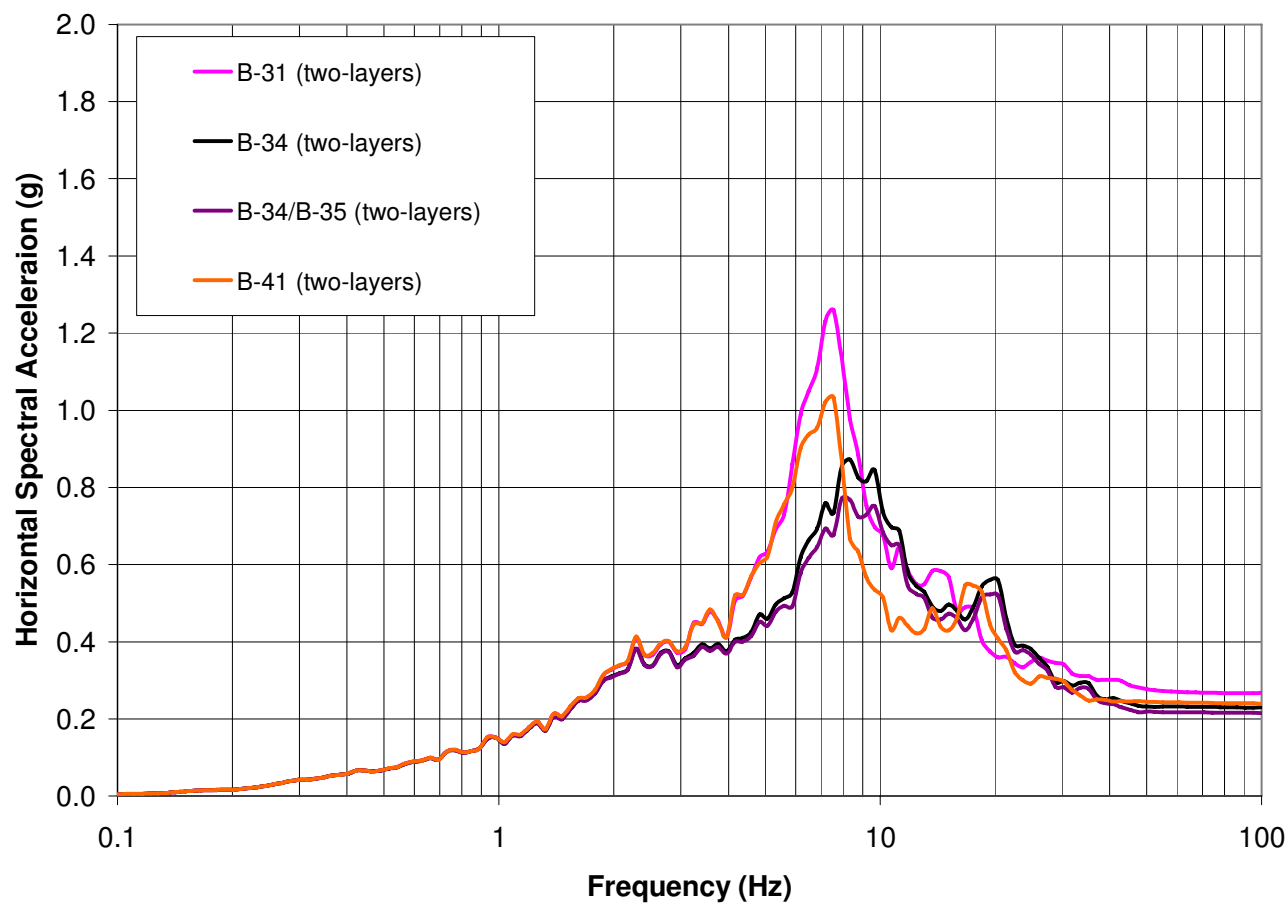

Figure A-3. PC 3 (2,500 yr) soil surface 5\% damped spectra of two-layer soil profiles for: (a) H1 and (b) $\mathrm{H} 2$. 
(a)

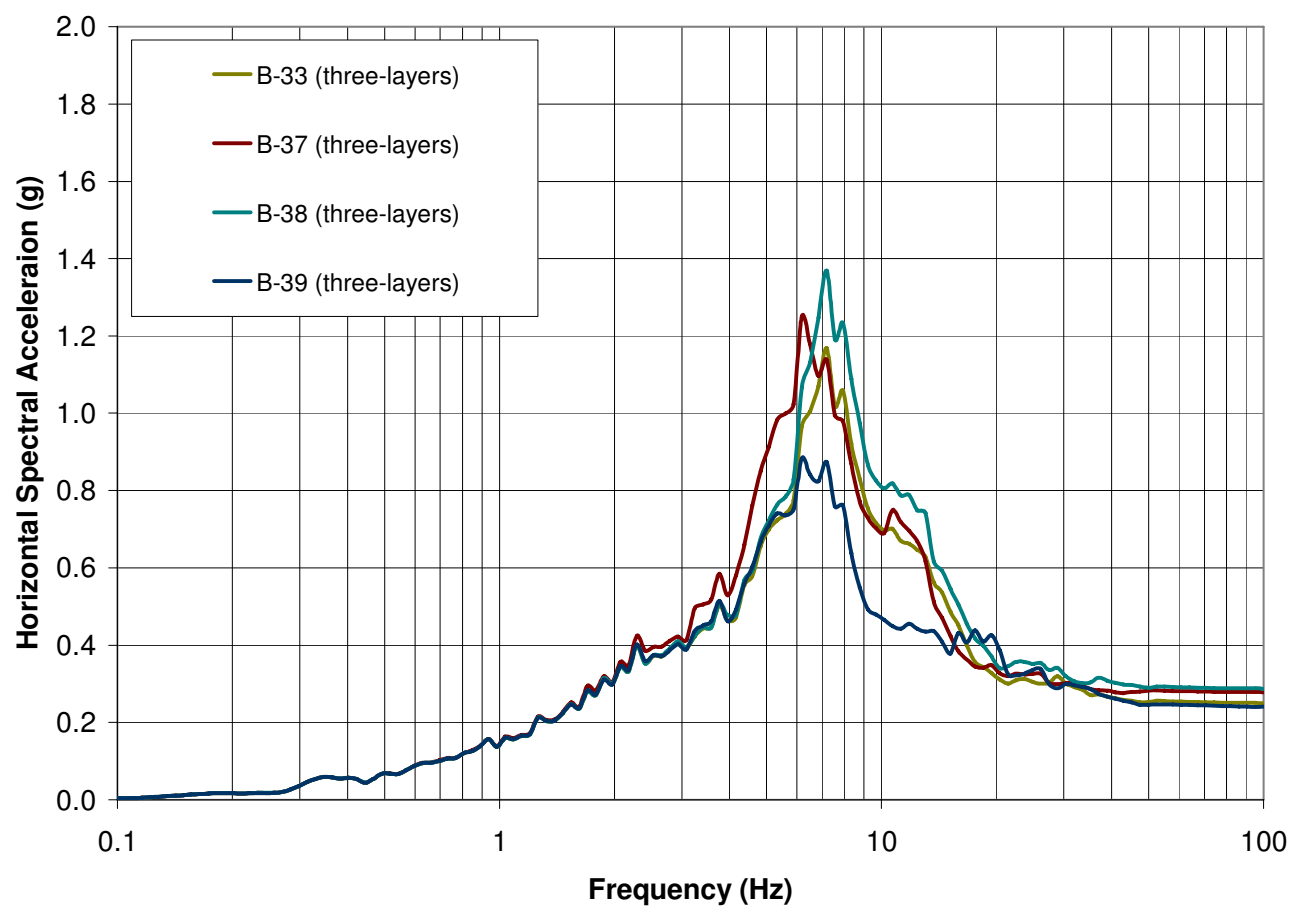

(b)

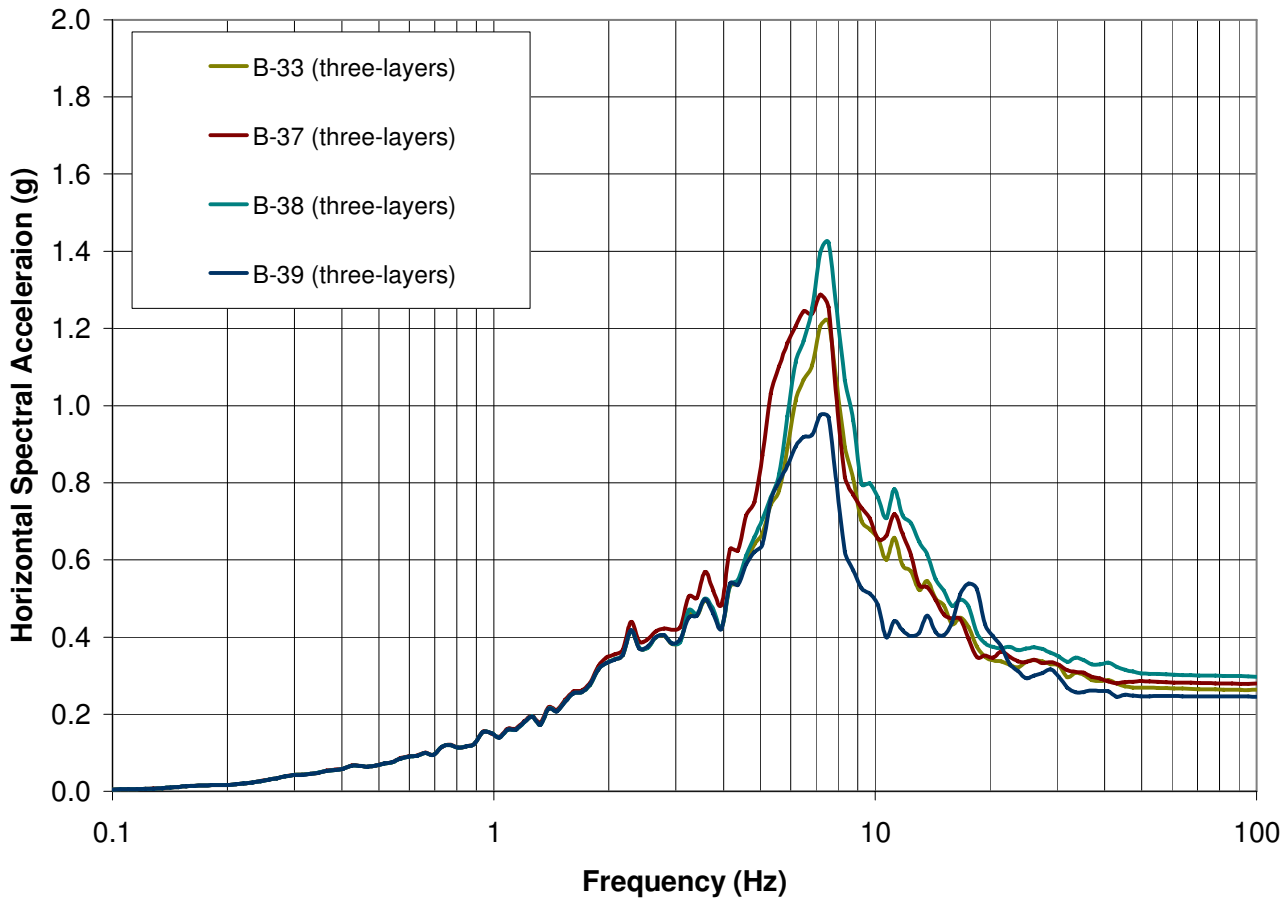

Figure A-4. PC 3 (2,500 yr) soil surface 5\% damped spectra of three-layer soil profiles for: (a) H1 and (b) $\mathrm{H} 2$. 
(a)

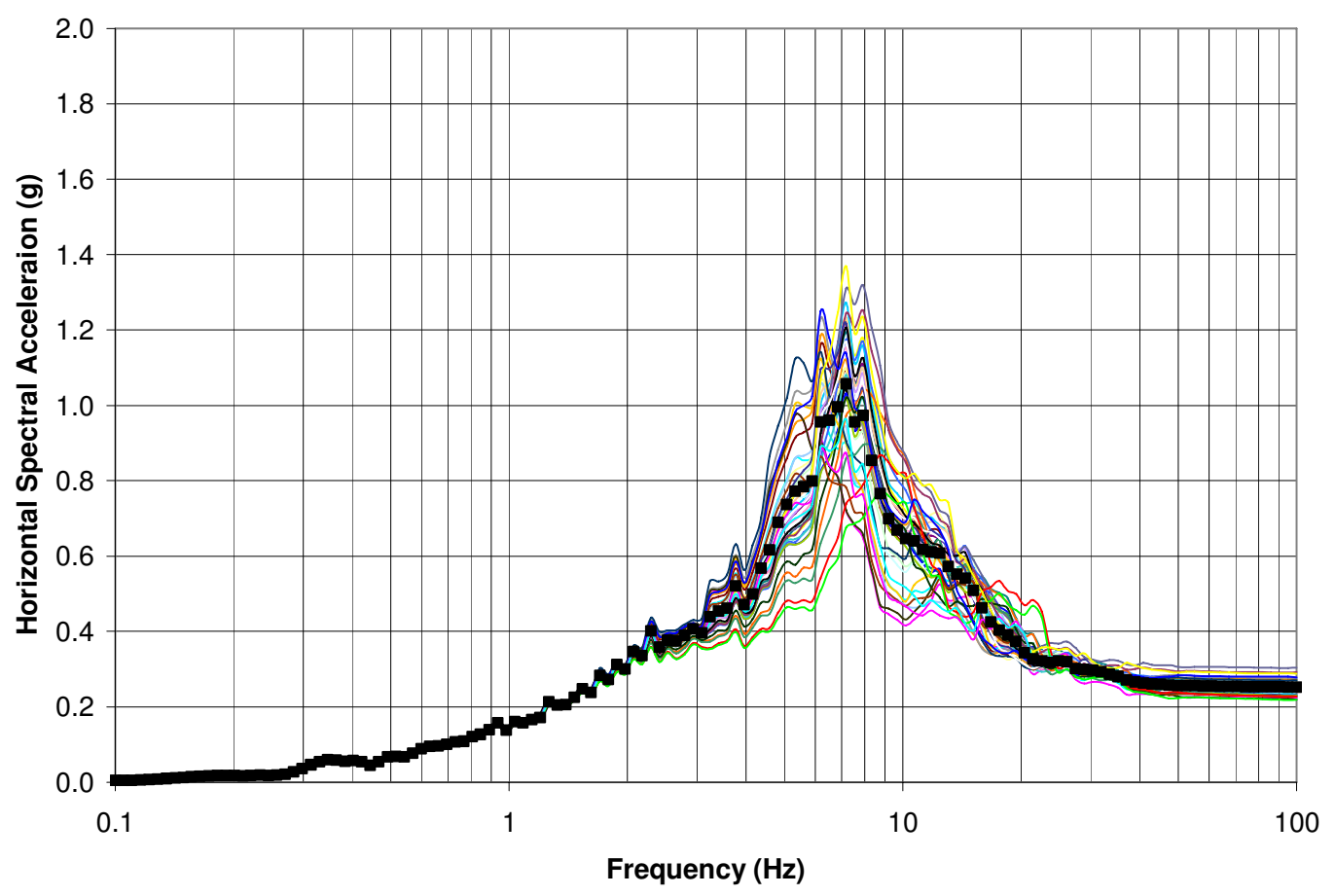

(b)

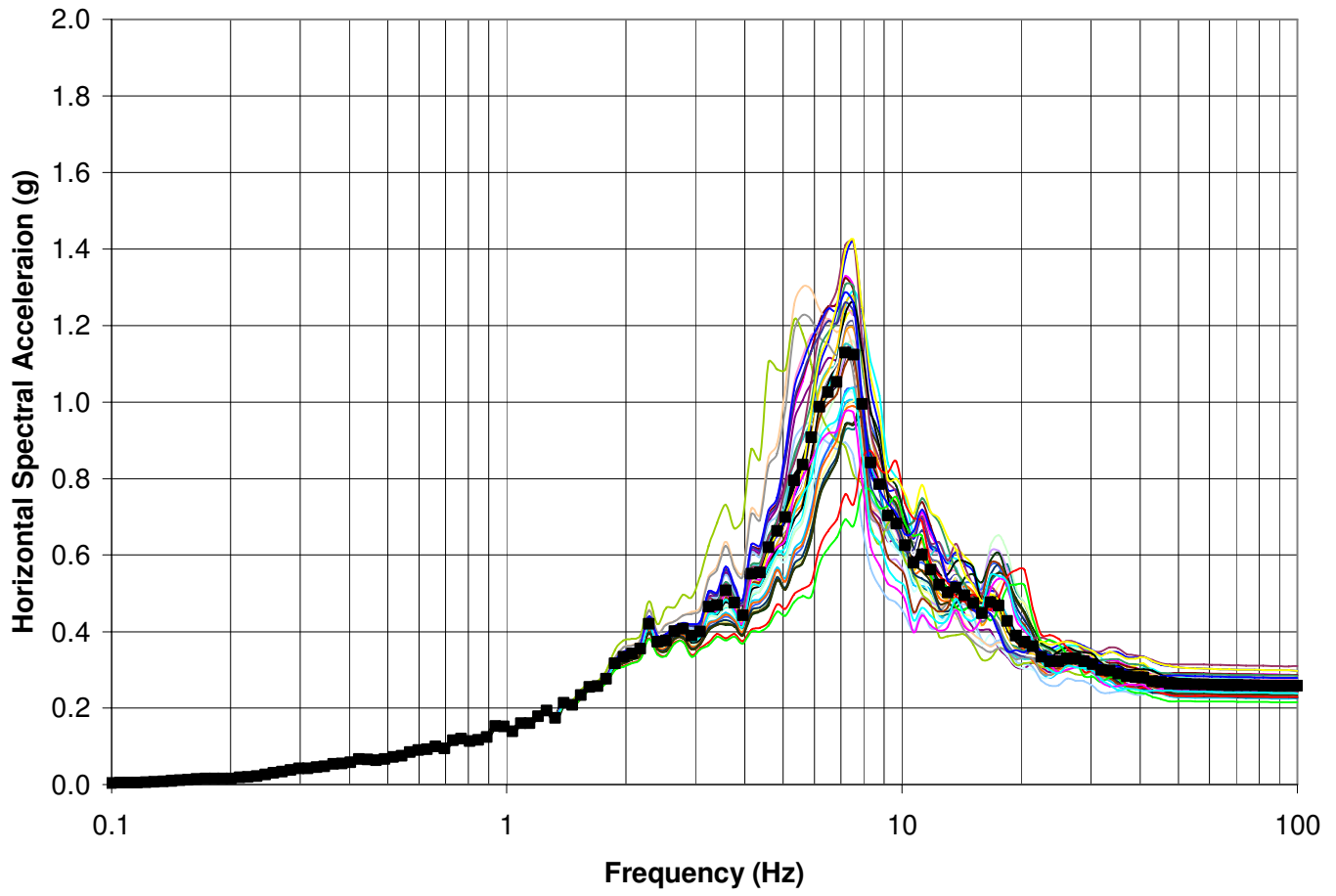

Figure A-5. PC 3 (2,500 yr) mean (black jagged line) and soil surface 5\% damped spectra (colored lines) for: (a) H1 with 30 soil profiles that have the normal distribution of $\mathrm{G}$ and each individual borehole; (b) $\mathrm{H} 2$ with 30 soil profiles that have the $\log$ normal distribution of $\mathrm{G}$ and each individual borehole. 
(a)

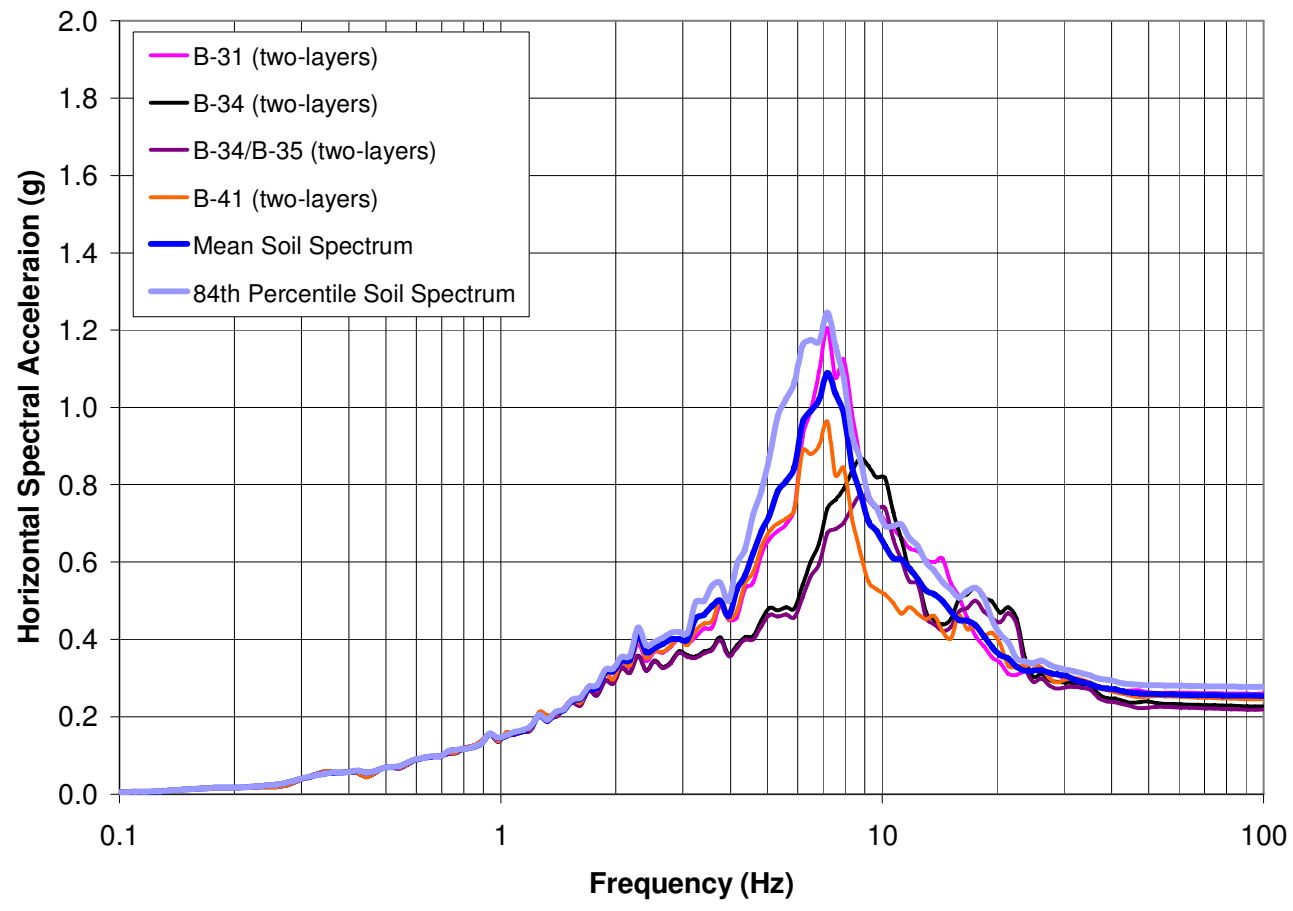

(b)

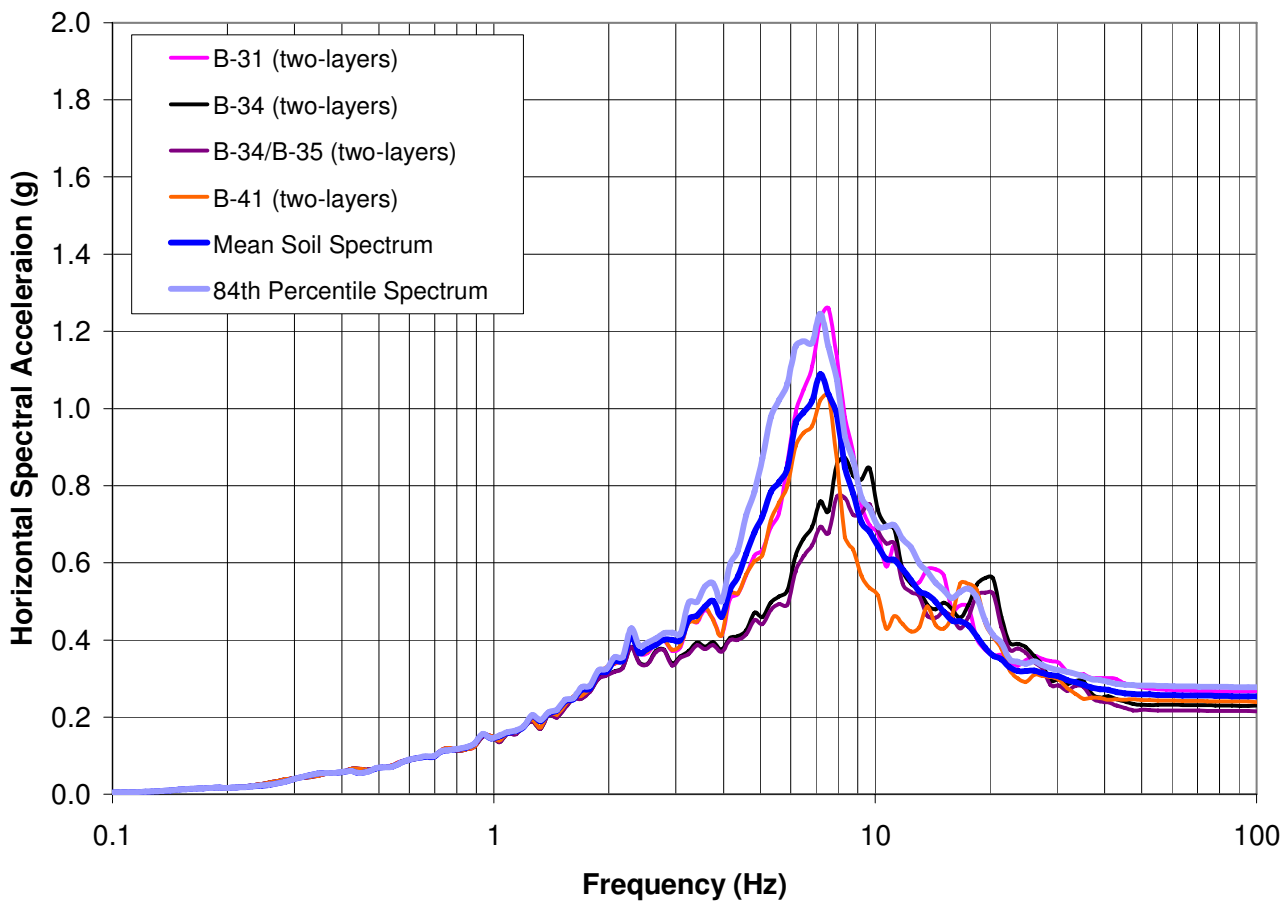

Figure A-6. Mean and $84^{\text {th }}$ percentile PC 3 (2,500 yr) soil 5\% damped spectrum of 30 random soil profiles for the log normal distribution of shear modulus and individual borehole soil surface spectra of two-layer soil profiles for: (a) H1 and (b) H2. 
(a)

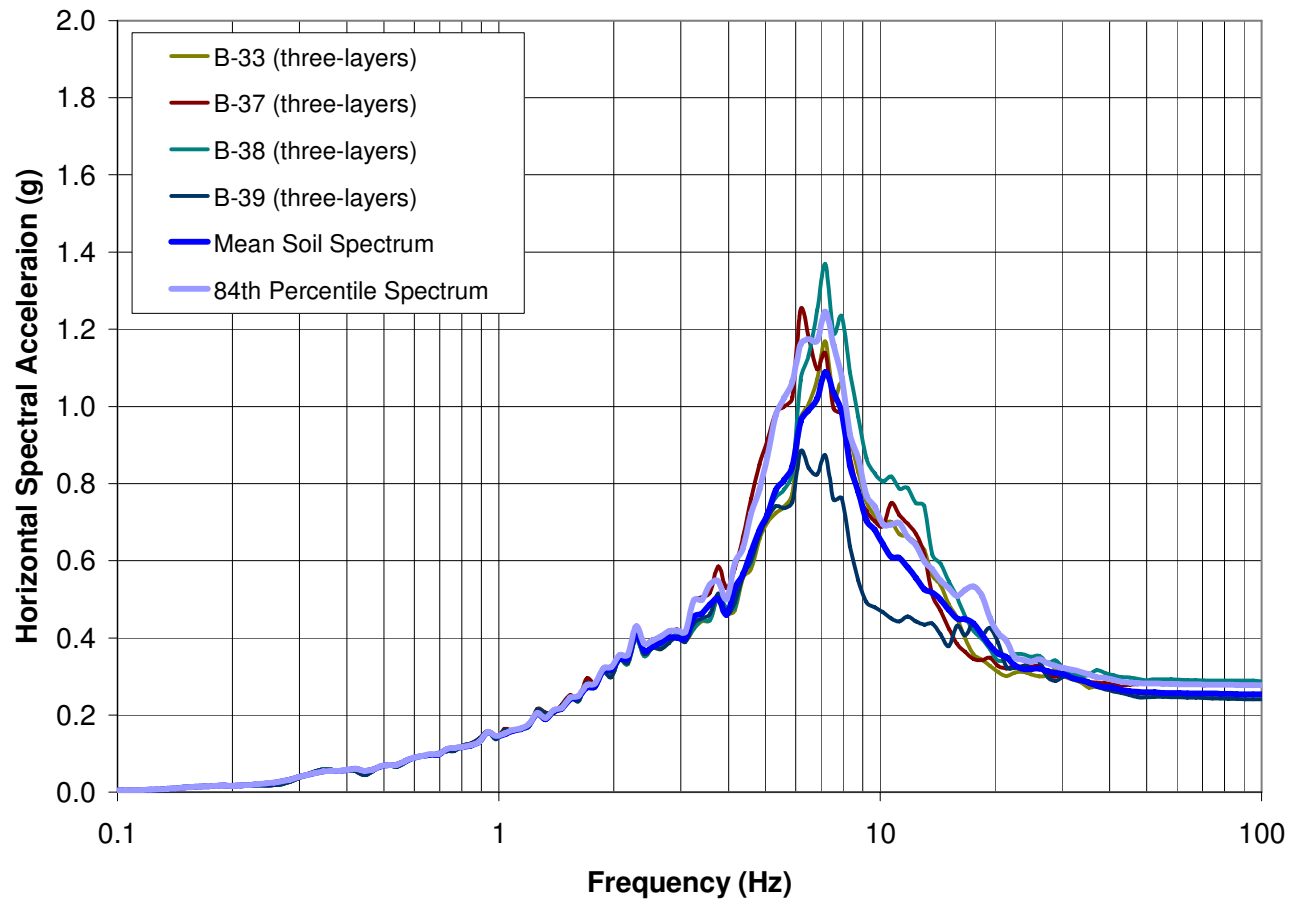

(b)

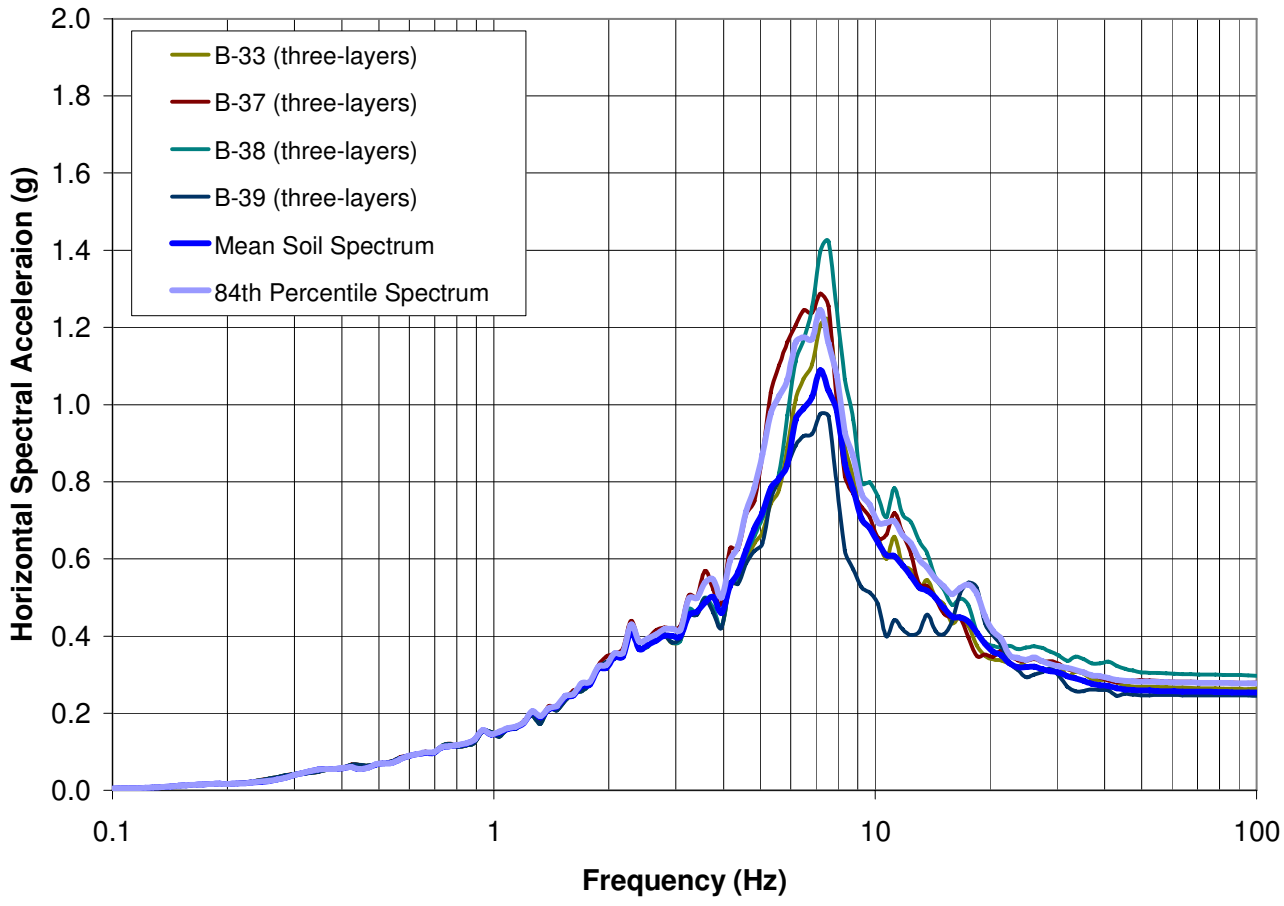

Figure A-7. Mean and $84^{\text {th }}$ percentile PC 3 (2,500 yr) soil $5 \%$ damped spectrum of 30 random soil profiles for the log normal distribution of shear modulus and individual borehole soil surface spectra of three-layer soil profiles for: (a) H1 and (b) H2. 
(a)

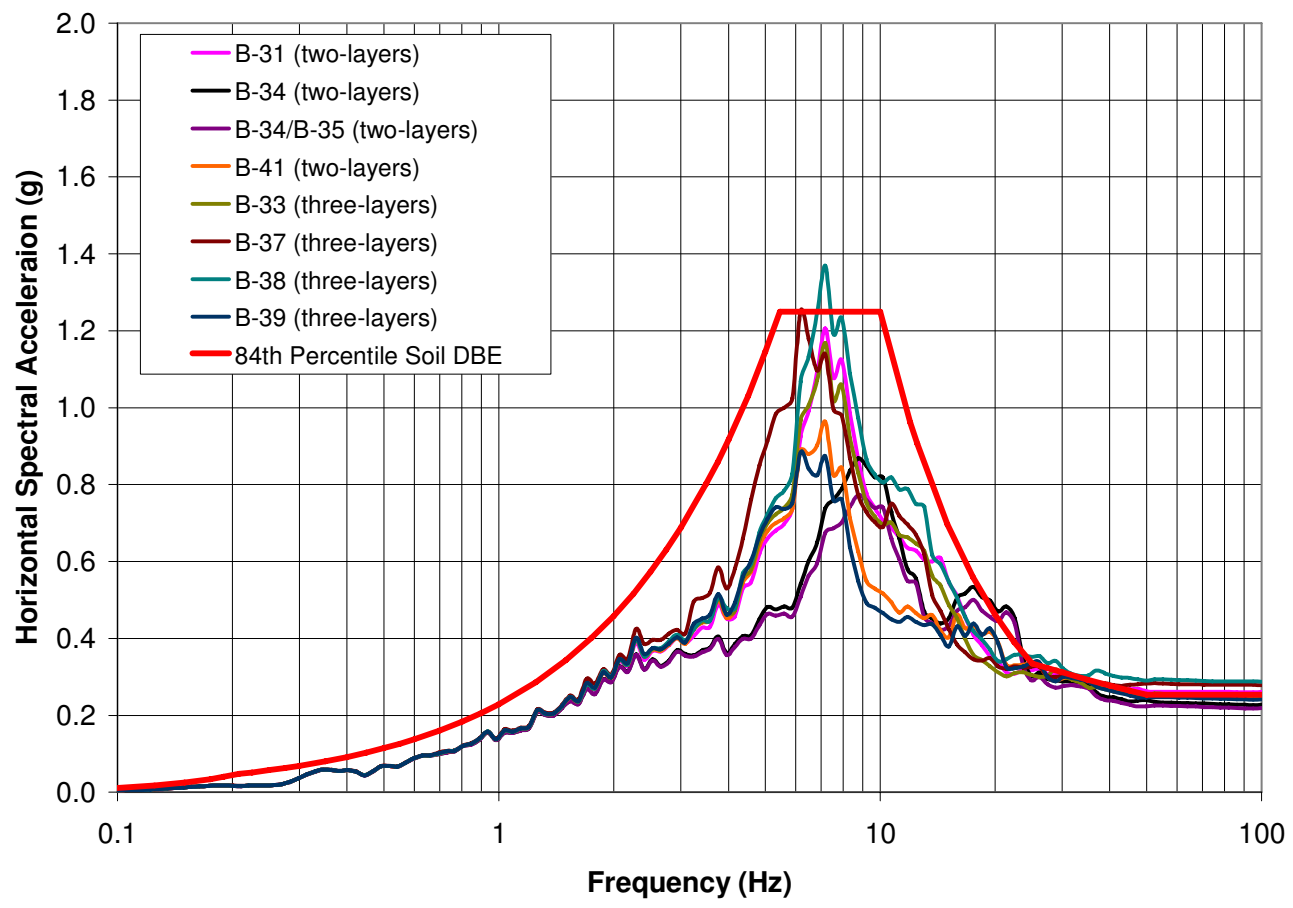

(b)

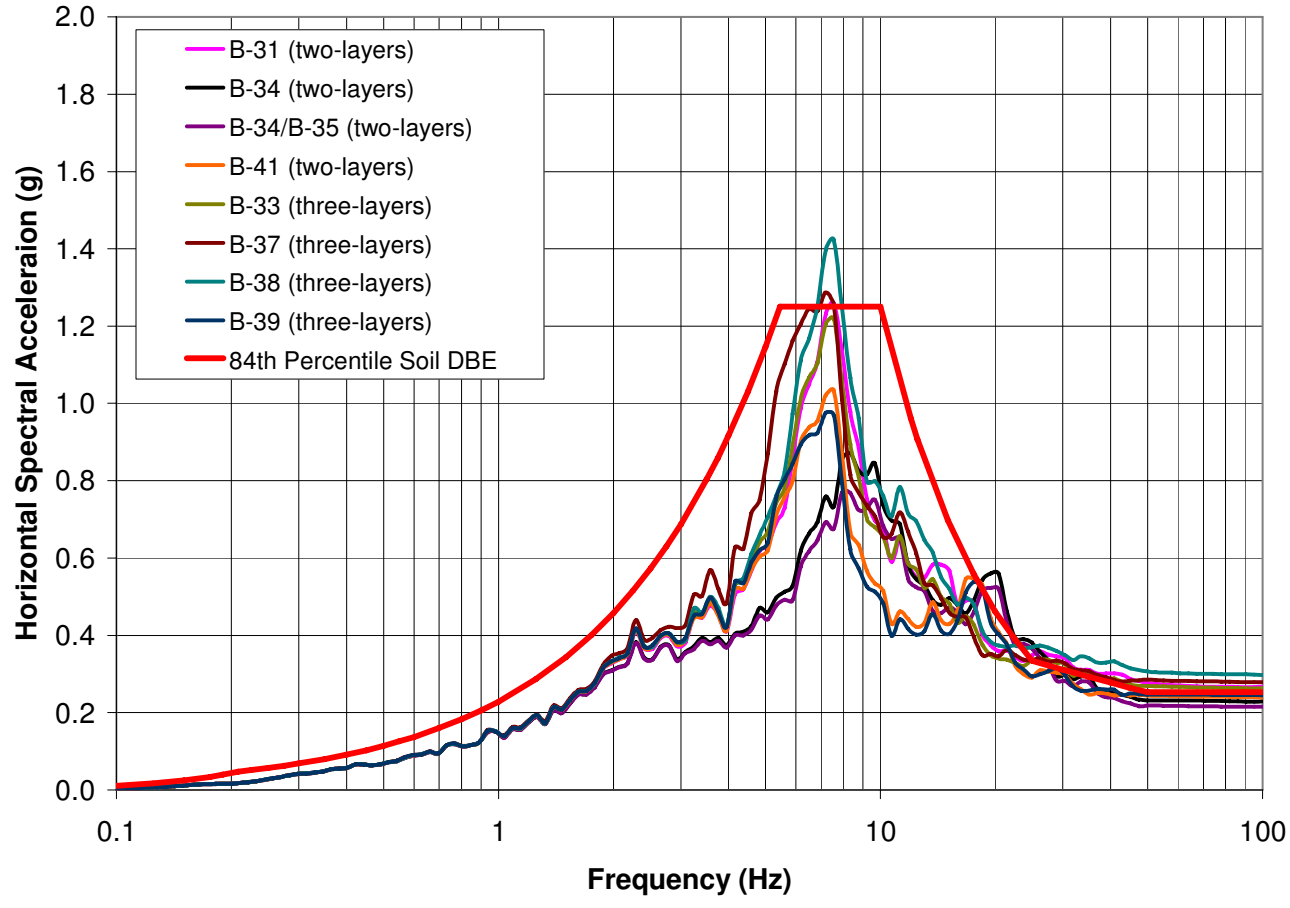

Figure A-8. $84^{\text {th }}$ percentile horizontal PC 3 (2,500 yr) soil DBE 5\% damped spectrum and all individual borehole soil surface spectra for: (a) $\mathrm{H} 1$ and (b) $\mathrm{H} 2$. 


\section{Appendix B}

\section{Time Histories and Arias Intensity Plots}


(Intentionally Blank)

Revision 1 


\section{Appendix B \\ Time Histories and Arias Intensity Plots}

\section{Mean Soil DBE Time Histories}

Acceleration, velocity, and displacement time histories corresponding to the mean horizontal and vertical IWTU soil DBE spectra (Tables 7 and 11) are shown in Figures B-1, B-2, and B-3, respectively. The time histories were developed as discussed in Section 4.

\section{Arias Intensity Plots}

Arias intensities were computed for the rock and soil DBE time histories. Plots of the arias intensity were generated for the two horizontal and one vertical INTEC/RTC/RWMC/PBF PC 3 (2,500 yr) rock DBE acceleration time histories. The BLINE02 program was used to generate the arias intensity of each time history (Abrahamson 1996). Figures B-4 and B-5 show the plots for the horizontal components (H1 and $\mathrm{H} 2)$ and the vertical component, respectively. Plots of the arias intensity of the INTEC/RTC/RWMC/PBF PC 3 (2,500 yr) acceleration rock DBE time histories show smooth increases from 0 to 15 seconds then they generally level out from 15 to 41 seconds.

Plots of the arias intensity were also generated for the mean and $84^{\text {th }}$ percentile IWTU PC 3 Soil DBE acceleration time histories. Figures B-6 and B-7 show the plots for the mean horizontal and vertical components, respectively. Figures B-8 and B-9 show the plots for the $84^{\text {th }}$ percentile horizontal and vertical components, respectively. The arias intensity plots of the mean and $84^{\text {th }}$ percentile IWTU PC 3 Soil DBE acceleration time histories show smooth curves. 

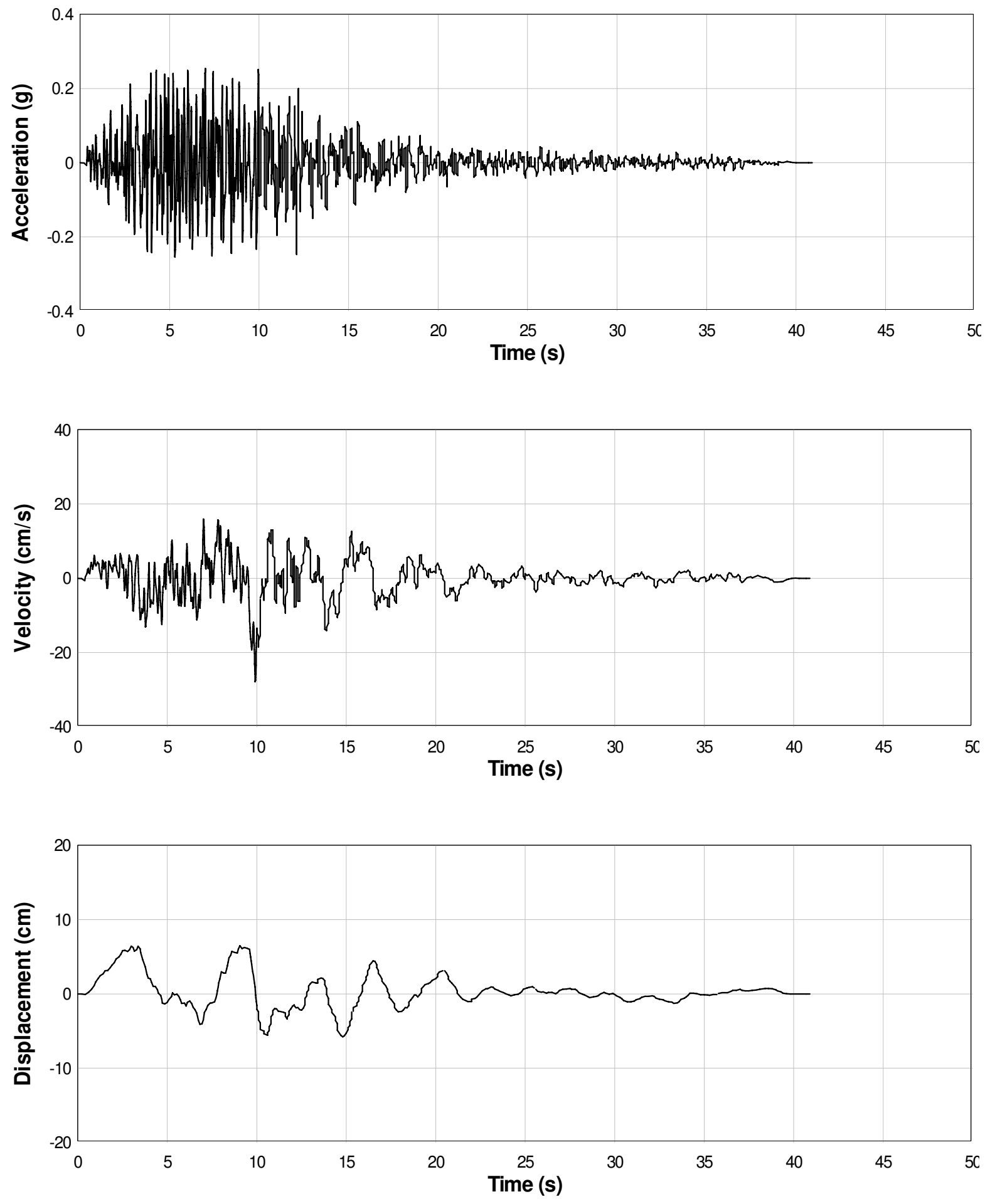

Figure B-1. Mean IWTU PC 3 (2,500 yr) Soil DBE time histories for the horizontal 1 component. 

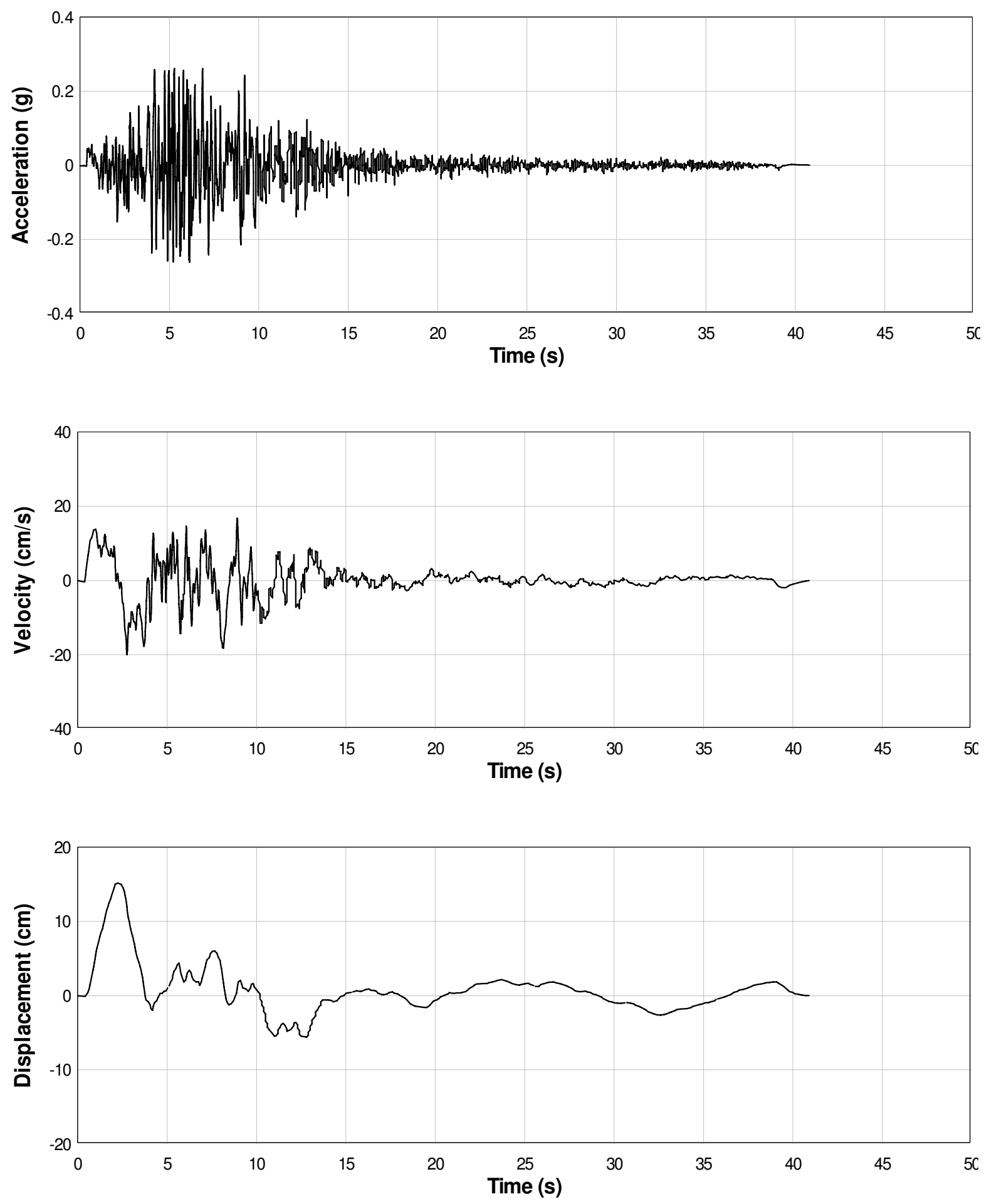

Figure B-2. Mean IWTU PC 3 (2,500 yr) Soil DBE time histories for the horizontal 2 component. 

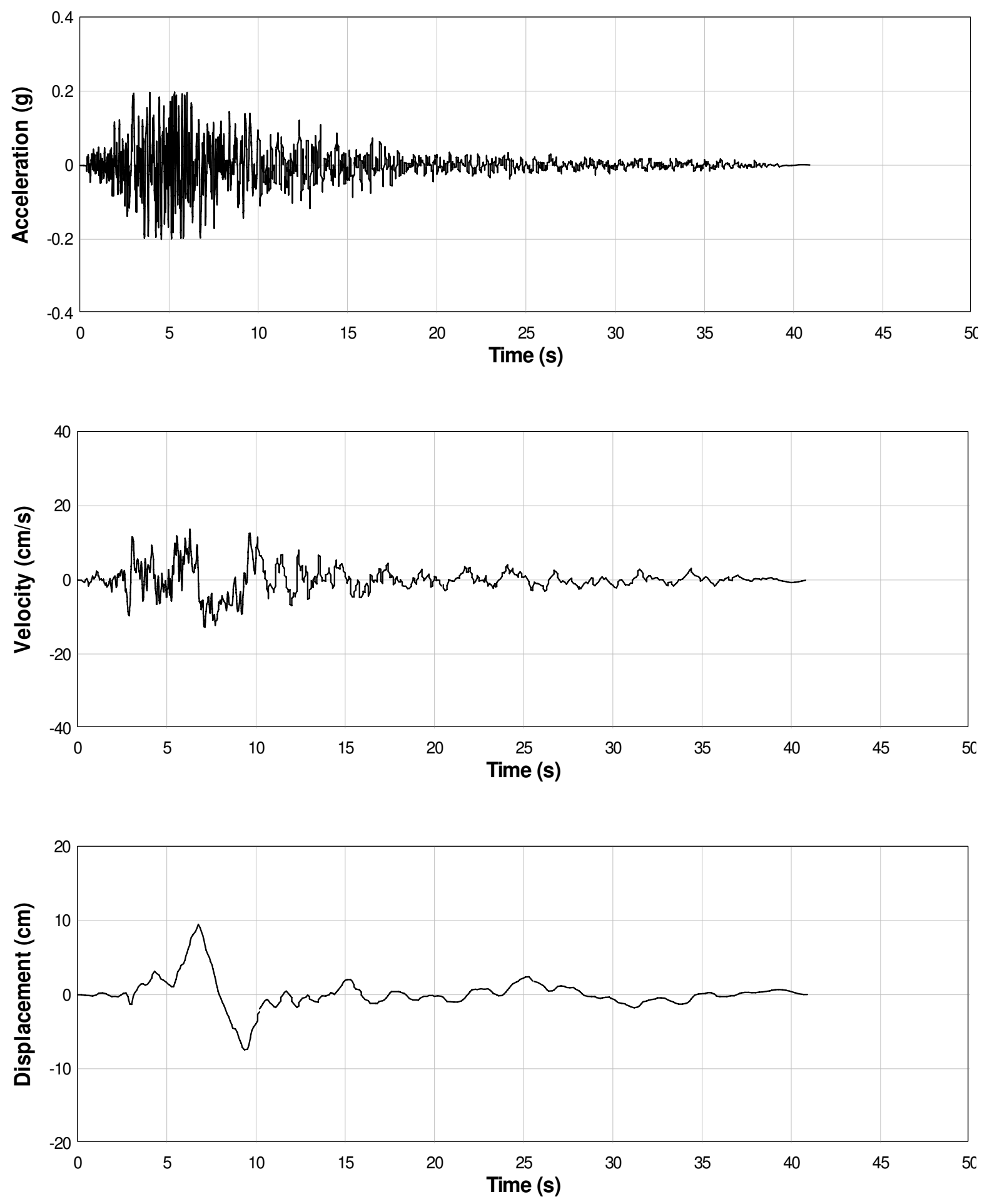

Figure B-3. Mean IWTU PC 3 (2,500 yr) Soil DBE time histories for the vertical component. 
(a)

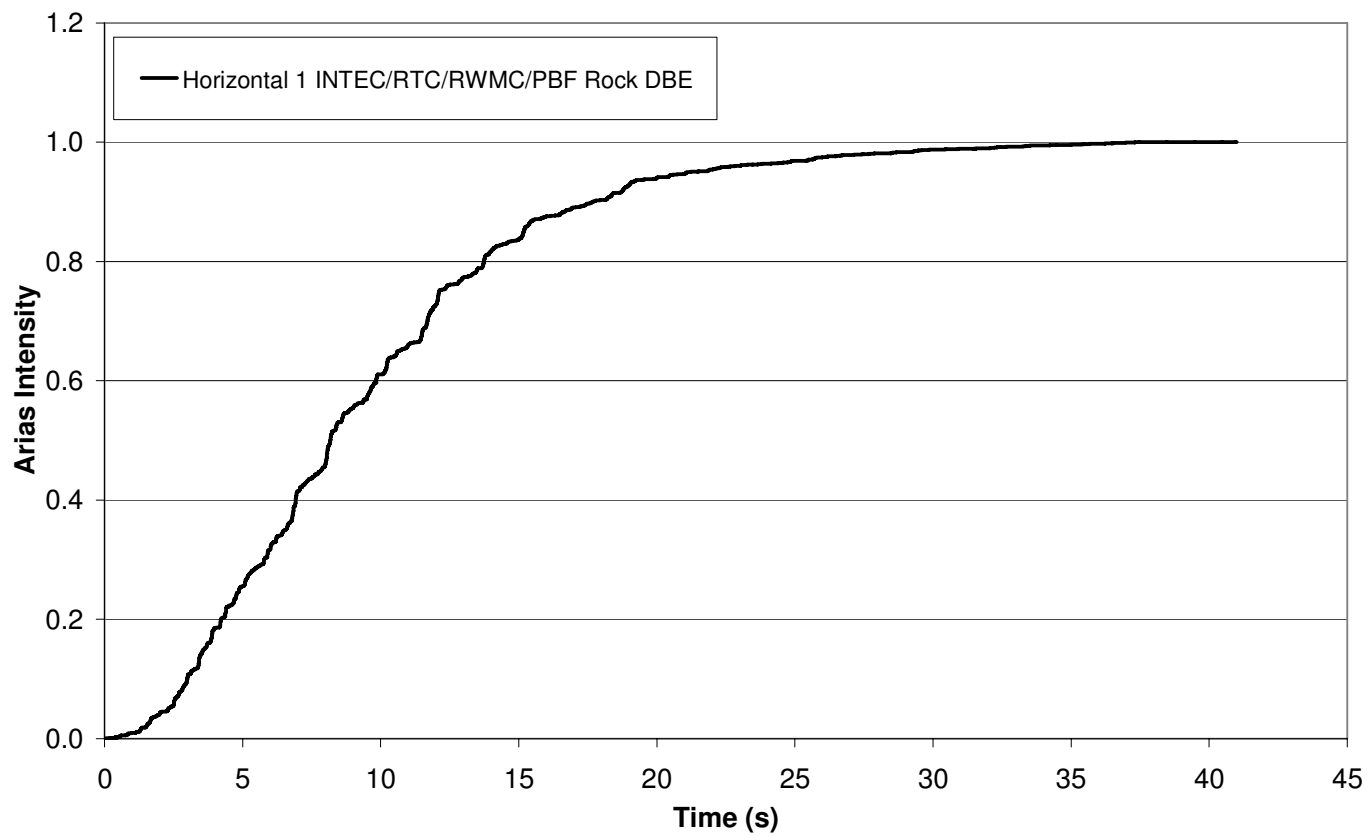

(b)

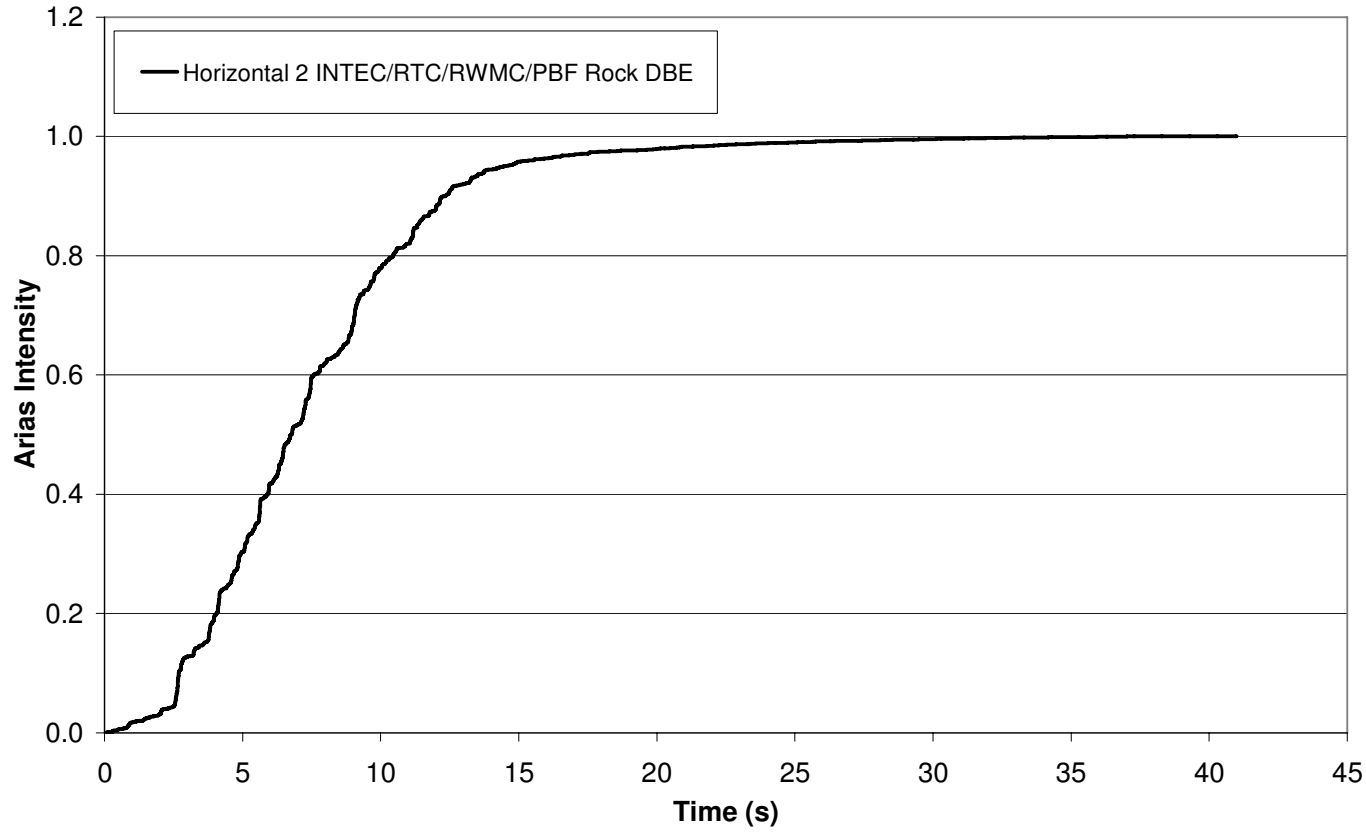

Figure B-4. Arias intensity of the horizontal INTEC/RTC/RWMC/PBF PC 3 (2,500 yr) Rock DBE acceleration time histories for: (a) $\mathrm{H} 1$ and (b) $\mathrm{H} 2$. 


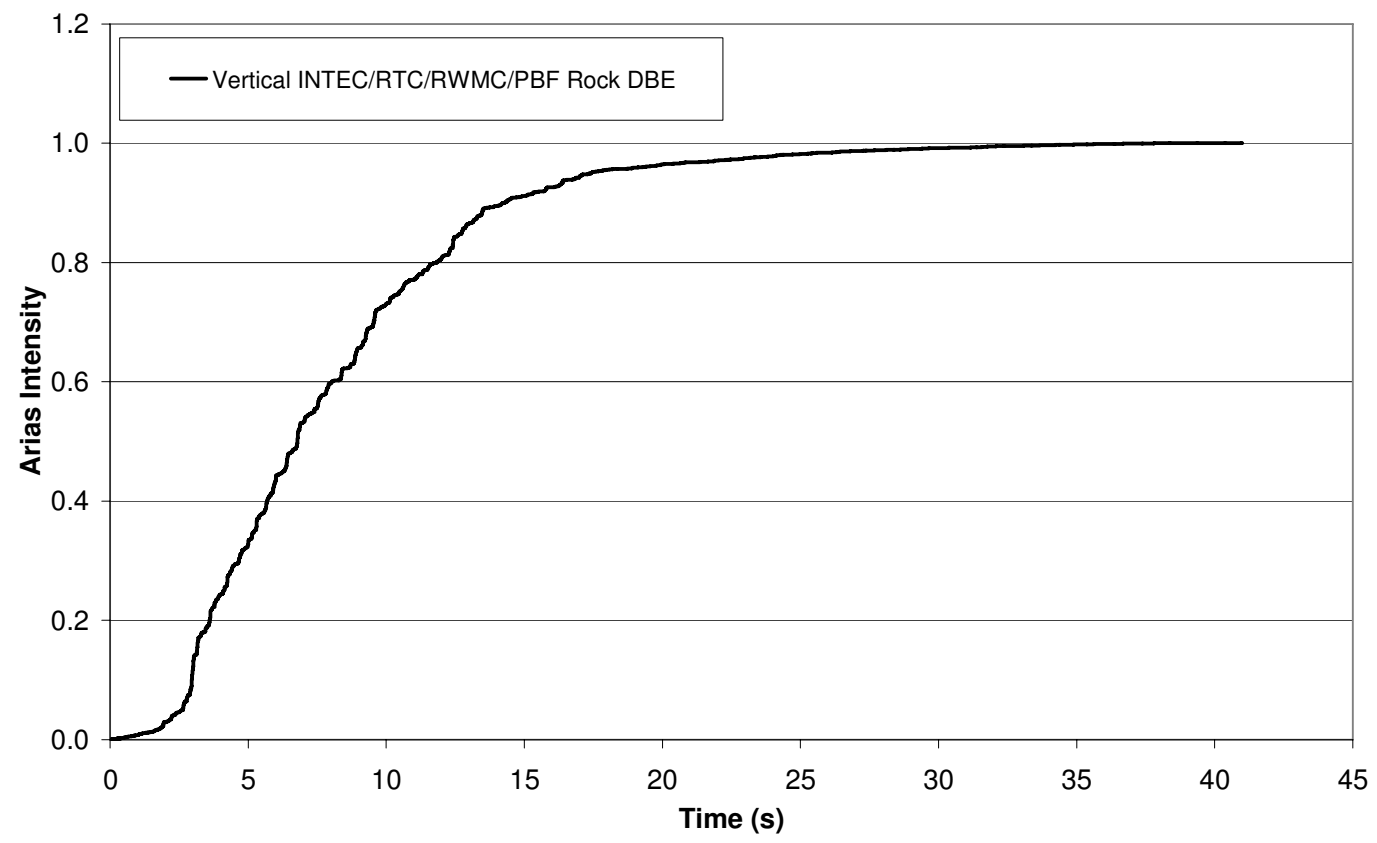

Figure B-5. Arias intensity of the vertical INTEC/RTC/RWMC/PBF PC 3 (2,500 yr) Rock DBE acceleration time history. 
(a)

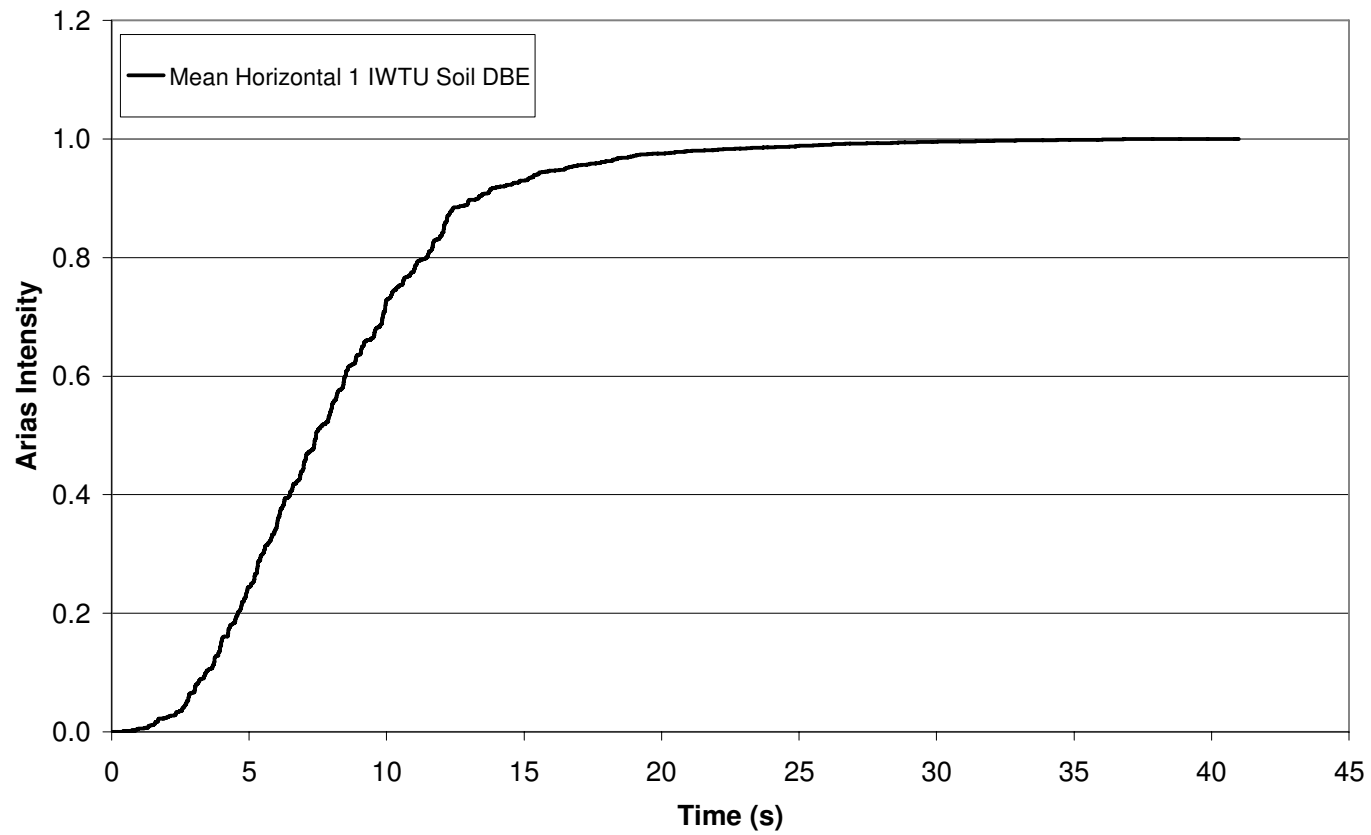

(b)

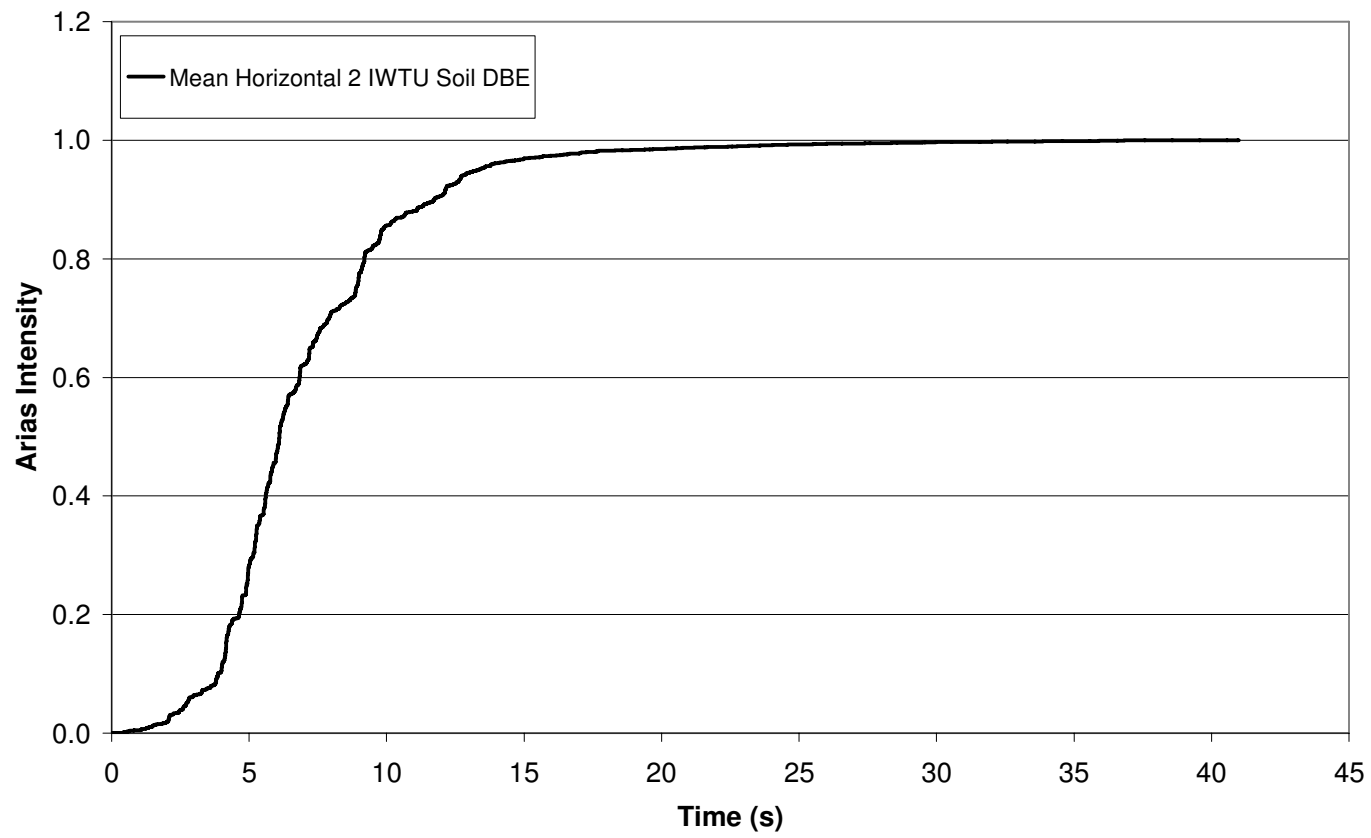

Figure B-6. Arias intensity of the mean horizontal IWTU PC 3 (2,500 yr) Soil DBE acceleration time histories for: (a) H1 and (b) H2. 


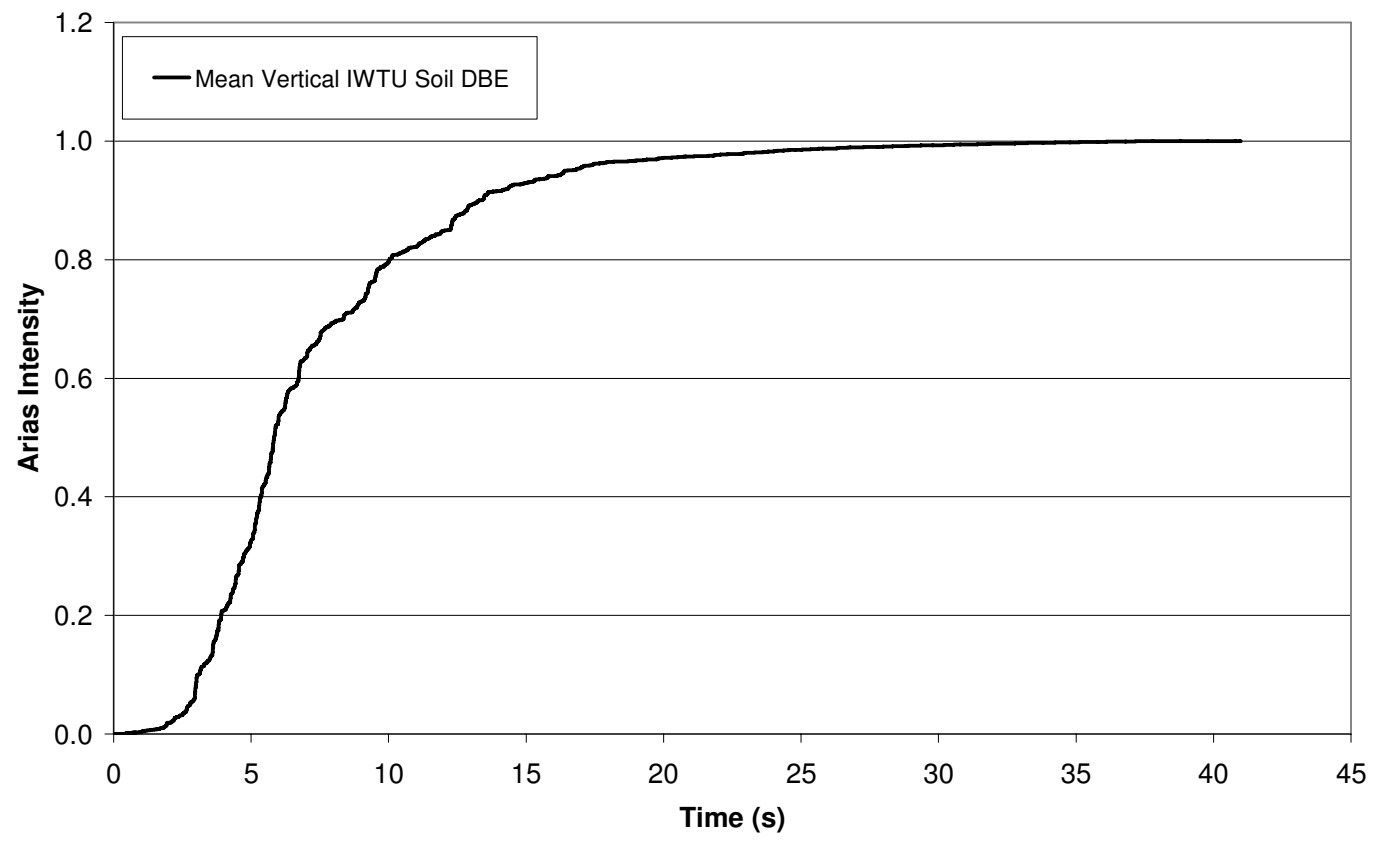

Figure B-7. Arias intensity of the mean vertical IWTU PC 3 (2,500 yr) Soil DBE acceleration time history. 
(a)

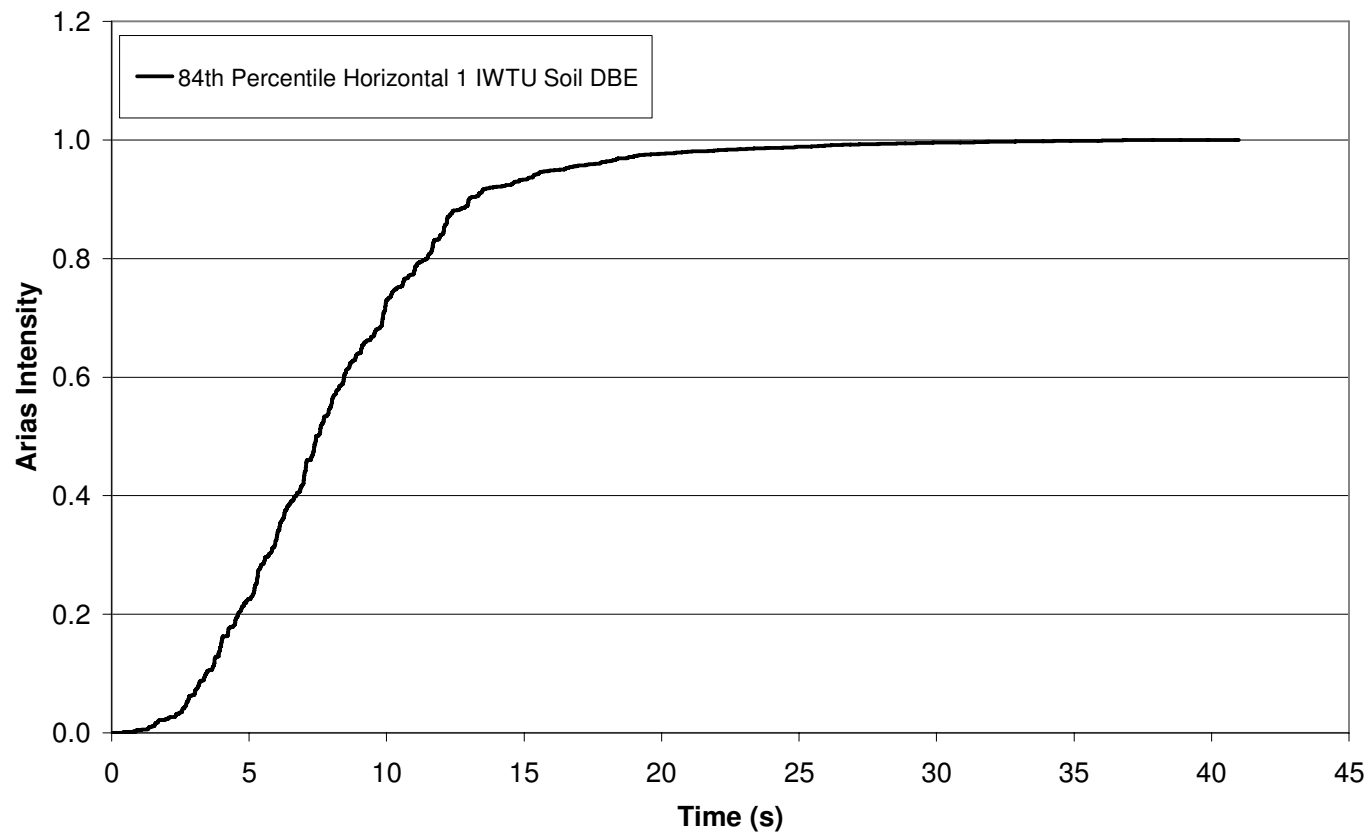

(b)

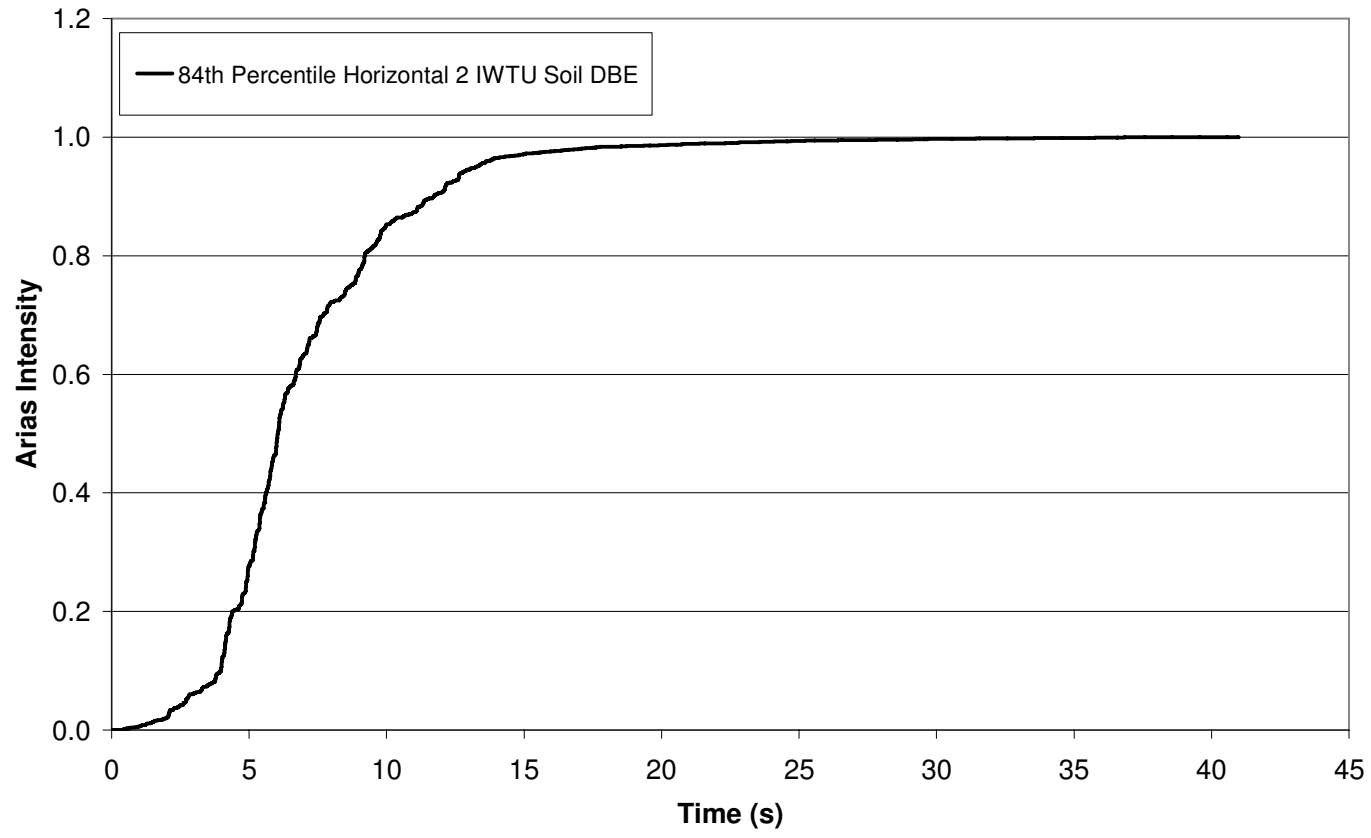

Figure B-8. Arias intensity of the $84^{\text {th }}$ percentile horizontal IWTU PC $3(2,500 \mathrm{yr}) 84^{\text {th }}$ percentile Soil DBE acceleration time histories for: (a) H1 and (b) H2. 


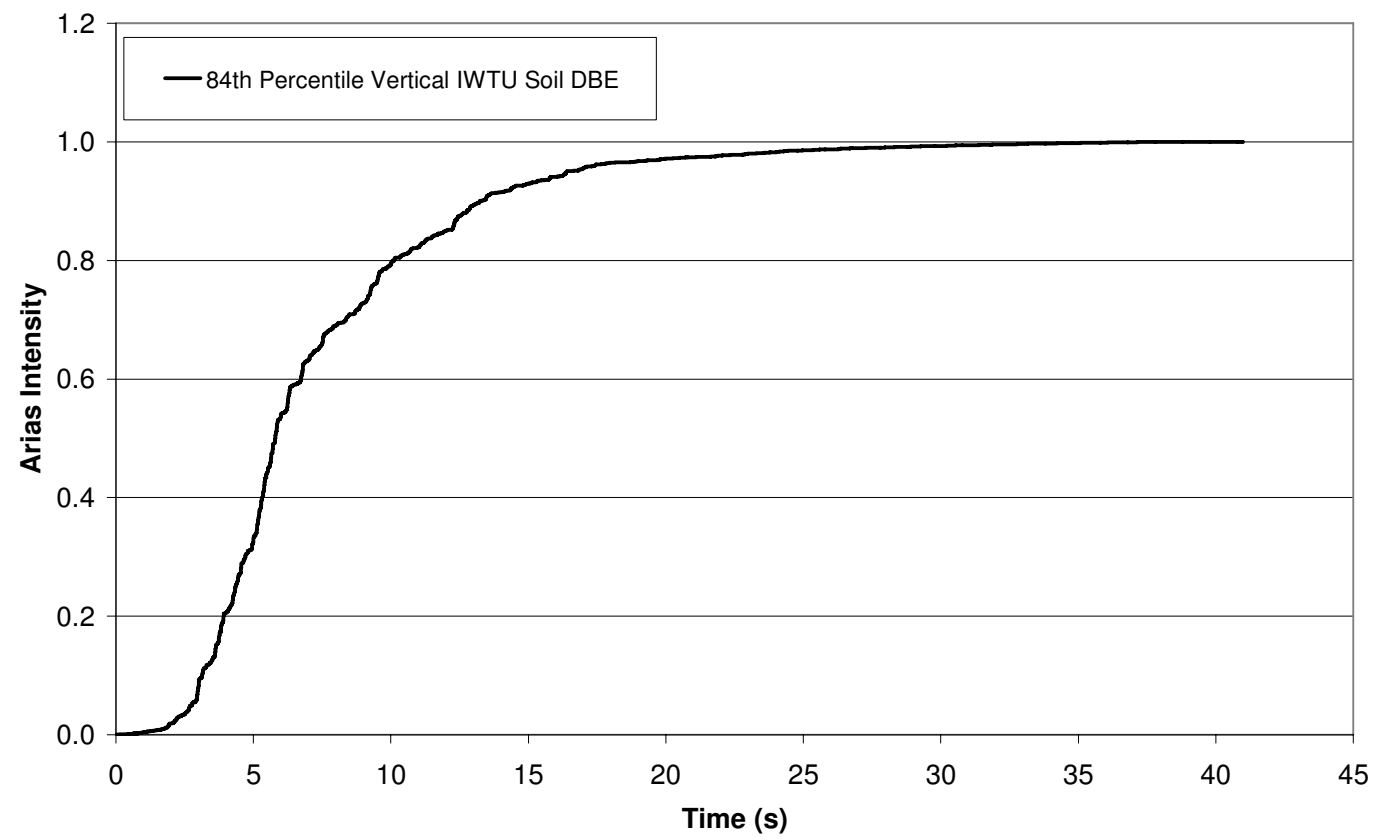

Figure B-9. Arias intensity of the $84^{\text {th }}$ percentile vertical IWTU PC $3(2,500 \mathrm{yr}) 84^{\text {th }}$ percentile Soil DBE acceleration time history. 


\section{Appendix C \\ Sensitivity Analyses}


(Intentionally Blank)

Revision 1 


\section{Appendix C}

\section{Sensitivity Analyses}

Additional site response analyses were performed to evaluate effects to mean spectral peaks resulting from 1) choice of degradation model for the alluvial soils; and 2) amount of variability of G for sets of random soil profiles (soil and rock layers). Results of the site response analyses indicate the amount of variability in $\mathrm{G}$ of the soil profiles has the greater effect on the mean spectral peak levels than degradation models. Degradation models do influence mean spectral peaks for a given set of random soil profiles.

Three additional mean soil surface spectra were generated using the same set of 30 random soil profiles with the log normal distribution of $\mathrm{G}$ and three different degradation models. The set of 30 random soil profiles chosen for these analyses has COVs equivalent to factors of less than 0.32 for the soil $(0.28,0.20,0.17)$ and rock $(0.32)$ layers and is shown in Figure $2 \mathrm{~b}$. This set of 30 random soil profiles and the degradation model "Darendeli/Menq CU 40" (Figures 6 and 7) was used to compute the mean soil spectrum shown in Figure 16 (noted as "Mean - Log Normal Dist. G").

For the additional site response analyses, the following three degradation models (listed with reference names for the plots) were used in SHAKE2000 runs for the alluvial soil layers (Layers A and B):

1. "Darendeli/Menq CU 100" model at soil depths of 10 and $35 \mathrm{ft}$. This set of curves was developed by Pyke (2006) and was recommended for use at IWTU in May 2006. The curves were used in preliminary site response analyses with preliminary soil and rock properties for IWTU performed in advance of the draft report by Kleinfelder, Inc. (2007). The values are listed in Tables C-1 and $\mathrm{C}-2$ and shown in Figures $\mathrm{C}-1$ and C-2.

2. "EPRI (Pyke 2007)" model for alluvial soils at depths of 0-20 ft and 20-50 ft. These curves were developed by Pyke (2007), who computed the curves by extrapolating the Gilroy No. 2 gravel curves (EPRI 1993) from deeper (140 ft) to shallower soil depths $(0-50 \mathrm{ft})$ and adjusting for confining pressure. The values are listed in Tables C-3 and C-4 and shown in Figures C-3 and C-4.

3. "EPRI (Payne 2006)" model for alluvial soils at depths of 0-20 ft and 20-50 ft. These curves are from EPRI (1993) and were used by Payne (2006) in development of the RTC/INTEC PC 3 Soil DBE spectrum. The values are listed in Tables C-5 and C-6 and shown in Figures C-5 and C-6.

The "Darendeli/Menq CU 100" curves were applied in the same manner as the "Darendeli/Menq CU 40" curves. The curves for $10 \mathrm{ft}$ were applied to the thickness range of Layer A (0-13 ft), and the curves for $35 \mathrm{ft}$ to the thickness range of Layer B (13-47 ft). Both sets of "EPRI" curves were applied to Layers A and B based on the depth of the sub-layer for the ranges of 0-20 and 20-50 ft, which is the same approach used by Payne (2006).

An additional four mean soil surface spectra were generated using the same new set of 30 random soil profiles that have higher COVs and the four degradation models. First, the starting soil profile listed in Table C-4 was developed for soil and rock layers that have COVs equivalent to factors of 0.50 . The median $\mathrm{G}$ for each soil and rock layer listed in Table 3 was multiplied by 1.5 to compute each new upper bound $\mathrm{G}$. The upper bound $\mathrm{G}$ of each layer was used with the respective median $\mathrm{G}$ to calculate COV (in $\log$ units) using Equations 2 and 3 listed in Section 2.1.3.3). Second, the starting soil profile in Table C-7 was used as input to the SPRAND program to produce the new set of 30 random soil profiles with a $\log$ 
normal distribution of $\mathrm{G}$ shown in Figure C-7. The new set of 30 random soil profiles with the larger $\mathrm{COV}$ has greater variability is the distribution of $\mathrm{G}$ for the soil and rock layers, which is observed by comparing Figures $2 b$ and C-7.

Horizontal soil response spectra were generated using the SHAKE2000 program and the two horizontal INTEC/RTC/RWMC/PBF PC 3 (2,500 yr) acceleration rock time histories. The set of 30 random soil profiles (Figure 2b) were used as input to SHAKE2000 with each of the three degradation models. Plots of each mean and set of 30 random soil surface spectra for the two horizontal components are shown in Figures C-8, C-9, and C-10. The new set of 30 random soil profiles with the larger COVs were used with each of the degradation models in SHAKE2000 to produce four mean soil surface spectra for each horizontal component and are shown in C-11, C-12, C-13, and C-14.

As discussed in Section 2.2.4, one horizontal mean soil surface spectrum was computed for the H1 and $\mathrm{H} 2$ components using average horizontal spectral amplification factors and the average rock spectrum. Additionally, mean strain and damping profiles as a function of depth were computed from the SHAKE2000 output for all computations. The plots are shown in Figures C-15 through C-22.

The mean soil surface spectra from the seven additional site response analyses were compared to each other and the IWTU SSI spectrum. For these comparisons, the mean soil surface 5\% damped spectrum derived from the set of 30 random soil profiles with the log normal distribution of G (Figure $2 \mathrm{~b}$ ) and using "Darendeli/Menq CU 40" was chosen as the "standard" mean spectrum (shown in Figure 16 as "Mean - Log Normal Dist. G"). Comparisons are first made between the mean soil surface spectra for the same set of soil profiles that have COVs less than 0.32 (Figure 2b) and the four different degradation models (which includes the "Standard" spectrum). Comparisons are then made between the mean soil spectra computed using the four degradation models and the two sets of soil profiles with different COVs.

The mean spectral peaks of the three degradation models with soil profiles that have COVs equivalent to factors less than 0.32 (Figure $2 b$ ) and the "Standard" spectrum are within $16 \%$ of each other (Figure C-23). The mean spectral peaks are 12 to 30\% higher than the IWTU SSI spectrum and the largest exceedance is for the mean spectral peak of the "Standard" spectrum (Table C-8). The mean spectral peak with the lowest exceedance is "Darendeli/Menq CU 100" (Figure C-23). This comparison shows that the use of "Darendeli/Menq CU 40" degradation model with the set of 30 random soil profiles in Figure 2b resulted in the highest mean spectral peak relative to the other degradation models.

Use of the "Darendeli/Menq CU 100" degradation model with the soil profiles in Figure 2b resulted in the lowest mean spectral peaks. For this degradation model, the individual spectral peaks are spread over a wider range of frequency relative to the other site response analyses. The mean spectral peaks for "Darendeli/Menq CU 100" range from 3.5 to $7.2 \mathrm{~Hz}$ (Figure C-8) whereas the mean spectral peaks for the individual spectra with the other three degradation models range from 5.2 to $8 \mathrm{~Hz}$, with the majority at 7.2 Hz (Figures 10, C-9, and C-10). Use of the "Darendeli/Menq CU 100" degradation model causes a shift toward lower frequencies due to changes in G (or Vs) of the soil layers more different from those of the other degradation models used. There is a slight shift in frequency from 7.2 to $7.9 \mathrm{~Hz}$ (Table C-8) for the "EPRI (Payne 2006)" mean spectral peak. The "EPRI (Payne 2006)" mean spectral peak is lower than the "Standard" spectral peak, but not as low as the "Darendeli/Menq CU 100" mean spectral peak. Since the mean soil spectrum is calculated using spectral accelerations as a function of frequency, shifts in any of the 30 individual spectral peaks from $7.2 \mathrm{~Hz}$ to other frequencies will result in the decrease of the mean spectral peak.

For site response analyses using the "Darendeli/Menq CU 40" curves, the "Standard" spectrum (COVs less than equivalent factors of 0.32) and the mean soil spectrum for soil profiles that have COVs equivalent to factors of 0.50 (Figure C-7) are within 17\% of each other (Figure C-24). Both spectra 
exceed the IWTU SSI spectrum, the "Standard" spectrum by $30 \%$ and the other by $11 \%$ (Table C-8). This comparison indicates that the lower mean spectral peak resulted from having greater variability of $\mathrm{G}$ in the soil profiles when combined with the "Darendeli/Menq CU 40" degradation model. The lower mean spectral peak for the larger COVs equivalent to factors of 0.50 is the result of the wider range of frequencies for the individual spectral peaks from 2.5 to $8.5 \mathrm{~Hz}$ (Figure $\mathrm{C}-11$ ).

The mean spectral peaks of the four degradation models with soil profiles that have the COVs equivalent to the factors of 0.50 are within $30 \%$ of each other (Figure C-25). This percentage is about twice the percentage for the differences of the mean spectral peaks using the four degradation models and the soil profiles that have COVs equivalent to the factors of less than 0.32. Additionally, three of the mean spectral peaks shown in Figure C-24 exceed the IWTU SSI spectrum by up to $20 \%$, whereas the mean soil spectrum for "Darendeli/Menq CU 100" is $11 \%$ less. The results of these comparisons emphasize the importance of amount of variability of $\mathrm{G}$ in sets of random soil profiles. For each site response analysis using the COVs equivalent to factors of 0.50 , the mean soil spectrum is calculated using individual spectral peaks that occur at wide frequencies ranges from 3 to $11 \mathrm{~Hz}$ (Figures C-11, C-12, C13, and C-14). As observed previously, the widest range of individual spectral peak frequencies results from using "Darendeli/Menq CU 100” (Figure C-12).

Overall, the results of these comparisons indicate that the choice of degradation model ("Darendeli/Menq CU 40") combined with the site-specific variability of G (smaller COVs $<0.32$ for soil and rock layers) at IWTU results in higher mean spectral peaks than those computed by Payne (2006). The primary reason are the different COVs used to produce the random soil profiles in each analysis. The COVs for the Payne (2006; Appendix Table A-1) are equivalent to factors of 0.74 (Upper Alluvial Soil), 0.50 (Lower Alluvial Soil), 0.60 (Clay), and 0.74 (Rock), which is much greater than those used for the IWTU site response analyses. Use of the "Darendeli/Menq CU 40" degradation model with the set of 30 random soil profiles generated from the COVs equivalent to factors less than 0.32 also results in higher spectral peaks than those for the other degradation models (Figure C-23). 
Table C-1. "Darendeli/Menq CU 100" shear modulus (G) reduction and damping curves for alluvial soils at $10 \mathrm{ft}$ depth (Pyke 2006).

\begin{tabular}{cccc}
\hline Log $($ Shear Strain $-\%)$ & G/Gmax & Log $($ Shear Strain $-\%)$ & Damping Ratio $(\%)$ \\
\hline-4.00 & 0.97 & -4.00 & 0.4 \\
-3.70 & 0.95 & -3.70 & 0.6 \\
-3.52 & 0.93 & -3.52 & 0.7 \\
-3.30 & 0.90 & -3.30 & 1.1 \\
-3.00 & 0.83 & -3.00 & 1.9 \\
-2.70 & 0.73 & -2.70 & 3.4 \\
-2.52 & 0.66 & -2.52 & 4.5 \\
-2.30 & 0.56 & -2.30 & 6.3 \\
-2.00 & 0.42 & -2.00 & 9.1 \\
-1.70 & 0.29 & -1.70 & 11.9 \\
-1.52 & 0.22 & -1.52 & 13.3 \\
-1.30 & 0.16 & -1.30 & 14.8 \\
-1.00 & 0.09 & -1.00 & 16.3 \\
-0.70 & 0.05 & -0.70 & 17.2 \\
-0.52 & 0.04 & -0.52 & 17.5 \\
-0.30 & 0.03 & -0.30 & 17.6 \\
-0.15 & 0.02 & -0.15 & 17.5 \\
0.00 & 0.01 & 0.00 & 17.4 \\
\hline & & &
\end{tabular}


Table C-2. "Darendeli/Menq CU 100" shear modulus (G) reduction and damping curves for alluvial soils at $35 \mathrm{ft}$ depth (Pyke 2006).

\begin{tabular}{cccc}
\hline Log $($ Shear Strain $-\%)$ & G/Gmax & Log $($ Shear Strain $-\%)$ & Damping Ratio $(\%)$ \\
\hline-4.00 & 0.98 & -4.00 & 0.3 \\
-3.70 & 0.97 & -3.70 & 0.4 \\
-3.52 & 0.96 & -3.52 & 0.5 \\
-3.30 & 0.93 & -3.30 & 0.8 \\
-3.00 & 0.88 & -3.00 & 1.5 \\
-2.70 & 0.80 & -2.70 & 2.6 \\
-2.52 & 0.73 & -2.52 & 3.6 \\
-2.30 & 0.63 & -2.30 & 5.3 \\
-2.00 & 0.48 & -2.00 & 8.2 \\
-1.70 & 0.33 & -1.70 & 11.4 \\
-1.52 & 0.26 & -1.52 & 13.2 \\
-1.30 & 0.18 & -1.30 & 15.3 \\
-1.00 & 0.11 & -1.00 & 17.4 \\
-0.70 & 0.06 & -0.70 & 18.8 \\
-0.52 & 0.04 & -0.52 & 19.2 \\
-0.30 & 0.03 & -0.30 & 19.4 \\
-0.15 & 0.02 & -0.15 & 19.4 \\
0.00 & 0.01 & 0.00 & 19.2 \\
\hline & & &
\end{tabular}


Table C-3. "EPRI (Pyke 2007)" shear modulus (G) reduction and damping curves for alluvial soils from 0 to $20 \mathrm{ft}$ depth.

\begin{tabular}{|c|c|c|c|}
\hline Log (Shear Strain - \%) & $\mathrm{G} / \mathrm{Gmax}$ & Log (Shear Strain - \%) & Damping Ratio (\%) \\
\hline-4.00 & 1.00 & -4.00 & 1.0 \\
\hline-3.70 & 0.99 & -3.70 & 1.1 \\
\hline-3.52 & 0.97 & -3.52 & 1.3 \\
\hline-3.30 & 0.95 & -3.30 & 1.5 \\
\hline-3.00 & 0.90 & -3.00 & 2.1 \\
\hline-2.70 & 0.82 & -2.70 & 3.1 \\
\hline-2.52 & 0.75 & -2.52 & 4.0 \\
\hline-2.30 & 0.65 & -2.30 & 5.4 \\
\hline-2.00 & 0.51 & -2.00 & 8.1 \\
\hline-1.70 & 0.36 & -1.70 & 11.4 \\
\hline-1.52 & 0.28 & -1.52 & 13.7 \\
\hline-1.30 & 0.20 & -1.30 & 15.0 \\
\hline-1.00 & 0.12 & -1.00 & 15.0 \\
\hline-0.70 & 0.07 & -0.70 & 15.0 \\
\hline-0.52 & 0.05 & -0.52 & 15.0 \\
\hline-0.30 & 0.03 & -0.30 & 15.0 \\
\hline-0.15 & 0.02 & -0.15 & 15.0 \\
\hline 0.00 & 0.01 & 0.00 & 15.0 \\
\hline
\end{tabular}


Table C-4. "EPRI (Pyke 2007)" shear modulus (G) reduction and damping curves for alluvial soils from 20 to $50 \mathrm{ft}$ depth.

\begin{tabular}{|c|c|c|c|}
\hline Log (Shear Strain - \%) & G/Gmax & Log (Shear Strain - \%) & Damping Ratio (\%) \\
\hline-4.00 & 1.00 & -4.00 & 1.0 \\
\hline-3.70 & 0.99 & -3.70 & 1.0 \\
\hline-3.52 & 0.98 & -3.52 & 1.1 \\
\hline-3.30 & 0.97 & -3.30 & 1.3 \\
\hline-3.00 & 0.94 & -3.00 & 1.7 \\
\hline-2.70 & 0.88 & -2.70 & 2.3 \\
\hline-2.52 & 0.83 & -2.52 & 2.9 \\
\hline-2.30 & 0.75 & -2.30 & 4.0 \\
\hline-2.00 & 0.61 & -2.00 & 6.0 \\
\hline-1.70 & 0.46 & -1.70 & 8.9 \\
\hline-1.52 & 0.38 & -1.52 & 10.9 \\
\hline-1.30 & 0.28 & -1.30 & 13.7 \\
\hline-1.00 & 0.18 & -1.00 & 15.0 \\
\hline-0.70 & 0.10 & -0.70 & 15.0 \\
\hline-0.52 & 0.07 & -0.52 & 15.0 \\
\hline-0.30 & 0.05 & -0.30 & 15.0 \\
\hline-0.15 & 0.03 & -0.15 & 15.0 \\
\hline 0.00 & 0.02 & 0.00 & 15.0 \\
\hline
\end{tabular}


Table C-5. "EPRI (Payne 2006)" shear modulus (G) reduction and damping curves for alluvial soils from 0 to $20 \mathrm{ft}$ depth (EPRI 1993).

\begin{tabular}{|c|c|c|c|}
\hline Log (Shear Strain - \%) & G/Gmax & Log (Shear Strain - \%) & Damping Ratio (\%) \\
\hline-4.00 & 1.00 & -4.00 & 1.4 \\
\hline-3.50 & 1.00 & -3.50 & 1.4 \\
\hline-3.00 & 0.98 & -3.00 & 1.8 \\
\hline-2.50 & 0.90 & -2.50 & 2.8 \\
\hline-2.00 & 0.73 & -2.00 & 5.1 \\
\hline-1.50 & 0.49 & -1.50 & 9.4 \\
\hline-1.00 & 0.27 & -1.00 & 15.5 \\
\hline-0.50 & 0.11 & -0.50 & 22.3 \\
\hline 0.00 & 0.04 & 0.00 & 27.6 \\
\hline
\end{tabular}

Table C-6. "EPRI (Payne 2006)" shear modulus (G) reduction and damping curves for alluvial soils from 20 to $50 \mathrm{ft}$ depth (EPRI 1993).

\begin{tabular}{|c|c|c|c|}
\hline Log (Shear Strain - \%) & G/Gmax & Log (Shear Strain - \%) & Damping Ratio (\%) \\
\hline-4.00 & 1.00 & -4.00 & 1.3 \\
\hline-3.50 & 1.00 & -3.50 & 1.3 \\
\hline-3.00 & 0.99 & -3.00 & 1.4 \\
\hline-2.50 & 0.94 & -2.50 & 2.0 \\
\hline-2.00 & 0.82 & -2.00 & 3.7 \\
\hline-1.50 & 0.59 & -1.50 & 7.1 \\
\hline-1.00 & 0.36 & -1.00 & 12.6 \\
\hline-0.50 & 0.16 & -0.50 & 19.4 \\
\hline 0.00 & 0.07 & 0.00 & 24.9 \\
\hline
\end{tabular}


Table C-7. Properties of the IWTU three-layer starting soil profile for the log normal distribution of shear modulus $(\mathrm{G})$ with COV equivalent to the factor of 0.5 .

\begin{tabular}{|c|c|c|c|c|c|c|}
\hline Layer & $\begin{array}{l}\text { Thickness } \\
\text { Range (ft) }\end{array}$ & $\begin{array}{c}\text { Average } \\
\text { Density (kcf) }\end{array}$ & $\begin{array}{l}\text { Median G } \\
\text { (ksf) }^{b}\end{array}$ & $\begin{array}{l}\text { Median Vs } \\
(\mathrm{ft} / \mathrm{s})^{\mathrm{c}}\end{array}$ & $\begin{array}{l}\text { Coefficient of } \\
\text { Variation - COV } \\
\quad{ }^{\mathrm{d}}(\log 10)\end{array}$ & $\begin{array}{l}\text { Equivalent } \\
\text { Factor }\end{array}$ \\
\hline A & 9 to 13 & 0.1184 & 2070 & 750 & 0.053 & 0.50 \\
\hline B & 25 to 29 & 0.1248 & 9197 & 1540 & 0.044 & 0.50 \\
\hline $\mathrm{C}$ & 2 to $10^{\mathrm{e}}$ & 0.1257 & 9387 & 1550 & 0.044 & 0.50 \\
\hline $\mathrm{D}$ & Half-space & 0.1599 & 83115 & 4089 & 0.036 & 0.50 \\
\hline \multicolumn{7}{|c|}{$\begin{array}{l}\text { a. Average densities from (Kleinfelder, Inc. } 2007 \mathrm{a} ; 2007 \mathrm{~b} \text { ). Units are kcf }-\mathrm{kips} / \mathrm{ft}^{3} ; \mathrm{ksf}-\mathrm{kips} / \mathrm{ft}^{2} ; \mathrm{kips}-1000 \\
\text { b. } \mathrm{G}_{\mathrm{M}} \text { calculated by: 1) converting borehole Vs measurements to } \mathrm{G} \text { using average density; and 2) performing } \\
\text { statistical calculations using } \log _{10} \mathrm{G} \text { data. }\end{array}$} \\
\hline $\begin{array}{l}\text { c. Mediar } \\
\text { d. COV v } \\
\text { e. Thickn }\end{array}$ & $\begin{array}{l}\text { s calculated by } \\
\text { calculated usi } \\
\text { range exceed }\end{array}$ & $\begin{array}{l}\text { converting } \mathrm{G}_{\mathrm{M}} \text { usi } \\
\mathrm{g} \log _{10} \mathrm{G} \text { data. } \\
\text { maximum layer th }\end{array}$ & average dens & count for so & column height range. & \\
\hline
\end{tabular}


Table C-8. Spectral peak accelerations of mean soil surface spectra and difference from IWTU SSI Spectrum.

\begin{tabular}{|c|c|c|c|}
\hline \multirow{2}{*}{ Surface Spectrum Name } & \multicolumn{2}{|c|}{ Spectral Peak } & Difference from IWTU SSI \\
\hline & $\begin{array}{l}\text { Acceleration } \\
(\mathrm{g})\end{array}$ & $\begin{array}{l}\text { Frequency } \\
(\mathrm{Hz})\end{array}$ & $\begin{array}{c}\text { Constant Spectral Acceleration } \\
\text { Level }(\%)\end{array}$ \\
\hline
\end{tabular}

Set of 30 Random Soil Profiles $(\mathrm{COV}<0.32)$ in Figure $2 b$

"Standard" (Darendeli/Menq CU 40) $\quad 1.0892 \quad 30$

$\begin{array}{llll}\text { "Darendeli/Menq CU 100" } & 0.9403 & 7.180 & 12\end{array}$

$\begin{array}{llll}\text { "EPRI (Pyke 2007)" } & 1.0552 & 7.180 & 25\end{array}$

$\begin{array}{llll}\text { "EPRI (Payne 2006)" } & 0.9923 & 7.930 & 18\end{array}$

Set of 30 Random Soil Profiles (COV 0.5) in Figure C-7

$\begin{array}{llll}\text { “Darendeli/Menq CU 40” } & 0.9296 & 7.180 & 11\end{array}$

$\begin{array}{llll}\text { “Darendeli/Menq CU 100" } & 0.7733 & 7.180 & -8\end{array}$

$\begin{array}{llll}\text { "EPRI (Pyke 2007)" } & 0.9033 & 7.180 & 7\end{array}$

$\begin{array}{llll}\text { "EPRI (Payne 2006)" } & 1.0072 & 7.180 & 20\end{array}$

a. Negative indicates the spectral peak acceleration is less than the IWTU SSI constant spectral acceleration. 
(a)
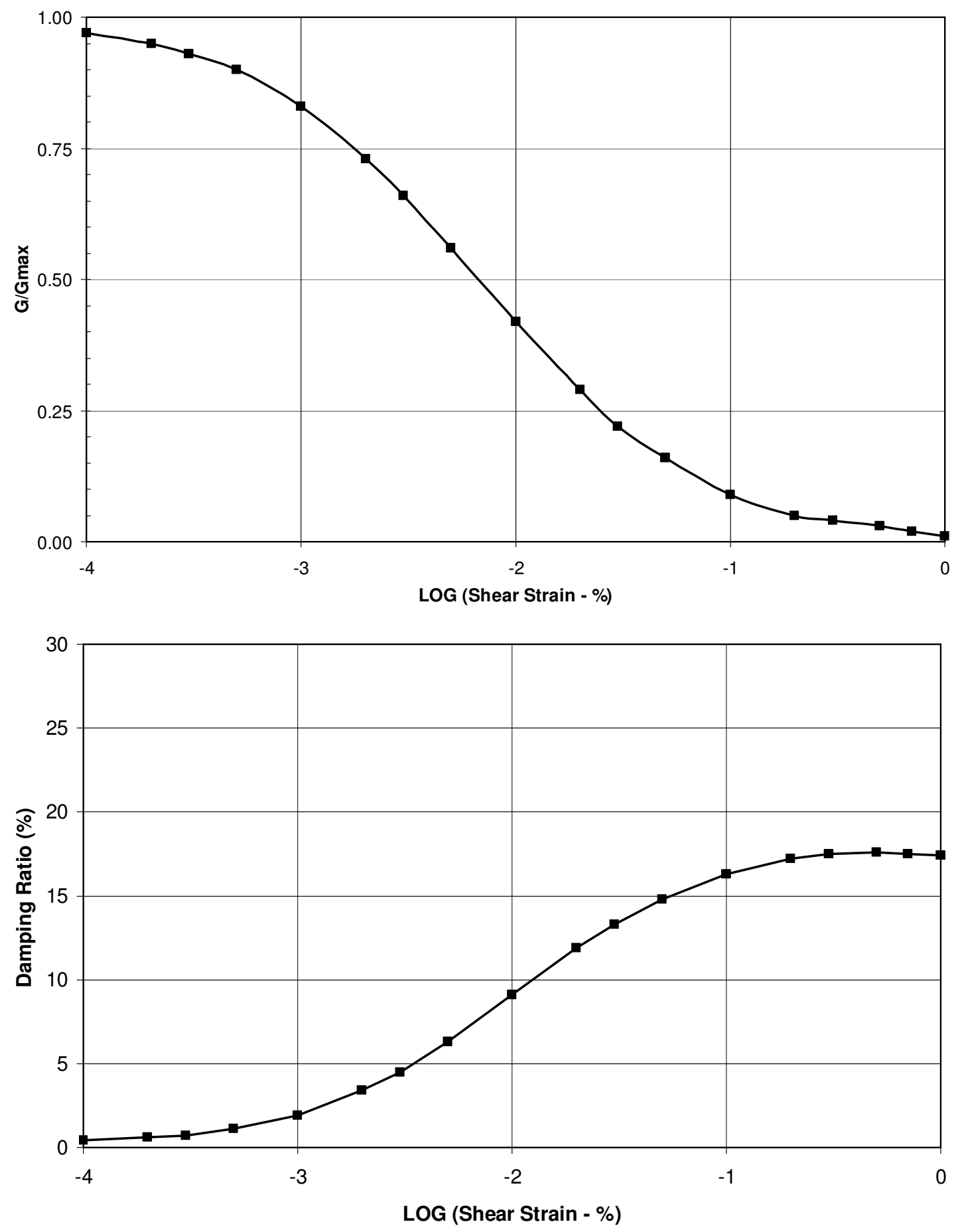

Figure C-1. "Darendeli/Menq CU 100" at $10 \mathrm{ft}$ depth (Pyke 2006): (a) shear modulus (G) reduction; and (b) damping curves. 
(a)

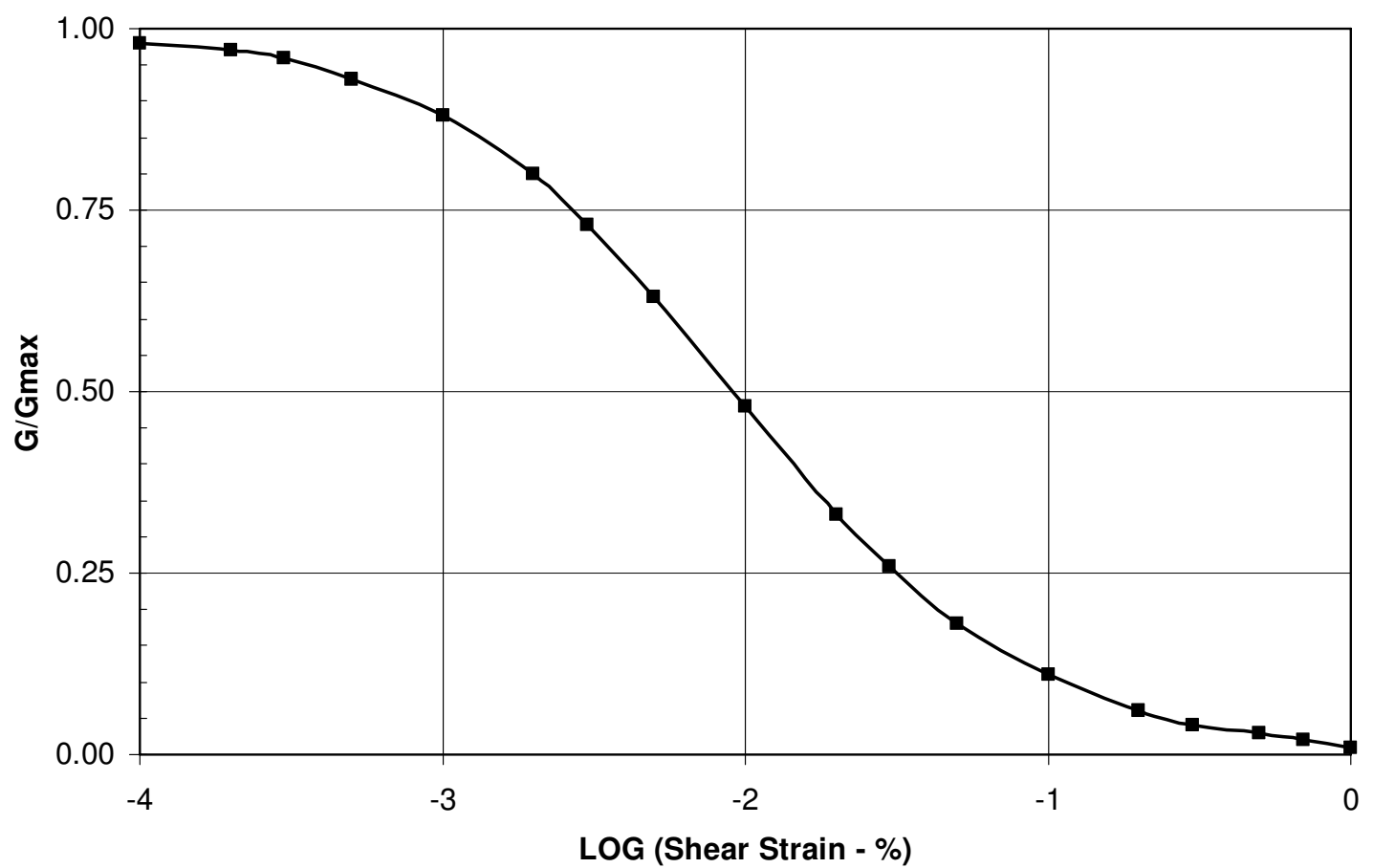

(b)

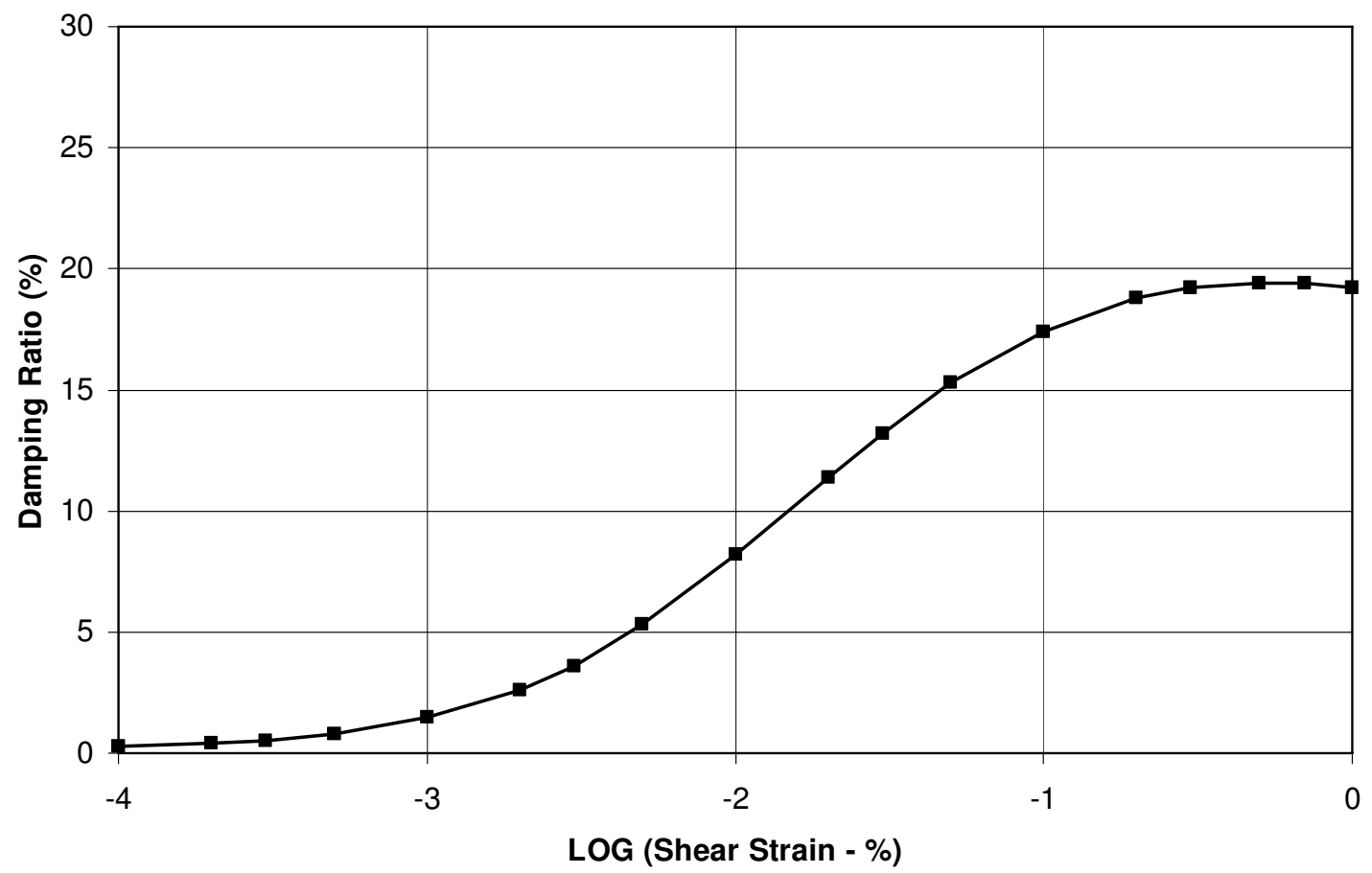

Figure C-2. "Darendeli/Menq CU 100" at $35 \mathrm{ft}$ depth (Pyke 2006): (a) shear modulus (G) reduction; and (b) damping curves. 
(a)

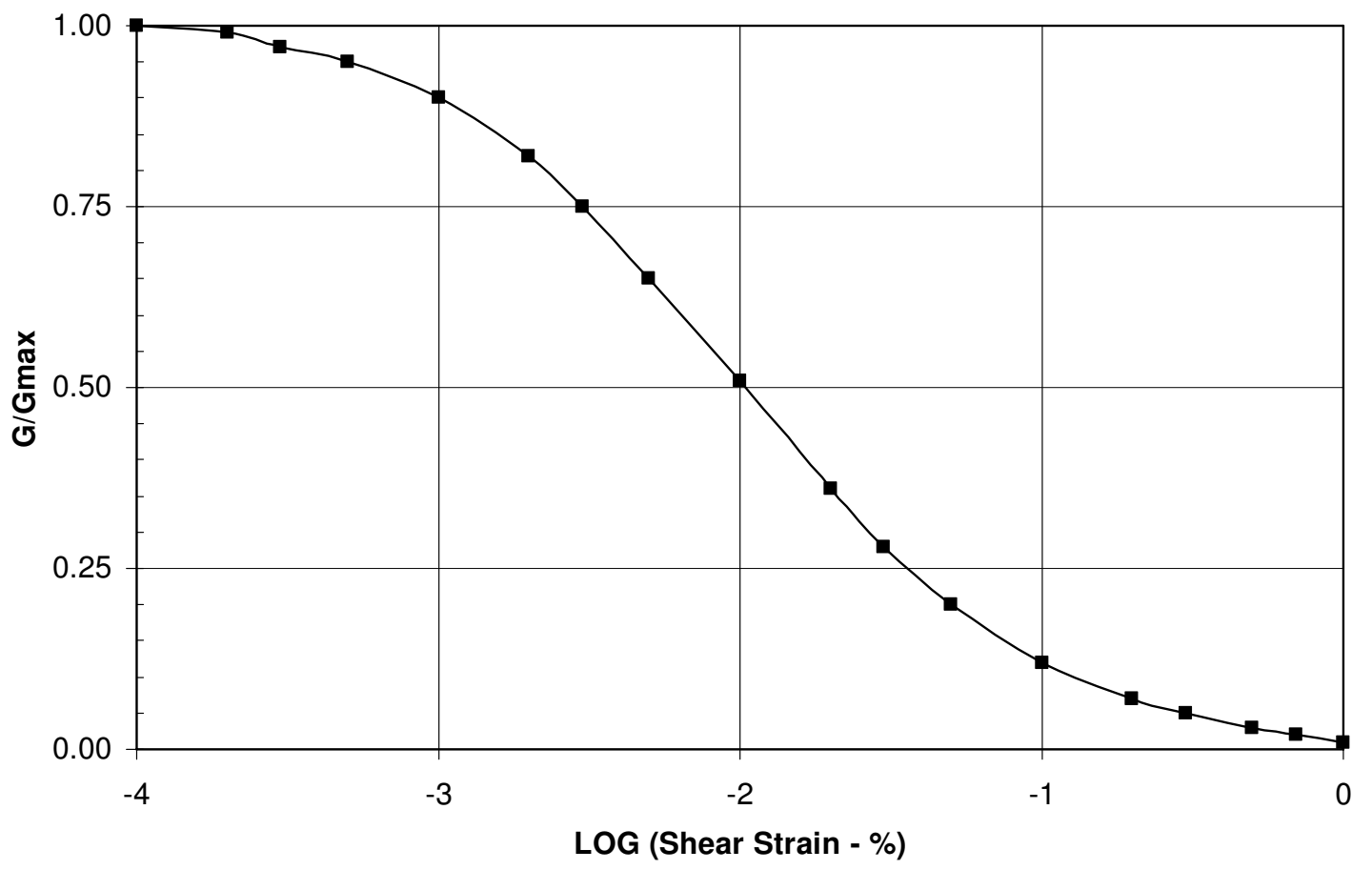

(b)

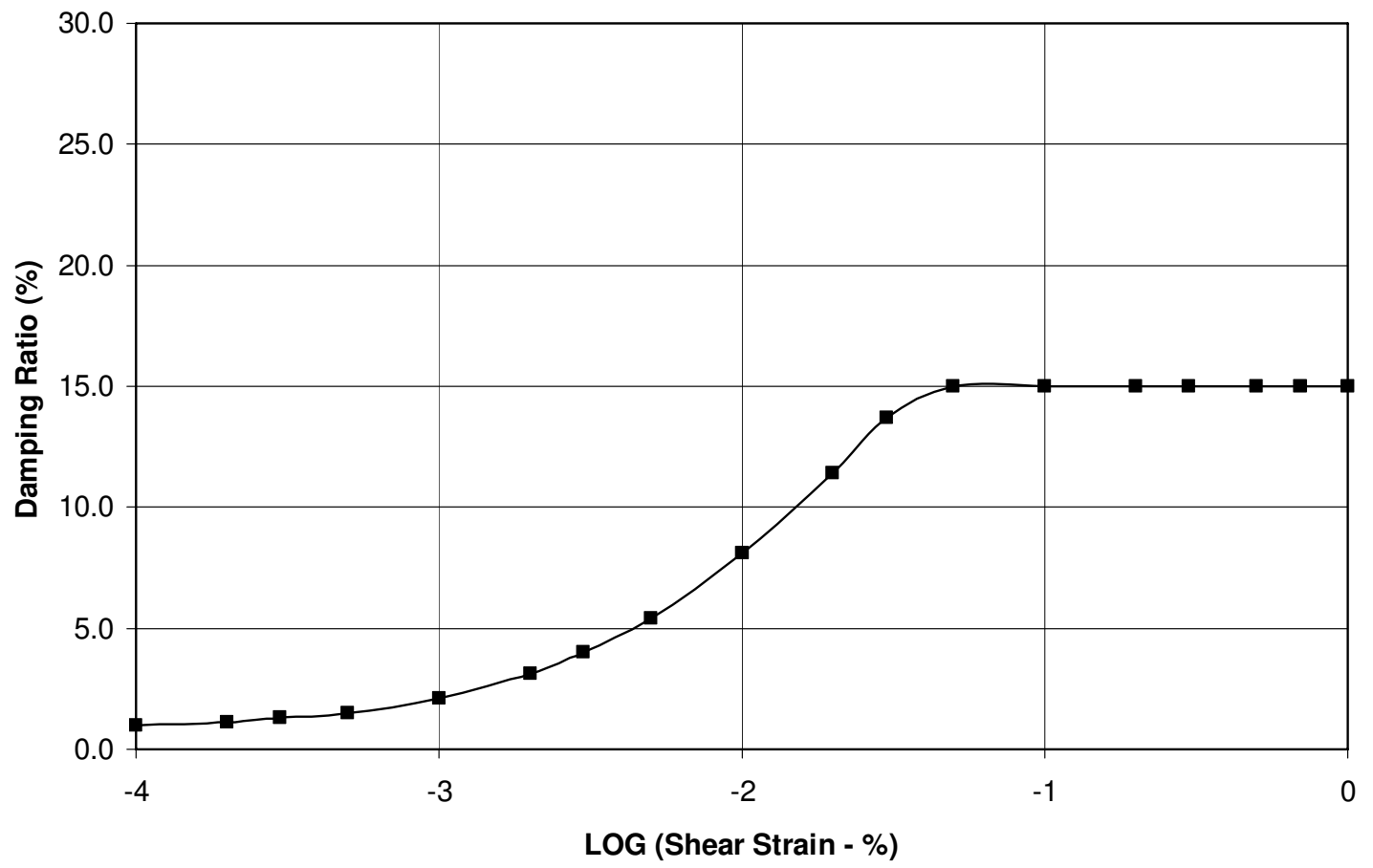

Figure C-3. "EPRI (Pyke 2007)" 0-20 ft depth range: (a) shear modulus (G) reduction; and (b) damping curves. 
(a)
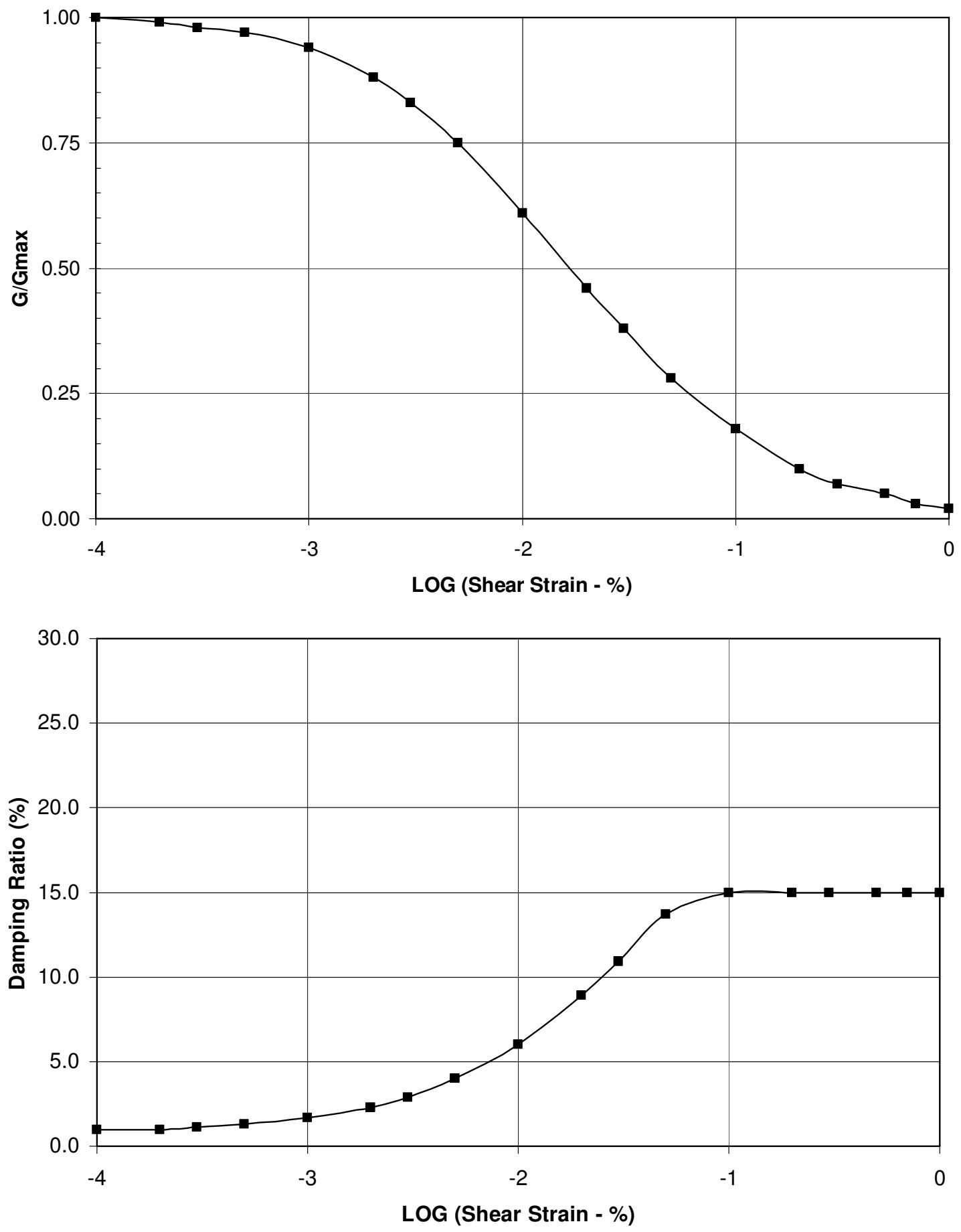

Figure C-4. "EPRI (Pyke 2007)" 20-50 ft depth range: (a) shear modulus (G) reduction; and (b) damping curves. 
(a)

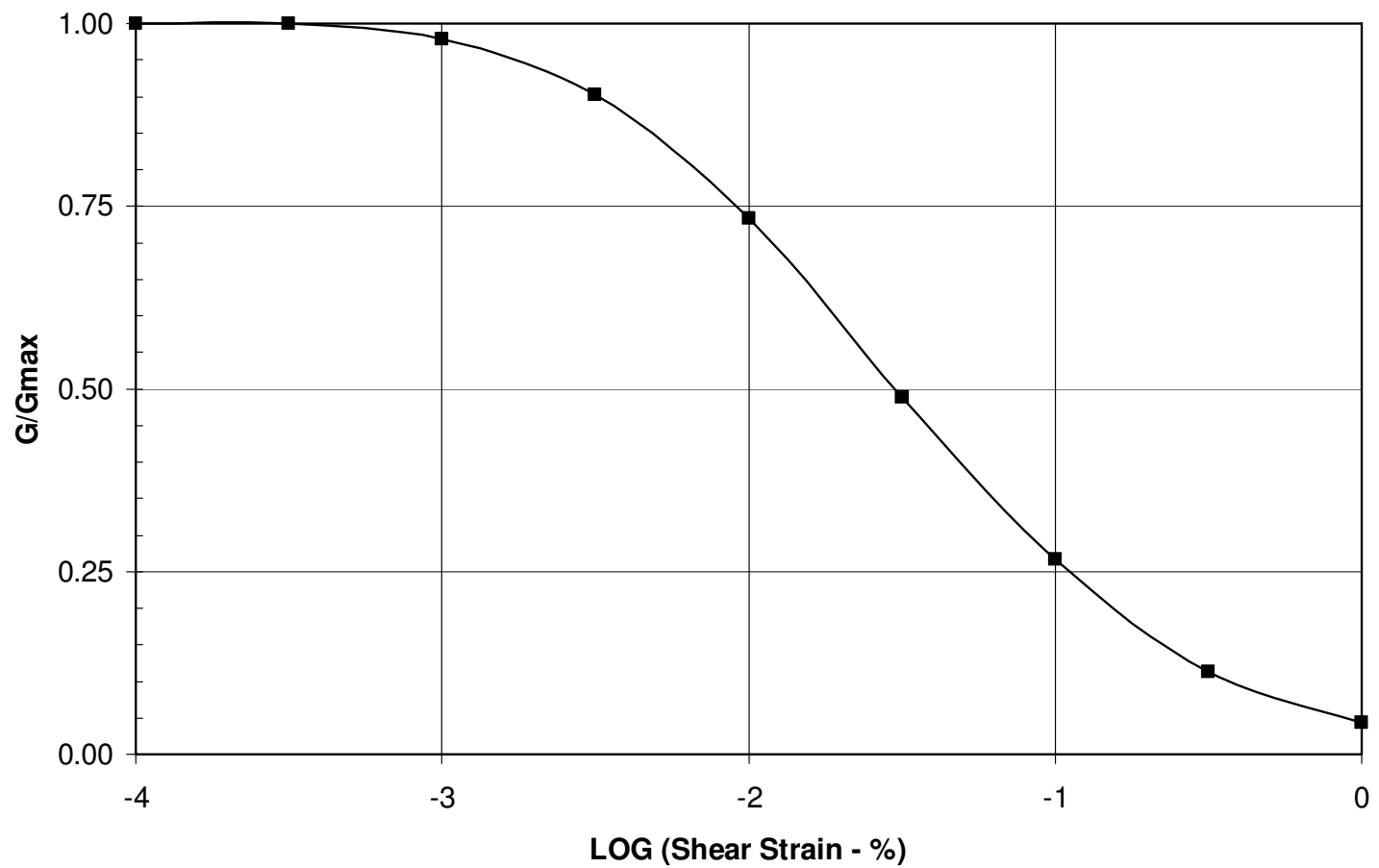

(b)

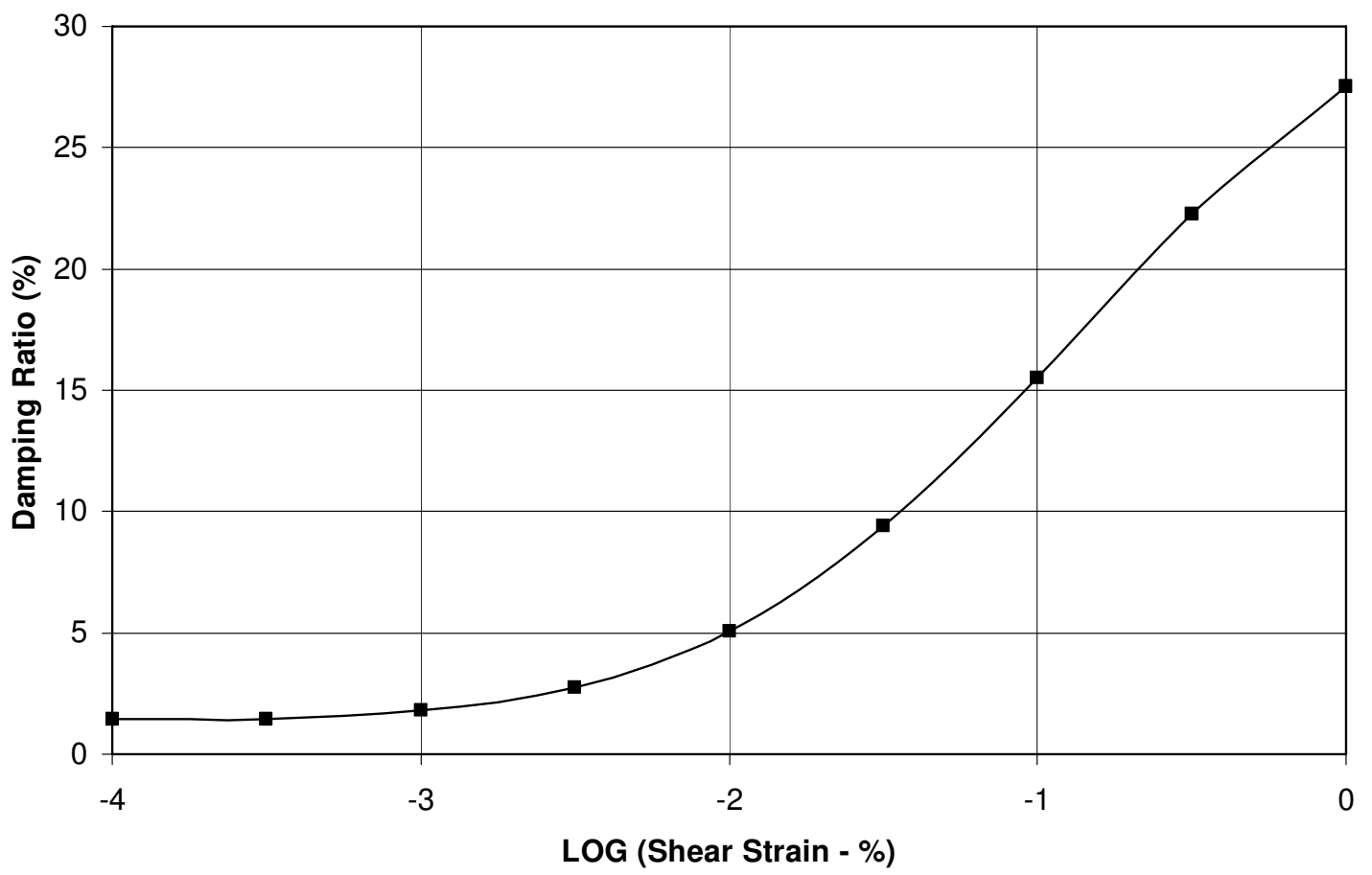

Figure C-5. "EPRI (Payne 2006)" 0-20 ft depth range: (a) shear modulus (G) reduction; and (b) damping curves. 
(a)

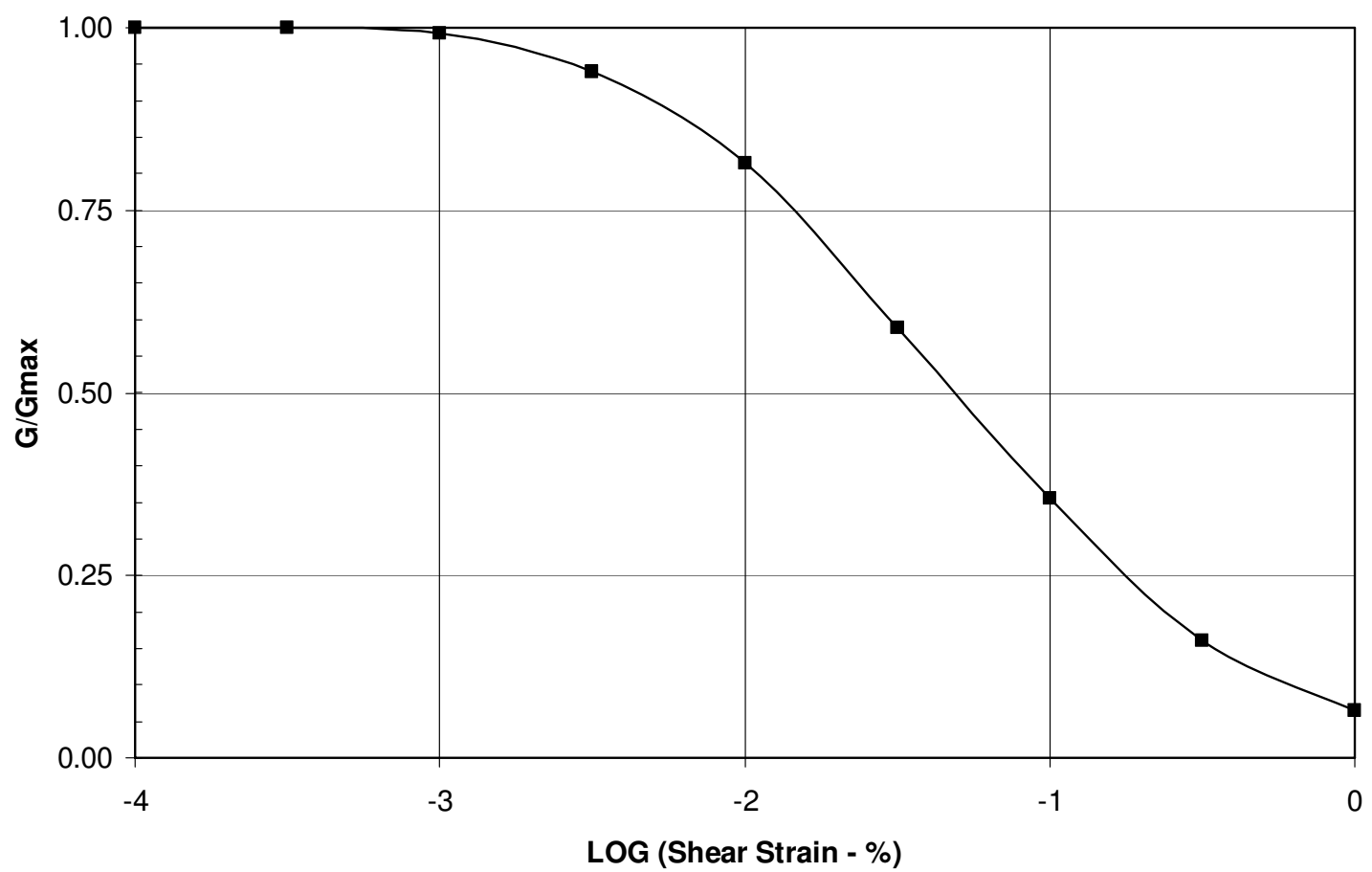

(b)

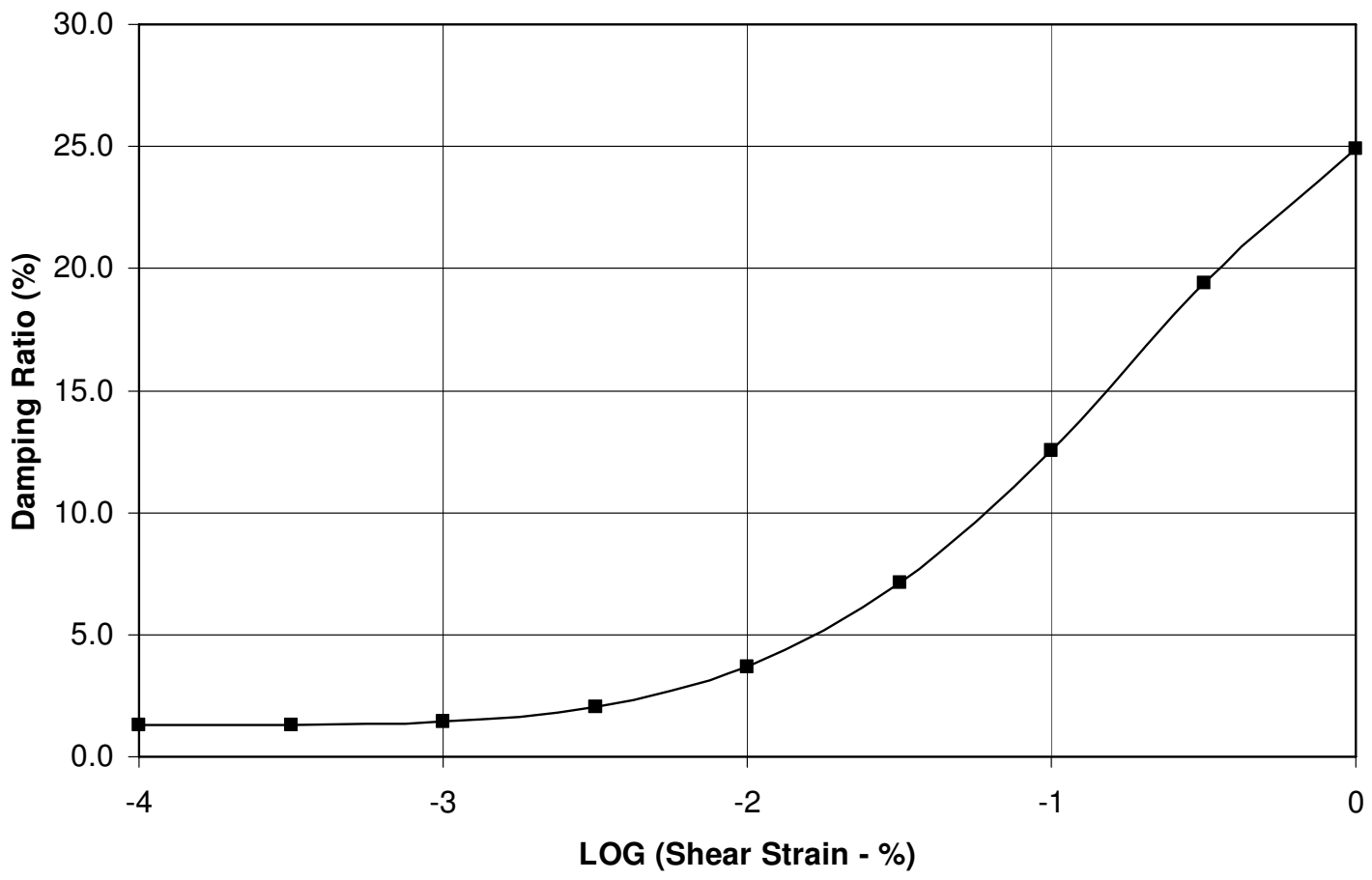

Figure C-6. "EPRI (Payne 2006)" 20-50 ft depth range: (a) shear modulus (G) reduction; and (b) damping curves. 


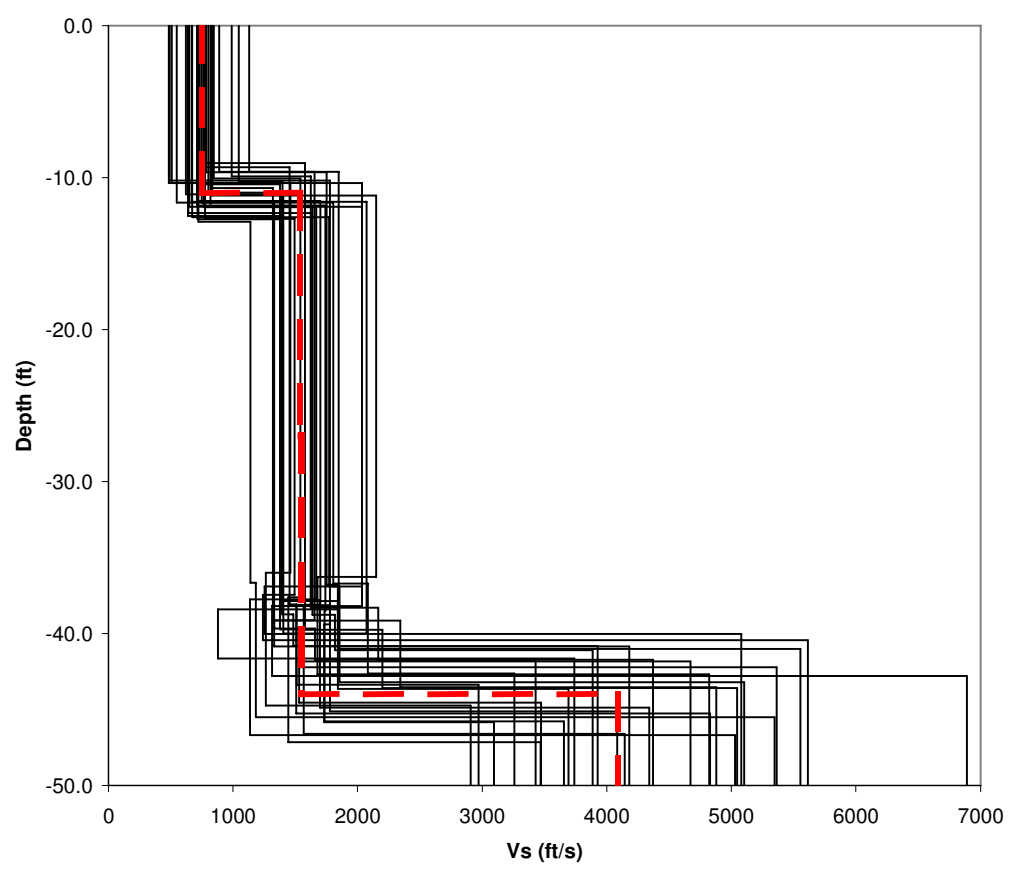

Figure C-7. Plot of thirty random (thin black lines) and starting soil profile (red dashed line) for the log normal distributions of shear modulus with $\mathrm{COV}$ equivalent to the factor of 0.5 . 
(a)

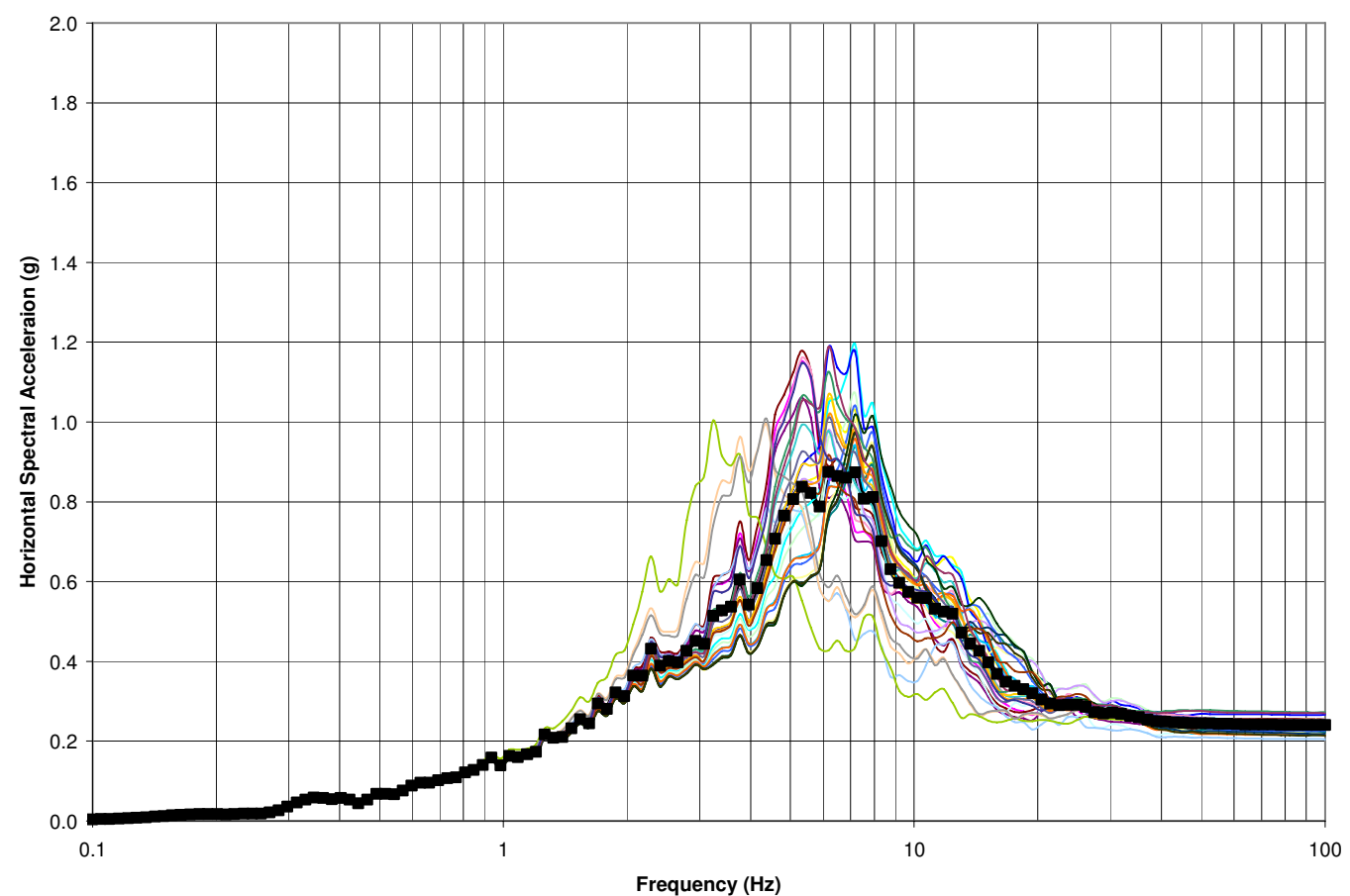

(b)

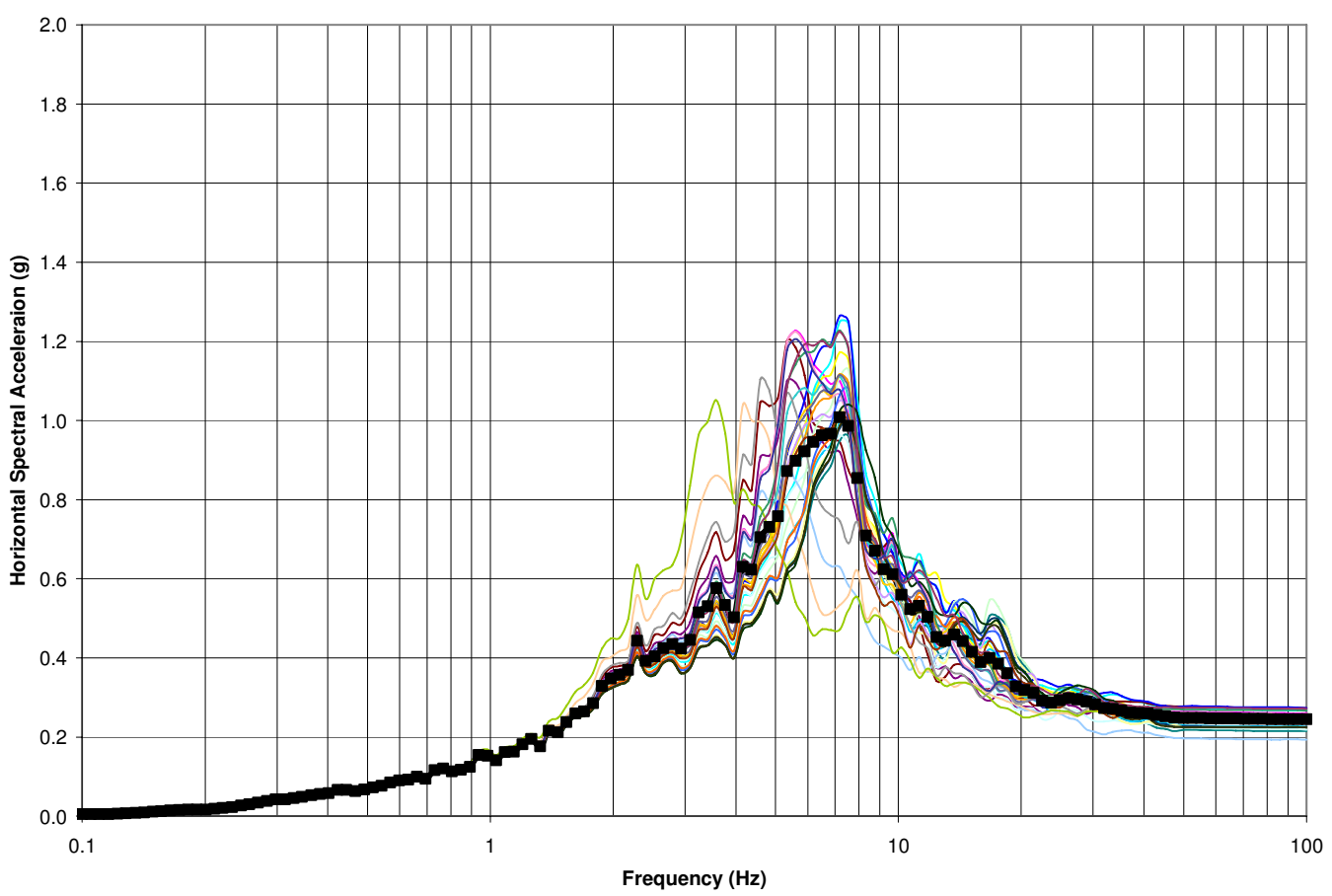

Figure C-8. PC 3 (2,500 yr) mean (black jagged line) and 30 soil surface 5\% damped spectra (colored lines) for: (a) $\mathrm{H} 1$ and (b) $\mathrm{H} 2$ corresponding to random soil profiles with log normal distribution of $\mathrm{G}$ (COVs < 0.32) and degradation model "Darendeli/Menq CU 100" (Pyke 2006). 
(a)

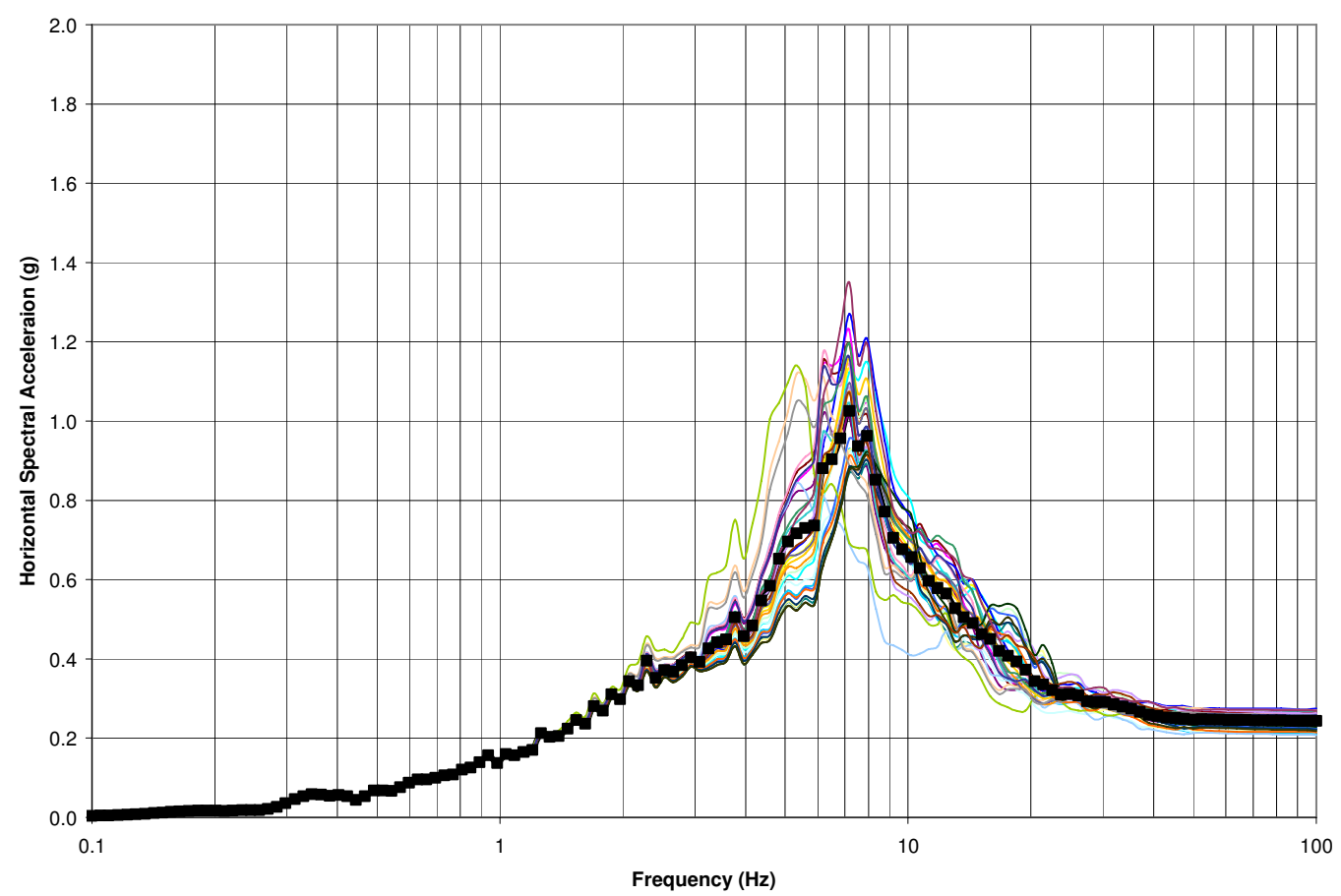

(b)

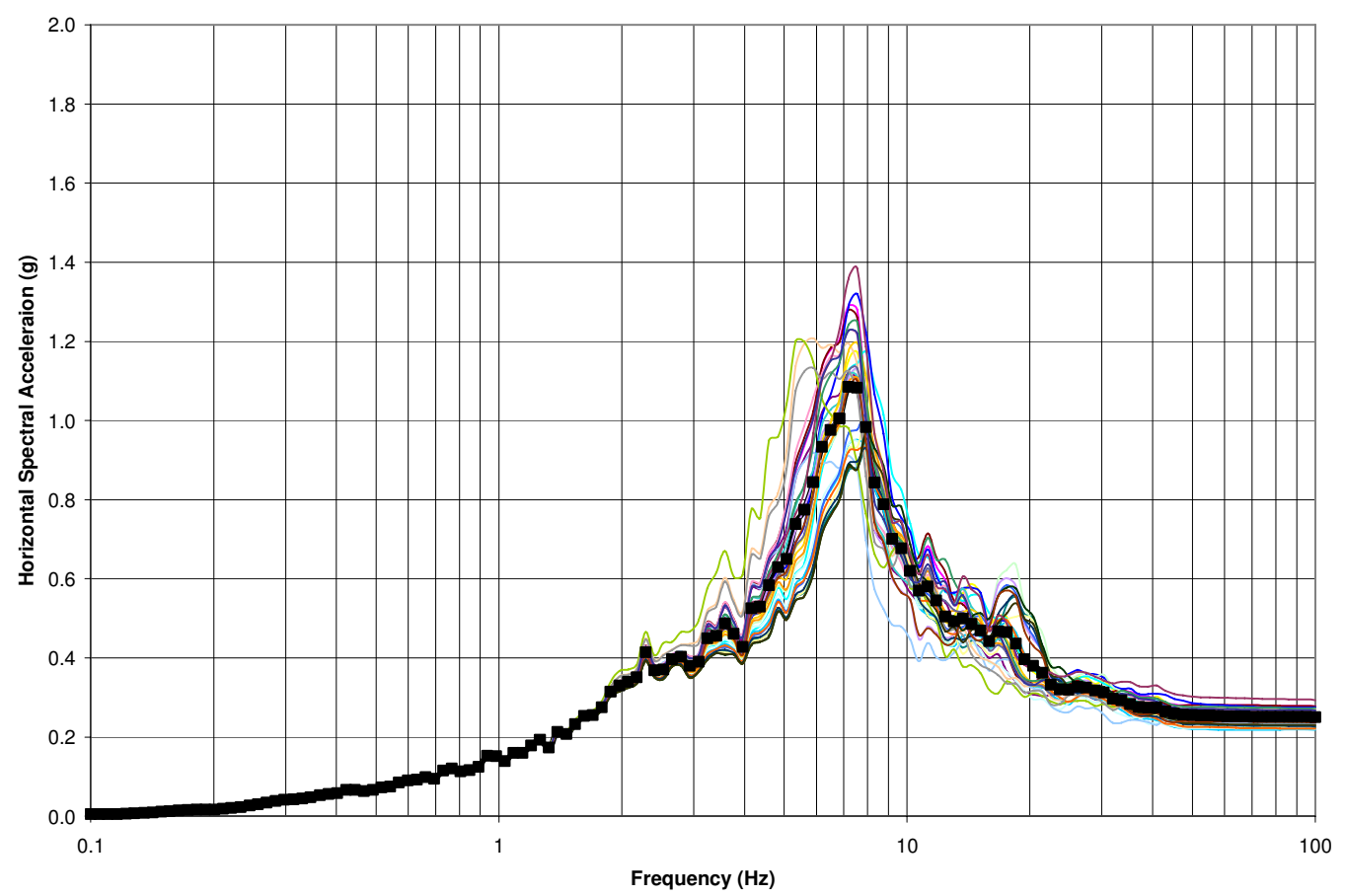

Figure C-9. PC 3 (2,500 yr) mean (black jagged line) and 30 soil surface 5\% damped spectra (colored lines) for: (a) $\mathrm{H} 1$ and (b) $\mathrm{H} 2$ corresponding to random soil profiles with normal distribution of $\mathrm{G}$ (COVs $<0.32$ ) and degradation model "EPRI (Pyke 2007)". 
(a)

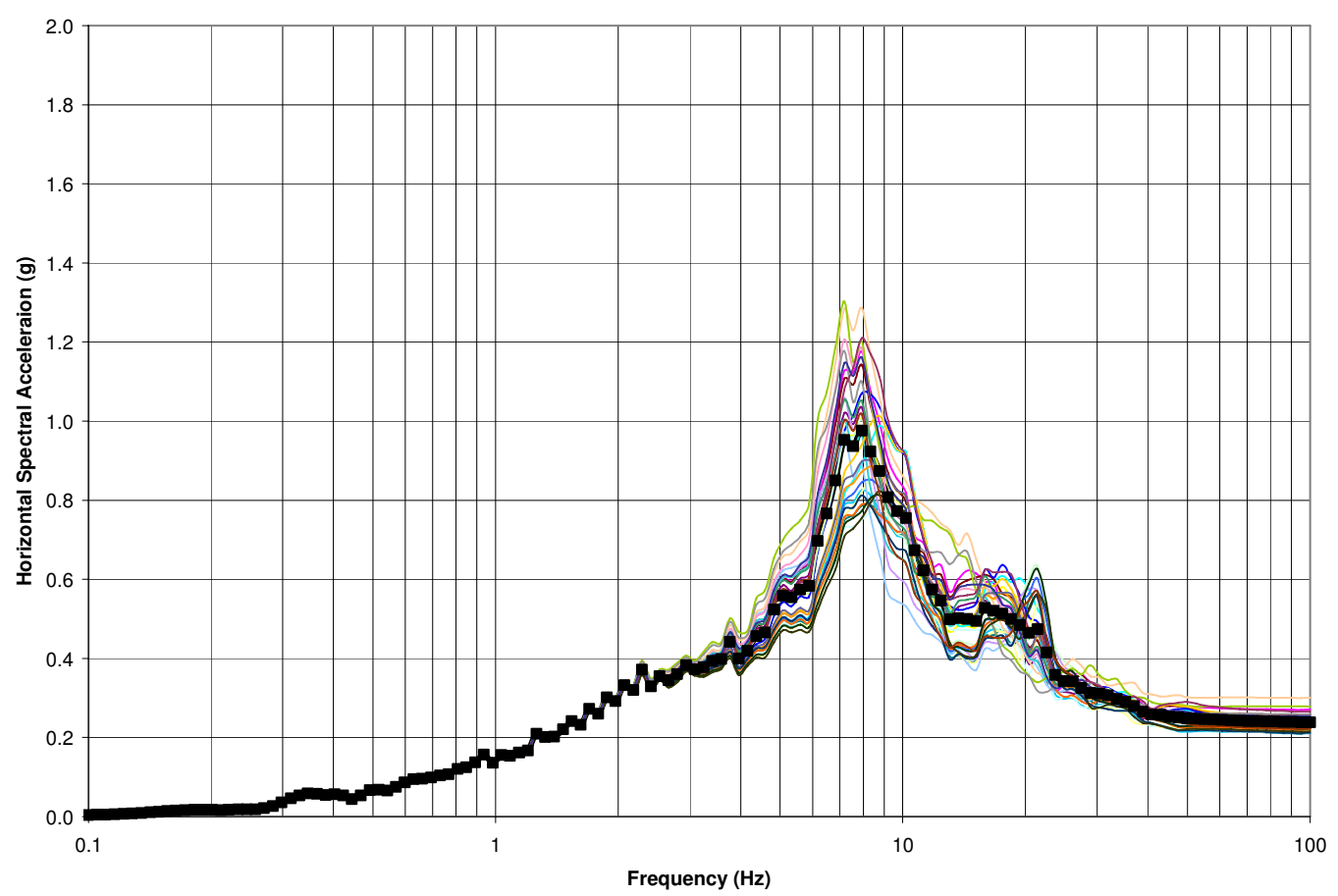

(b)

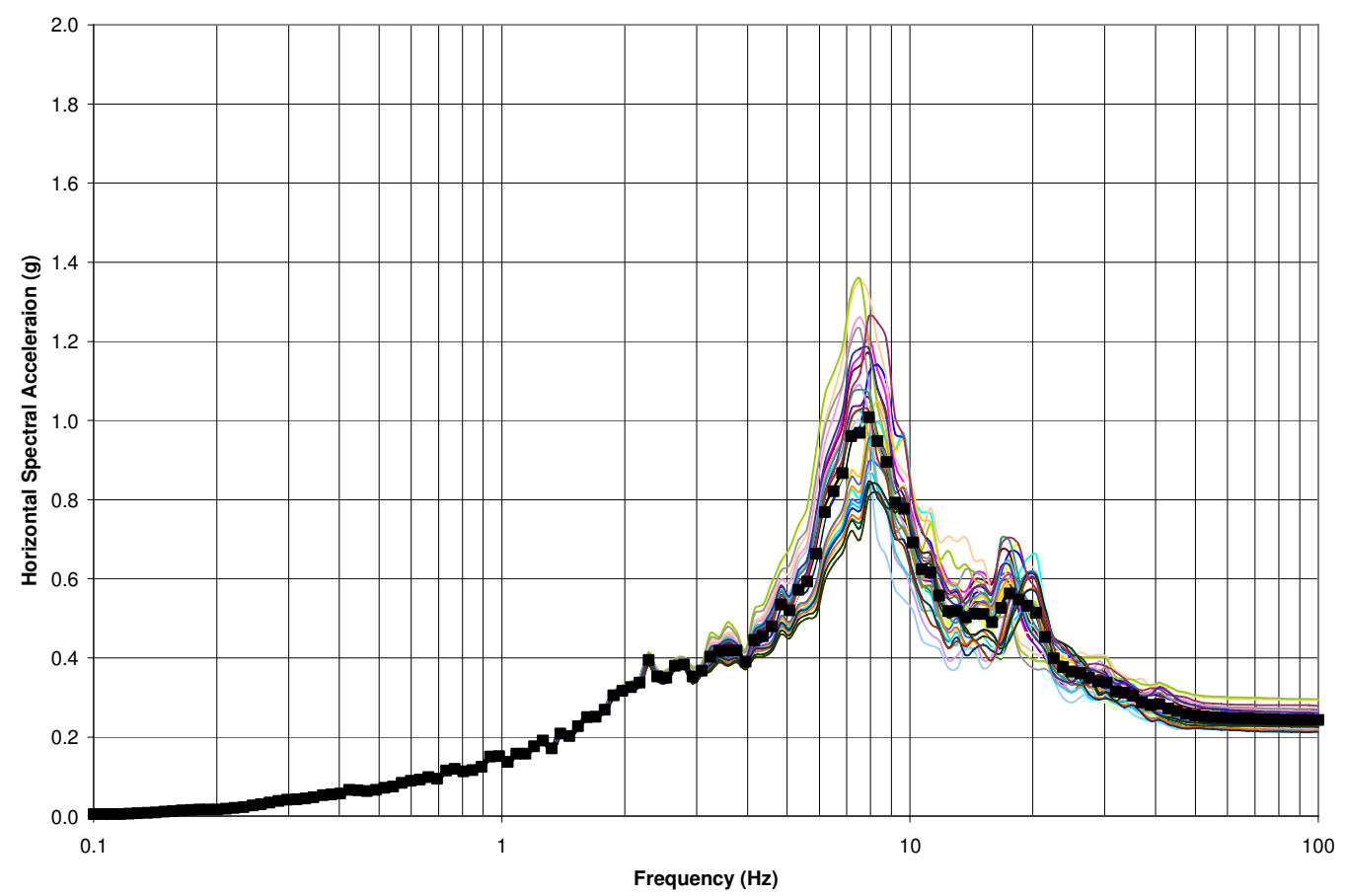

Figure C-10. PC 3 (2,500 yr) mean (black jagged line) and 30 soil surface 5\% damped spectra (colored lines) for: (a) $\mathrm{H} 1$ and (b) $\mathrm{H} 2$ corresponding to random soil profiles with log normal distribution of $\mathrm{G}$ (COVs < 0.32) and degradation model "EPRI (Payne 2006)". 
(a)

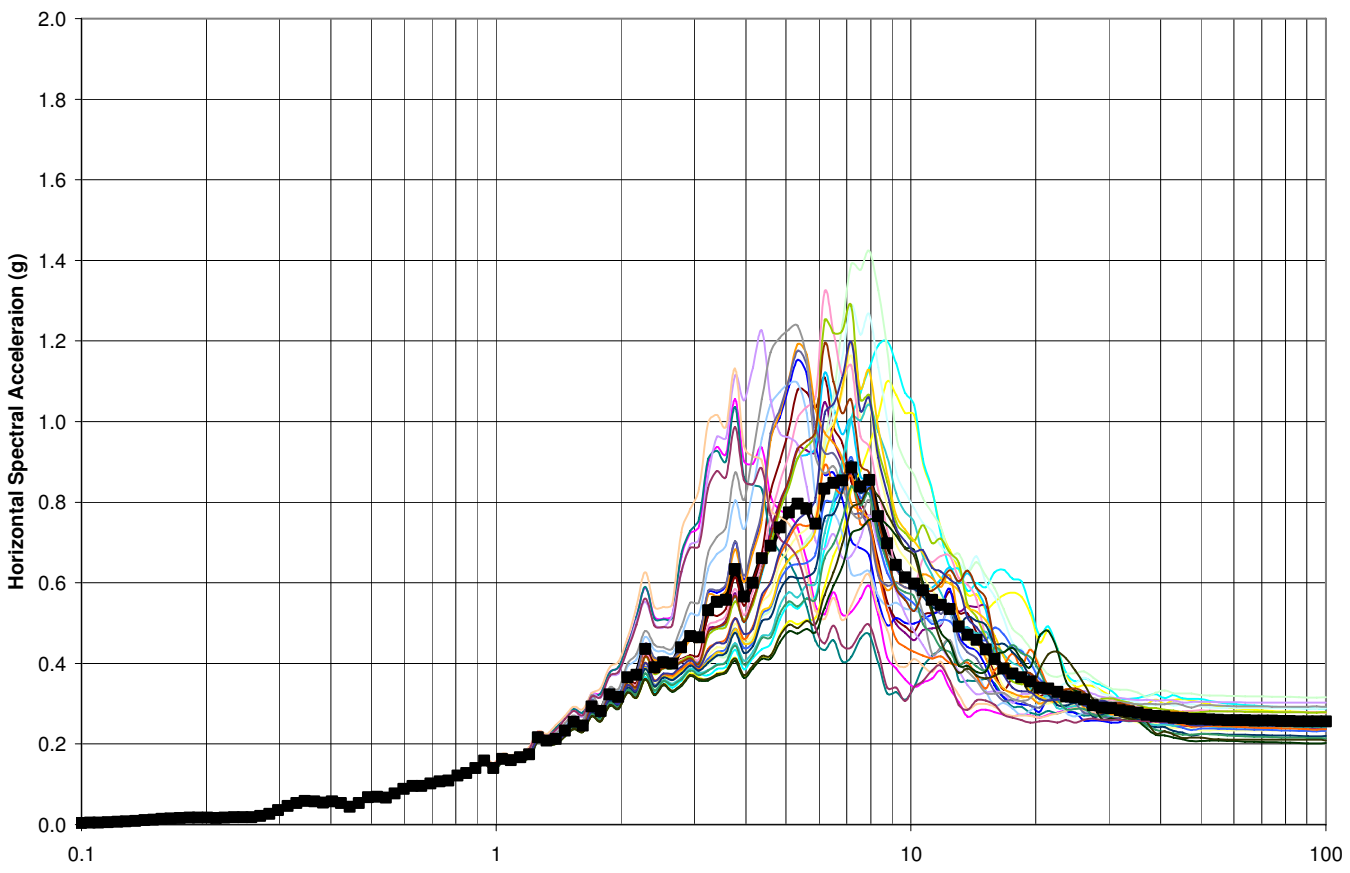

(b)

Frequency $(\mathrm{Hz})$

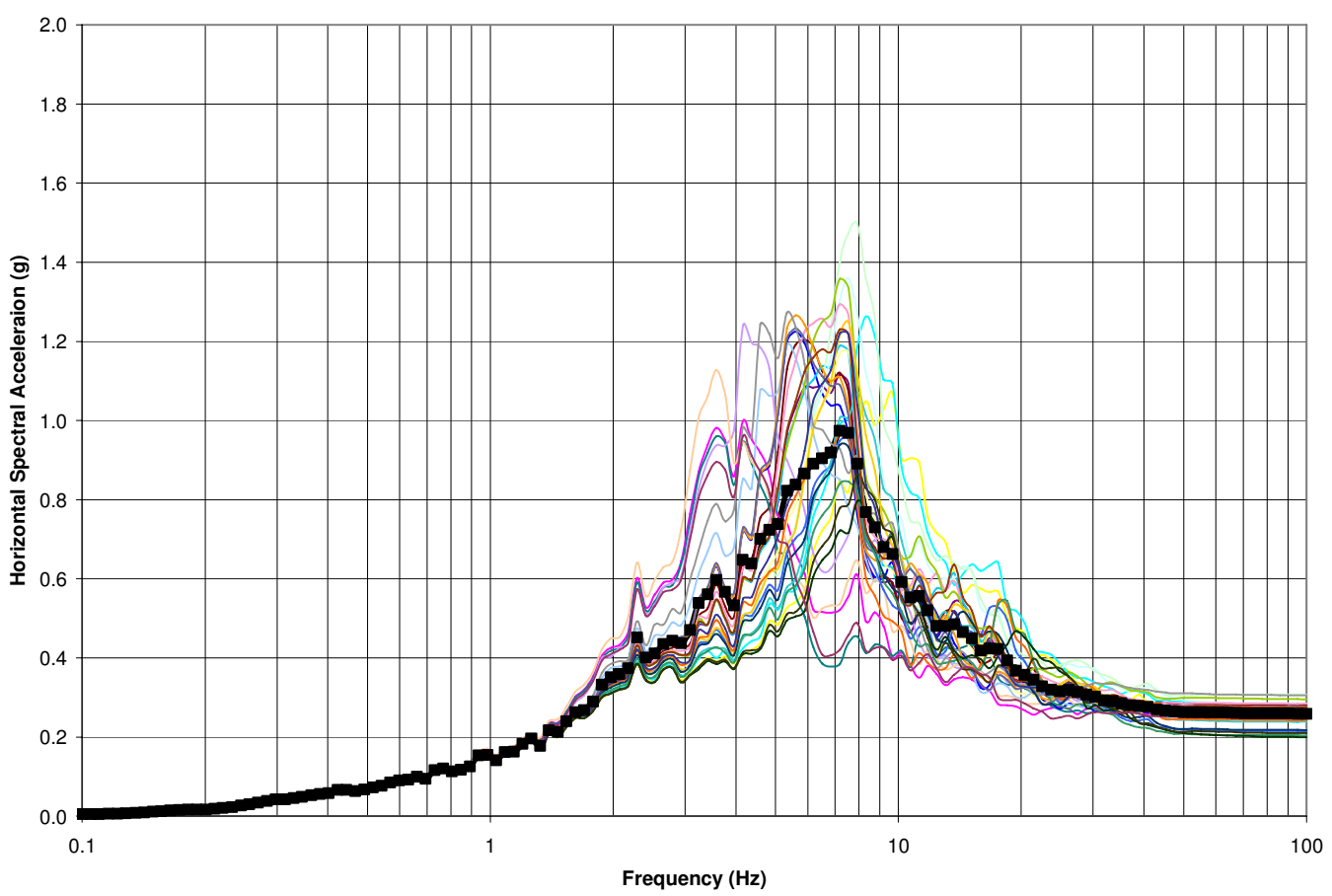

Figure C-11. PC 3 (2,500 yr) mean (black jagged line) and 30 soil surface 5\% damped spectra (colored lines) for: (a) $\mathrm{H} 1$ and (b) $\mathrm{H} 2$ corresponding to random soil profiles with larger COV (0.5), log normal distribution of G, and degradation model "Darendeli/Menq CU 40" (Pyke 2007). 
(a)

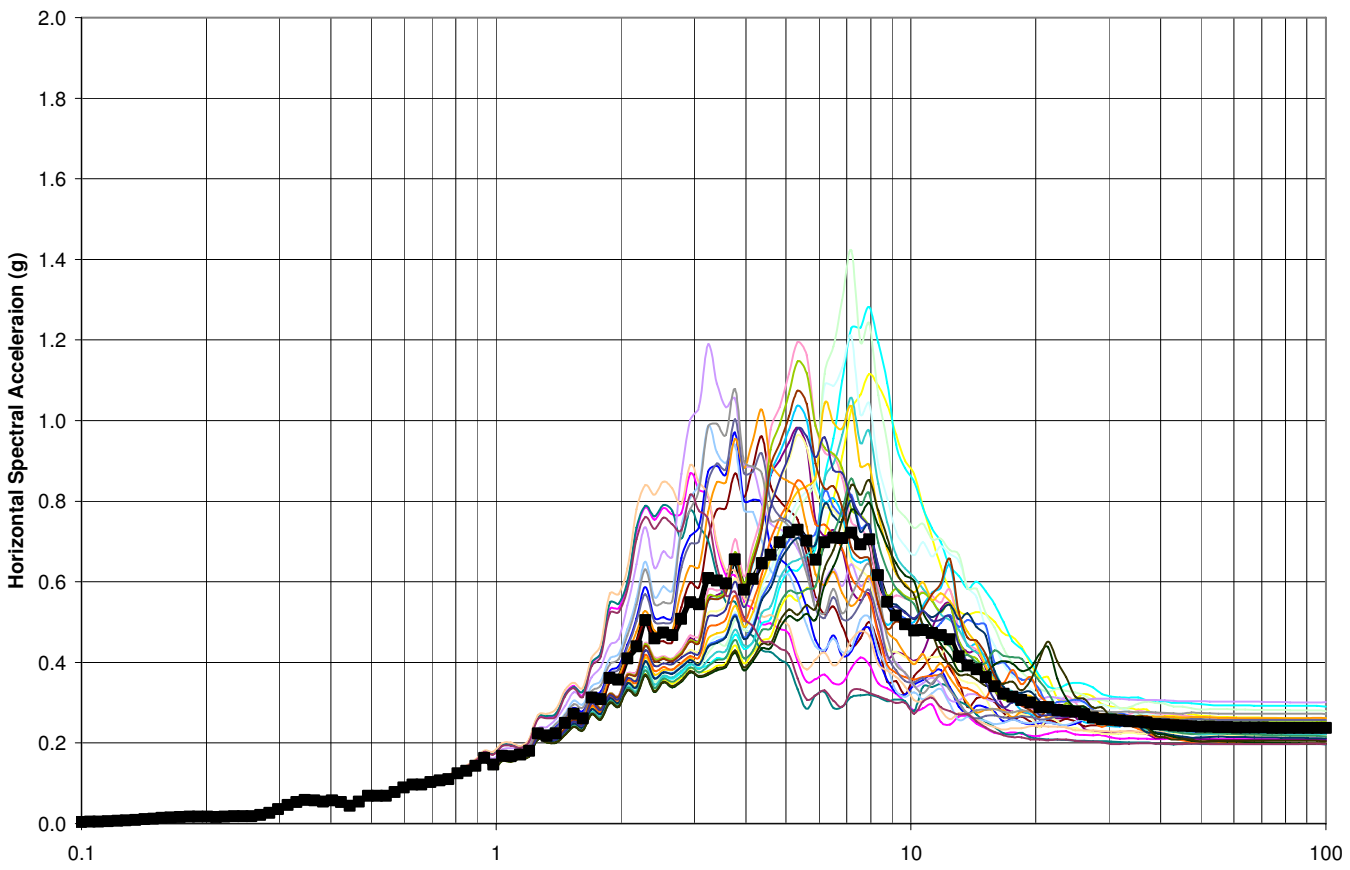

(b)

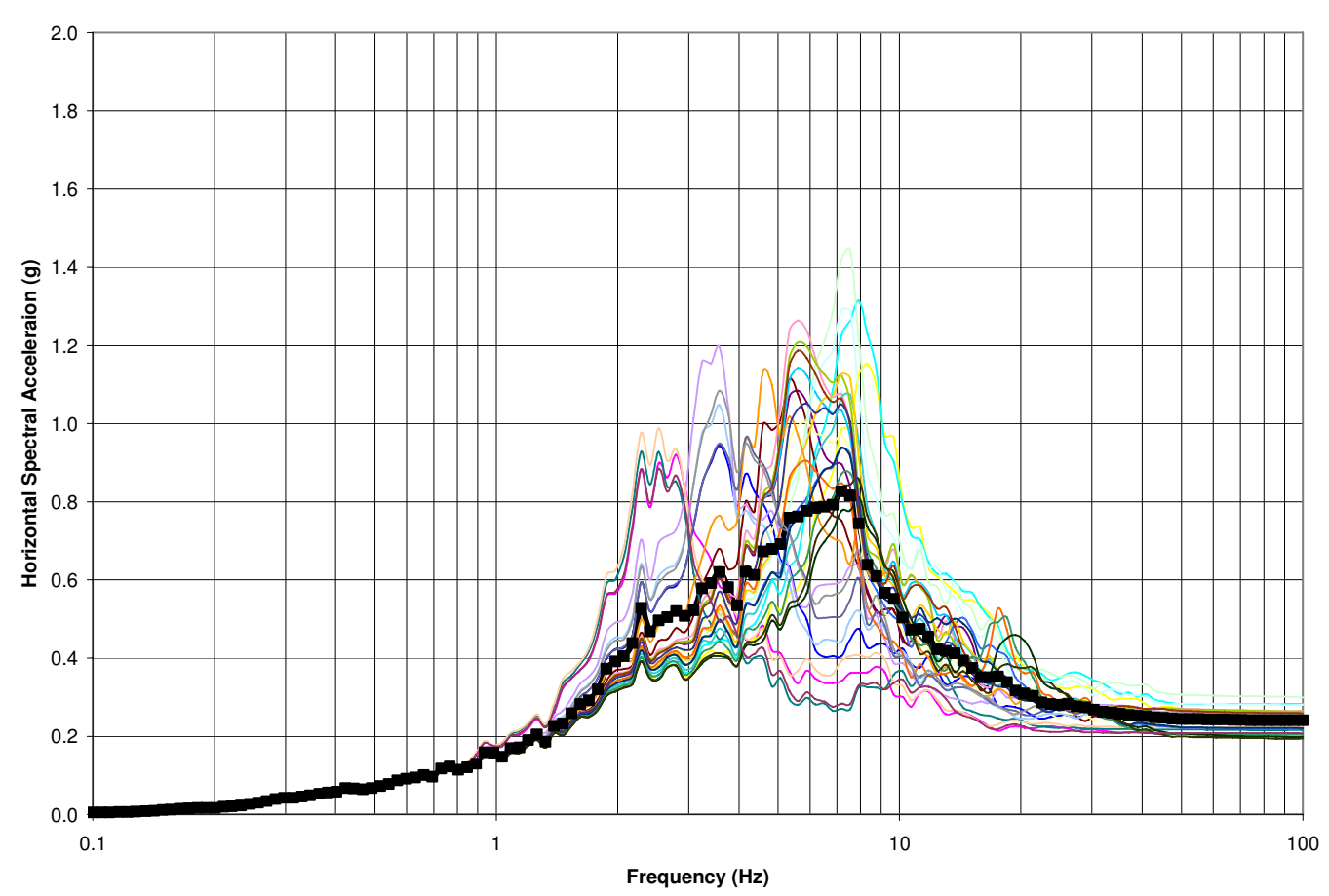

Figure C-12. PC 3 (2,500 yr) mean (black jagged line) and 30 soil surface 5\% damped spectra (colored lines) for: (a) $\mathrm{H} 1$ and (b) $\mathrm{H} 2$ corresponding to random soil profiles with larger $\mathrm{COV}(0.5), \log$ normal distribution of G, and degradation model "Darendeli/Menq CU 100” (Pyke 2006). 
(a)

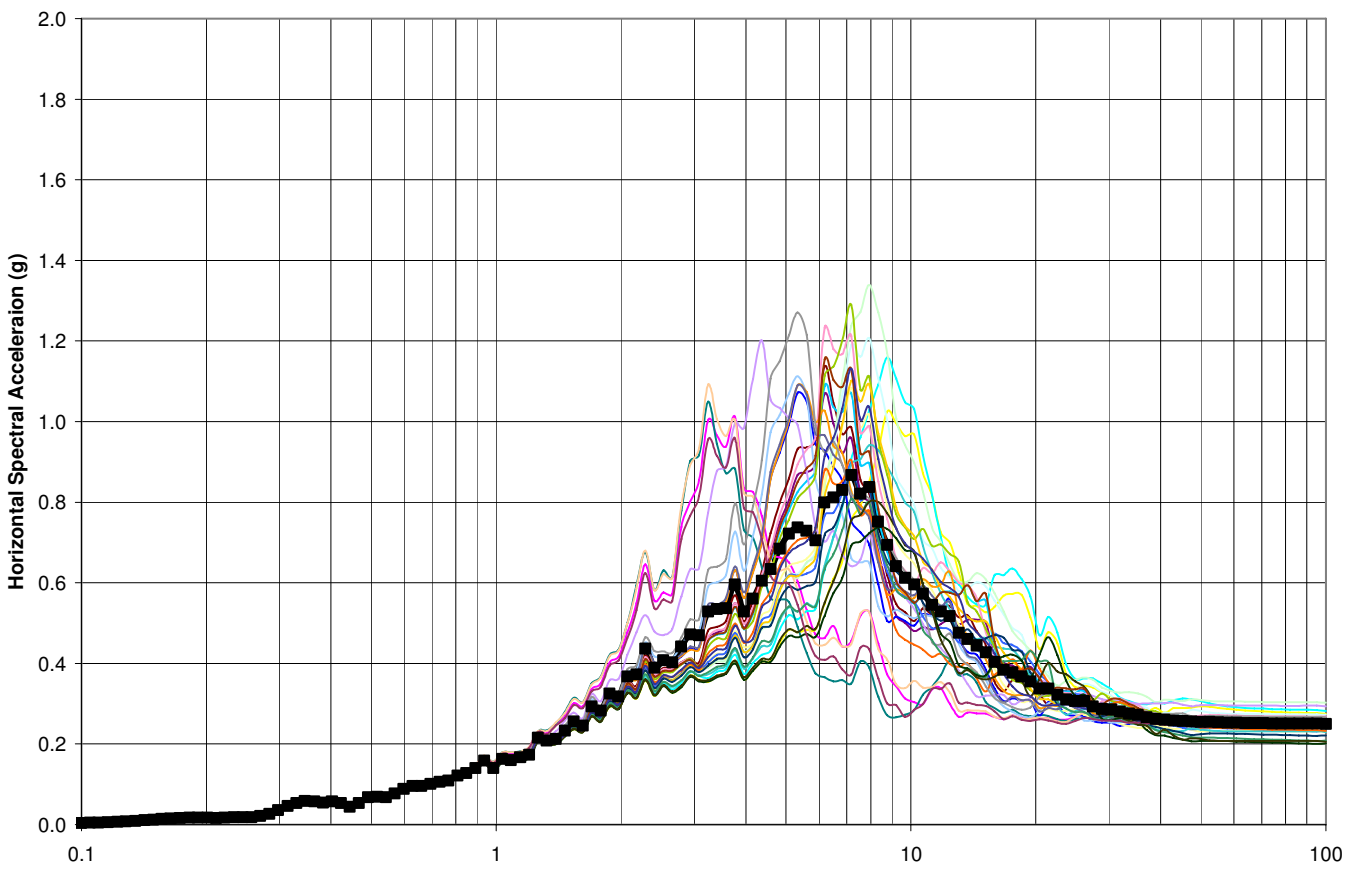

(b)

Frequency $(\mathrm{Hz})$

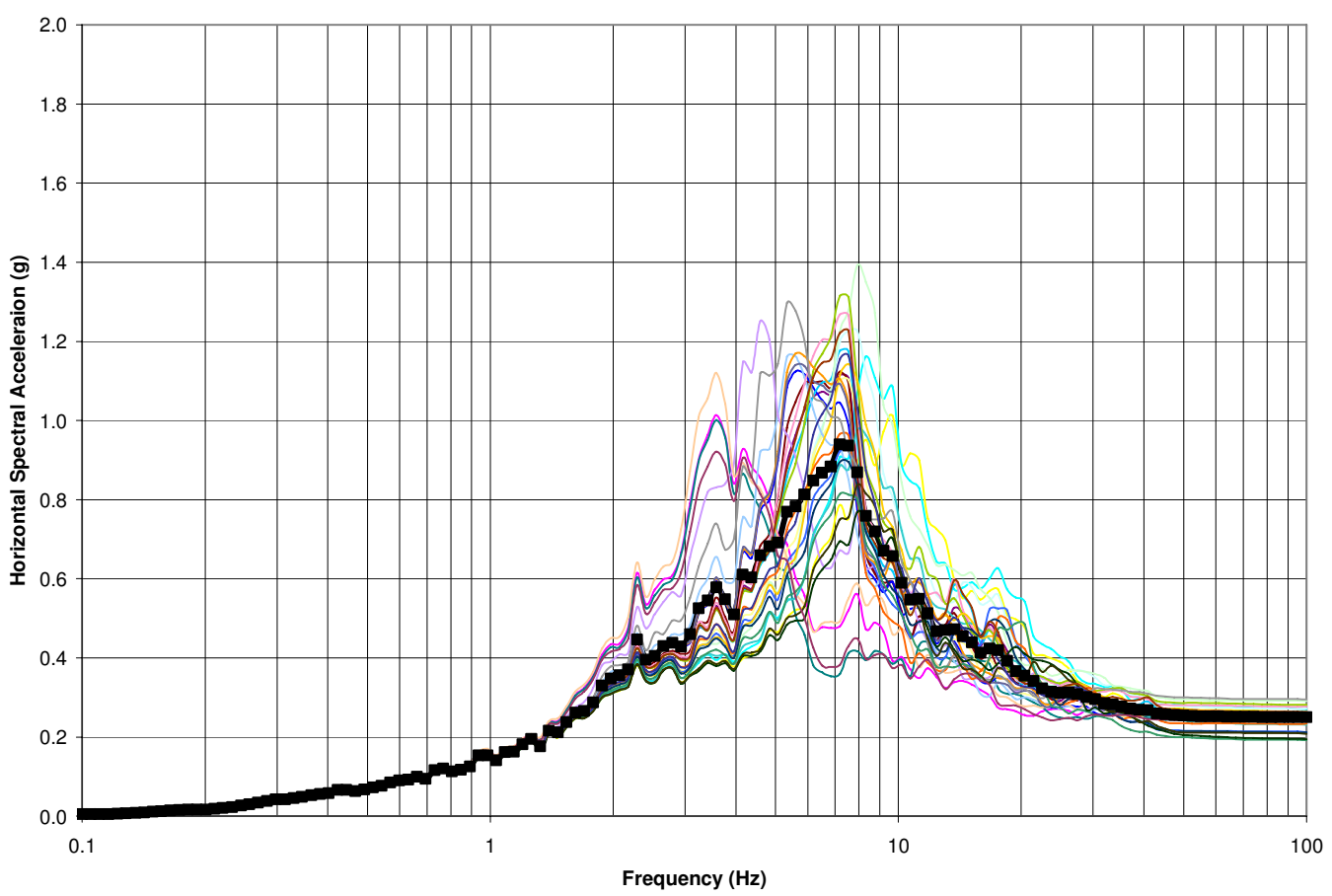

Figure C-13. PC 3 (2,500 yr) mean (black jagged line) and 30 soil surface 5\% damped spectra (colored lines) for: (a) $\mathrm{H} 1$ and (b) $\mathrm{H} 2$ corresponding to random soil profiles with larger COV (0.5), log normal distribution of G, and degradation model "EPRI (Pyke 2007)". 
(a)

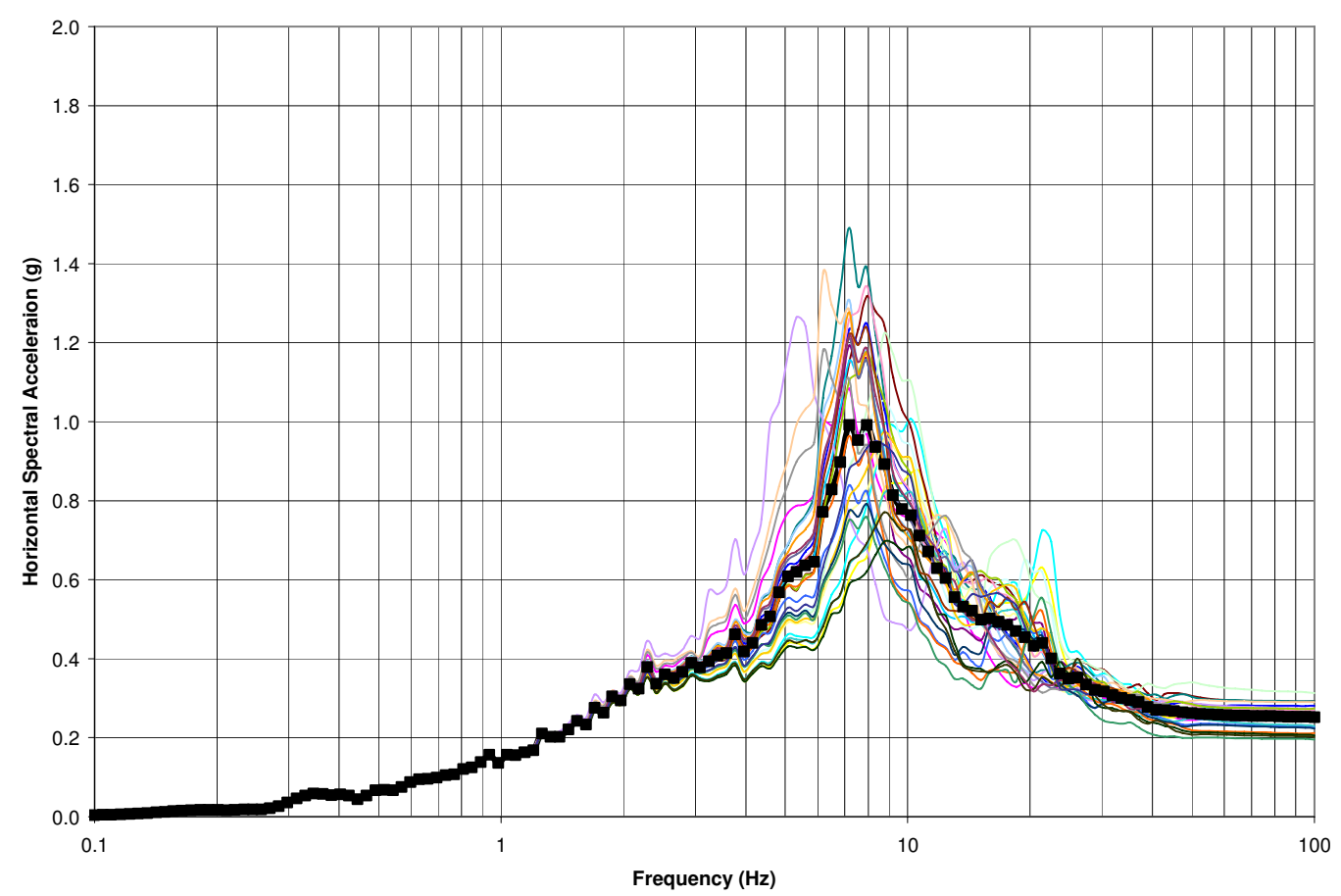

(b)

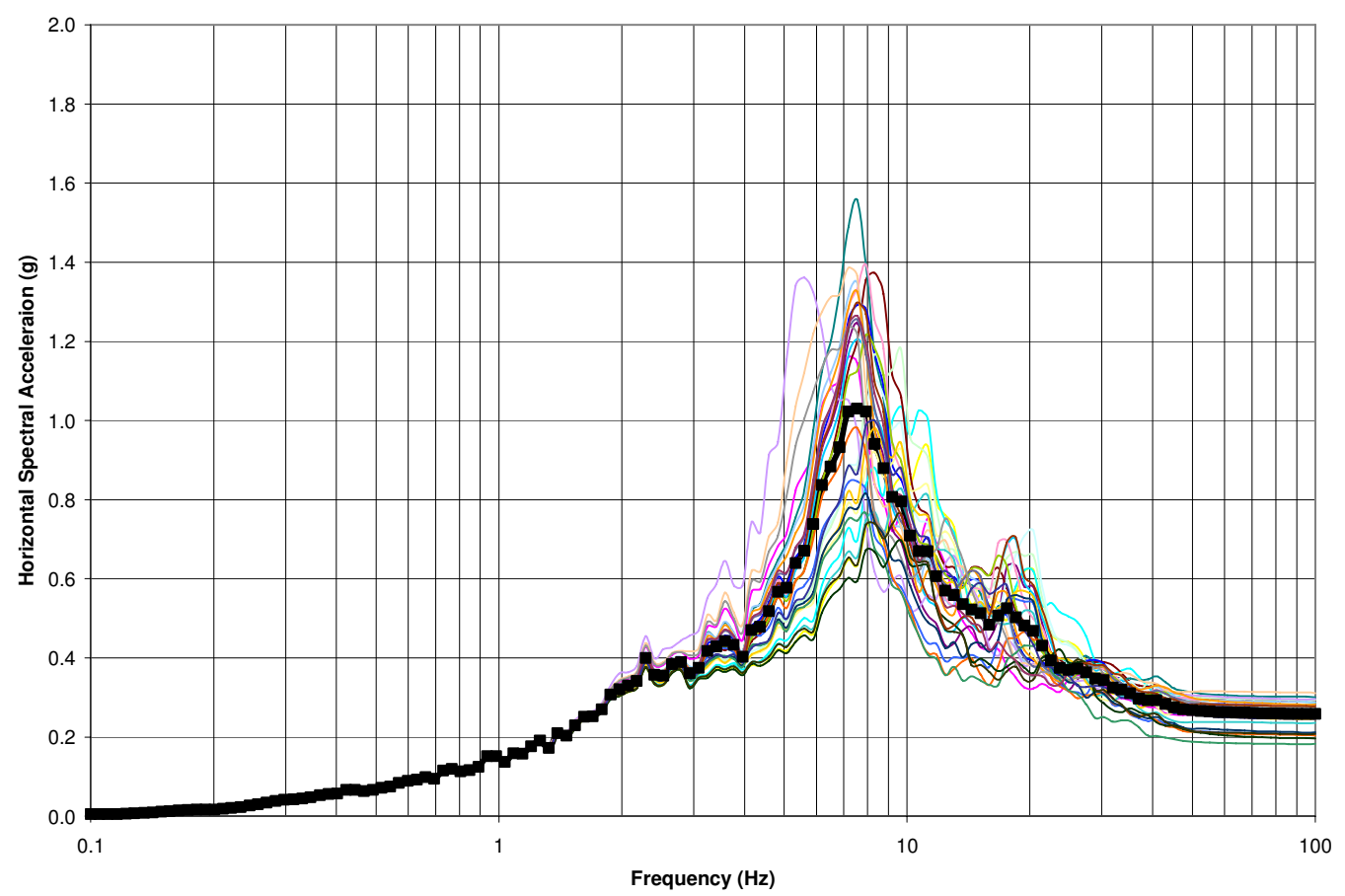

Figure C-14. PC 3 (2,500 yr) mean (black jagged line) and 30 soil surface 5\% damped spectra (colored lines) for: (a) $\mathrm{H} 1$ and (b) $\mathrm{H} 2$ corresponding to random soil profiles with larger $\mathrm{COV}(0.5), \log$ normal distribution of G, and degradation model "EPRI (Payne 2006)". 
(a)
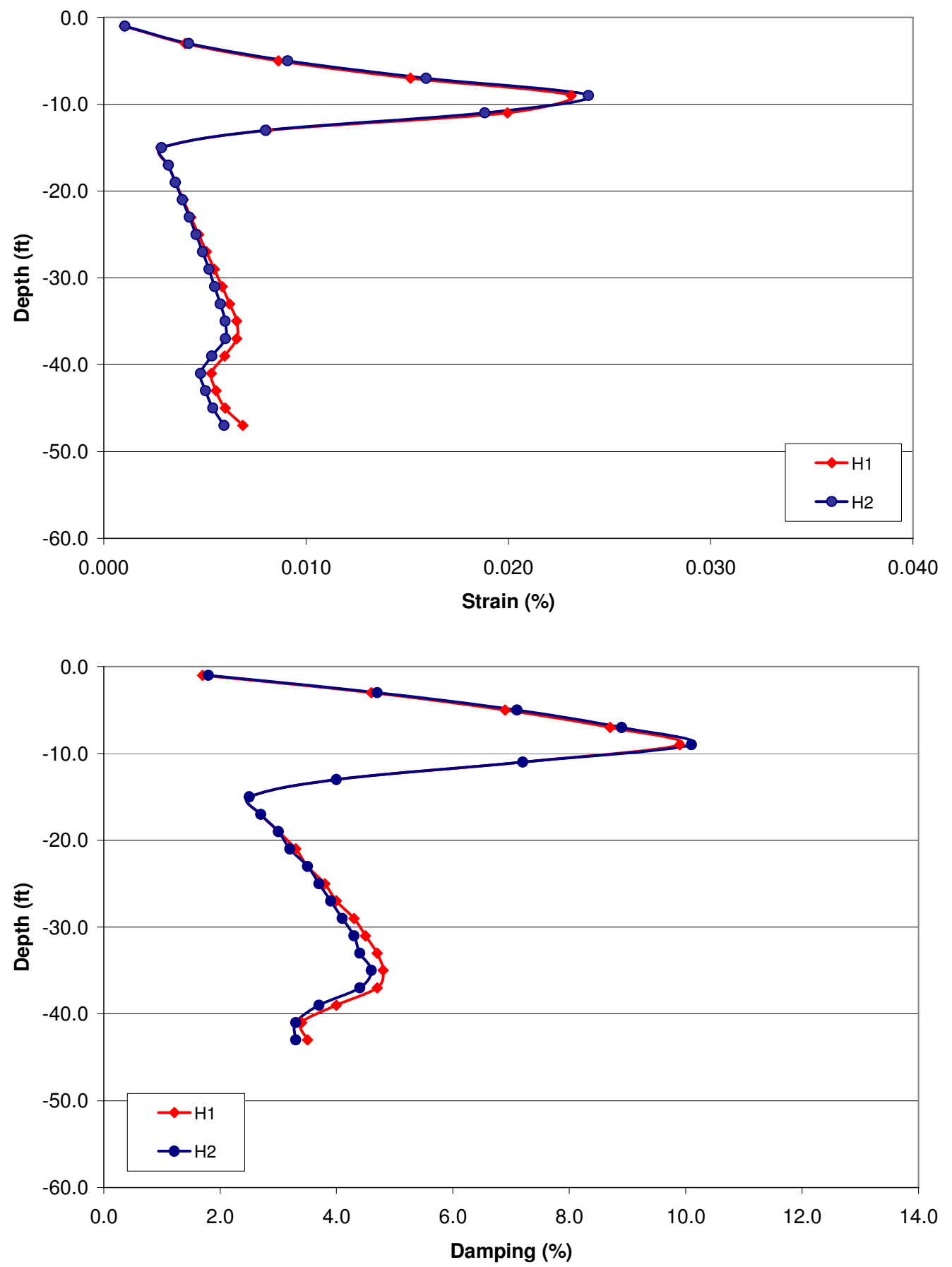

Figure C-15. Average PC 3 (2,500 yr) soil (a) strain and (b) damping computed from the output of SHAKE2000 for 30 random soil profiles with the log normal distribution of $\mathrm{G}(\mathrm{COVs}<0.32)$ and degradation model "Darendeli/Menq CU 40" (Pyke 2007). 
(a)

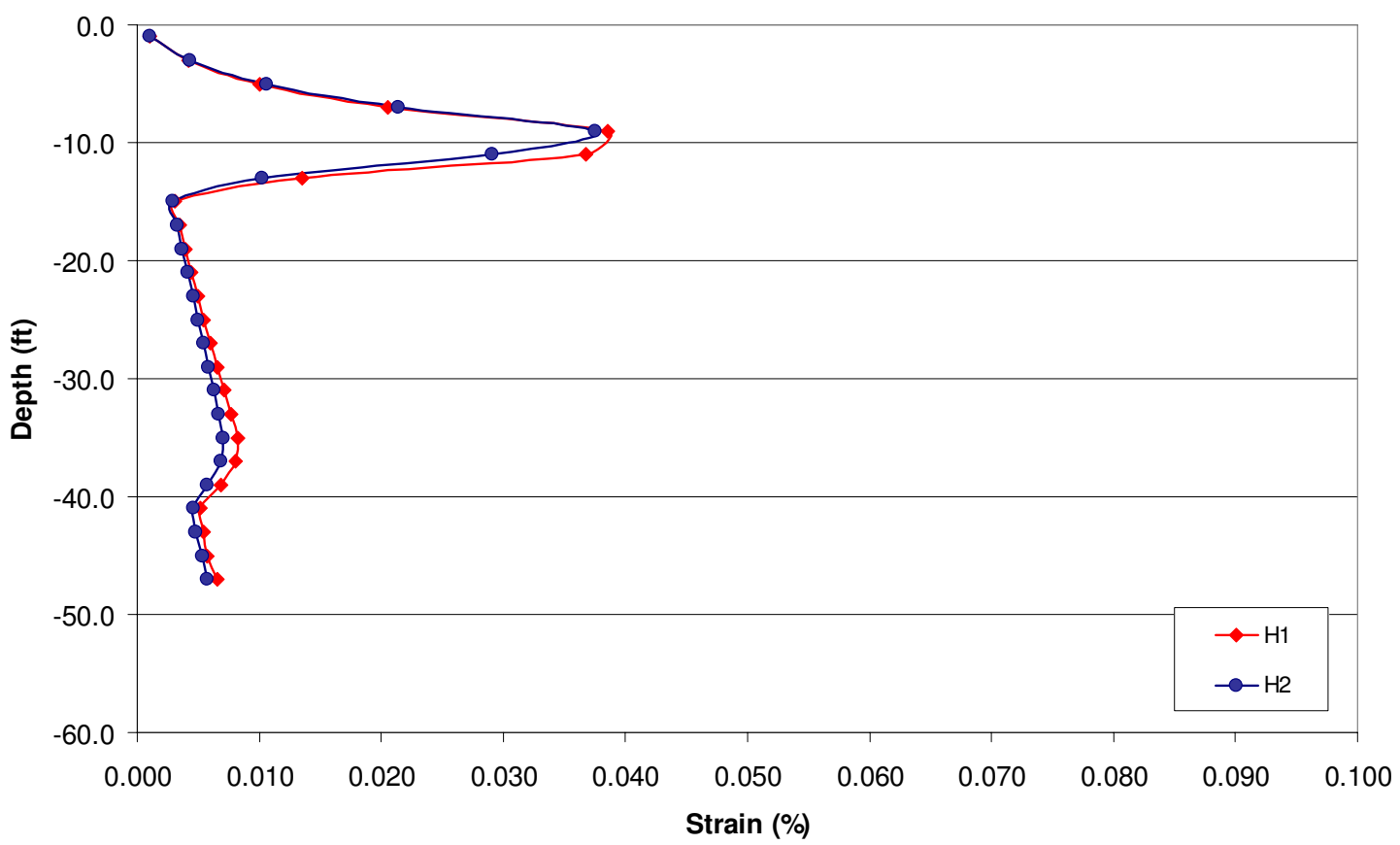

(b)

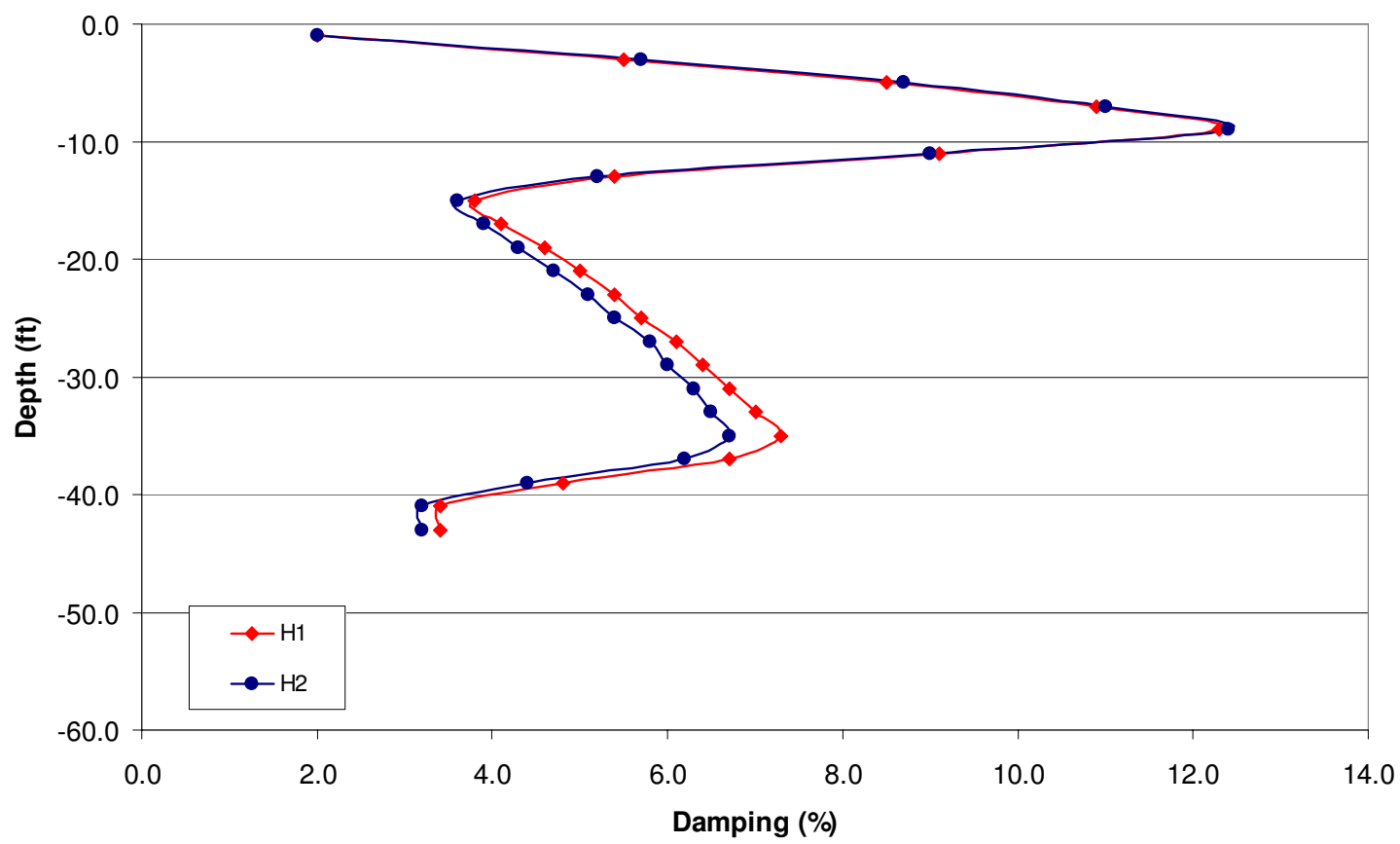

Figure C-16. Average PC 3 (2,500 yr) soil (a) strain and (b) damping computed from the output of SHAKE2000 for 30 random soil profiles with the log normal distribution of $\mathrm{G}(\mathrm{COVs}<0.32)$ and degradation model "Darendeli/Menq CU 100" (Pyke 2006). 
(a)
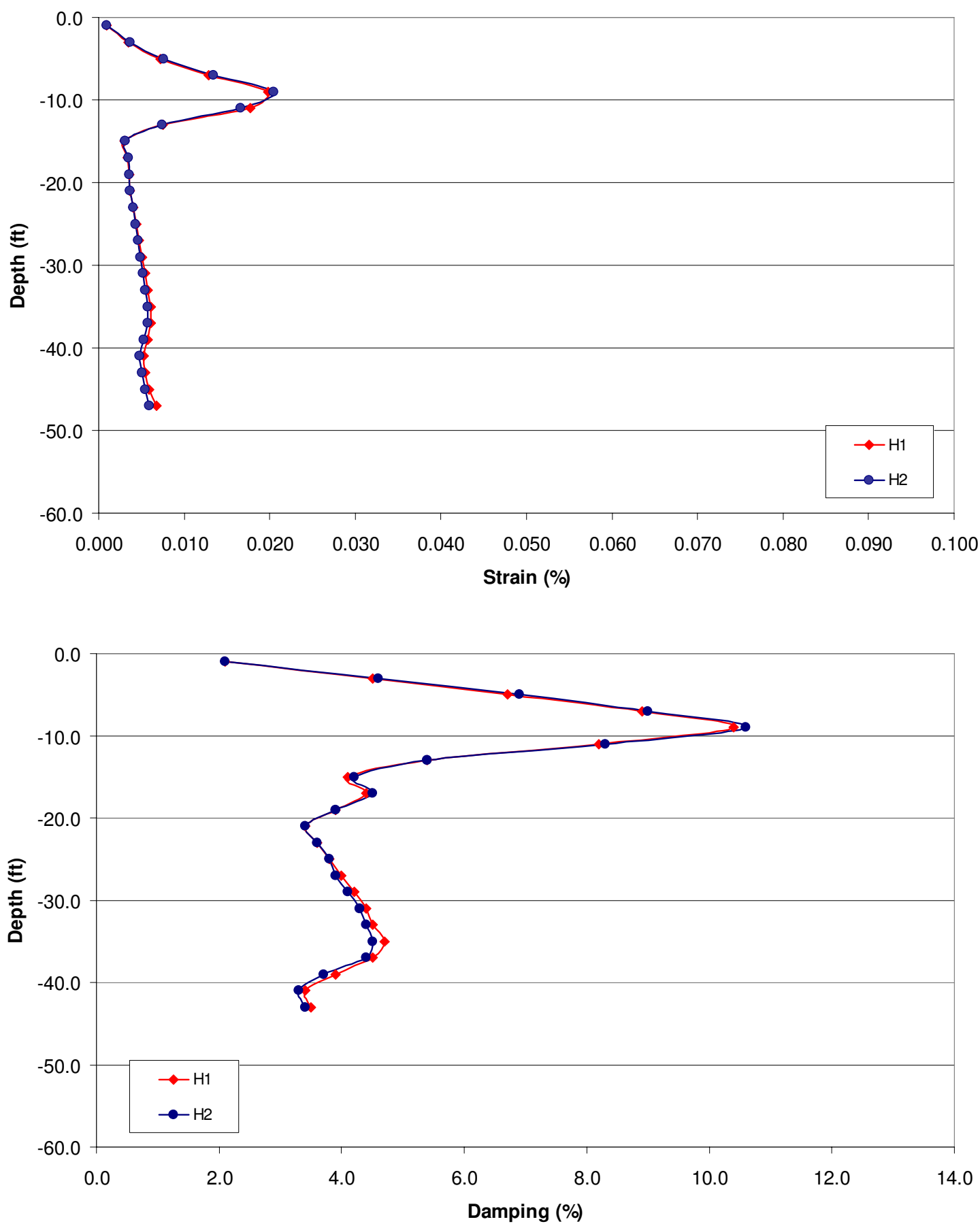

Figure C-17. Average PC 3 (2,500 yr) soil (a) strain and (b) damping computed from the output of SHAKE2000 for 30 random soil profiles with the log normal distribution of $\mathrm{G}(\mathrm{COVs}<0.32)$ and degradation model "EPRI (Pyke 2007)". 
(a)
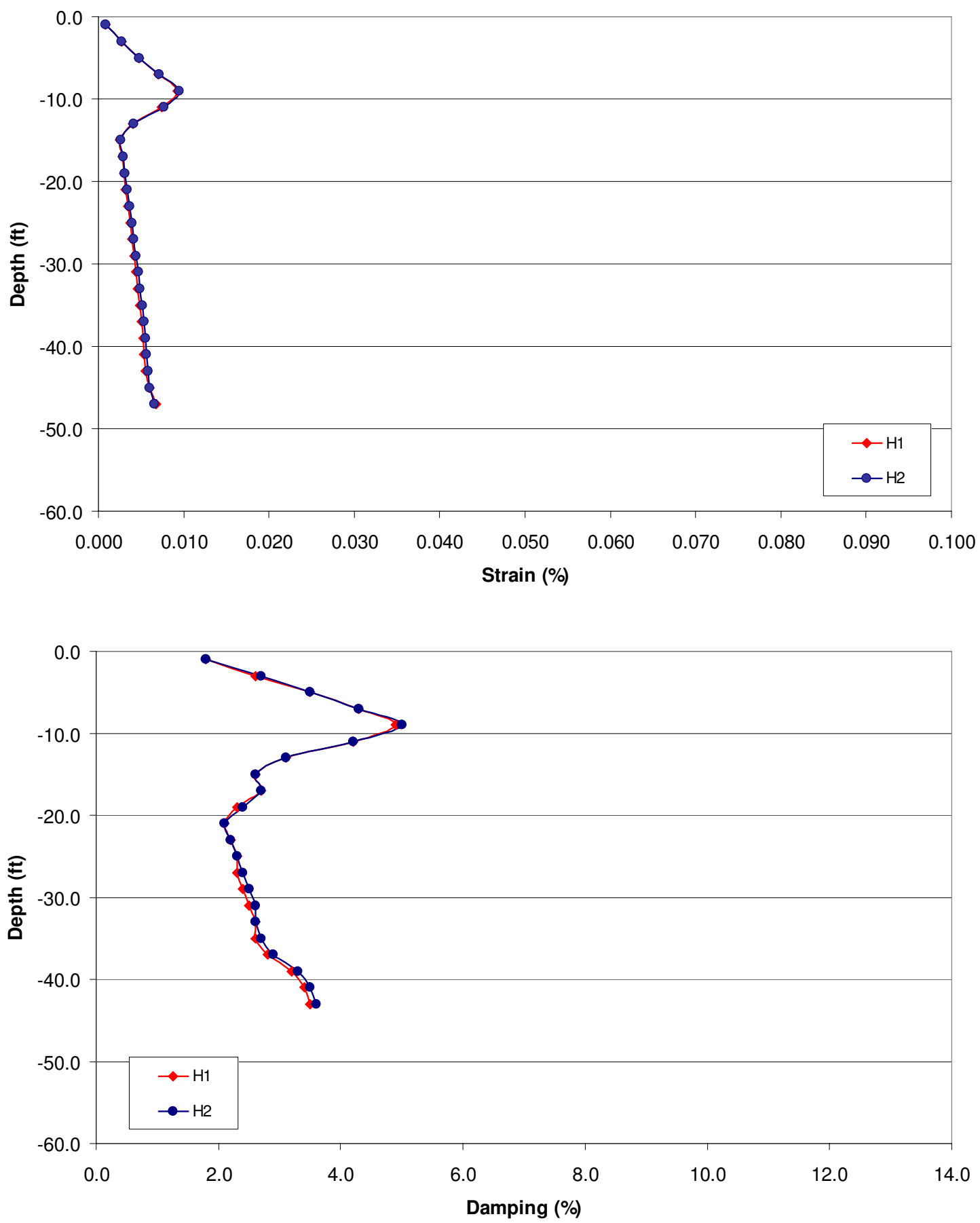

Figure C-18. Average PC 3 (2,500 yr) soil (a) strain and (b) damping computed from the output of SHAKE2000 for 30 random soil profiles with the log normal distribution of $\mathrm{G}(\mathrm{COVs}<0.32)$ and degradation model "EPRI (Payne 2006)". 
(a)

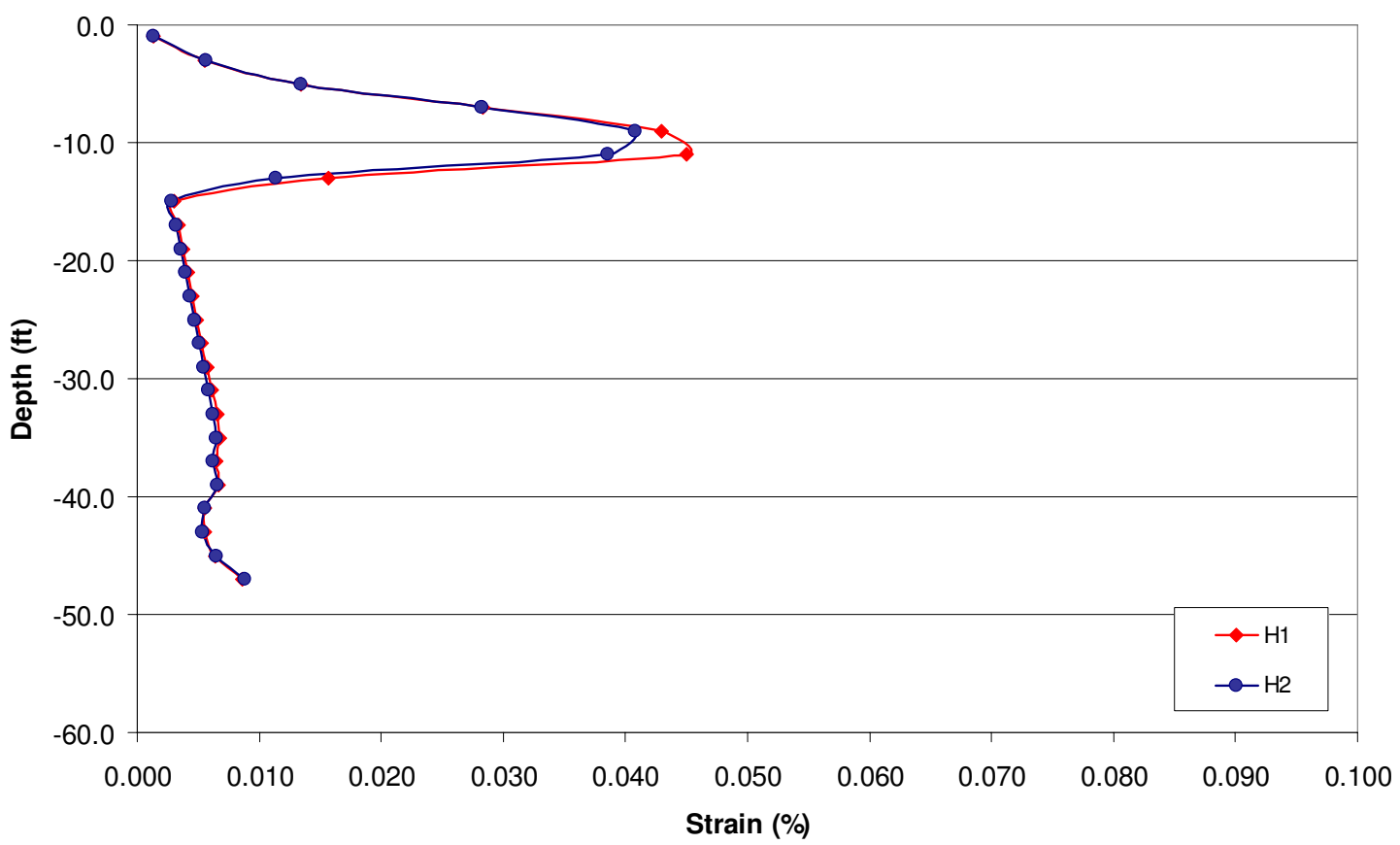

(b)

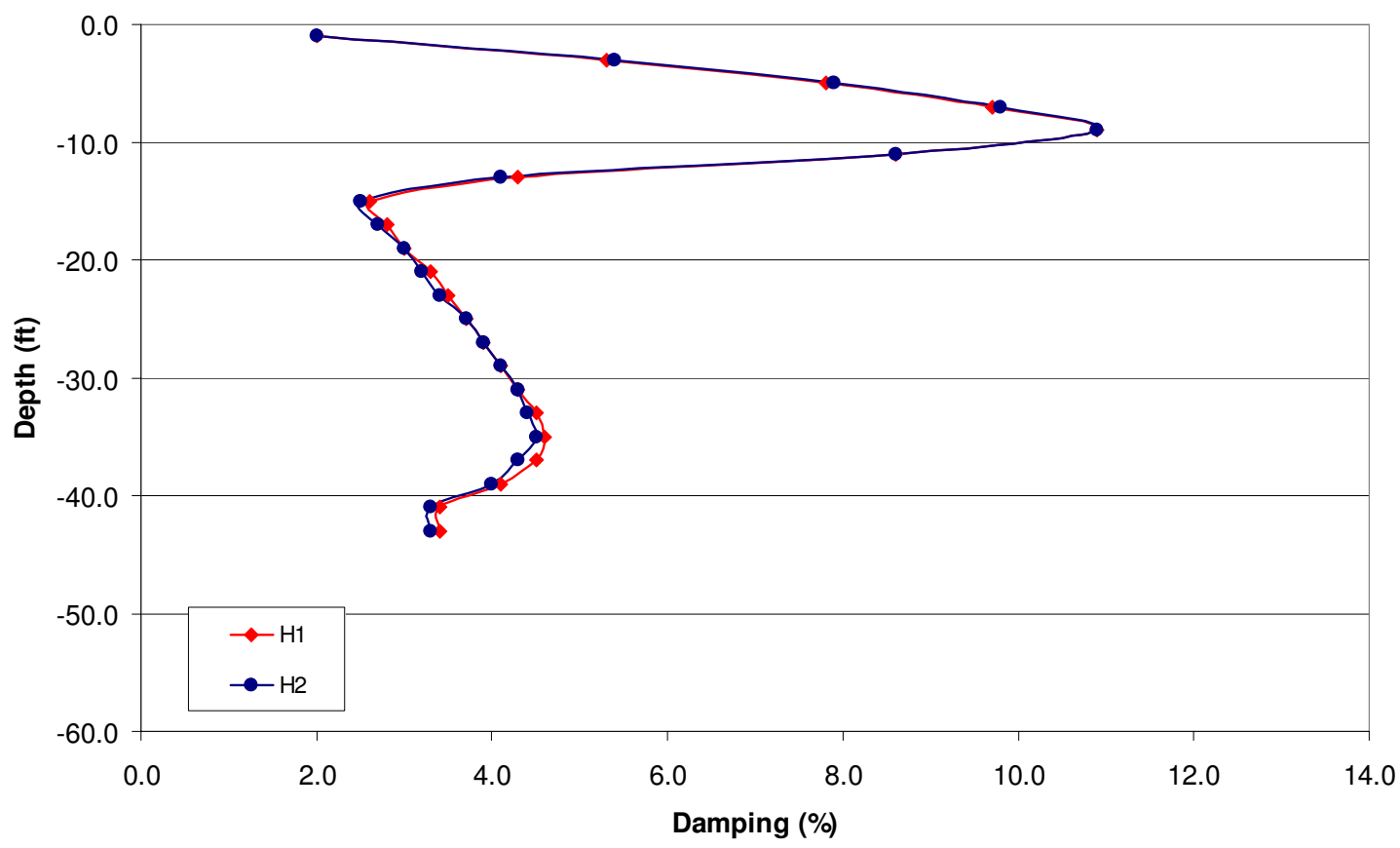

Figure C-19. Average PC 3 (2,500 yr) soil (a) strain and (b) damping computed from the output of SHAKE2000 for 30 random soil profiles with the log normal distribution of G, larger COV (0.5), and degradation model "Darendeli/Menq CU 40" (Pyke 2007). 
(a)

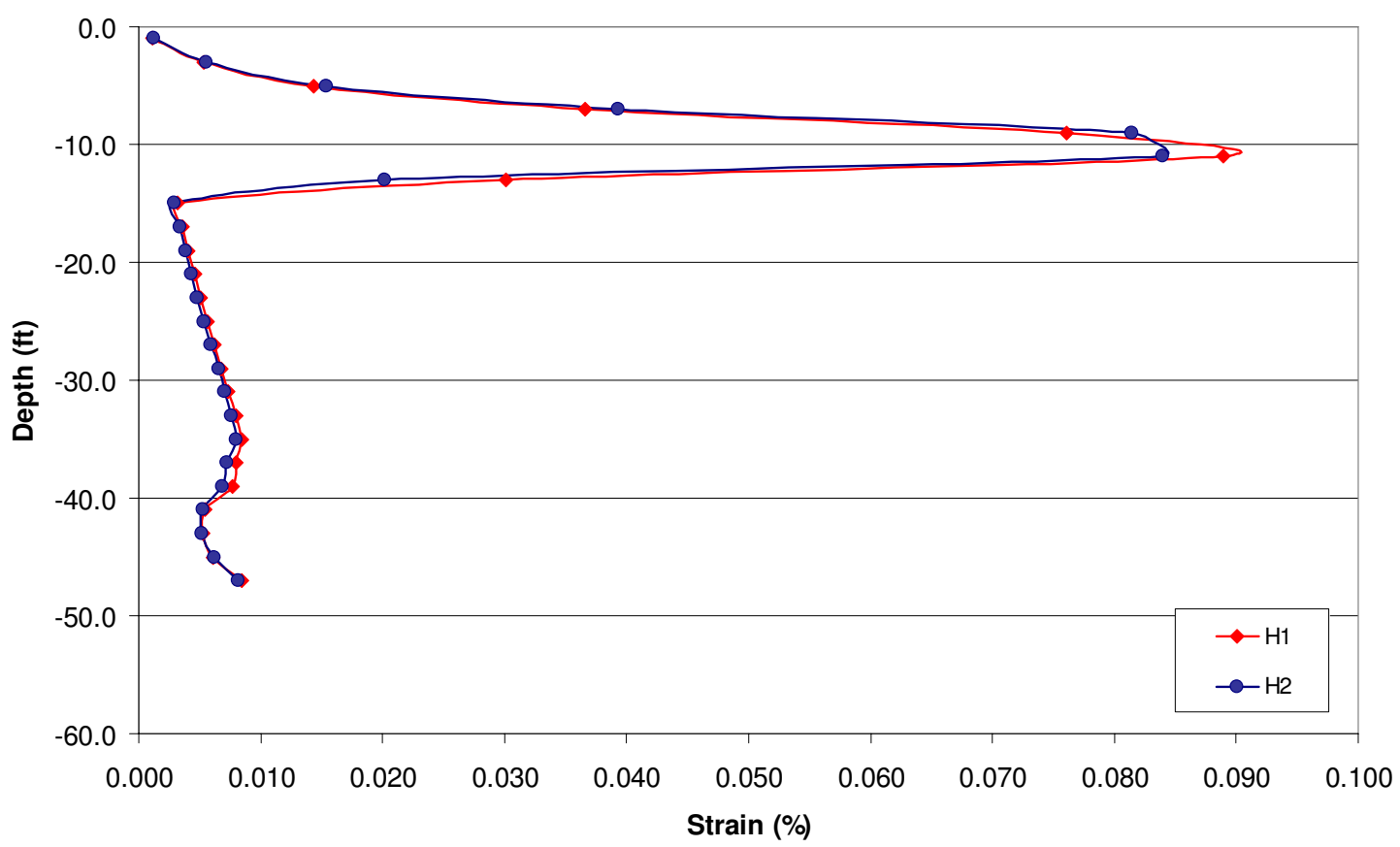

(b)

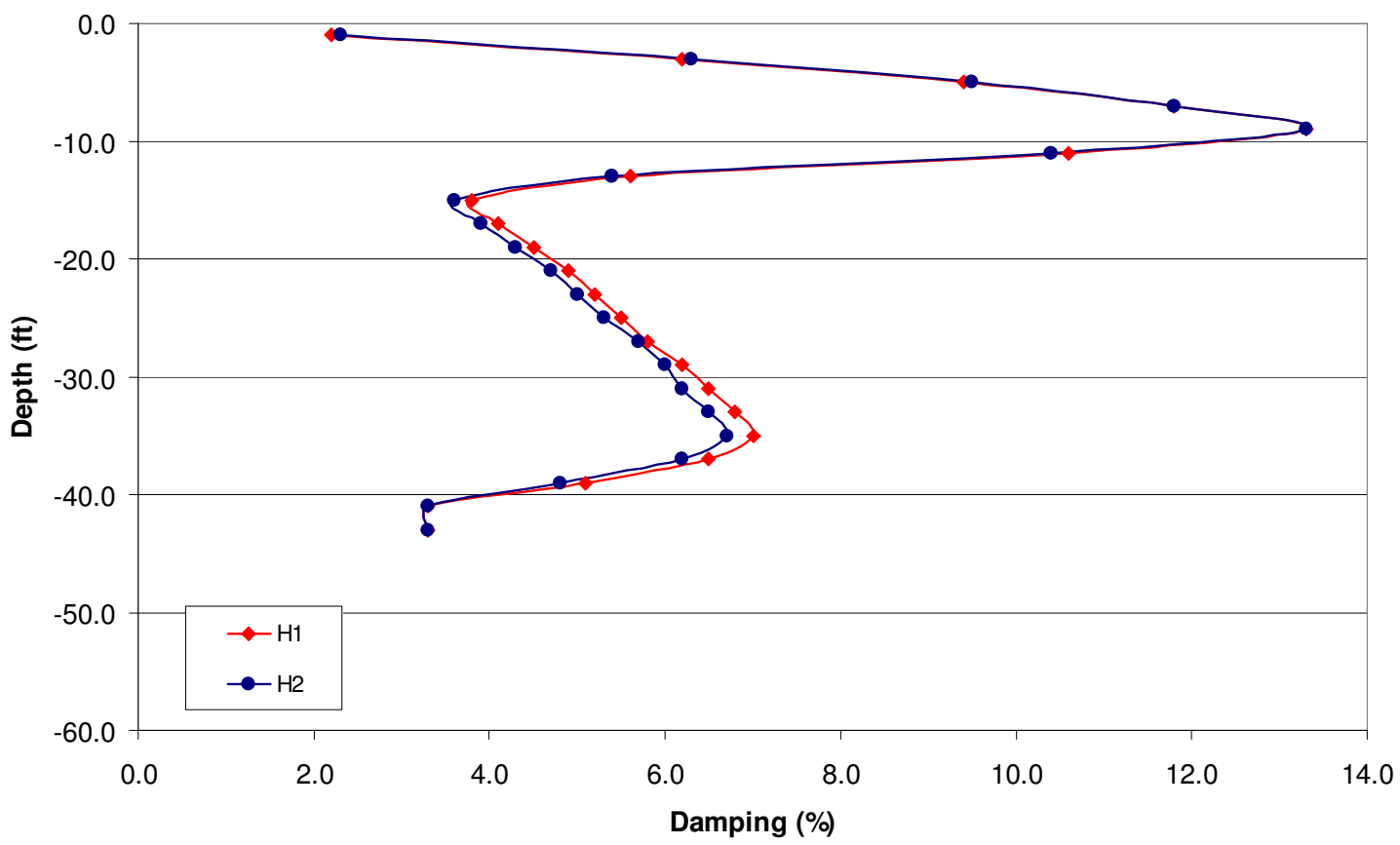

Figure C-20. Average PC 3 (2,500 yr) soil (a) strain and (b) damping computed from the output of SHAKE2000 for 30 random soil profiles with the log normal distribution of G, larger COV (0.5), and degradation model "Darendeli/Menq CU 100" (Pyke 2006). 
(a)
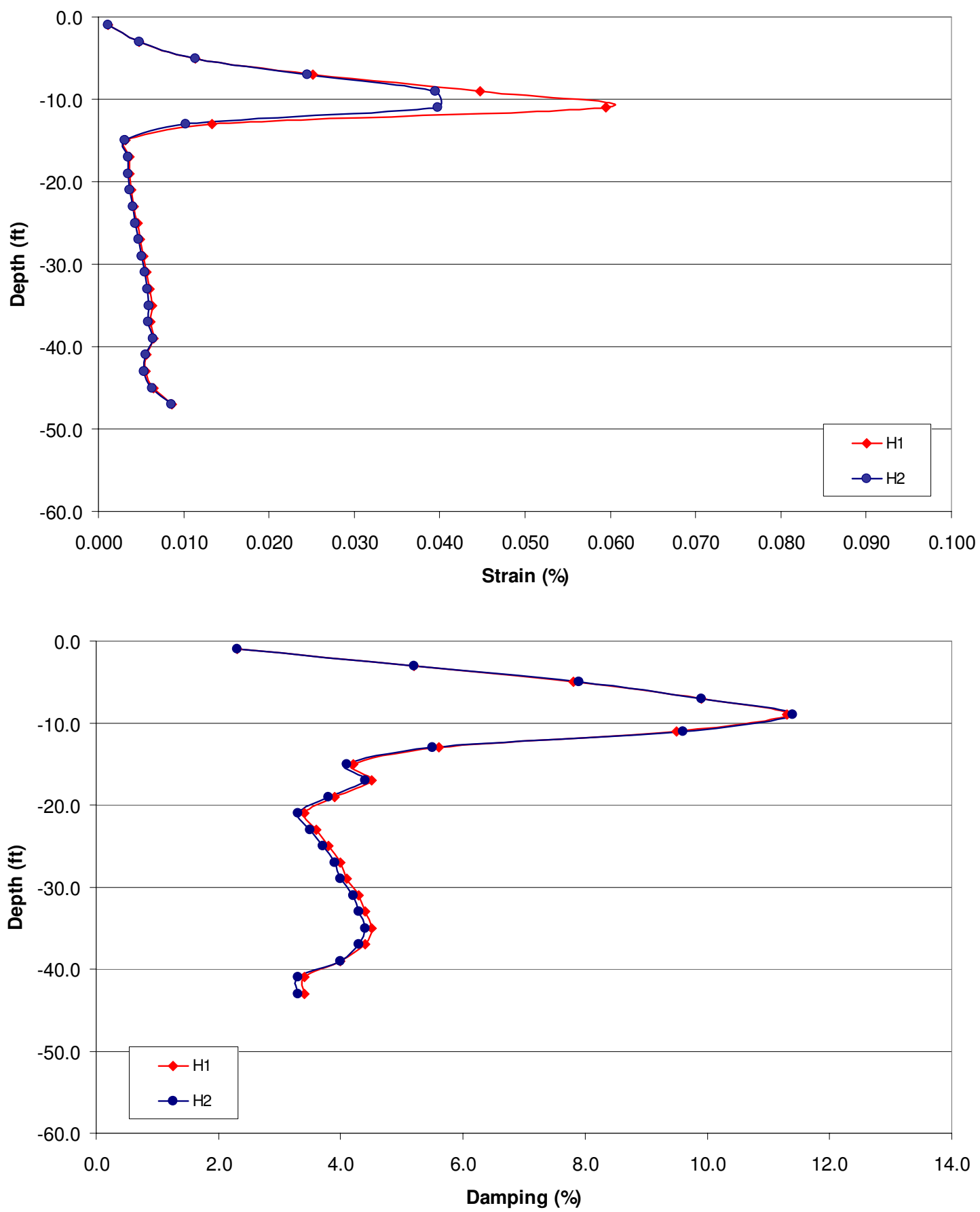

Figure C-21. Average PC 3 (2,500 yr) soil (a) strain and (b) damping computed from the output of SHAKE2000 for 30 random soil profiles with the log normal distribution of G, larger COV (0.5), and degradation model "EPRI (Pyke 2007)". 
(a)

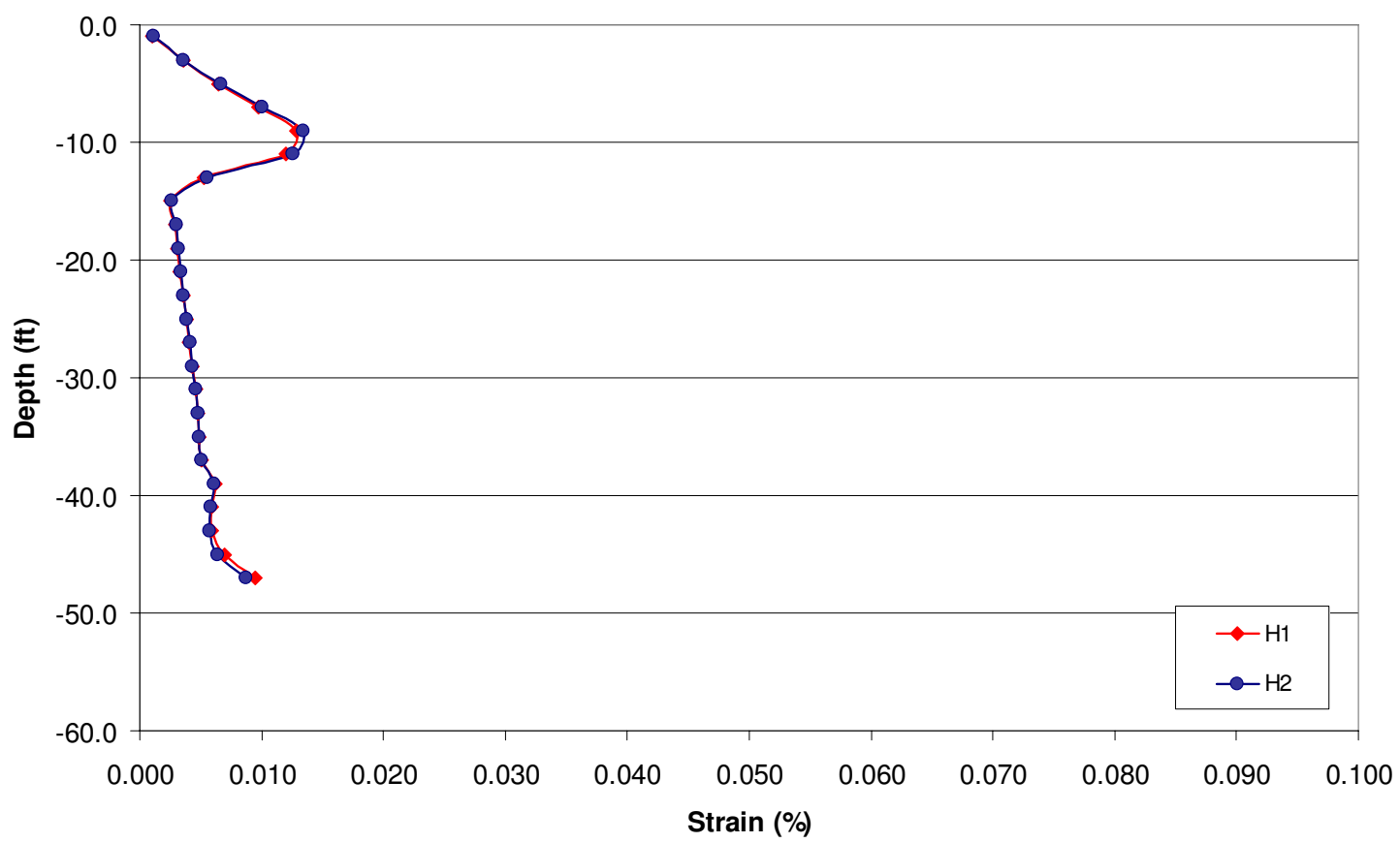

(b)

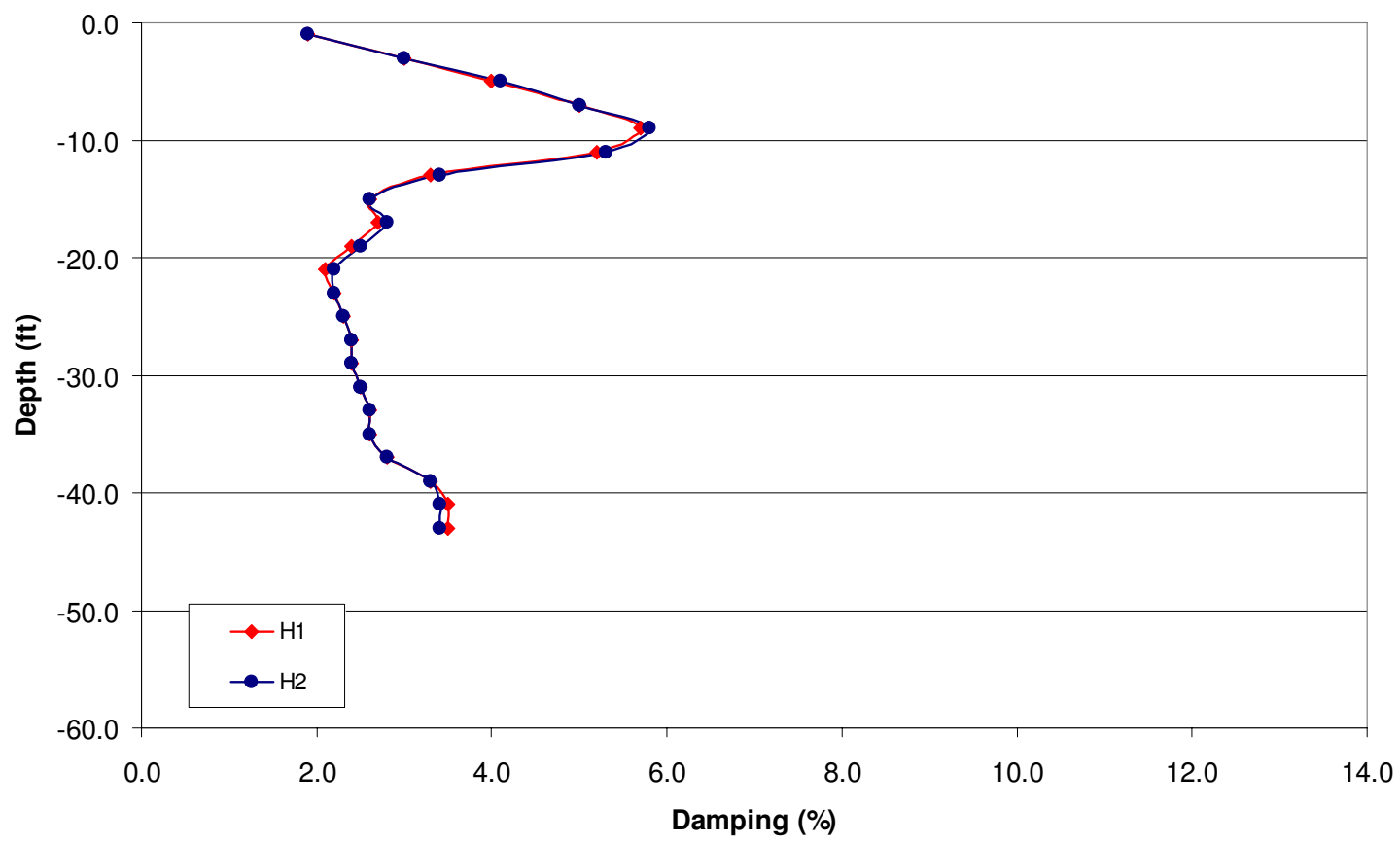

Figure C-22. Average PC 3 (2,500 yr) soil (a) strain and (b) damping computed from the output of SHAKE2000 for 30 random soil profiles with the log normal distribution of G, larger COV (0.5), and degradation model "EPRI (Payne 2006)". 


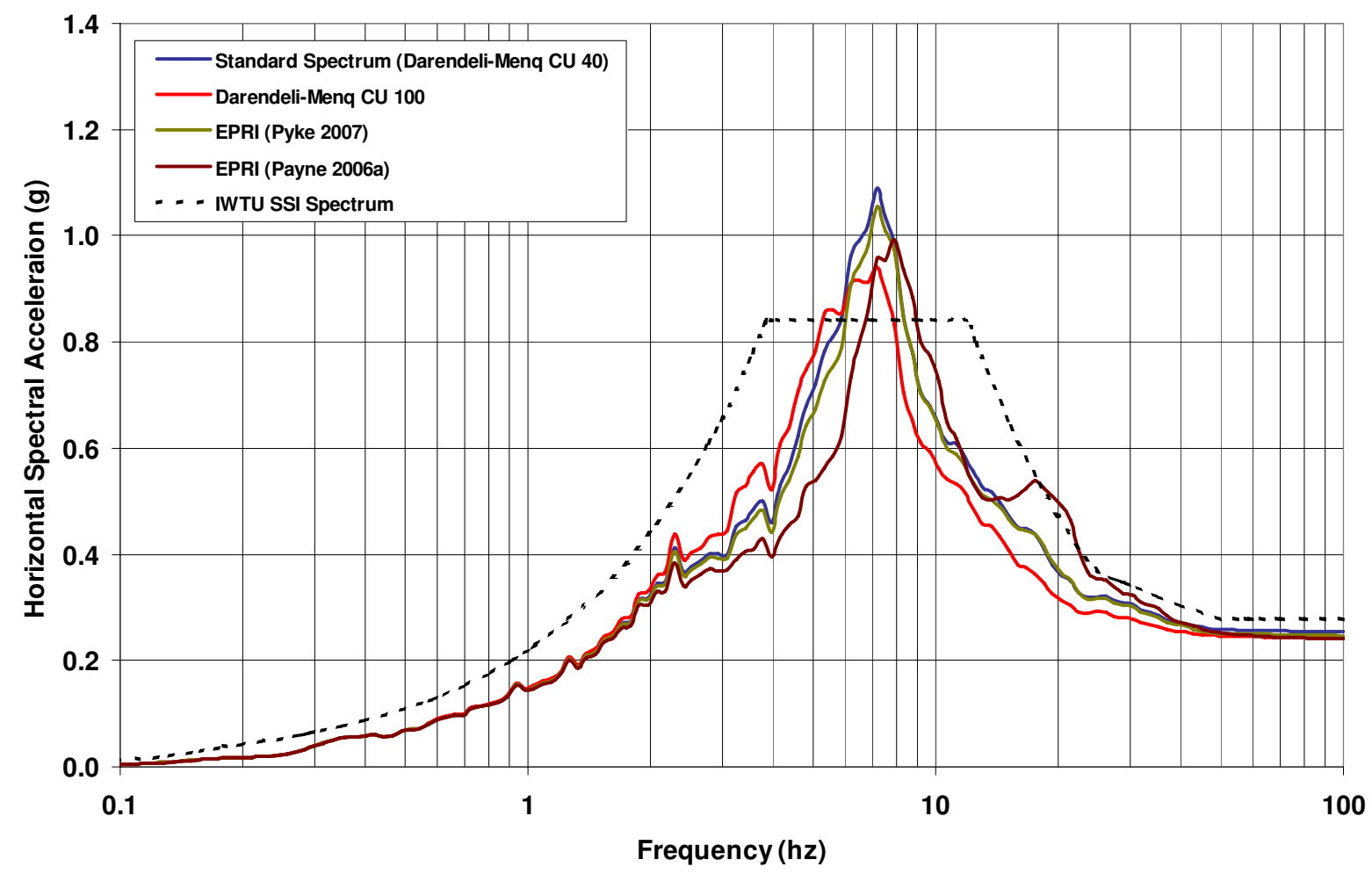

Figure C-23. Horizontal PC 3 (2,500 yr) mean soil surface 5\% damped spectra for the "Standard Spectrum" ("Darendeli/Menq CU 40"), "Darendeli/Menq CU 100", "EPRI Pyke (2007)", and "EPRI (Payne 2006)". The mean soil surface spectra are computed for the same set of 30 random soil profiles with $\log$ normal distribution of $\mathrm{G}(\mathrm{COV} s<0.32)$. 


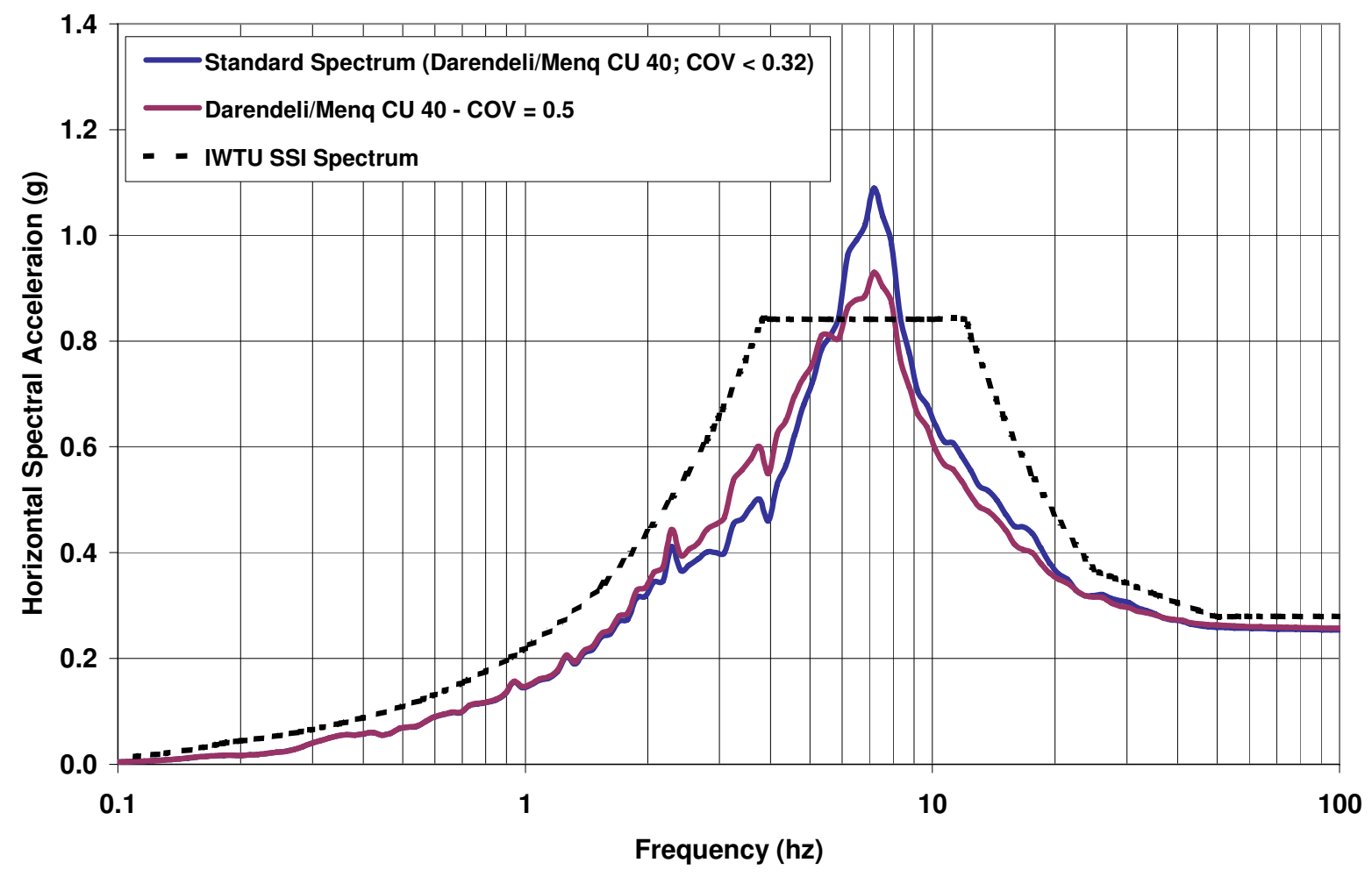

Figure C-24. Horizontal PC 3 (2,500 yr) mean soil surface 5\% damped spectra with soil profiles for the $\log$ normal distribution of $\mathrm{G}$ and two different COVs $(<0.32$ and 0.5$)$. The mean soil surface spectra were computed for each set of 30 random soil profiles using the same degradation model, "Darendeli/Menq CU 40". 


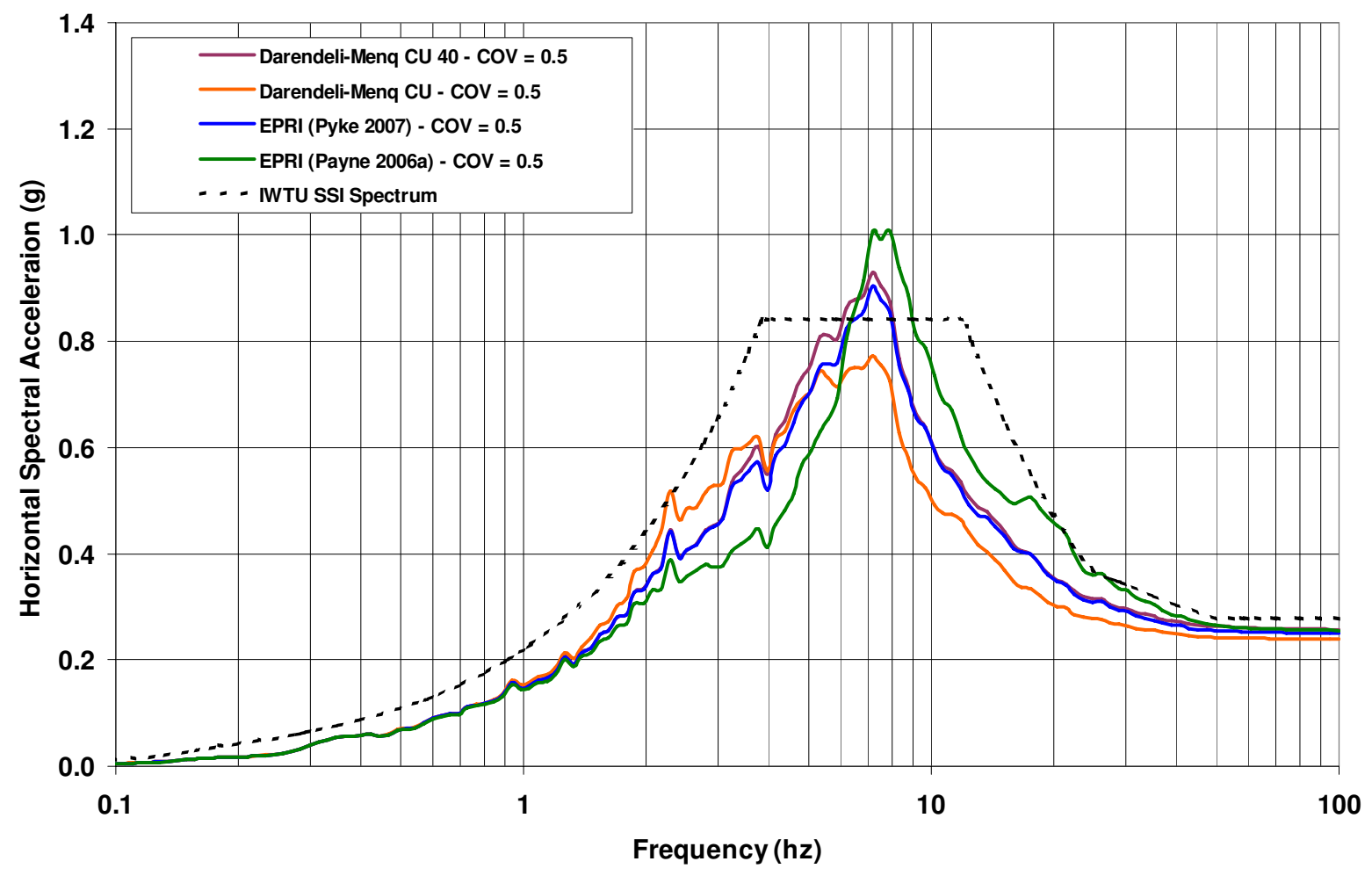

Figure C-25. Horizontal PC 3 (2,500 yr) mean soil surface 5\% damped spectra "Darendeli/Menq CU 40", "Darendeli/Menq CU 100", "EPRI Pyke (2007)", and "EPRI (Payne 2006)" for the same set of soil profiles with log normal distribution and COV equivalent to the factor of 0.5 . 
(Intentionally Blank) 


\section{Appendix D \\ Spectral Matches}


(Intentionally Blank)

Revision 1 


\section{Appendix D \\ Spectral Matches}

The starting horizontal acceleration time histories generated from SHAKE2000 were used as seeds to develop the horizontal soil DBE time histories. The horizontal time histories correspond to soil profiles number 4 for the $\mathrm{H} 1$ component and number 12 for the $\mathrm{H} 2$ component (EDF-7905). The vertical rock DBE acceleration time history (Figure 5) was used as the seed time history to develop the vertical DBE time history.

The spectra computed for the horizontal and vertical rock DBE time histories relative to their corresponding DBE target spectrum meet the acceptance criteria in NUREG/CR-6728 (NRC 2001):

1. No spectral point of the DBE time history spectrum falls more than $10 \%$ below the target spectrum.

2. No spectral point of the DBE time history spectrum exceeds the target spectrum by more than $30 \%$.

3. No more than nine adjacent frequency points of the DBE time history spectrum fall below the target spectrum.

The approach in NUREG/CR-6728 is consistent with the guidance in ASCE/SEI 43-05 (ASCE 2005) and is technically adequate to meet the requirements of ASCE 4-86 (see ASCE 2000), which is recommended by DOE Standards. Figures D-1 and D-2 show the spectral matches for development of the mean horizontal and vertical IWTU Soil DBE acceleration time histories. Figures D-3 and D-4 show the spectral matches for the $84^{\text {th }}$ percentile horizontal and vertical IWTU Soil DBE acceleration time histories. 
(a)

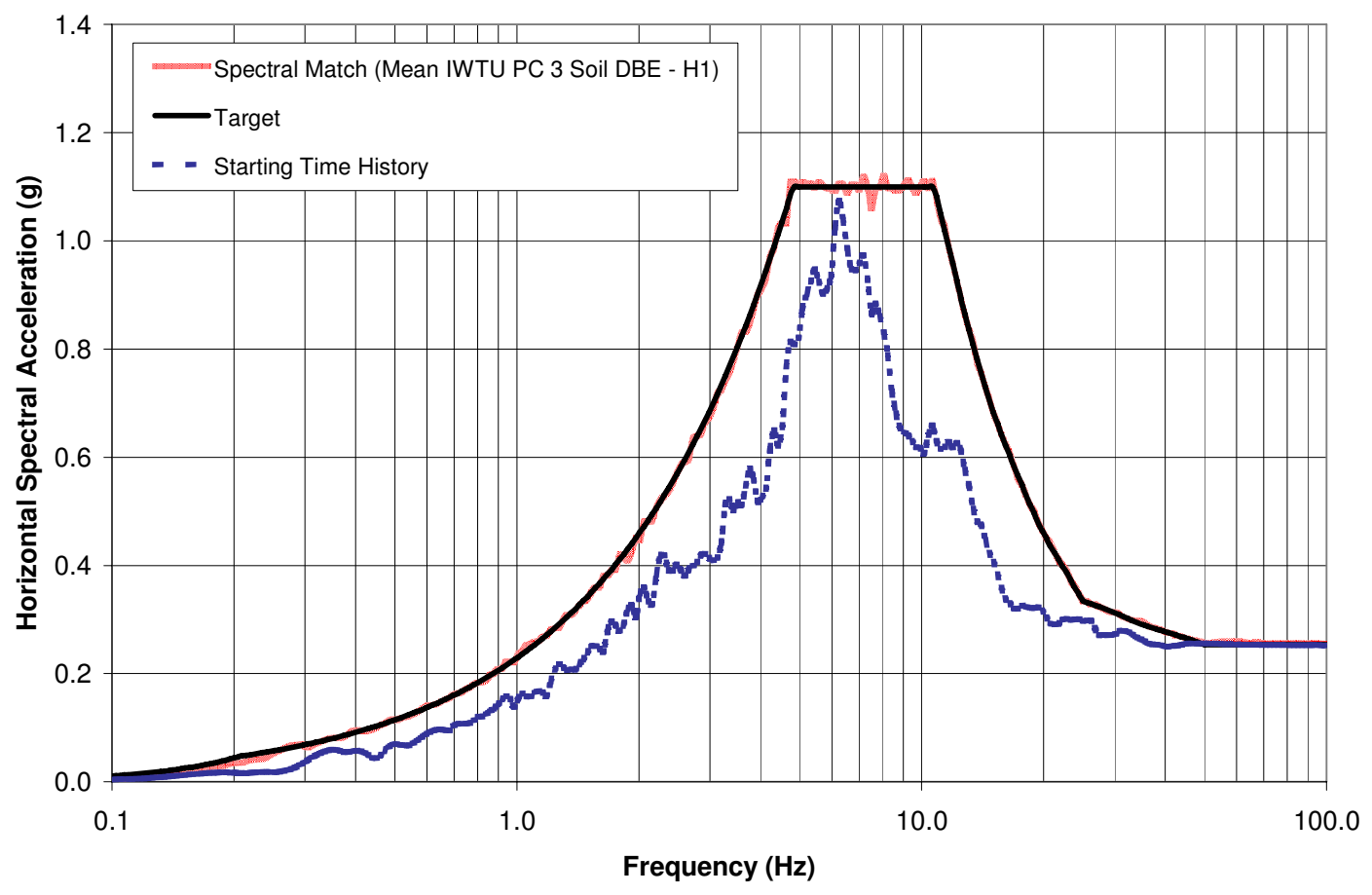

(b)

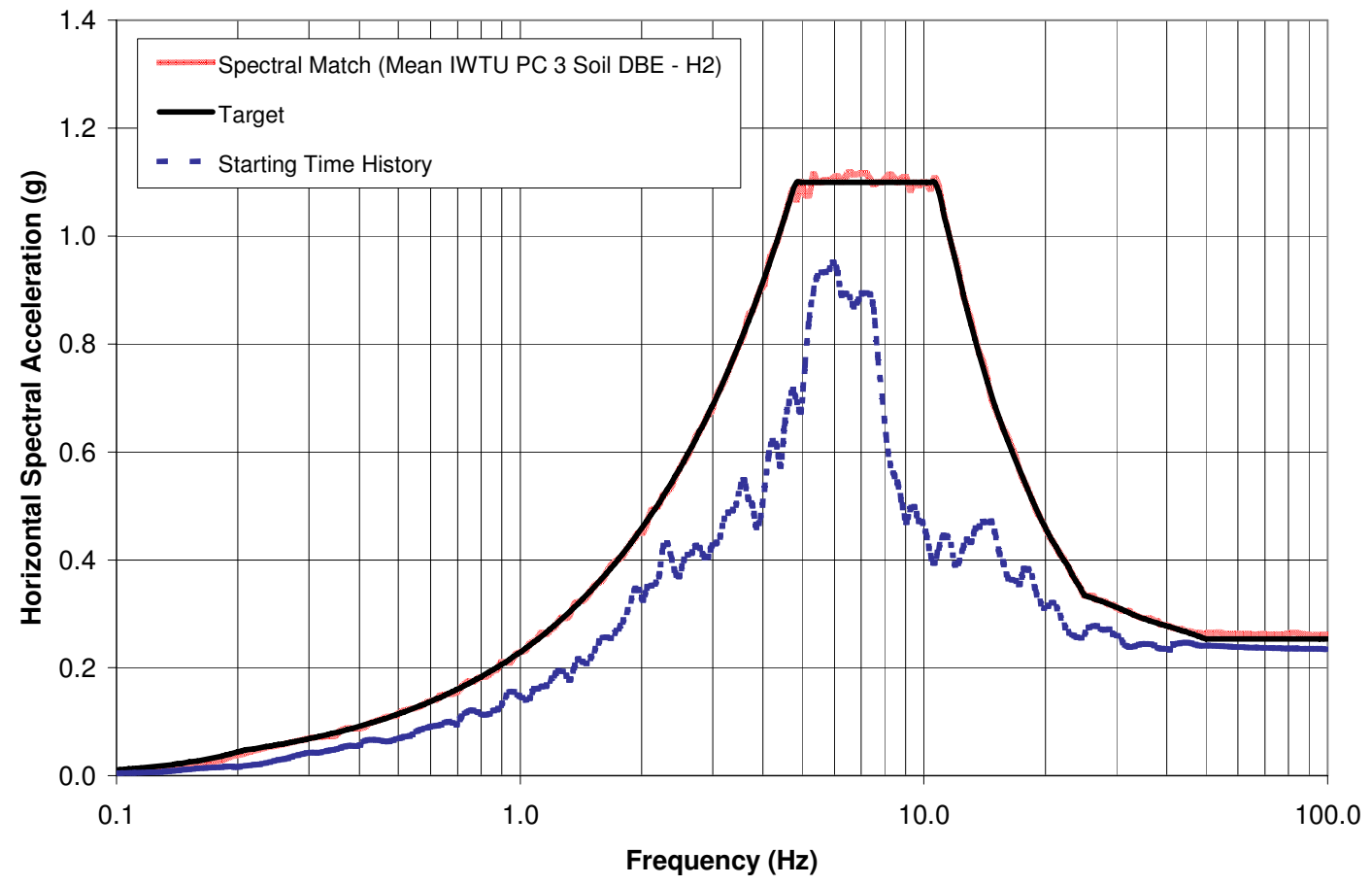

Figure D-1. Plot showing the starting time histories, targets, and matching DBE time histories of the 5\% damped spectra for the mean IWTU PC 3 (2,500 yr) soil DBE horizontal (a) H1 and (b) H2 components. 


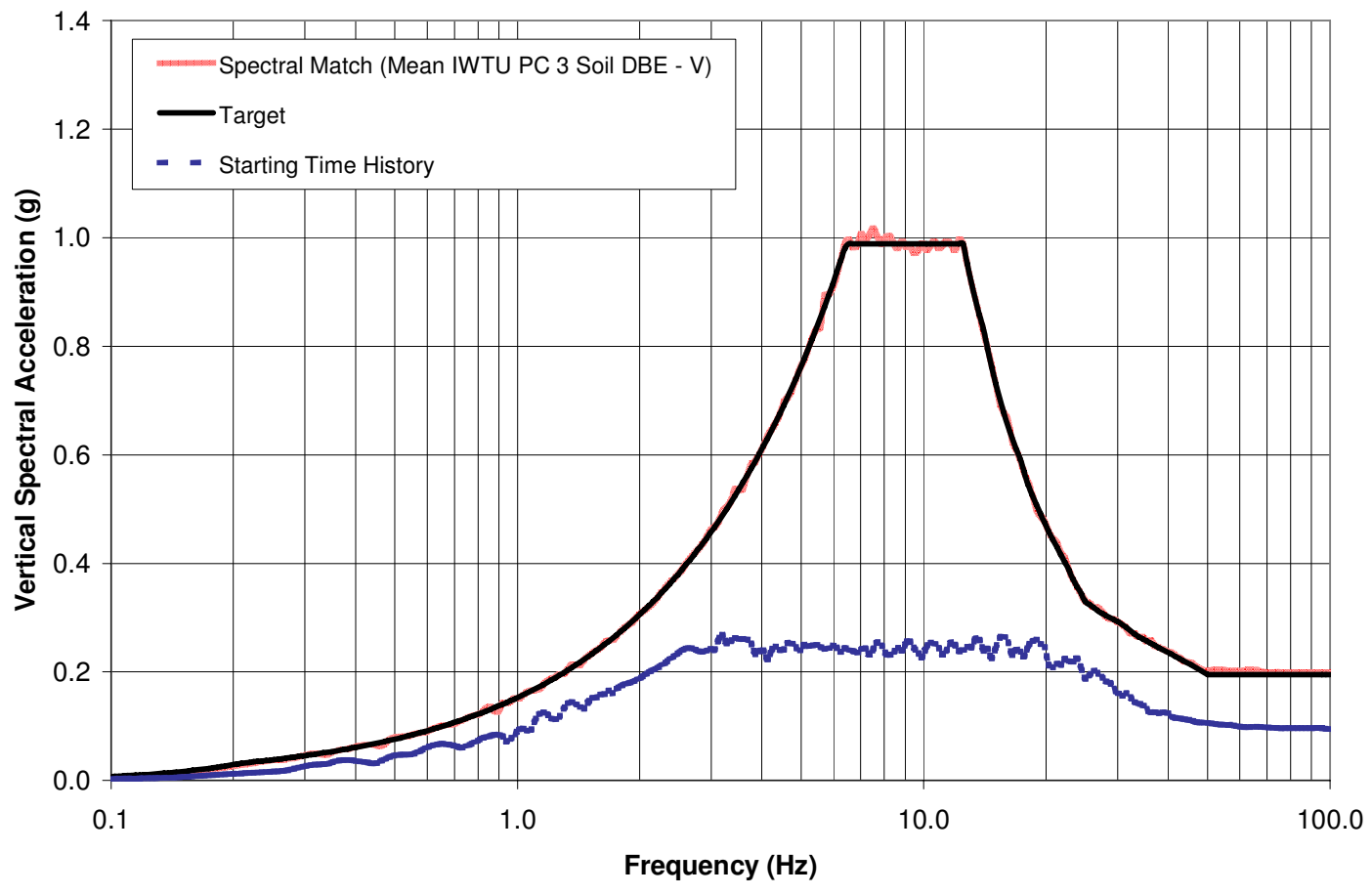

Figure D-2. Plot showing the starting time history, target, and matching DBE time history 5\% damped spectra for the mean IWTU PC 3 (2,500 yr) soil DBE vertical component. 
(a)

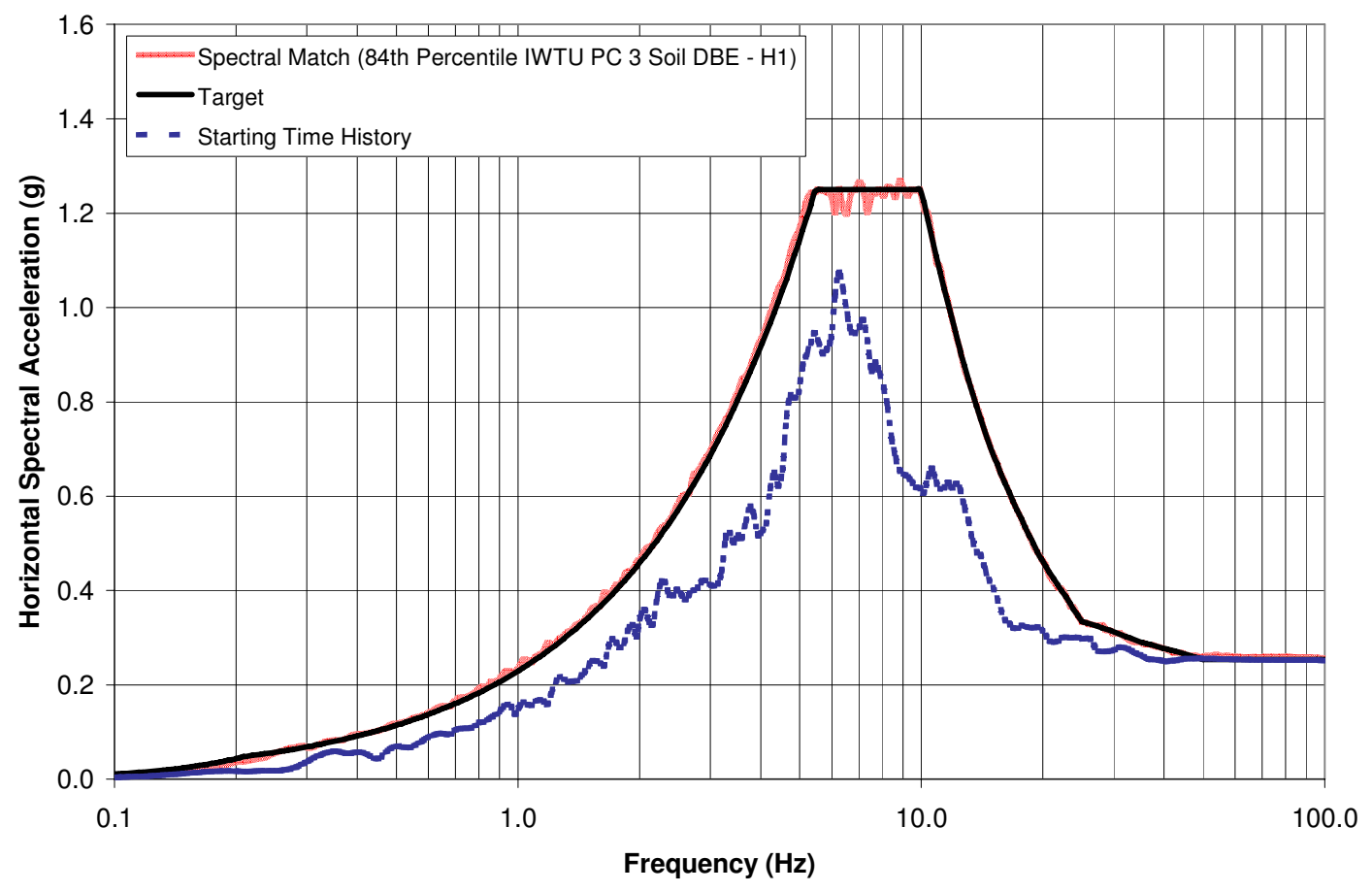

(b)

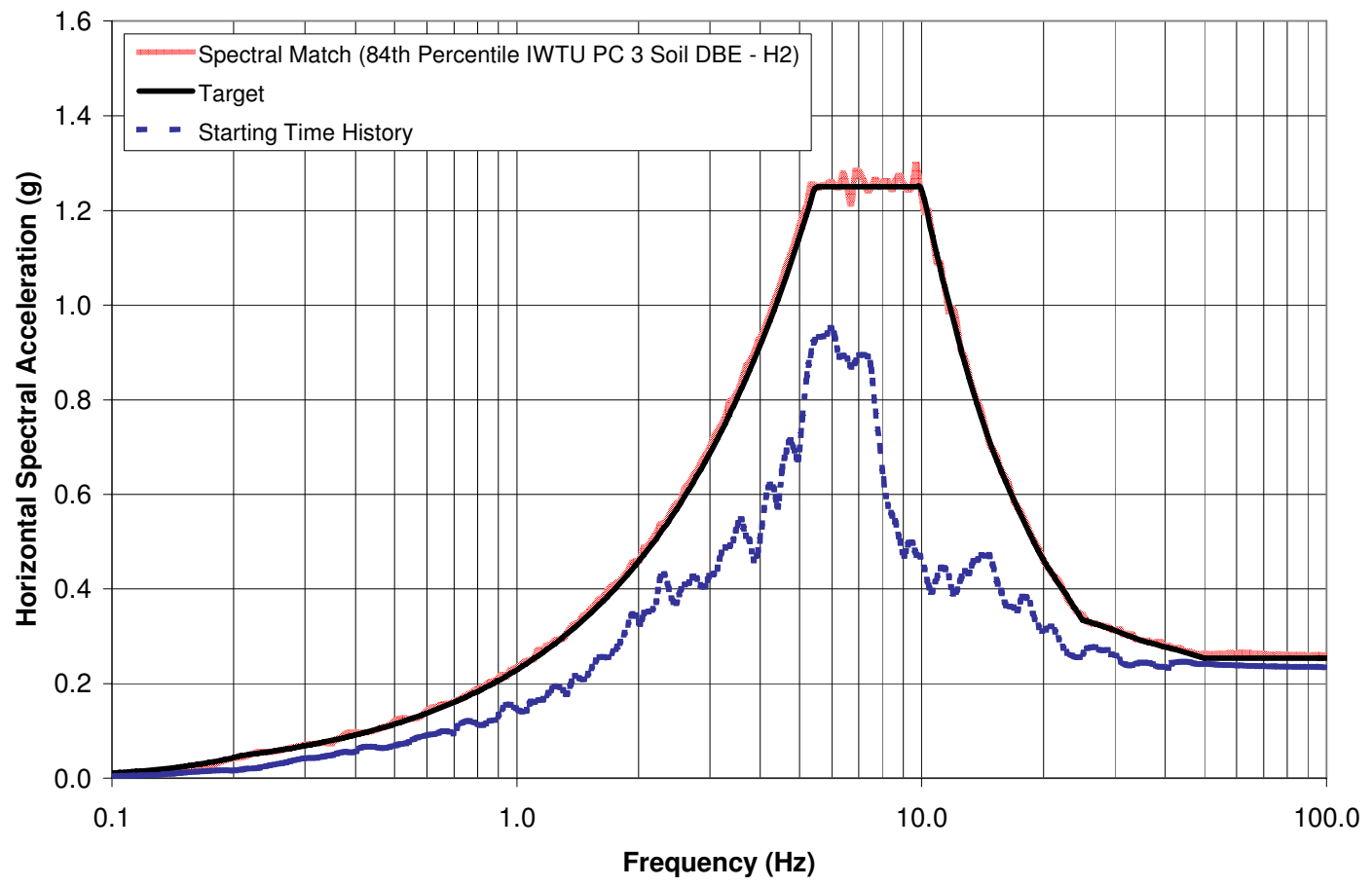

Figure D-3. Plots showing the starting time histories, targets, and matching DBE time histories of the $5 \%$ damped spectra for $84^{\text {th }}$ percentile IWTU PC 3 soil DBE horizontal (a) H1 and (b) H2 components. 


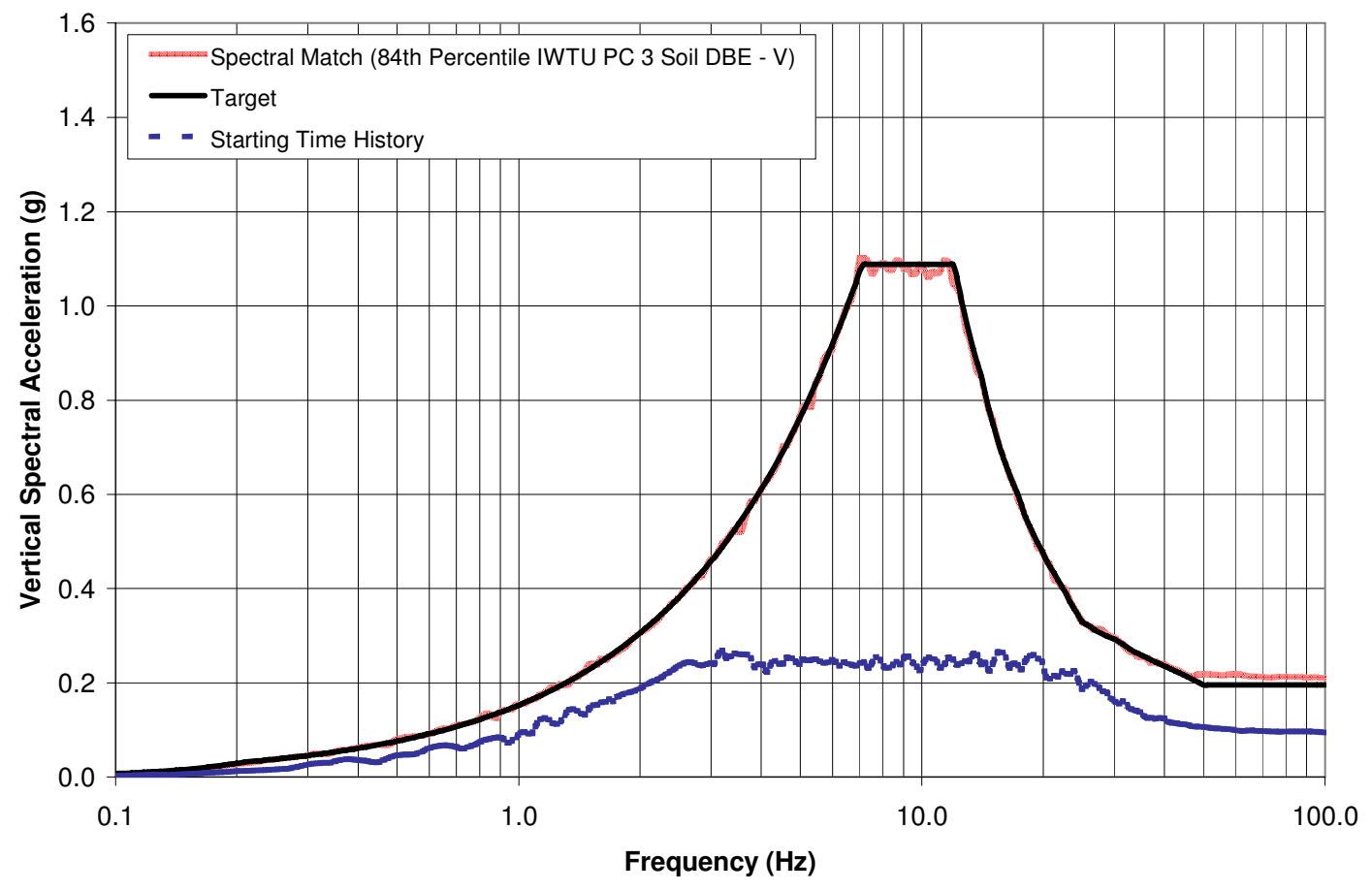

Figure D-4. Plot showing the starting time history, target, and matching DBE time history 5\% damped spectra for the $84^{\text {th }}$ percentile IWTU PC 3 (2,500 yr) soil DBE vertical component. 
(Intentionally Blank) 


\section{Appendix E \\ Strain-Compatible Soil Property Calculations}


(Intentionally Blank)

Revision 1 


\section{Appendix E \\ Strain-Compatible Soil Property Calculations}

Strain-compatible soil properties for Vs and damping were calculated based on ratios of iterated Vs from the output of SHAKE2000 to low-strain Vs for input for the input soil profiles to SHAKE2000. This approach was recommended to calculate the iterated Vs and damping as function of depth in place of computing the best estimate, upper bound, and lower bound iterated Vs and damping for log normal distributions at each depth (Per. Comm. Carl Costantino 2007). Iterated Vs and damping were calculated as a function of depth to incorporate the higher strains observed across the boundary of Layers A and B (see Figures 11, 12, 13 and 14). The BRP recommended calculating the best estimate, lower bound, and upper bound iterated Vs and damping assuming log normal distributions (Houston 2007a).

The best estimate, upper bound, and lower bound iterated Vs and damping calculated as function of depth for the log normal distribution resulted in anomalously high values for the upper bound at depths that cross the boundary between Layers A and B (Figure E-1). The reason for high upper-bound values is the iterated Vs and damping in the soil layers at depths that cross this boundary no longer have log normal distributions. Bimodal distributions of Vs are illustrated in Figure E-2, which shows the iterated shear modulus at depths of 11 and $13 \mathrm{ft}$ from the output of SHAKE2000. Bimodal distributions are attributed to the following:

- $\quad$ Sorting iterated Vs by $\pm 1 \mathrm{ft}$ at the SHAKE2000 specific depths of $1,3,5,7 \ldots 43 \mathrm{ft}$ samples the iterated Vs and damping for both layers A and B.

- Vs of Layers A and B do not overlap due to small COVs of less than 0.32 for the log normal distribution of $\mathrm{G}$.

- $\quad$ Layer A has a median Vs of $750 \mathrm{ft} / \mathrm{s}$ and Layer B has a median Vs of $1540 \mathrm{ft} / \mathrm{s}$.

This same effect is expected to occur at the boundary between Layers B and C, but is less obvious because the median Vs are similar. The median Vs of Layer C is $1550 \mathrm{ft} / \mathrm{s}$ so the resulting iterated Vs similar for Layers B and C, even though different degradation models were used in the SHAKE2000 computations. Figure E-3 does not show bimodal distributions for iterated shear modulus at depths of 29 and $31 \mathrm{ft}$, which cross the boundary between Layers B and C.

In previous calculations of strain-compatible soil properties for INL site response analyses, bimodal distributions were not observed (Payne 2006). This is attributed to the approach used to calculate iterated Vs and damping as a function of soil layer type and not as a function of depth. 
(a)

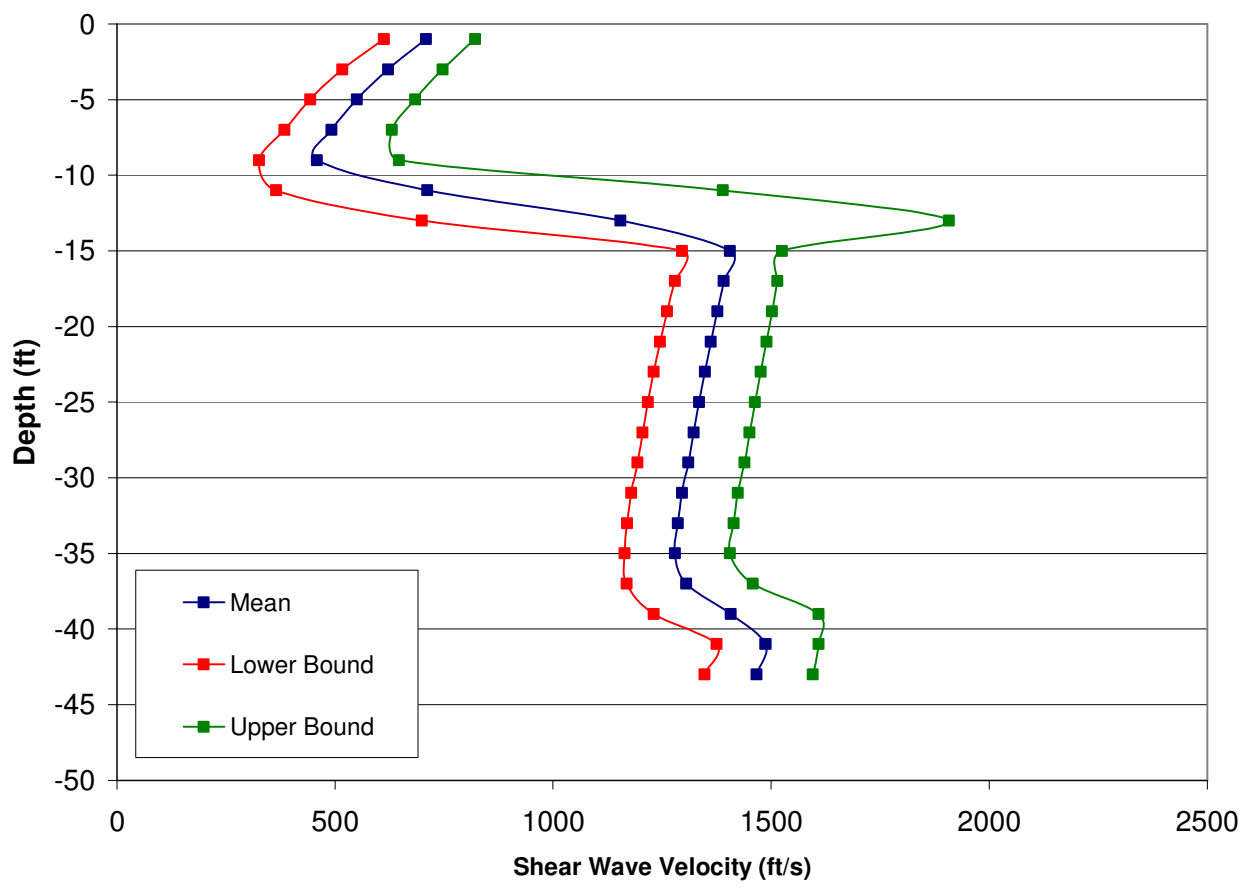

(b)

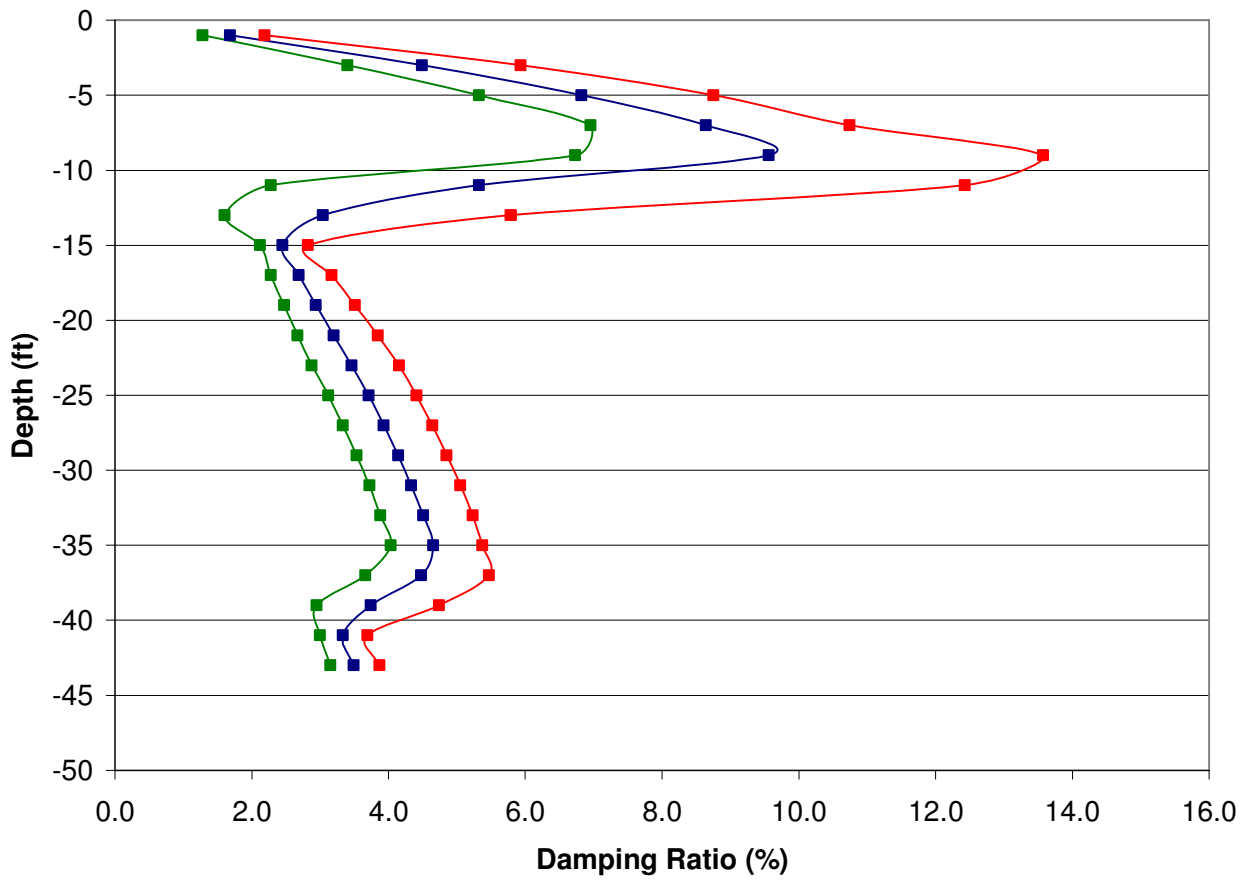

Figure E-1. Iterated shear wave velocities and corresponding damping ratios for best estimate, upper bound, and lower bound calculated using a log normal distribution of soil profiles from SHAKE2000. Iterated shear wave velocities at depths of 11 and $13 \mathrm{ft}$ have bimodal distributions. 
(a)

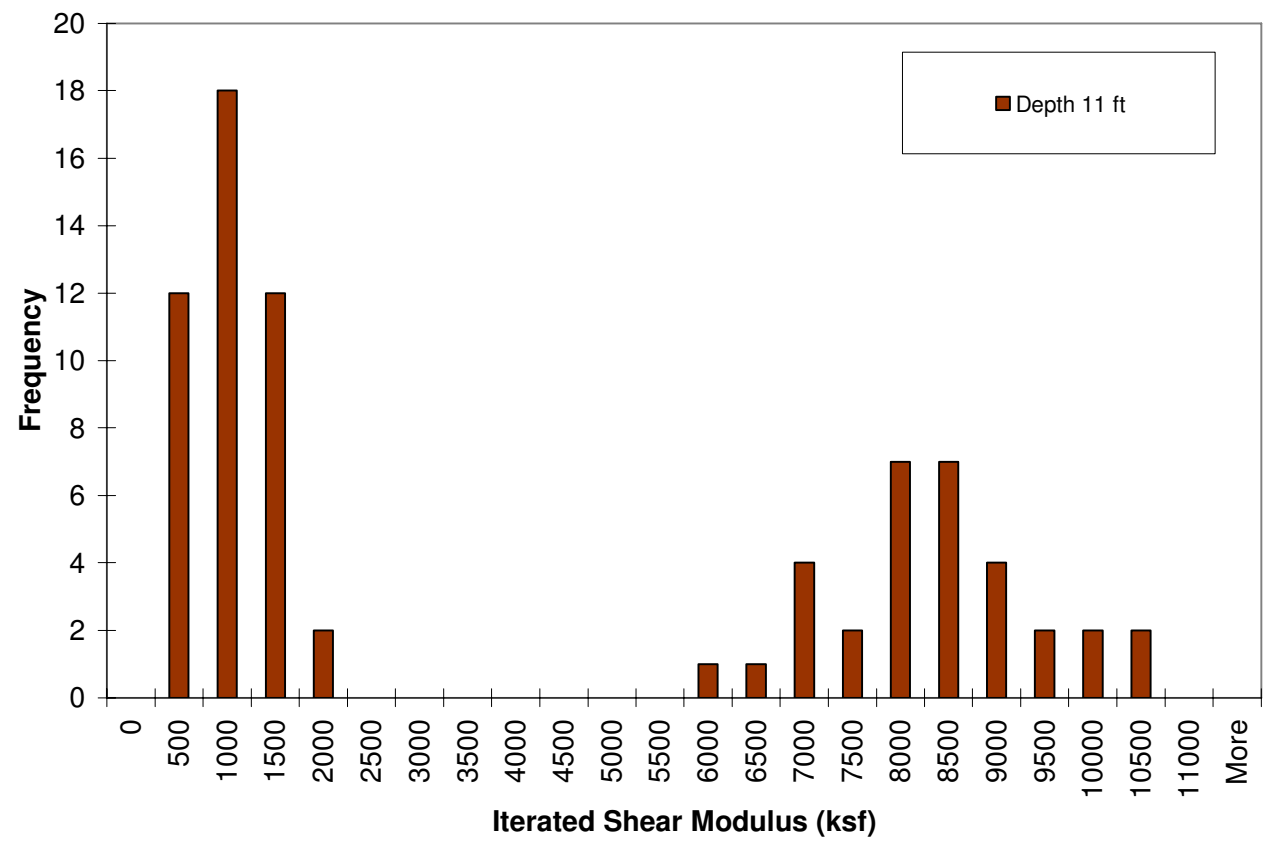

(b)

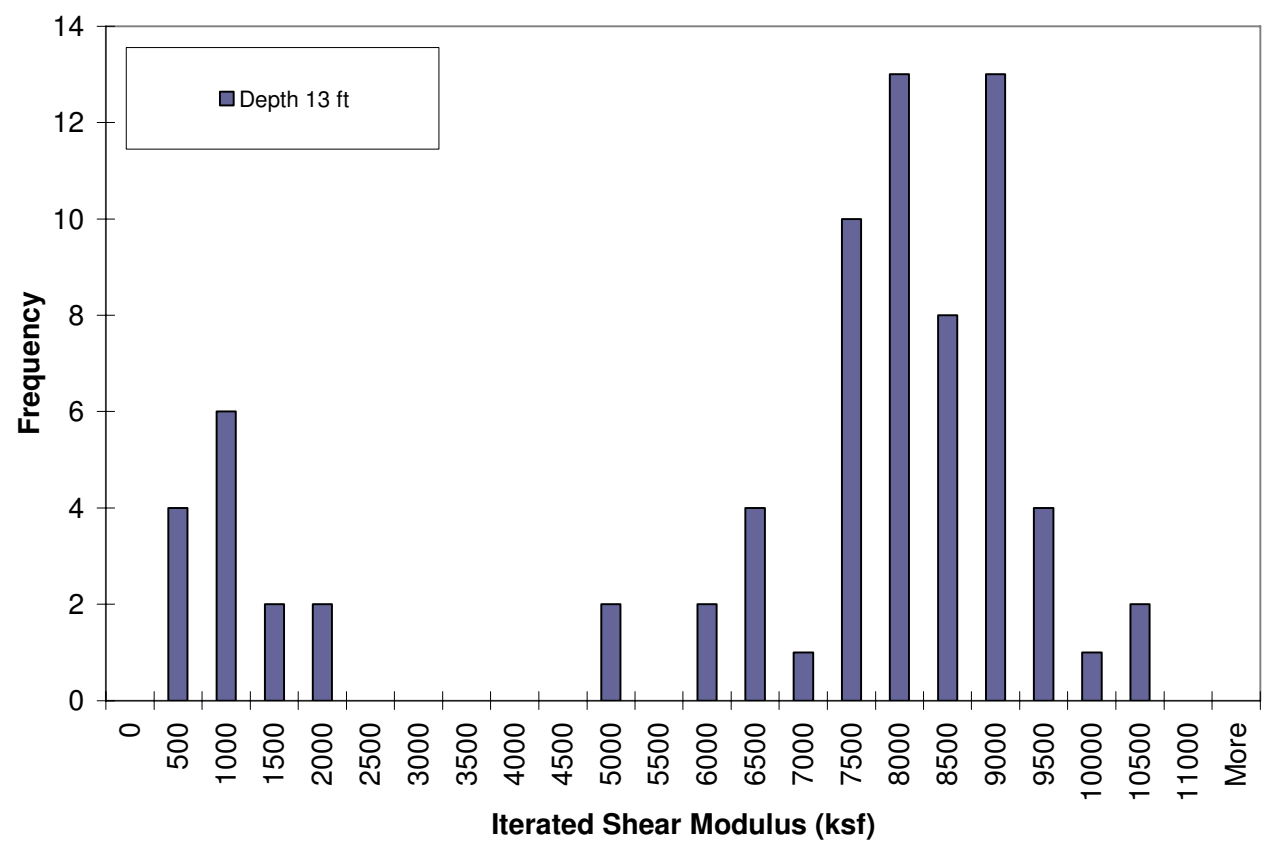

Figure E-2. Histograms show bimodal distributions of iterated shear modulus for soil profiles depths of a) $11 \mathrm{ft}$ and b) $13 \mathrm{ft}$ that cross the boundary between Layers A and B. 
(a)

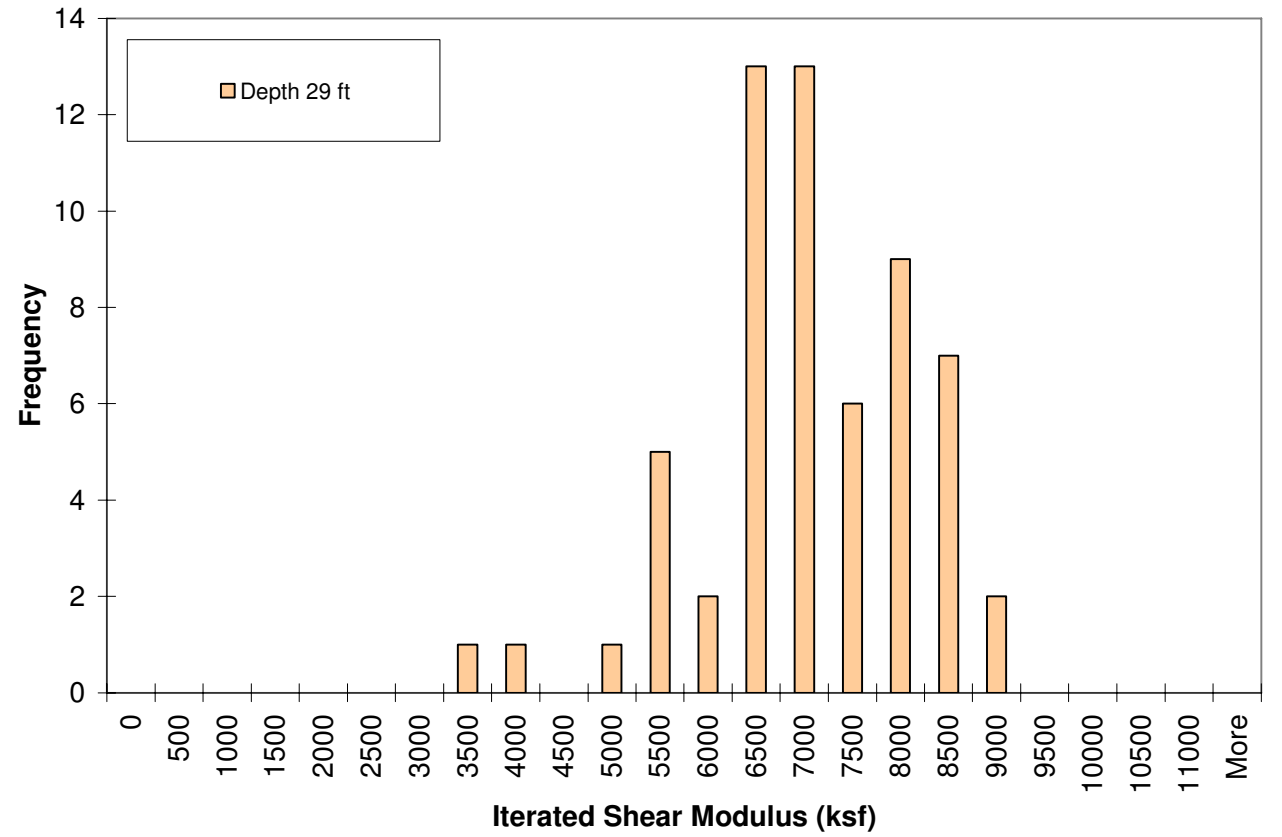

(b)

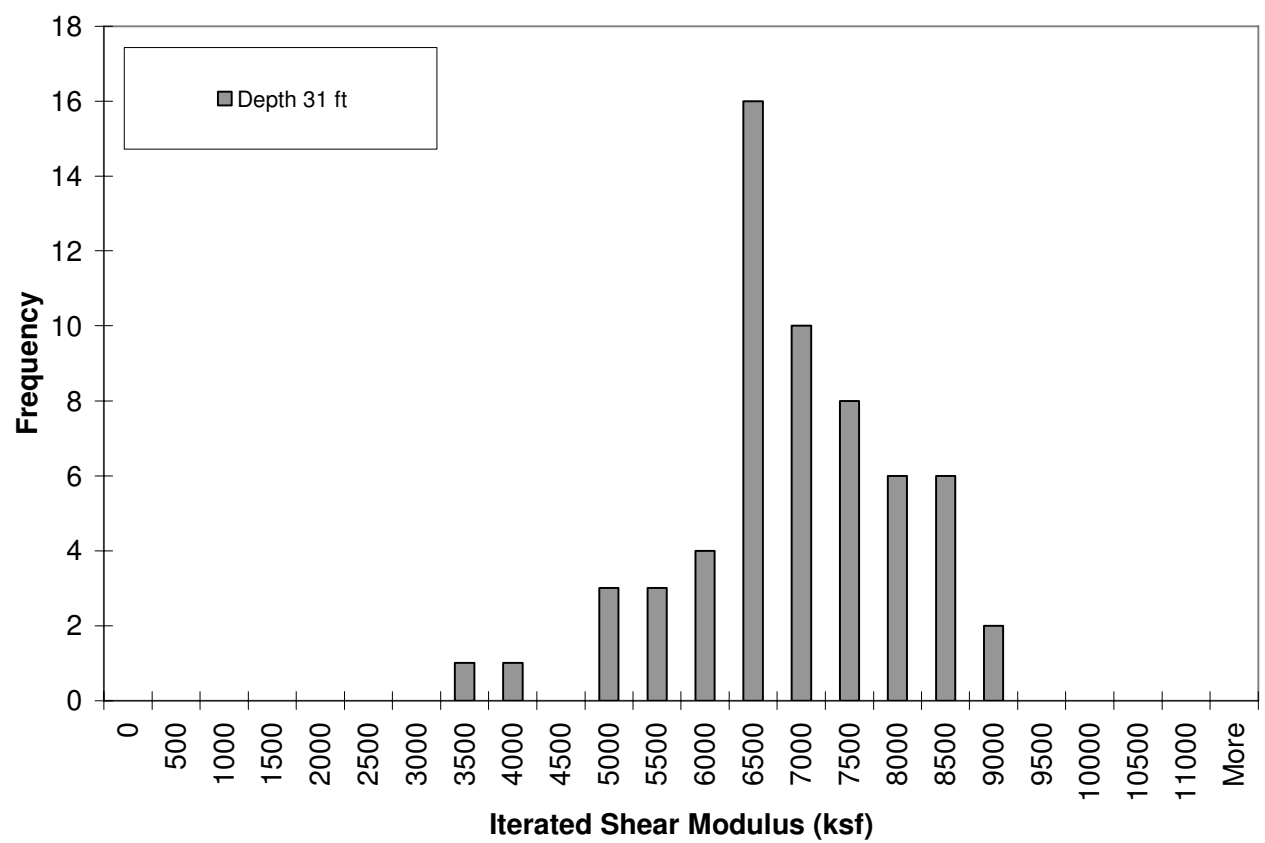

Figure E-3. Histograms show the distributions of iterated shear modulus for soil profiles depths of a) 29 $\mathrm{ft}$ and b) $31 \mathrm{ft}$ that cross the boundary between Layers B and C. 